Portland State University

PDXScholar

Summer 7-31-2019

\title{
Interrogating the Construction and Representations of Criminalized Women in the Academic Social Work Literature: a Critical Discourse Analysis
}

Sandra Marie Leotti

Portland State University

Follow this and additional works at: https://pdxscholar.library.pdx.edu/open_access_etds

Part of the Criminology Commons, and the Social Work Commons Let us know how access to this document benefits you.

\section{Recommended Citation}

Leotti, Sandra Marie, "Interrogating the Construction and Representations of Criminalized Women in the Academic Social Work Literature: a Critical Discourse Analysis" (2019). Dissertations and Theses. Paper 5117.

https://doi.org/10.15760/etd.6996

This Dissertation is brought to you for free and open access. It has been accepted for inclusion in Dissertations and Theses by an authorized administrator of PDXScholar. Please contact us if we can make this document more accessible: pdxscholar@pdx.edu. 
Interrogating the Construction and Representations of Criminalized Women in the Academic Social Work Literature: A Critical Discourse Analysis

\section{by}

Sandra Marie Leotti

A dissertation submitted in partial fulfillment of the requirements for the degree of

Doctor of Philosophy

in

Social Work and Social Research

Dissertation Committee:

Stéphanie Wahab, Chair

Ben Anderson-Nathe

Mary Oschwald

Melissa Thompson

Portland State University

2019 
C 2019 Sandra Marie Leotti 


\begin{abstract}
In the United States today, there are 2.3 million people behind bars in jails and prisons. Mass incarceration has swept up the United States to such a degree that we are known globally for holding more people in correctional facilities than any other country in the world. Although women have always reflected, and still do reflect, a smaller proportion of the correctional population, over the last 40 years, their rates of criminalization and imprisonment have far outpaced that of men. Drastic increases in the criminalization of women are intimately connected to the entrenchment of social disadvantage enabled under neoliberal globalization. Neoliberal transformations in the economy have contributed to women's poverty across the globe and have brought an increasing number of women into contact with the criminal justice system. The rising incarceration rate of women, and the disproportionate rate of women of color in U.S. prisons is a timely and urgent issue and one that social work is poised to address. Indeed, some of our most prominent national organizations recognize mass incarceration as an urgent issue that merits the attention of social workers. As such, it is prudent to examine social work's engagement with this issue.

This study employed a Critical Discourse Analysis (CDA) of social work scholarship in order to: 1) explore current constructions of criminalized women in social work; 2) understand the knowledge produced through such constructions; and 3) explore how that knowledge supports/shapes practice with criminalized women. Specifically, this study draws on Jäger and Maier's (2009) framework for performing a Foucauldianinspired CDA. This approach centers Foucault's conceptualizations of discourse and the
\end{abstract}


workings of power and builds on the work of Jürgen Link to examine the function of discourse in legitimizing and securing dominance.

Data include a sample of 49 articles published in social work high impact journals from 2000-2018. A keyword search was performed to locate articles with an explicit focus on incarcerated/criminalized women. Only articles dealing with a U.S. context were included. Analysis occurred on two levels consisting of a structural analysis to identify initial coding schema and a detailed analysis of select articles. Detailed analysis attended to: context of text; surface of text; rhetorical means; content and ideological statements. These two levels of analysis led to an overall synoptic analysis, or final assessment of the overall discourse. Multiracial feminism, discourse theory, and Foucault's concept of governmentality anchored the research and provided the theoretical framework for analysis.

The overarching finding is that social work high impact journals privilege a psychological discourse and that the assessment and management of risk has supplanted a holistic approach to meeting client needs and addressing mass incarceration. This, I conclude, reflects a neoliberal political climate and aligns social work with penal institutions in troubling ways. Criminalized women are overwhelmingly constructed as risky in the sample. Embedded in this construction is a strong neoliberal discourse on knowing and changing the "responsibilized" self. The implied knowledge claims that flow from these constructions rely on the use of "objective" and often depoliticized explanations for crime and criminal justice involvement. I show how this depoliticization is accomplished through a variety of neutralizing strategies, which ultimately serve to depoliticize social work itself. I highlight how, by primarily constituting criminalized 
women as risky, social work necessarily responds to her with individualized service delivery aimed at regulating and changing the behavior of individuals. I argue that in its reliance on practices of risk management and a preference for micro-level service delivery, social work deploys regulatory practices that further neoliberal governance (Parton, 1998; Webb, 2003).

Further, I discovered a profound ethical dissonance between social work's engagement with criminalized women and social work values. Specifically, I found that social work discourse passively accepts the logic of punishment and supports dominant ideology surrounding gender and crime while concurrently attempting to redress the consequences of such constructions through social justice values. I conceptualize this as a discursive struggle over the meaning and purpose of social work, a struggle that embodies some of the most salient historical and contemporary tensions in our field related to our professional identity and an increasing drive toward professionalization (Reisch, 2013).

I argue that social work's growing dedication to practices that seek to adjust the psychological fortitude of criminalized women relies on broader cultural discourses of responsibilization, which reproduce, rather than interrupt, criminalization, and divert attention away from the need for social and economic change. My analysis exposes how social work is implicated in processes of criminalization, and propels a shift in emphasis from individualized service delivery, aimed at changing the behavior of individuals, to launching interventions that tackle structural injustice and inequity. Understanding the subtle and productive work of power to undermine our "good intentions" and aspirations 
for social justice requires us to rethink explanations for crime and our understandings regarding the purpose and necessity of the criminal justice system. 


\section{Dedication}

To my dear friend Mac, who had to take leave of this world before finishing his own

Ph.D. I miss you and think about you every day. And to my sweet grandmother who couldn't wait to have a "doctor" in the family. I'm sorry it took so long.

May you both rest in peace.

And

To my 30s, it's been nice knowing you. 


\section{Acknowledgements}

First and foremost, I would like to thank my chair, Stéphanie Wahab. There are not words to describe my gratitude and indebtedness to you. I never imagined that my path would be graced by such a brilliant, fierce, and deeply generous scholar. I am in awe of your intellectual bravery and human decency. Thank you for your support and guidance, and for always drawing me into a deeper dialogue with my work. I would also like to thank the rest of my committee: Ben Anderson-Nathe, Mary Oschwald, and Melissa Thompson. It has been an honor and a privilege to work with each of you through the years. Your input and feedback have made me a better thinker and scholar.

The road to this dissertation has been long and circuitous. The list of people who have accompanied me, endured me, supported me, and nurtured me along the way is vast. I specifically want to thank Jennifer Muthanna and Kevin Cherry. We have been in this together from the beginning, or very close to the beginning. You have stuck by me through it all. Thank you for believing in me, inspiring me, and proofreading for me. I love you both. I also want to thank my oldest friends Courtney Johnson and Jacob Amadon. In spite of geographical distance and vastly different lives, you both remain a force that keeps me grounded, continually reminding me of who I am in this world. To everyone else who has been in, out, and around, you know who you are. You are in my heart. Finally, this past year has been full of surprising connections and reconnections with people who have helped me remember why a career in academia is still a worthwhile pursuit. I'm looking forward to the next chapter together. 
TABLE OF CONTENTS

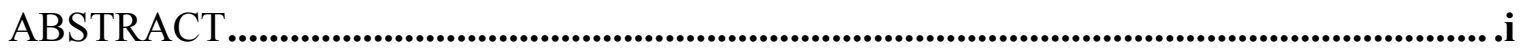

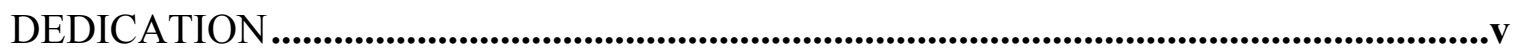

ACKNOWLEDGEMENTS .......................................................................................................vi

LIST OF TABLES............................................................................................................................ ix

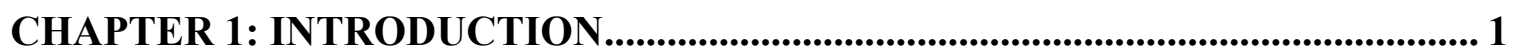

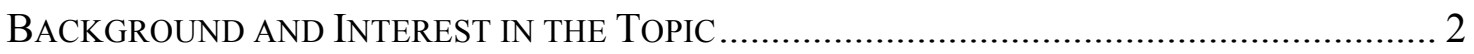

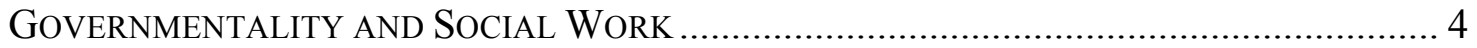

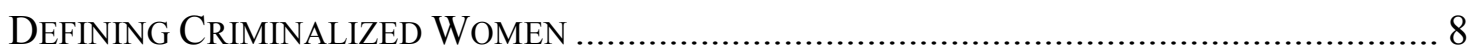

TRANSCARCERATION AS A FORM OF GOVERNMENTALITY ............................................ 12

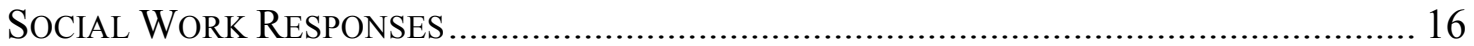

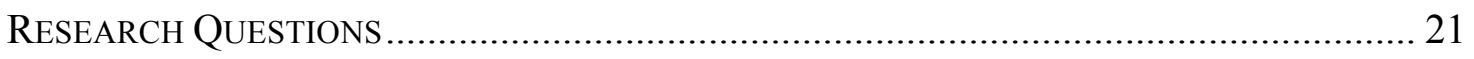

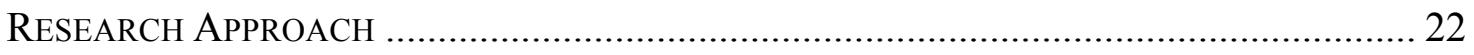

OUTLINE OF THE CHAPTERS …………………………….................................... 25

CHAPTER 2: THEORETICAL INFLUENCES .......................................................... 29

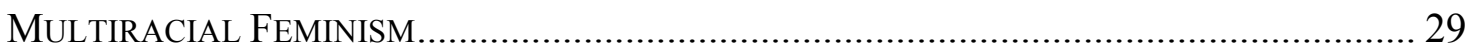

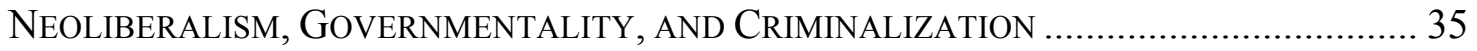

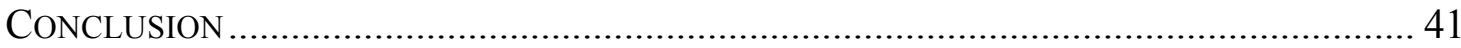

CHAPTER 3: CONTEXTUALIZING THE RESEARCH............................................ 43

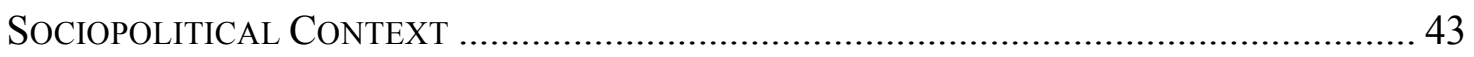

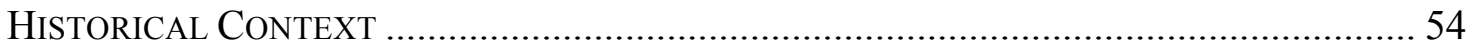

CONTEMPORARY INSTITUTIONAL RESPONSES ........................................................ 70

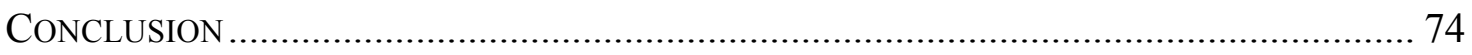

CHAPTER 4: RESEARCH DESIGN ............................................................................ 78

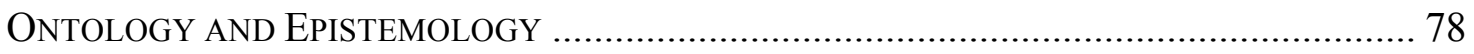

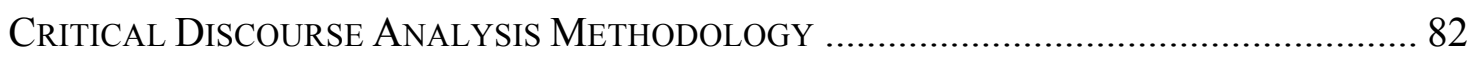

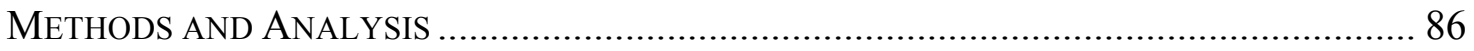

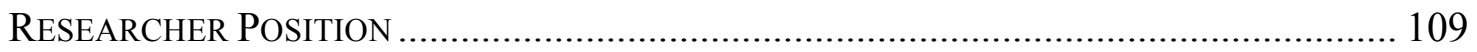


Evaluative CRITERIA AND ETHICAL CONSIDERATIONS ...................................... 110

CHAPTER 5: FINDINGS AND ANALYTICAL DISCUSSION ............................ 115

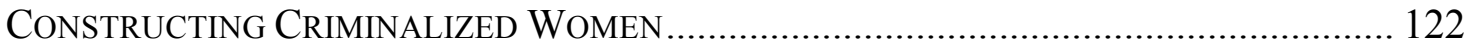

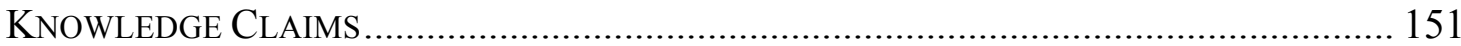

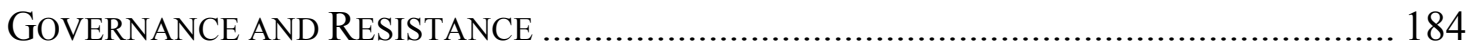

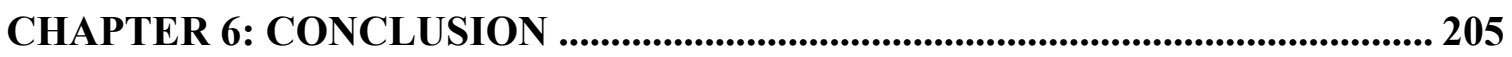

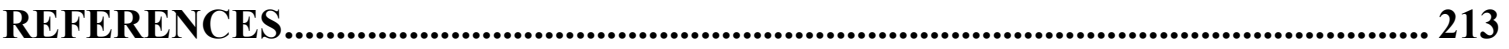

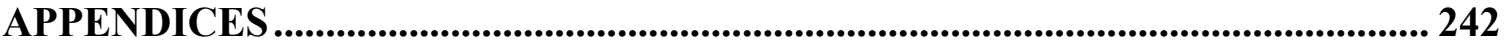

APPENDIX A: List OF SOCIAL WORK JOURNALS GENERATED FROM EIGENFACTOR. 242

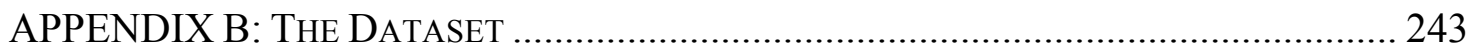

APPENDIX C: Number of Articles, Per Journal, Included in SAMPle ............ 248

APPENDIX D: DETAILED BREAKdown of ARTICLES PER JOURNAL......................... 249

APPENDIX E: TEMPLATE FOR STRUCTURAL ANALYSIS ........................................ 252

APPENDIX F: ILlUSTRATION OF STRUCTURAL AND DETAILED ANALYSIS ............... 253

APPENDIX G: CATEGORIES FOR ANALYSIS AT THE LEVEL of LANGUAGE ................ 267 
LIST OF TABLES

TABle 1: JÄGER \& MAIER'S AdAPTED Framework FOR DETAILED ANALYSIS ..............107 


\section{Chapter 1: Introduction}

The last forty years have seen a dramatic increase in the incarceration of women worldwide (Carlton \& Segrave, 2016). Consequently, the mass incarceration of women has become a growing and complex field of scholarly interest. There is a considerable amount of research regarding women entangled in the criminal justice system and a range of related issues including: "pathways" to criminal justice involvement, experiences in prison, treatment options, and the consequences of criminalization for children, families, and communities. Scholars have also begun to investigate the lives of women postincarceration and the ways in which criminalization extends beyond direct involvement with the criminal justice system and intersects with other systems impacting the lives of criminalized women, specifically social service systems. Such research has particular implications for social work practice and research, yet it is a topic rarely covered in schools of social work and marginally discussed in the literature. Therefore, it is difficult to intuitively understand where social work stands in relation to issues of criminalized women and what useful practice and research look like in this area.

The study that lies in these pages is a Critical Discourse Analysis of how criminalized women are discursively constructed in social work high impact journals. The aim was to make visible the current constructions of criminalized women in social work, to understand the knowledge that is produced through such constructions, and to explore how that knowledge supports/shapes certain kinds of research and practice with criminalized women. This chapter is an introduction to the study and the organization of the dissertation. First, I provide a discussion of my own background and what brought me to this topic. Then I discuss the rationale, approach, and significance of the research. The 
last section provides an overview of how the dissertation is structured and what to expect in each chapter.

\section{Background and Interest in the Topic}

Though my professional experience and academic studies have included a range of seemingly disparate topics, a consistent interest and focus has included various aspects of the increasing criminalization of women in the United States and other industrialized nations. I first became aware of the issues facing criminalized women in 2004, while interning at a mentoring program for youth with incarcerated parents. Concurrently, I was attending an MSW program and learning more about the socio-political realities that shape people's lives. I was learning to think about the power relations embedded in the helping relationship and to ultimately re-think everything I thought I knew about the world and the way in which I imagined myself as a social worker. This presented problems for me in the "real world" of social work practice.

The work at the mentoring program, like that of many social work agencies, relied on narratives of blame and responsibility. The agency viewed the children of incarcerated parents as victims, not of an unjust system or structural inequality, but of irresponsible and "deviant" parents. Mothers were held particularly accountable. Because of their deviations from the gendered expectations placed on motherhood, incarcerated mothers were seen as being doubly deviant and especially at fault for their child's predicament. Thus, the mentoring agency further stigmatized the mothers for not conforming to societal norms of motherhood and womanhood.

Alongside my experience at the mentoring program, I was learning about the structural factors that often lead people to commit "crime" and about the racism deeply 
embedded within the criminal justice system. I was coming to see that crime and imprisonment have more to do with social failings than individual failings. The culture within the mentoring agency was driven by neoliberal discourse and ideology centered on the myth of meritocracy, which saw people as responsible for their own positioning in the world. I could not make sense of the contradictions between what I was learning in my master's program and the way these social workers practicing in the "real world" engaged in their work. As a dewy eyed MSW student, I did not understand at the time that this was, in fact, the norm; an MSW student intern who hung around and questioned the agency's entrenched narratives was not exactly a welcome entity. I felt alienated and unsettled by the space between my education and the practice inside this agency. Needless to say, my internship there was short lived. I moved on to placements that were a better fit with my politics and values, and I was able to regain a certain sense of security in social work. Still, the issue of incarcerated women had captured my attention and I continued to explore this as a topic of study while in my MSW program.

I graduated from that program so excited and proud to be a social worker. Even now, writing those words brings tears to my eyes. It's disheartening to think about the eager hopefulness embedded in my social work education and the almost immediate fall from grace that came upon entering the world of doing social work as a job. I think of my own students and the way I teach them to think about the world, their clients, and their roles as social workers, and I wonder if I am doing them a disservice. Is it only a matter of time before progressively minded students meet disillusionment and isolation in real world social work practice? How do I prepare them for the dilemmas and contradictions they will inevitably face? 
In the first draft of my proposal for this dissertation, my chair commented that I did not leave much space for social work to interrupt the process of reifying neoliberal ideology. I struggle with this because my initial education in social work is what brought me to the place of even being able to notice, analyze, and ultimately challenge such processes. I think about the keen optimism my education brought me and I wonder: when did I become so cynical about social work? After much reflection, I do not think the cynicism is completely unwarranted. My practice experience has taught me that social workers often label, diagnose, and police clients "for their own good." The conditions that shape the lives of those same clients are rarely considered. Instead, practice strategies are deployed which focus on the assessment and management of risk, all the while claiming that that's what is best for the client, or as Margolin (1997) puts it, "under the cover of kindness."

Upon entering my doctoral program, I wanted to resume studies regarding incarcerated women, but I also needed to find a way to make sense of what I was seeing in my own practice experience. It was from this that I became particularly interested in the ways in which criminalization extends beyond the criminal justice system and the role of social services in the expanding net of carceral control. It is here that feminist and post-structural scholarship reinvigorated my intellectual life.

\section{Governmentality and Social Work}

Though I was not familiar with this term at the time, I realize now that much of what I was struggling with in my own practice experience was trying to find my place in what Foucault (1991) calls the web of governmentality in which social work participates. Foucault conceptualized governmentality as a regime of power that permeates the fabric 
of society and dictates norms for behavior. Grounded in post-structural understandings of power, governmentality rests on the assumption that power and knowledge join to create discourse, and through discourse we come to accept reality. Discourse leads to shared ideas, images, and representations that become dominant, or as Gramsci (1971) dubbed them, hegemonic. Power, then, operates both structurally and ideologically and "is exercised and relational rather than merely oppressive or repressive" (Strega, 2005, p. 225). It is everywhere and everything.

As Foucault saw it, the knowledge claims and practices of the social sciences play a large role in governmentality by legitimizing notions of what is normal and healthy (Parton, 1998). Individuals then internalize and act on these criteria for normalization and go on to regulate their own behavior and the behavior of others based on such criteria. According to Foucault, notions of power as being solely centralized are misleading and incomplete (Rose, 2000). Rather, he saw power as diffuse and spread throughout society and centered the idea that power does not just act on subjects, but also constitutes their roles in society and their subjectivities (Larner, 2000).

Drawing on such analyses, Rossiter (2001) discusses governmentality in relation to the discourses of helper and helped, which she sees as constituting social work's identity and practice. She states that "civilizing missions produce the Other in need of help, thereby sustaining the identity of the helper as good, innocent, and helpful" (para. 6). She goes on to highlight how power relations between helper and helped are then obscured while sustaining a singular identity and role for each. She argues that what we think of as "doing social work is an identity position that facilitates governmentality" (para. 16). Such analyses raise many questions regarding the "problem of helping," 
questions related to who has the power to define what help is or looks like, who gets to decide what is best for another, what constitutes outcomes or success, and ultimately, whose knowledge is privileged. Such questions weigh on me when I consider the nature of social work practice. Orlie (1997) labels the deployment of expert knowledge as a potential trespass, not for any malicious intent, but rather for what it leaves out. Social workers manage and control the conduct of others through "common sense" (and I would add that this common sense is often classed, racialized, and gendered) expectations for behavior, which leave out many other explanations for behavior. For example, Pollack (2013) demonstrates how women's post-prison experiences and identities are shaped through their relationships with mental health professionals and parole officers. The women in her study highlight the ways in which discourses of risk are embedded in these interactions. They speak of how professional narratives of risk often reign at the expense of how they understood their own experiences and needs. Pollack contends that how we are known and how we come to know ourselves through the discourses of those in power are epistemic concerns. Her discussion highlights how professional discourse becomes imbued with truth. In her study, mental health professionals had the power to decide how a woman's situation would/should be understood and what knowledge regarding a woman's identity would be considered valid. Therefore, the deployment of expert knowledge has the potential to be not only an act of trespass, as seen by Orlie, but also an act of epistemic violence (Pollack, 2013).

Governmentality analyses are not new to social work and have inspired much discussion and debate on neoliberal evolutions in the welfare state and other forms of governance (Parton, 1998; Pollack, 2008; Rossiter, 2000; Webb, 2003). Scholars have 
made the case that with the rise of privatization, managerialism, and professionalization, social work is inevitably involved in processes of governmentality. Further, governmentality scholars posit that social services and punishment are inextricably linked under a neoliberal political framework and that "mechanisms of discipline" are not confined solely within the boundaries of the criminal justice system (Garland, 2004; Rivest \& Moreau, 2015). For example, Green (2007) examined how risk plays out in community-based services for adults. Drawing on Webb's (2006) and Kemshall's (2002) analyses which linked the rise of risk societies in late modernity to a narrow focus on individual choice, freedom, and responsibility in social policy and social work practice, Green illustrated how various layers of risk thinking infiltrate the practice of social workers so much that the pressure placed on practitioners to assess and manage risk is the most influential force shaping their practice. He explains that as the obligations of social workers become entrenched with the fulfillment of stringent regulations and procedures, the demand placed upon them to assess and manage risk moves social workers away from being in partnership with clients and toward governing them.

Similarly, scholars have noted that neoliberal processes and demands have moved social work away from a commitment to social justice and macro level work toward a preference for individual level service delivery (Gray \& McDonald, 2006; Webb, 2001). Gutierrez, Parsons, and Cox (1998) illustrate this point in their content analysis of the use of empowerment in social work journals. They found that most articles claiming empowerment focused on micro-level, individualized understandings of the concept. Furthermore, they contend that the focus on self-control, autonomy, and choice strips 
empowerment of its political meaning rooted in raising consciousness in order to promote collective action toward alleviating oppression.

\section{Defining Criminalized Women}

Before moving forward, it is important to discuss how I conceptualize the criminalization of women. These conceptualizations anchor the rationale for this research. Similar to governmentality scholars, feminist scholars have noted that the meaning of women's criminalization is "not to be found within official legal or penal rhetoric, rather it [can] be located within the practices, conventions, and discourses of the wider aspects of social life and social control" (Barton, 2005, p. 8). Social control occurs at the micro and macro levels, through both overt and covert mechanisms such as the use of force, ideology, socialization, and resource distribution. Foucault (1995) said, "In its function, the power to punish is not essentially different from that of curing or educating" (p.303). In line with this sentiment, I define the criminalization of women less in terms of criminal behavior and more in terms of the social control of gender.

Rafter (1990) defines social control as "the mechanisms by which powerful groups consciously or unconsciously attempt to restrain and to induce conformity, even assent, among less powerful but nonetheless threatening segments of society" (p. 157). Criminalization, then, refers to the selective application of criminal law to social behavior and involves regulation of such behavior through surveillance, policing, and punishment (Danner, 1996). The criminalization of women does so in uniquely gendered ways by making certain acts that are more likely to be committed by women, such as sex work, drug use while pregnant, low-level drug involvement, and certain crimes of poverty a crime. 
Here, it is prudent to pause and discuss some problems with the category "woman." Scholars of color, lesbians, and working class feminists have critiqued feminist scholarship that neglects attention to race, class, sexuality, and other dimensions of difference when examining the experiences of women (Collins, 1990; Rubin, 1986; Steedman, 1986). They argue that using gender as the only or primary analytic category creates essentialized definitions of women and universalizes women's experiences and needs. Crenshaw (1991) and others highlight the importance of utilizing an intersectional framework that examines how interlocking oppressions and intersecting identities shape gendered experiences. An intersectional framework acknowledges that the meanings of gender and women's experiences are not universal, but rather bound up in other identities such as race, class, and sexuality. While I acknowledge gender's significance and utilize the word "woman" throughout this dissertation, I also rely on an intersectional framework that considers gender in relation to other identities. Because not all women are criminalized in the same way or for the same things, and because women are subject to social control based not on gender alone, but on how their multiple identities intersect, an intersectional analysis is necessary in order to more fully understand how interlocking oppressions and intersecting identities shape the gendered experiences of criminalized women.

Feminist scholars have been at the forefront of challenging and interrogating the social construction of crime, as well as the ways in which dominant discourses individualize and pathologize women's “criminality” (Boyd, 2006; Comack \& Balfour, 2004; Faith, 1993; Laberge, 1991; Pollack, 2007). These scholars make the case that, contrary to dominant ideology, criminal behavior and "crime" itself are defined more by 
policy and the prevailing socio-political and economic climate than by faults and deficiencies located within the individual. From this analytic viewpoint, common labels used to identify criminalized women, such as "criminal," "female offender," "woman in conflict with the law," and "woman in trouble," obscure the structural factors (i.e., poverty) related to the context of law breaking. Further, such labels dehumanize those entangled in disciplinary arrangements.

Laberge illustrates specific concerns with the category "criminal":

Firstly, the notion reinforces the impression that crime is the manifestation of a personal essence. By now, a large literature has developed around the recognition that crime is an historical construct. There is no consensus on what constitutes 'crime', nor is the term itself neutral. Once this is recognized, it is impossible to maintain that 'crime' is a fundamental characteristic of a given individual. Secondly, what we study is a social product, the outcome of interactions between women and state agencies. The nature of the correspondence between the 'dark figure' of criminality and the official volume of criminality is unknown to us....Thirdly, the designation of 'criminal' elicits powerful and usually very negative images.....Even a summary examination of the criminality generated by women very clearly reveals the non-dangerous nature of women's infractions (1991, p. 50).

Like Foucault (1995), Laberge situates her argument in the recognition of crime as a social and historical construct. Highlighting the diverse meanings of "crime" across time and space disrupts the belief that crime is a natural phenomenon occurring within problematic individuals. 
The terms "criminalized women" and "women's criminality" have very different meanings and allow different pictures to unfold concerning what/who is problematic. In the latter, the concern is on the behavior of an individual woman. In the former, the concern is on how women are constructed as "criminal" and how they are regulated because of that construction. Furthermore, the ways in which multiple identities and social locations intersect to prescribe meaning and construct a woman as "criminal" are crucial to understanding the underlying systems of oppression and inequality inherent in the criminal justice system. As Neve and Pate (2005) state, "it is clear that it is the law that is increasingly coming into conflict with people, especially poor, racialized, and disabled women, rather than women who are coming into conflict with the law" (p. 27).

A sketch of the incarcerated female population helps bring these points into focus. Women involved in the criminal justice system are disproportionately from economically disadvantaged groups, with women of color being vastly overrepresented (Carson, 2018; Kajstura, 2018). Nationally, the likelihood of being incarcerated is 1 in 118 for White women, as compared to 1 in 45 for Hispanic women, and 1 in 19 for Black women (Sentencing Project, 2018). The element of racism is so prevalent that Michelle Alexander (2012) refers to mass incarceration as the most pressing racial justice issue of our time. Women are increasingly (and mostly) incarcerated for drug offenses, property crimes, and public order offenses ${ }^{1}$ (Carson, 2018; Kajstura, 2018). The violent crimes for which women are typically incarcerated are largely in relation to defense or the murder of an abusive partner (Comack, 2014). Constructions of incarcerated women (and I would

\footnotetext{
${ }^{1}$ Public order offenses are comprised of violations that are seen to interfere with public life. Prostitution, public drunkenness, and loitering are examples of public order offenses.
} 
say most incarcerated populations) as dangerous and a risk to public safety are inaccurate; they are based on anomalies and sensationalized media representations, which shape commonsense understandings (i.e. dominant discourses) of crime and what defines a "criminal" (Comack, 2014).

A more accurate picture shows that women are primarily convicted for crimes of poverty that reflect systemic inequalities and discrimination based on their gendered, racialized, and classed social locations. Understanding the characteristics of who is likely to be criminalized, and for what, highlights the role that race and poverty play in the lives of criminalized women. When we are able to understand the nature and extent of women's law breaking as well as the context in which that law breaking takes place, we can conceptualize that women are criminalized more than they are actual criminals.

\section{Transcarceration as a Form of Governmentality}

As discussed previously, institutions of governmentality that serve to regulate and discipline behavior already exist; however, I would argue that once someone is criminalized, the forms of governmentality that shape their life take on a different nature and are largely responsible for contributing to "success" or reinforcing criminalization (Maidment, 2006). Researchers have documented that criminalized women come into contact with and are adversely impacted by various institutions of governmentality before and long after incarceration (Carlton \& Segrave, 2016; Maidment, 2006; Richie, 2001; Shantz, Kilty, \& Frigon, 2009). These institutions include child welfare, education, health, and welfare: all spheres in which social work plays an obvious role. Bhattacharjee (2002) discusses how such agencies are becoming infiltrated with a "culture of law enforcement" increasingly serving policing and surveillance functions. For example, 
some scholars note how mandated workfare programs and increasingly stringent eligibility criteria for welfare recipients mirror the techniques of surveillance, regulation, and control embodied in the criminal justice system (McCorkel, 2004; Pollack, 2010). Further, Parton (1998) highlights how penal risk management practices have become ubiquitously taken up in child protective services through the use of risk assessments. With the power to discursively define what appropriate behavior and "success" look like, as well as to bestow needed resources, these institutions have taken a central role, right alongside criminal justice, in maintaining dominant notions of social $\operatorname{order}^{2}$ (Johnson, 1996). In fact, researchers document that when people are no longer institutionalized, other less visible social, legal, and medical structures step in more subtly to provide regulation and control (Maidment, 2006). For example, community based programs (such as mental health courts, mandated drug treatment programs, and house arrest, among others) are utilized as less punitive "alternatives" to incarceration but still target and regulate behaviors that would typically be criminalized. Scholars label this widening of the net of social control as "transcarceration" (Lowman \& Menzies, 1986; Maidment, 2006).

Transcarceration is a way of conceptualizing criminalization outside the immediate context of the prison; it suggests that the primary mechanisms of control have moved beyond institutionalization and into the community and home. Transcarceration attends to the "shifting conceptual frontiers between social control and coercive control" (Lowman, Menzies, \& Palys, 1987, p. 2) and the blurring of boundaries between the two.

\footnotetext{
${ }^{2}$ Dominant notions of social order can be thought of as acceptable patterns of relating and behaving.
} 
Building on Cohen's (1985) conceptualizations of social control as inclusive (institutional settings) and exclusive (community settings), transcarceration asserts a view of formal social control that is broader than incarceration and institutionalization (Lowman \& Menzies, 1986). Shaped by white, middle class assumptions of normality, transcarceral controls are also inherently gendered and racialized and include ideology and strategies pertaining to welfare, reproduction, education, and health (Davis \& Faith, 1987; Maidment, 2006). Maidment (2006) expounds on this when she says, Transcarceration, then, looks to cross-institutional arrangements between the systems of criminal justice, mental health, and social welfare, in which 'clients' of the criminal justice system are shuffled from one section of the help-control continuum to another. By managing 'clients' in or outside the institutional setting, the correctional machinery expands to encompass health, welfare, social services, child protection, education, and housing-all of which translates into decentralized control and increasingly entails the fitting together of subsystems rather than the consolidation of one agency in isolation from its alternatives ( $p$. 269).

In other words, social control is broader, less visible, and more effective (Davis \& Faith, 1987). Or as Balfour (2006) posits, punishment is relocated into the community. In an analysis of a community-based electronic monitoring program, Maidment (2002) illustrates how community corrections serve as a regulating force in women's lives with explicitly gendered outcomes. In her study, she traced the differences in the way men and women experienced the program. She found that for men, the program was useful and a 
welcome change to life in prison; they had adequate amounts of support and usually lived with women (mothers or partners) who would take care of their children and daily household needs. For women, who often had sole responsibility for their homes and children (and were also under supervision of child welfare), the electronic monitoring proved to be a burden that was not always a welcome alternative to incarceration. The women in her study were expected to be fully engaged mothers, but the restrictions placed on their mobility through the electronic monitoring interfered with their ability to adequately fulfill their responsibilities as heads of households and as mothers. Further, whereas men's relationships with women were often deemed a protective factor in that they provided a solid support network to prevent parole violations and recidivism, women's relationships with men, especially if there had been a history of domestic violence, were far more likely to be deemed as a risk factor for recidivism, thereby increasing restrictions and monitoring. This is a stark example of the discursive and material effects that come from conflating victimization with risk for women on parole. The conflation constructs the woman as "risky," which then prompts increased restrictions and monitoring. Increased restrictions further limit her freedom and her ability to meet the various mandates of the agencies she is bound up in, thereby evoking more ill suited constructions of her identity (i.e. risky, dangerous, neglectful mother, criminal) which prompt further regulation and intrusion into her life. The cycle goes on. "Risk thinking" (which I will discuss more in depth later in this dissertation) normalizes notions of appropriate conduct, thereby creating a "risky" other who then needs to be further surveilled under the gaze of the "expert." 
In this way, while women may avoid a return to prison, they seldom break free of legal, medical, and "psy" professions. Social work plays a notable role here in relation to being the managers of child welfare requirements, the gatekeepers for social assistance provisions, and the deliverers of many mandated substance abuse and mental health treatment programs. Intrusion into women's lives is taken up by regulatory rather than criminalizing processes, by community agencies that receive governmental funding. As Balfour (2006) states, the "social control networks of surveillance and observation within the community have expanded the gaze of the state" (p. 170). Thus, criminalization extends beyond the context of the criminal justice system and includes transcarceral mechanisms of control such as community supervision, behavioral restrictions, and mandated treatment (Maidment, 2006). Transcarceration, as I see it, is a specifically criminalized form of governmentality.

\section{Social Work Responses}

As others have noted, social work occupies a significant space in deploying regulatory practices that further neoliberal governance (Carton, 2014; Parton, 2008; Pollack, 2008). In particular, social work's increased focus on the assessment and management of risk and growing dedication to practices that seek to adjust the psychological fortitude of individuals give it its increasing foothold in neoliberal governance. Given the diffuse systems of social control that structure the lives of criminalized women upon release from prison (as conceptualized by governmentality and transcarceration), I believe it is necessary to turn our gaze toward the professional systems that play a role in regulating the lives of criminalized women (Davis \& Shaylor, 
2001). From the lens of governmentality, it is these professionals who play a role in reinforcing or interrupting processes of criminalization.

Social work has historically been situated in a positivist school of criminological thought regarding practice with "offenders" and crime prevention (Roberts \& Springer, 2007; Wilson, 2010). The characteristics of positivist criminological thought include an attempt to explain and predict criminal behavior and, thus, modify it through individualized intervention. In an attempt to predict criminality, risk assessments are used to identify and target people who are "at-risk" of certain behaviors. In other words, social work, despite its embrace of an ecological model, has historically assumed a view that crime and criminal behavior are caused by individual factors, such as mental illness (Wilson, 2010). This is problematic because it frames women's involvement in crime as merely psychological in nature (Pollack, 2008) and lends itself to individualized responses and interventions, which erase the link between inequality and criminality (Donohue \& Moore 2009; Kendall, 2004; Shaw \& Hannah-Moffat, 2004). Still, as I will show in this dissertation, individualized treatments (which focus on individual choice and even empowerment) have become the dominant model of service delivery in social work with criminalized women. They are deeply gendered and aimed at changing women's thoughts, attitudes, and behaviors (Balfour, 2006; McKim, 2008; Pollack, 2007).

For example, in an examination of the reintegration experiences of women released from prison, Pollack (2010) illustrates how therapeutic programming with criminalized women works in specifically gendered ways. She emphasizes the role that the assessment and management of risk in social work practice plays in shaping women's subjectivities upon release from prison. Grounded in assumptions that criminal behavior 
in women is linked to low self-esteem, social work efforts to rehabilitate them focus on reducing women's risk by raising their self-esteem. The logic goes that greater selfesteem will empower women to make better decisions. Yet, as Pollack points out, this logic ignores the reality that choice is constrained by social and power relations, and that the choices people makes are not always the result of poor self-esteem, but rather the result of the options and opportunities (or lack thereof) available to them.

Similarly, Goodkind (2009) illustrates how individualized framings are deeply embedded in residential treatment programs for young women involved in the criminal justice system. She found that programs, which professed a feminist approach to their work with young women, operationalized their feminism by way of empowerment groups which sought to build self-esteem and enhance confidence among the young women. Her interviews with program staff revealed the underlying assumption that the enhancement of self-esteem and independence was necessary to mitigating poor decision making and reducing risk for recidivism. Goodkind contends that the focus on self-esteem is ultimately disempowering because it ignores how one's power to act is shaped by larger social conditions and relations. Additionally, she points out that the available evidence does not support a causal link between low self-esteem and delinquent behavior, which further problematizes empowerment as a strategy for risk management.

These examples highlight how efforts to build self-esteem in order to reduce deviant behavior miss the mark in that they conflate freedom and agency, and construct the self as contained within the personal rather than as a product of larger social relations (Hannah-Moffat, 2004). In effect, self-esteem based practices reify neoliberal discourse and intensify patterns of transcarceration. Cruikshank (1993) explicitly links the 
bolstering of an individual's self-esteem and self-determination to processes of governmentality. She states, "Self-esteem is a technology of citizenship and selfgovernment for evaluating and acting upon ourselves so that the police, the guards, and the doctors do not have to" (p. 330). By internalizing notions of normalization, people can then become sensible managers of their own risk. Further, Pollack (2010) discusses how a woman's ability to attain things such as parole, welfare, housing, and custody of her children hinges on her willingness to cooperate with efforts to normalize them.

In the context of mass incarceration and transcarceration, it is inevitable that criminalized women will be answerable to and come in contact with many different human service professionals, particularly social workers, in their daily lives. In turn, many social workers can expect to work with criminalized populations. As stated in an NASW report on the state of criminal justice social work in the United States:

There are many thousands of social workers working in criminal justice settings, working with criminal justice populations, or both. It is likely that most criminal justice social workers also practice in the areas of behavioral health and case management (Wilson, 2010, p. 2).

The life experiences of many criminalized women include poverty, racism, severe trauma, substance abuse, and mental health problems (Chesney-Lind, 2002; Franklin, 2008; Sokoloff, 2005). This creates a set of complex needs and challenges for criminalized women, particularly when re-entering a community after incarceration, while under community-based supervision, or while trying to access needed services (Richie, 2001; Spjeldnes \& Goodkind, 2009). The pressures and demands of child welfare and criminal justice systems can be overwhelming, yet negotiating the 
complexities of these systems is central to their lives and crucial to their "success." Recognizing this, an National Association of Social Workers (2009) criminal justice briefing makes the following recommendations:

- Address issues surrounding and leading to disproportionate rates of incarceration for individuals of racial or ethnic minorities, juveniles, women, and undocumented individuals.

- Increase participation of professional forensic social workers and other mental health providers to assure culturally competent treatment and intervention for the growing population of incarcerated individuals, including mental health and substance abuse services.

- Assure safe, humane, and equitable treatment for all incarcerated individuals.

- Increase access to health care, educational, and vocational opportunities to assist incarcerated individuals with transitioning back to their communities. (p. 331332)

Providers, immersed in their own area of practice, may not be adequately informed of these complex issues and, thus, may be ill prepared to effectively meet the needs of their criminal justice involved clientele or to assist them in navigating the terrain (Roberts \& Springer, 2007). Indeed, recent research and an NASW policy statement on Social Work in the Criminal Justice System highlight the fact that despite increased exposure to and practice with criminalized populations, it is a topic inadequately covered in the social work curriculum and scantly addressed in the literature (Epperson et al., 2013; Jemal \& Graham, 2017; Wheeler \& McClain, 2015). Still, instructors in schools of 
social work often rely on the scholarly literature as an important pedagogical tool. Given the prominence of high impact journals, it is not unreasonable to assume that instructors may, though perhaps not exclusively, rely on them on a regular basis. Thus, it is prudent to explore how/if criminalized women and attendant issues are represented within that literature.

\section{Research Questions}

As such, I focused my dissertation research on a critical examination of the constructions of criminalized women that permeate the social work high impact journals. Further, I examined the implications these constructions have for shaping social work practice and research. Specifically, this dissertation examines social work high impact journals as a form of social work discourse. Discourse here is defined as "a way of knowing or constructing knowledge about a particular topic of practice: A cluster of ideas, images, or practices, which provide ways of talking about, forms of knowledge and conduct associated with, a particular topic, social activity or institutional site in society" (Hall, 1997, p. 5). Further, discourse is an "institutionalized way of talking that regulates and reinforces action and thereby exerts power" (Jäger \& Maier, 2009, p. 35). The role of discourse is paramount in constructing and creating meaning, attitudes, and knowledge about people. My analysis focused on interpretations of discursive practices: constructions and representations of criminalized women, how criminalized women are positioned and discussed in the texts, the knowledge that emerges from these constructions, and how social work(ers) is positioned and discussed in relation to criminalized women. 
Using a Critical Discourse Analysis (CDA) methodology, I investigated the following questions:

1. How do social work high impact journals construct and represent criminalized women?

2. What particular knowledge claims about criminalization and criminalized women are made through these constructions?

3. What implications do these constructions and knowledge claims have for social work practice and research with criminalized women?

\section{Research Approach}

Critical Discourse Analysis (CDA) was particularly well suited to address these questions for a number of reasons. Firstly, CDA addresses the way power and inequality are enacted and reproduced in text (van Dijk, 2001). Additionally, it has the researcher take an explicit political position by exposing and, ultimately, resisting dominance and inequality. Further, rooted in Foucault's theories of power and discourse, CDA begins with the assertion that power and knowledge(s) emerge from discursive practices (Chouliaraki \& Fairclough, 1999). CDA aims to identify knowledge(s) embedded in discourse and to examine how such knowledge is then materialized and embodied in social practices, how it creates subjects, and how it regulates conduct (Jäger \& Maier, 2009). In other words, how knowledge is connected to power. Suffice it to say at this point that this kind of critical exploration on discourse and knowledge has important structural implications for the future of social work.

While framing criminalization as a social rather than individual problem, I used CDA to explore how criminalized women are represented in social work high impact 
journals and the discursive effects these representations have on research and practice with criminalized women. Further, I was interested in understanding how/if social work participates in the criminalization/transcarceration of certain women as evidenced by this literature.

Multiracial feminism, post-structural notions of discourse, and Foucault's concept of governmentality anchored this research and provided the theoretical and analytical lens through which I explored the research questions. Situated within both critical and poststructural meta-theoretical frameworks, this structure provided a platform for attending to issues related to material reality as well as the social constructions of power and identity. Melding such distinct perspectives into a broader theoretical framework is not without its tensions. Pease (2002) asks, "If we argue that power is widely diffused through networks of social relations does it dissolve the critical theorists' claim that dominant groups possess power over subordinate groups?" (pg. 139). He thinks not, and goes on to assert that Foucault's view of power is not entirely incompatible with critical theory; acknowledging that power is diffuse does not require an acknowledgment that power is distributed, or used, equally among social actors. Further, Daly (1997) suggests that “working the boundary between 'the discursive' and 'the real world' out there" (p. 42) is not only possible, but also preferable. She contends that "working the boundary" provides fuller analyses of the social world and opens theoretical space for methodological innovation in the social sciences.

I agree with the assertions of Pease and Daly, and believe that the use of both critical and post-structuralist perspectives allows me to reject essentialism while still recognizing the very real ways subjectivities are constructed and confined by and within 
institutions. Denzin (2002) states that "everyday life represents a site where power, ideology, gender and social class circulate and shape one another" (p. 27). From a critical perspective, the intersections of sexism, racism, and classism shape how crime is constructed, who is viewed as worthy and unworthy, innocent and guilty, how individuals come into contact with the system, and the way the system responds to them once they are there (Chesney-Lind, 2006). From a post-structural perspective, the articulation of power plays out in the way language constructs subjectivities (Daley, 2010); constructions of deviance and crime are used to control those who defy standards for normality and to prescribe sanctions through which their conduct is regulated. Poststructuralism acknowledges gender and crime as social constructions, and therefore allowed me to attend to the ways in which these constructions emerge to shape knowledge about individuals as well as social work practice with them.

More specifically, my research focuses on the ways in which written language prescribes meaning and how such meanings shape the manner in which social workers intervene. This is more than just a semantic issue. Language is the primary vehicle through which knowledge is embodied and legitimized, shaping what it is possible to know in any given historical context (Foucault, 1972). Language sets the stage for the development of identities and subject positions: both the "criminal" and the "expert" identity/role. I pose these important discussions in the framing of my research as I wade through the terrain of social work scholarship in relation to criminalized women.

As previously discussed, I utilized CDA to explore the language used to construct images, representations, and knowledge about criminalized women in social work discourse. The ultimate goal of my project was to make visible the current constructions 
of criminalized women in social work, what knowledge is produced through such constructions, and how such knowledge sanctions certain kinds of research and practice with criminalized women, for the purpose of opening spaces of possibility for alternative discourses prescribing social work practice to emerge.

The implications of this research are significant. Social control/regulatory practices operate across spheres and institutions to criminalize women, and social work is likely to be one of these spheres. The need for this research is thus situated in a society where women are increasingly subject to punitive sanctions for decidedly non-criminal acts and where punishments continue to be inflicted long after women have been incarcerated and released. As Bosworth and Flavin (2007) assert, "we create a climate where the person's debt to society is never paid. We are, in effect, permanently disenfranchising an entire class of people and jeopardizing their survival" (p.218). Therefore, I hope my analysis provides useful insights and tools for thinking differently about criminalized women and the role of social work in relation to them.

\section{Outline of the Chapters}

Chapter 2 explains and contextualizes the criminalization of women using two distinct yet compatible frameworks of analysis: multiracial feminism and Foucault's notion of governmentality. Used in conjunction, multiracial feminism and governmentality offer a conceptual framework for exploring the construction of criminalization of women in contemporary social work discourse. These major theoretical models have informed my understanding of the issue and shaped my research questions. Drawing on Foucault's idea of governmentality, I outline how women are uniquely regulated and criminalized by diffuse networks of power through neoliberal 
policy and ideology. Multiracial feminism helps explain how gender, race, class, sexuality, and other categories determine which women are criminalized, what they are criminalized for, and the severity of their criminalization. Together, they provide a platform for analyzing the globalized political and economic realities that impact women and lead to criminalization. These perspectives make it possible to dispute dominant discourses concerning women's offending which individualize and pathologize women; they allow me to shift the focus away from individuals and onto the systems of social control that serve to define and confine "normality" and "deviance." In Chapter 2, each theory is first explained and then analyzed in relation to the issue at hand. Though a bit out of the ordinary, I believe that presenting theory before the literature review will give readers a necessary lens through which to more fully understand my engagement with the contemporary and historical context.

Chapter 3 provides an overview of the relevant literature. Here, I more fully locate the issue of criminalization within a broader sociopolitical context. This review explores the experiences of criminalized women in relation to the power regimes in which they are situated. I review historical and contemporary trends in order to trace the major ideological threads that shape current day penal policy and contemporary social service interventions. This is important because, by highlighting the various approaches to dealing with criminal behavior across time, we can see that ideas of crime and "the criminal" are socially constructed. Discourse both shapes and is shaped by social practices (van Dijk, 2001), as such social work interventions can be seen as taking an active role in constructing an "other" to be managed and "helped." After all, in order for there to be a deviant, there must be a normal; and in order to be a helped there must be a 
helper. Therefore, in the process of labeling and diagnosing clients, social work also comes to define itself. Yet such distinctions are neither straightforward nor natural, as such value-laden concepts are not impartial and are constituted in the discourses of those in power. When the construction of something goes unquestioned, its significance becomes naturalized and taken for granted (Juhila, Poso, Hall, \& Parton, 2003). Therefore, Chapter 3 (and this entire dissertation) is an attempt to disrupt taken-forgranted assumptions that drive research and practice.

Chapter 4 includes an overview of the methodology and research design. Tightly wound with the chosen methodology of CDA are theories related to language, power, and truth. Thus, in addition to a discussion of research pragmatics (methods and analysis), this chapter includes an extended discussion of ontology, epistemology, and the theoretical concepts framing CDA methodology. In closing Chapter 4, I review the limitations of my research, evaluative criteria, and ethical considerations.

Chapter 5 presents the study findings and provides an analytic discussion addressing the research questions. I discuss a number of co-existing constructions present in the data, focusing heavily on the overriding construction of risk. I trace the manner in which the construction of risk both relies on and reinscribes a strong neoliberal discourse on knowing and changing the "responsibilized" self. I then show how depoliticized explanations for crime and criminal justice involvement emerge through these constructions. I argue that these depoliticized knowledge claims serve to effectively depoliticize social work itself and foster a larger discursive struggle over the meaning and purpose of the profession. I end by highlighting how the construction of risk lends itself to individualized responses and interventions aimed at regulating and changing the 
behavior of individuals. I argue that in its reliance on practices of risk management and a preference toward micro-level service delivery, social work deploys regulatory practices that further neoliberal governance (Parton, 1998; Webb, 2003).

In the concluding chapter, I summarize the analysis and implications of this study and speak to the possibilities for future directions in social work research, practice, and education. A central aspect of this discussion encourages an ongoing critique of risk discourses and the ways in which hegemonic practice scripts within social work contribute to processes of criminalization and the expansion of the carceral state. 


\section{Chapter 2: Theoretical Influences}

This chapter discusses the theoretical influences that form the conceptual framework of this research. As stated previously, multiracial feminism and Foucault's notion of governmentality have informed my conceptualization of the criminalization of women as well as the development of my research questions. Specifically, they have helped me connect women's criminalization to the social, political, and economic concerns generated by neoliberal globalization and to conceptualize how power functions within social work practice. Together, they allow me to see how interlocking structural inequalities interface with micro-level interactions to construct policy and ideology. This conceptual framework attends to the role of discourse in shaping subjectivities and power relations.

\section{Multiracial Feminism}

Unable to locate themselves within theories resting primarily on the lives of white middle class women, women of color have articulated intersectional theories for analyzing gender (Collins, 1990; Crenshaw, 1991; Mehrotra, 2010; Phoenix \& Pattynama, 2006). One such theory, multiracial feminism, was conceived by women of color as a response to the tendency within mainstream feminism to universalize experiences of gender. Multiracial feminism centers race as a pervasive structuring category but also recognizes how "race shapes and is shaped by a variety of other social relations" (Zinn \& Thornton Dill, 1996, p. 325). The cornerstone of multiracial feminism is its focus on power relations inherent in difference. It focuses on how privilege and oppression shape individual opportunity and experience as well as larger cultural norms and ideology. 
The following concepts distinguish multiracial feminism from other feminisms. First, gender constructions and relations are based upon other intersecting and interlocking identities (Burgess-Proctor, 2006; Zinn \& Thornton Dill, 1996). In other words, people are gendered in relation to other locations such as race, class, sexuality, age, ability, etc. Additionally, people are socially situated within systems of power and privilege. Patricia Hill Collins (1990) refers to systems of inequality that are interlocking, not additive, which work together to shape identity and status as the "Matrix of Domination." Within this framework, systems and identities work through each other, and people experience their identities in different ways depending on their intersecting subjectivities within social structures.

Second, systems of power are seen to occur and intersect at all levels of society. For instance, gender, race, class, and sexuality play out in micro-level social interactions, cultural ideology, standards set for normality, and macro-level social policy (BurgessProctor, 2006; Zinn \& Thornton Dill, 1996). Systems of power operate together to create privilege as well as oppression; systems of race, class, and gender work simultaneously to create disadvantages for some, and opportunity and advantage for others. Individuals can be both oppressed and privileged simultaneously. In this way, multiracial feminism applies not only to racialized women, but also to white women and people of various genders ${ }^{3}$, classes, and sexualities (Zinn \& Thornton Dill, 1996).

Third, multiracial feminism highlights the relational nature of power. Power relations structure women's differences; differences are thought to be connected in structured, systematic ways. (Burgess-Proctor, 2006; Zinn \& Thornton Dill, 1996).

\footnotetext{
${ }^{3}$ A caveat being that multiracial feminism does not explicitly address the gender binary.
} 
Further, dominance and subordination mutually influence one another. In other words, some women are privileged precisely because other women are disadvantaged and vice versa. In this way, multiracial feminism avoids essentialism of the category "woman." Lastly, multiracial feminism attends to social structure as well as human agency (Burgess-Proctor, 2006; Zinn \& Thornton Dill, 1996) in its recognition of how structured systems of race, class, gender, etc. shape opportunity and available choices. In other words, we make choices (exert agency) based on the conditions that shape our lives and the opportunities available to us, which are largely shaped by our identities and social locations.

By "underscoring race as a power system that interacts with other structured inequalities to shape genders" (Zinn \& Thornton Dill, 1996, p. 324), multiracial feminism highlights the fact that race affects all women but in different ways, namely by privileging some and disadvantaging others. This is particularly crucial in an analysis of the criminalization of women because of how Whiteness works to construct idealized notions of femininity and "appropriate" behavior, which then become held up as the norm for all women.

Intersections of identity, social locations, and "crime." As multiracial feminism purports, social identities shape how we interact with our environment and how we are constructed by society (Zinn \& Thornton Dill, 1996). Social identities reflect not only how individuals experience themselves in the world, but also how the world responds to them (Shields, 2008; Winker \& Degele, 2011). Women are qualitatively as well as quantitatively criminalized in different ways based on their social locations. Intersecting identities define and shape how behavior is labeled as normal or deviant, 
who is more likely to be criminalized, and how woman are criminalized. Therefore, interlocking systems of oppression contribute to what constitutes crime, who is defined as "criminal," and how those individuals are dealt with within systems of power.

Conceptions of crime, who is deemed as "criminal," and the behaviors that are constituted as "criminal" are based on dominant political, economic, and social ideologies of any given time (Abramovitz, 1997). In Gregg Barak’s (2004) words:

To begin with, we regard the criminal justice system as a culturally powerful, label conferring institution that has evolved in relation to the changing definitions of 'crime' over time. Additionally, we view the defining of 'crime' and 'criminals' as a product of moral agents, social movements, political interests, and media dissemination. In other words, what becomes a 'crime' and who becomes a 'criminal' are politically, economically, and socially constructed phenomena reproduced daily through various discussions in the streets, the home, the school, the church, the government, the courts, the airwaves, and other cultural bodies ( $\mathrm{p}$. 8).

The ways in which intersecting identities construct a woman as normal or deviant, and by extension, a "criminal," are crucial to understanding the underlying systems of oppression and inequality inherent in the criminal justice system. As I will illustrate in the next chapter, women have traditionally been judged based on concepts of "appropriate" female behavior and ideological myths of womanhood. Women's involvement with the criminal justice system, in particular, has been fashioned by historical notions of femininity, which in turn have been shaped by race, class, and sexuality, among other categories. Dominant notions of femininity evolved in relation to 
white, heterosexual, and privileged class contexts. Simultaneously, racism, heterosexism, and classism work to deny access to gender norms for certain groups of women. Furthermore, women who do not or cannot meet idealized notions of femininity are subject to various forms of suspicion, surveillance, and punitive measures. For instance, Theodore Roosevelt once asserted that white women who did not, or refused to have, large families were criminals against their race (Abramovitz, 1994).

Dominant notions of femininity not only color definitions of female criminality, but also shape how women are judged and treated when they come into contact with the law, both as victims and as perpetrators. For instance, Crenshaw (1989) discussed how Black women have historically fallen outside the protection of rape statutes as courts have instructed juries not to assume the chastity of Black women in the same way they do for White women. Certain women, based on their intersecting identities, are more likely to be labeled risky or deviant. This extends to social service systems as well. For example, in a study of the child protection system, Reich (2005) illuminated how the risk assessment of a mother's likelihood to harm her child often involved the mother's ability to exhibit a readiness to put the needs of her children before her own.

While recognizing that criminalization is just one mechanism through which privilege and inequality are maintained, the ways in which the criminal justice system enacts and reinforces structural oppression are profound (Travis, 2002). The disproportionate rates of incarceration among poor women and women of color are, in and of themselves, telling. Yet they also reflect larger systems of discrimination and structural sources of inequality. As Laberge (1991) said, "The combination of sex, race and social class creates specific groups who vary in their capacity to elude penal 
treatment, or, if in contact with penal agencies, to neutralize its negative effects" (p. 51). Surveillance and policing are concentrated in communities of color (Pewewardy \& Severson, 2003) and sentencing policies tend to be more punitive for people from marginalized social locations (Brewer \& Heitzeg, 2008). For instance, white-collar crimes, which have a devastating impact on society and are more likely to be committed by privileged classed individuals, are less likely than other types of crimes to be noticed and prosecuted; when they do garner attention, they are often dealt with in a much less punitive manner than other types of crimes (Pewewardy \& Severson, 2003). Further, when people from more privileged positions do come into contact with the law, they are less likely to be perceived at threatening or "risky" by the authorities and more likely to have greater access to needed resources, such as quality defense attorneys. This allows privileged individuals to subvert some of the more punitive sanctions that are readily applied to those who occupy marginalized social locations (Sanchez, 2007).

Feminists are increasingly advocating for an intersectional approach to analyzing the criminalization of women (Chesney-Lind, 2006; Ogle \& Batton, 2009; Shields, 2008). Multiracial feminism is particularly useful in such an analysis because it shifts our gaze from micro to macro, from individual behaviors to positions in society, which are shaped by interlocking identities and "isms." For example, Richie (1996) shows how intersecting systems of gender, race, and class are correlated to the criminal offenses committed by Black women who experience interpersonal violence. In her analysis, Richie explains how "some women are forced or coerced into crime by their culturally expected gender roles, the violence in their intimate relationships, and their social position in the broader society" (p. 133). 
Multiracial feminism's emphasis on race and interlocking oppressions that shape opportunity and experience is particularly salient in relation to Foucault's idea of governmentality and its corresponding interrogation of neoliberalism. Viewed through the conceptual lens of governmentality, government is re-conceptualized more broadly as actions and interventions that influence, structure, or regulate conduct and is not limited to the actions of the state, but also includes various institutions of socialization including school, medicine, the family, and various helping professions, like social work. These ideas are explained further in the following section.

\section{Neoliberalism, Governmentality, and Criminalization}

Governmentality. Toward the end of his life, Foucault articulated the notion of governmentality, which built on his previous ideas of power/knowledge and how they join to create discourse through which we come to accept reality. According to Foucault, notions of power as being solely centralized are misleading and incomplete (Rose, 2000). Rather, power is diffuse and spread throughout society and centers the idea that "political power does not just act on political subjects, but constructs them in particular ways" (Larner, 2000, p. 19). Consequently, governmentality has inspired much discussion and debate on neoliberal evolutions in the welfare state and other forms of governance. Emerging out of increasing globalization and deindustrialization, neoliberal ideology rests on the central tenets of individualism, choice and responsibility, market driven economics, laissez faire, and minimal government (Brewer \& Heitzeg, 2008; Comack, 2006; Mallory, 2006; Pollack, 2008). This set of values has driven shifts in policy agendas from a Keynesian approach, which saw government as necessary to ensure the basic social wellbeing of all, to one of deregulation and privatization (Larner, 2000). 
Neoliberal ideology eroded government commitment to social welfare and brought forth the evisceration of health, education, and social services in favor of policies that focus on individual responsibility and market based rationalities (Comack, 2006; Neve \& Pate, 2005). The dismantling of state responsibility for public good has brought with it a hyper focus on the individual as both the cause of and the solution to social problems. With this we see an increased reliance on disciplinary measures to manage social ills (Fisher \& Reese, 2010). In other words, the expansion of neoliberal policies involved a rolling back of the welfare state and a rolling out of the carceral state. The consequences of this are staggering: high rates of unemployment, inadequate tax structures, and subsequent cuts in social, welfare, educational, and medical spending. The depletion of a strong social safety net has thus resulted in high rates of poverty, homelessness, substance abuse, violence, and inequality (Sudbury, 2002).

Furthermore, viewed from the conceptual lens of governmentality, neoliberalism's decree for less government does not equate to less governance, but rather shifting forms of governance (Carton, 2014). According to the ideas of governmentality, neoliberalism can be seen as "shaping both political programs and individual subjectivities" (Larner, 2000, p. 9) which in turn creates a populace of individual actors, groups, communities, and agencies that regulate society because they have internalized and adopted neoliberal notions of security and responsibilization; what Pollack and Rossiter (2010) refer to as the "entrepreneurial subject." Governmentality is described by Sanchez (2007) as the "tactics, technologies, and institutions that constitute governance through populations" (p. 169). In essence, larger geographical spaces and operations of social control based on neoliberal ideology are created and diffused throughout society. 
Rose (2000) points out that under neoliberal strategies of rule, people and places are governed not from above (the state) but through diverse and diffuse technologies of government, which include ideologies and practices, infused into the very fabric of existence. Everyday places such as the workplace, educational institutions, and health and welfare agencies become mechanisms for surveillance, regulation, and control of conduct. Technologies of government congeal so as to become commonplace and invisible (Sanchez, 2007). Under this framework, non-conformity, rather than illegal acts, implicitly becomes the focus of governance. Like the critique provided by multiracial feminism, governmentality highlights a system of power in which individuals become governed by themselves and their social interactions through the production, internalization, and regulation of norms, rather than just through the application of law.

Rose (2000) portrays neoliberal societies as designed for inclusion and exclusion. Inclusive spaces are created to ensure security and keep outsiders out. Insider and outsider status are shaped by social locations, which are structured into society across lines of race, class, and gender. People from marginalized social locations tend to occupy spaces of "exclusion" and are subject to multiple forms of risk management, such as surveillance and policing, to which those from more privileged positions are not. In addition, social and penal policies tend to be more punitive for people from marginalized social locations (Brewer \& Heitzeg, 2008; Burgess-Proctor, 2006; Travis, 2002). Larner (2000) states that "neo-liberalism is both a political discourse about the nature of rule and a set of practices that facilitate the governing of individuals from a distance" (p. 6). As such, understanding contemporary neoliberal strategies as a form of governmentality provides a practical method of exploring the criminalization of women in contemporary 
society; criminalized women often occupy multiple zones of exclusion, and these theoretical understandings can help shed light on why and how women are being criminalized and punished in increasing numbers.

Social work and discourses of risk. As stated previously, neoliberalism has brought forth a slew of political rationalities and governmental technologies that enable shifting forms of governance. That is, governance is no longer limited to actions of the state. Increasingly, non-state actors are stepping in to prescribe and regulate a politics of conduct that ultimately aligns with governmental interests. Social work figures prominently in this space and the last 40 years have seen a drastic reconfiguration in the role of social work. A push toward managerialism ${ }^{4}$ and professionalization alongside obligations to funders that value efficiency over effectiveness, adherence to evidencebased practice interventions, and documentation of measurable outcomes has transformed social work in a number of ways. Social work has seen an increasing emphasis on resource management and individual level service delivery over community organizing and macro-level analysis/change. Subsequently, the assessment and management of risk has supplanted a more holistic approach to meeting client needs. Such changes reflect the neoliberal political climate and align social work with penal institutions in troubling ways.

Pollack (2013) contends that the narrow definitions of "success" that flow out of evidence-based practices limit practitioners' ability to engage effectively with

\footnotetext{
${ }^{4}$ Managerialism emphasizes a reliance on economic efficiency and calls for accountability marked by superficial counts of contacts, time in service, targets, etc. It is argued that the social democratic goals of social work are undermined as the administration of social services increasingly reflects management practices typical of the private sector (Harlow, 2003; Rogowski, 2011).
} 
criminalized women and take away women's ability to define their experience and needs for themselves. For instance, in qualitative studies, peer counseling and support has been found effective in helping women successfully reintegrate into the community upon release from prison (Richie, 2001; Sowards et al., 2006). However, stringent rules applied to women after they have been criminalized (by both welfare systems and penal systems) often hinge their success on staying out of contact with peers (Pollack, 2013). This is premised on a logic embedded in "risk thinking" that sees interactions with other offenders as a risk factor rather than a resilience factor. Therefore, an aspect of reintegration that women view as helpful toward meeting their goals not only goes unrecognized, but is also penalized. Pollack (2013) further argues that the underlying philosophy of risk reduction strategies is problematic because it embeds social work practice in a framework of risk rather than welfare.

Feminist scholars label risk management strategies, which define needs in terms of risk, as "risk thinking," and view it as a product of neoliberal governing (Pollack, 2008). Risk thinking has a long history in penal systems (Hannah-Moffat, 2006) and has increasingly become ubiquitous in social work practice (Parton, 1998). A central element of risk thinking involves predicting the likelihood of harm to self, others, or society. Individual level interventions based on notions of empowerment and choice are closely aligned with risk thinking. Such interventions not only reinforce notions of an individual needing to be fixed (Donohue \& Moore, 2009; Maidment, 2007; Pollack, 2008), but in their reliance on "self-surveillance" and "self-regulation" also serve as another form of governmentality. Risk based interventions often emphasize empowerment, "healthy" choices, and the development of self-esteem and self-management skills. Such 
interventions function to create subjects who can act upon themselves so the authorities do not have to. Women who internalize discourses of choice and responsibility are more likely to be seen as lower risk and therefore have increased eligibility for parole and other leniencies.

This is problematic for a number of reasons. First, placing emphasis on the management and regulation of individual risk obscures structural factors, such as poverty, addiction, unemployment, homelessness, and inadequate social assistance that bring women into contact with the criminal justice system (Hannah-Moffat, 2006; Pollack, 2008). Second, practices built on risk thinking consequently pathologize women's coping skills and resistance to poverty and violence. After all, it is often social exclusion that propels many women to engage in strategies of survival that become branded as “criminal.” Rather than examining factors such as poverty, exposure to violence, unemployment, and lack of childcare as structural factors needing to be remedied, risk thinking turns the consequences of social exclusion and oppression into individual issues that should then be effectively managed and resolved through therapy and empowerment (Pollack, 2008). Within this framework, men who use violence and forms of institutional violence are not considered to be the risk in need of intervention. This issue is exemplified in violence prevention programming that relies on educating girls and women about healthy relationships and strategies to keep themselves safe. Though a necessary component to violence prevention work, the practice reifies the dominant discourse that holds girls and women responsible for the violence they experience.

Lastly, thinking in terms of risk is a powerful normalization mechanism and relies on universalized notions of "woman." For women, issues of normality and risk are bound 
up in dominant notions of femininity. When one is deemed to fall outside of what is considered a universal "normal," actions are then taken to change the character, selfesteem, or thinking patterns of the "risky" person (Pollack, 2008). Further, within neoliberal rationalities, risk-avoiding behavior is seen as a moral imperative as it involves issues of self-control, responsibility, and self-improvement (Lupton, 1999).

Neoliberalism would have us believe that "crime" is a result of a failure of a defective individual. A Foucauldian analysis, on the other hand, recognizes crime as a historical construct situated in time and space (Laberge, 1991; Rose, 2000). The construction of risk is no different. Pollack (2008) states,

The many biases inherent within risk assessments have been clearly illustrated. It has been argued that risk assessments themselves play a large role in constituting what is defined as risk. Risk assessments have also been found to be highly subjective and moralistic enterprises (p. 1274).

Hannah-Moffat (2006) asserts that interpreting social exclusion, victimization, and needs as risk essentializes differences among women, neglects attention to structural disadvantages, and imposes normative criteria for success that are often based on white middle class values. As such, strategies of risk management and "preventative" community programs can be said to expand, rather than displace, the reach of the criminal justice system.

\section{Conclusion}

This chapter discussed multiracial feminism and governmentality as theoretical lenses through which to further explore the construction of criminalization of women in contemporary social work discourse. These theoretical perspectives examine the 
relationship between criminalization, structural inequality, and neoliberal globalization. They help me conceptualize power as not only repressive, but also productive in terms of shaping subjectivities. Through this conceptual framework, one can see how the role of social work(er) is reconfigured under a neoliberal climate so as to function as a part of the widening net of transcarceral control. The next chapter provides an overview of the relevant literature in order to examine the lager sociopolitical and historical context within which this research is situated. 


\section{Chapter 3: Contextualizing the Research}

This chapter surveys the relevant literature related to the criminalization of women in order to provide a larger context to locate this study of how criminalized women are constructed in the social work academic literature. Having a detailed review of the broader socio-political and historical context on hand is necessary for my project because CDA requires multiple dimensions of analysis. CDA requires the analyst to move between text and context in order to focus on what the discourse says, what it does, and the conditions that make the discourse possible. Text analysis alone can take one only so far; texts need to be analyzed, not in isolation, but rather as situated within their larger contexts.

This review of the literature discusses (1) the sociopolitical context that has given rise to mass incarceration and increased criminalization of women; (2) the consequences of increased criminalization and mass incarceration; and (3) historical and more contemporary perspectives on, and interventions with, criminalized women. It is my hope that the conceptual framework presented in the previous chapter provides the basis for a deeper understanding of the elements discussed in this literature review.

\section{Sociopolitical Context}

The 1970s marked a period of systematic mass imprisonment and heavy reliance on formal social controls targeted primarily at marginalized populations (Sokoloff, 2005). Since the mid-seventies, the war on drugs and the rise of the prison industrial complex has spawned a dramatic increase in the incarceration of women worldwide (Bagley \& Merlo, 1995; Chandler, 2003; Sokoloff, 2005). Poor women and women of color disproportionately fill the space in prisons, jails, and community corrections and the 
majority are incarcerated for non-violent crimes $^{5}$ (Sentencing Project, 2018b). The United States, in particular, has the fastest growing rate and the highest number of incarcerated women in the world (Chandler, 2003). Between 1950 and1980, the United States opened two to three new state and federal facilities for women every ten years. Beginning in the 1980s, women began to be criminalized and incarcerated at unprecedented rates; in 1970 there were 5,600 women in jails and prisons, by 1995 there were 75,000 (Sudbury, 2002), in 2016 there were 213,722 (Carson, 2018). To accommodate these sharp increases, 34 new facilities for women were opened in the U.S. during the 1980s alone (Chesney-Lind, 2002).

It is important to note that the population of imprisoned men (particularly men of color) also grew dramatically during the same time. Although women have always, and still do, reflect a smaller proportion of the imprisoned population, their rates of imprisonment have far outpaced that of men's (Sentencing Project, 2018b; Sudbury, 2002). While the number of incarcerated men doubled between 1985 and 1995, the number of women tripled (Sudbury, 2002). Currently 1.2 million women are under the supervision of the criminal justice system, including prison, jail, probation, and parole (Sentencing Project, 2018). Community supervision (parole and probation) accounts for the largest proportion at just fewer than 1.1 million. This latter number is significant because, as Angela Davis reminds us, mass incarceration is not just about physical bodies that are celled, but also about all the people who are doing time on the outside (Praxis Center, 2018). Furthermore, community supervision mechanisms, despite professed intentions of diversion, often function as a back door to incarceration.

\footnotetext{
${ }^{5}$ Disproportionate to white, privilege classed women.
} 
Dramatic increases in criminalization are largely attributed to punitive social policies and sentencing enhancements that have emerged in the later part of the $20^{\text {th }}$ century, such as "three strikes you're out," mandatory minimums, and truth in sentencing (Franklin, 2008; Mauer \& King, 2007; Sentencing Project, 2018b). Sentencing enhancements have been adopted on both the federal and state level and have been driven largely by the "war on drugs" (Zhang et al., 2009). Mandatory minimum sentencing guidelines have replaced treatment and community service options when drugs are involved and reflect a policy choice to treat substance use and addiction as a criminal issue rather than a public health problem (Mauer \& King, 2007). Mandatory minimums increase not only the number of people being sentenced to prison but also the time they spend there, causing rates of incarceration and overcrowding to increase dramatically (Mascharka, 2000; Pallone \& Henessey, 2003; Zhang et.al,. 2009).

Sentencing enhancements frame incarceration as the intervention best suited to deal with the problem of "crime" (Drake, Aos \& Miller, 2009; Lipsey \& Cullen, 2007; Tripodi et. al., 2011). However, research has shown that the widespread belief that incarceration, as well as the threat of longer-term sentences acts as a deterrent, is inaccurate (JFA Institute, 2007; Mascharka, 2000; Mauer, 2011; Oregon Criminal Justice Commission, 2011). In order for the deterrence argument to hold water, one must have some understanding of the consequences of an action before committing said action and one must also actively think about those consequences before committing an act. However, studies have shown that offenders in general, and ones under the influence in particular, are less likely to think about the consequences of their actions in the moment of committing them (JFA Institute, 2007; Mauer, 2011). Further, scholars note that many 
people who commit crimes do not have prior knowledge of sentencing laws necessary in order to be deterred from their consequences (JFA Institute, 2007; Mascharka, 2000; Mauer, 2011). Overall, increased sentencing has not been shown to have a deterrent effect and research does not support the use of increased sentencing as an effective drug control strategy (Greene, 2004; Pew, 2009).

In fact, as documented in their meta-analysis of correctional rehabilitation, Lipsey and Cullen (2007) show that incarceration actually works to increase recidivism. Likewise, research on mandatory minimum sentencing policies has shown that they are ineffective at reducing crime and result in increased incarceration rates and criminal justice spending (Gill, 2008; Vincent \& Hofer, 1994). For instance, Oregon enacted its first mandatory minimum (Measure 11) in 1995, increasing the prison population by $66 \%$ in the first year (Greene, 2004; Oregon Criminal Justice Commission, 2011). To accommodate these increases, Oregon's correctional budget has since increased more than $250 \%$ to spending that is currently at about $\$ 1.4$ billion dollars per year (Oregon Legislative Fiscal Office, 2011). Sentencing expert Michael Tonry states, “As instruments of public policy, mandatory minimums do little good and much harm" (as quoted in Gill, 2008, p. 56).

Advocates of strict sentencing guidelines posit that removing discretion in the sentencing process creates uniformity in sentencing and counteracts racial disparities in the criminal justice system (Brewer \& Heitzeg, 2008; Comack, 2006). What these proponents fail to account for is the myriad ways in which discretion based on discrimination occurs before a defendant even steps foot in court, including surveillance, policing, and prosecution (Small, 2001). For instance, though judges are bound by 
sentencing guidelines, prosecutors can still use their discretion in determining the charge a defendant faces. Further, police routinely use their discretion, which many (myself included) would argue is shaped by cultural bias, in law enforcement practices. Thus, discretion is not removed but transferred (Mascharka, 2000; Tonry, 2007; Zhang et al., 2009). Additionally, instead of judiciary discretion, prosecutors are afforded more leverage when in the plea bargaining process (Oregon Criminal Justice Commission, 2011). Prosecutors decide the charge and the charge decides the sentence. This is problematic for many reasons.

First, prosecutorial decisions and plea-bargaining take place behind closed doors; therefore they are not subject to public scrutiny in the same way judicial decision-making may be (Mascharka, 2000; Tonry, 2006). Tonry (2006) states, "the resulting hypocrisy and lack of transparency compound the problems of unjust sentences and stark disparities" (p. 46). By removing accountability, the justice system is ultimately counterproductive toward the goal of uniformity in sentencing.

Second, research shows that in the plea bargaining process, higher-level drug dealers are more likely to give information for reduced sentences (Mascharka, 2000; Zhang et al., 2009). They often exchange the names of others, lower in the drug trade, for reduced charges. As a result, unintended populations, without the valuable information needed to plea, are brought into the court's grasp. So, although mandatory minimums intend to target high-level dealers in the drug trade, the plea-bargaining process instead criminalizes many others who hold only minor roles in the drug trade. Furthermore, it has been noted that high-level drug dealers are rarely caught with large amounts of drugs; 
they often employ couriers or "mules" who, if caught, often have no information to offer in exchange for a plea (Tonry, 2006).

Lastly, it has been noted that the plea-bargaining process uniquely and differentially impacts women (Allen et al., 2010; Balfour, 2006; Jefferson Smith \& Young, 2003). Women are the most likely to be low-level foot soldiers in the drug trade, working for, or with, people they will not or cannot willingly hand over to the authorities. Therefore, women are also the most vulnerable to arrest and punishment (Sudbury, 2002; Toscano, 2005). In this manner, the war on drugs has criminalized alarmingly more women than men (Balfour 2006; Sudbury, 2002; Toscano, 2005). In 2016, 25\% of females in state prisons and 56\% in federal prisons were convicted of a drug offense, compared to $14 \%$ and $47 \%$ of male prisoners respectively (Carson, 2018).

Social and economic neoliberalism. Mass incarceration and increased criminalization also reflect neoliberal social and economic changes within an already stratified society. Neoliberal transformations in the economy have contributed to women's poverty across the globe and have brought an increasing number of women into contact with the criminal justice system (Pollack, 2008). Increases in imprisonment rates have occurred concurrently with decreased spending in the areas of social services, education, and health. Research has shown that women's economic disadvantage coupled with the divestment of health and social services may increase their involvement in property crimes (Chesney-Lind, 2002). Indeed, it becomes clear that punitive changes in welfare and sentencing policies have contributed to women's lack of opportunity and subsequent increased criminalization. 
Here, I must draw attention to the fact that although all women are susceptible to the negative impacts of neoliberalism, poor women, trans women, and women of color are more adversely affected than white and privileged classed women (Chandler, 2003; Neve \& Pate, 2005). For instance, pregnant women of color are disproportionately subjected to discriminatory drug testing from the medical profession (Sudbury, 2002; Toscano, 2005). Although research proves no serious health effects for infants whose mothers used drugs without other confounding factors such as poverty and lack of prenatal care and nutrition, prenatal drug use is sanctioned in many states as a measure of child abuse or neglect and medical professionals are required to report suspected use of drugs during pregnancy to Child Protective Services (Sudbury, 2002; Toscano, 2005). Women who are pregnant and found using drugs may then be indicted on charges of manslaughter or child abuse and have their parental rights terminated (Bosworth, 2007; Chesney-Lind, 2002; Solinger et al., 2010). Punitive policies such as these have not been found to act as a deterrent to substance use, but they have been shown to act as a deterrent to accessing prenatal care which could mitigate or prevent any serious health effects of substance use for both mothers and infants (Stengel, 2014; Young, 1994).

Furthermore, current drug sentencing policies systematically imprison poor women of color because they target women and communities of color in specific and unique ways - so much so that some refer to the war on drugs as the "war on poor Black women" (Sokoloff, 2005). People of color are disproportionately impacted by punitive drug polices, particularly in the case of crack, for which the punishment is 100 times harsher than for that of powder cocaine (Pewewardy \& Severson, 2003). According to 
records, although only 34\% of crack users are African American, in 1994 they represented $90 \%$ of those charged with federal crack offenses (Pewewardy \& Severson, 2003). Further, as women of color are most likely to be the low level foot soldiers within the transnational drug trade, they are also the most susceptible to arrest and punishment (Sudbury, 2002; Toscano, 2005).

Many scholars note that the policy and funding changes which came about with the war on drugs and welfare reform are aimed at restricting upward mobility of the poor and blaming them for their plight (Bagley \& Merlo, 1995; Bosworth, 2007; ChesneyLind, 2002; Franklin, 2008; Sheldon, 2008; Sokoloff, 2005; Solinger et al., 2010). Fine and Weis (2000) centralize the discourse around structural violence:

While crime and violence are central concerns for poor and working-class women, building more and more prisons accelerates the undermining of poor and working class communities, and disrupts the lives of children who are then exported through the foster care system (p. 1144).

By decreasing funding for services for the poor and increasing funding for prisons, poverty is perversely criminalized. In other words, there is a direct relationship between neoliberal policies and the increased criminalization of poor women of color (Neve \& Pate, 2005).

The impact of neoliberal penal practices has had a profound effect on immigration policy as well. Gripped by anti-immigration sentiments, the U.S. has produced new regulations creating an increase in the incarceration of immigrant women (Bosworth, 2007; Solinger et al., 2010). Currently, the targets of these policies are primarily Latina women. What's unique to the past two or three decades are the ways in which prison 
building businesses are involved in creating and lobbying for punitive immigration policies. Now dubbed the "prison industrial complex," criminal justice is increasingly being farmed out by the state to for-profit industries (Chandler, 2003; Mallory, 2006; Neve \& Pate, 2005). The prison industrial complex describes the relationship among criminal justice, corporations, and policymakers, which serves the financial interests of the elite and results in the mass incarceration of marginalized populations. Fisher and Reece (2010) describe the prison industrial complex as "the broad range of powerful interests benefiting from and promoting incarceration" (p.5). Scholars and activists critical of the prison industrial complex are increasingly responding to it as an inherently racist system that is used as an inadequate response to social problems caused by globalization and neoliberalism (Sudbury, 2002). For the purpose of bolstering profit, the prison industrial complex has been proven to be a driving force for punitive immigration policy (Bosworth, 2007; Solinger et al., 2010). New for-profit detention centers are being built to accommodate solely immigrant women and children (Bosworth, 2007; Solinger et al., 2010). The long-reaching effects of neoliberal policies are compounded when collateral consequences, which serve to limit the opportunities and citizenship rights of those incarcerated and formerly incarcerated, are imposed at state and federal levels (Travis, 2002).

Collateral consequences. In addition to the visible embodiment of punishment experienced through incarceration and community corrections, there are also a plethora of less visible sanctions, called collateral consequences (Balfour, 2006; Travis, 2002). Collateral consequences refer to the "laws and regulations that serve to diminish the rights and privileges of those convicted of crimes" (Travis, 2002, p. 16). This relatively 
invisible punishment, unlike expansion of the prison and criminal justice system, goes largely unnoticed by society at large. Policies in child welfare, social assistance, voting, employment, education, and housing, to name a few, intersect in complex ways to exert social control and social exclusion before, during, and after contact with the law (Bosworth \& Flavin, 2007; Comack, 2006; Travis, 2002).

Collateral consequences are molded out of regulatory policies, enacted on the federal, state, and sometimes local level. They provide sanctions to those with convictions that extend beyond the prison walls. To name but a few: individuals convicted of a felony are permanently denied access to many of the rights of citizenship such as the right to vote, to own guns, and to hold public office (Travis, 2002). Those with felony convictions are denied access to federal student loans (Travis, 2002). In many states, those convicted of drug offenses can have their driver's license suspended and be denied access to public assistance (welfare), public housing, and food stamps (Travis, 2002). With expanded access to criminal background checks, many employers and rental agencies/landlords can deny jobs and housing based on past offenses (Brewer \& Heitzeg, 2008). These examples are particularly problematic since the conditions of probation/parole often include securing employment; likewise, welfare reform of 1996 requires that individuals work a certain number of hours in order to receive public assistance. All this becomes more and more unattainable for those convicted of felonies. In effect, collateral sanctions serve to restrict the mobility of "offenders," limit options for survival, and reinforce their status as criminalized. They undermine the goals of reintegration and increase recidivism rates. 
Further, such regulatory policies have uniquely gendered impacts. For instance, many women in prison are mothers who had primary care of the children before incarceration (Bosworth, 2007; Chesney-Lind, 2002; Solinger et al., 2010). The passage of the Adoption and Safe Families Act (ASFA) of 1997 initiates mandatory termination of parental rights after 15 months of a child's placement in foster care, thus serving as a double punishment for women with drug offenses whose sentences may start at 15 months as dictated by mandatory minimums (Bosworth, 2007; Chesney-Lind, 2002; Solinger et al., 2010). Additionally, child welfare requirements often include the ability to secure and maintain stable housing. However, the potential to be denied housing based on past convictions creates extra barriers for women who are trying to regain custody of their children. These examples highlight the gendered impact of intersecting punitive criminal justice and social/child welfare policies. Furthermore, given that women from marginalized social locations are more likely to be criminalized, it follows that marginalized communities will be differentially impacted by collateral sanctions. In this manner, criminalization serves to reinforce and perpetuate larger societal inequalities. Brewer and Heitzeg (2008) profoundly state:

The scale, scope, and extremes of negative consequences-both direct and collateral-for communities of color are new, especially for women, but the role of criminal justice in policing, prosecuting, imprisoning, and executing people of color has deep historical roots. What is not new is the racist and classist economic and political agenda that is foundational. The paradigms shift from essentialist to color blind and the practices of oppression are refined and renamed, but the 
resulting inequality remains much the same. The law and its attendant machinery were, and still are, enforcers of both White supremacy and capitalist interests (p. $630)$.

As I have shown, the consequences of criminalizing women do not begin or end with the criminal justice system. Ultimately, research shows that punitive sanctions and policies, in or out of prison, serve to further isolate and exclude already marginalized members of society (Lipsey \& Cullen, 2007; Pollack, 2005), and "fail to challenge the logic of punishment as a response to social problems" (Sudbury, 2000, p. 137). Felony disenfranchisement is yet another thread in the transcarceral net of control.

\section{Historical Context}

Mary Bosworth (2000) calls for the examination of the beliefs and social institutions of a society in a given time in order to accurately analyze women's criminalization. This is important because the current trends in criminalization reflect historical patterns of oppression and injustice across lines of gender, race, and class. Feminist historians highlight how the intersections of race, class, sexuality, and gender have "shaped not only which women were incarcerated, but also how they were treated inside" (Bosworth, 2000, p. 267). Today, these intersections also shape how they are treated once they return to their communities. In essence, female criminality cannot be explained, examined, or defined without including the historical context of gender constructions and unequal power relations in society at large. Therefore, the historical review that follows is an attempt to trace the emergence of discourses regarding sexuality and femininity that serve as the basis for criminalizing women who fall outside of dominant norms and expectations. In order to discuss differential treatment among 
various groups of women and to highlight the role that race, class, and sexuality play in shaping women's lives and the justifications for punishment, it is necessary to first set the stage by explaining larger dominant ideologies regarding gender and the forces that have established gender norms. I offer this as a caveat to the reader in order to make explicit that these dominant ideologies are built on standards to which not all women can conform. This historical review allows for a more thorough understanding of the development of the various approaches to explaining and penalizing female criminality as well as the role of social work in responding to the plight of criminalized women and shaping interventions for them.

The "Cult of True Womanhood." Prior to the $18^{\text {th }}$ century, gender norms did not serve to define femininity in the same ways as in later times. This is largely attributed to the agrarian economy of the time, in which economic production took place within households. The $19^{\text {th }}$ century brought forth a shift in market relations and the development of a middle class (Colvin, 1997; Pollock, 1995; Sheldon, 2008; Young \& Spencer, 2007). With the rise of a market economy, economic production was taken out of the household and the role of the "woman" began to change. No longer needed for economic production, women were relegated to roles of childbearing, nurturing, and daily household chores. This shift marked the introduction of a separate "women's sphere" in which home came to be seen as the realm of women, and work the domain of men (Colvin, 1997; Pollock, 1995). These material changes to economic and social life brought discursive changes to the ideology regarding femininity. The development of a “women's sphere” ushered forth notions of women's morality and sexual purity that did not exist in public discourse prior to the $19^{\text {th }}$ century (Freedman, 1981; Pollock, 1995). 
Ideas of "True Womanhood" which asserted that a woman's true nature is pure, selfless, asexual, and weak began to shape the lives of women (Colvin, 1997; Freedman, 1981; Pollock, 1995; Sheldon, 2008). Some women could conform to this new role more easily than others, but for those who could not or would not, deviations were met with disapproval and punishment (Colvin, 1997; Freedman, 1981; Pollock, 1995; Rafter, 1983; Sheldon, 2008; Young \& Spencer, 2007). Women had historically been punished for moral crimes and crimes of poverty, but these crimes now took on a new meaning based on a woman's social location. As Zedner (1991) remarks, "The female criminal, the prostitute, and the female drunk were held up as the very negation of the feminine ideal, a warning to other women to conform" (p. 320). Women who committed crimes were viewed in one of two ways, both based on the ideal of true womanhood. They were considered either 1) inherently different from most women, morally depraved, and unredeemable; or 2) "pure" women who were simply the victims of male lust. The former was the predominant view prior to the Civil War. In 1833, Francis Leiber stated, "A woman, when she commits a crime, acts more in contradiction to her whole moral organization, i.e., must be more depraved, must have sunk already deeper than a man" (Rafter, 1983, p. 138). It was thought that women, as the moral gatekeepers for society, injured society more through their criminality than men through theirs. Moreover, women were seen as responsible for men's immoral behavior (Colvin, 1997; Freedman, 1981; Pollock, 1995; Rafter, 1983; Sheldon, 2008).

The latter perspective, which purported a view of female criminality that held men responsible for the moral downfall of women, came out of the Female Reform Societies, largely led by feminists and social workers of the time, and had the greatest 
impact on policy during the late $19^{\text {th }}$ century (Colvin, 1997; Freedman, 1981; Pollock, 1995; Rafter, 1983; Sheldon, 2008). The approach of the Reform Societies marks a discursive distinction from viewing women who committed crimes as dangerous to viewing them as risky and at-risk (Lupton, 1999). The Reform Societies saw women as "civilizers of male society" and in need of rehabilitation as opposed to punishment.

However, the reformers had little impact on treatment of criminal women until the rise of the reformatories in the progressive era. In Antebellum America, female offenders were often referred to as "fallen women." The times epitomized the Madonna/whore duality in which women were viewed as "virginal, pure, asexual, and an uplifting influence. Yet, at the same time, women were also seen as Eve-like, both corrupt and corrupting" (Zedner, 1991, p. 320). However, this view of femininity did not apply to all women. Poor women and Black women were more likely than their White counterparts to be incarcerated and were viewed as especially heinous and beyond redemption (Young \& Spencer, 2007).

The mid $19^{\text {th }}$ century marked an increase in the criminalization of poverty among women. Women were displaced from factory work by immigration, and poverty among single women began to grow. During this time there was a decline in reform efforts among feminists and social reformers and an increase in charitable work, the emergence of which fit with larger societal beliefs of the time that held the poor responsible for their plight (Colvin, 1997; Freedman, 1981; Sheldon, 2008). Later, in the 1860s, the sphere of the woman once again expanded in response to the needs of a civil war (Colvin, 1997; Freedman, 1981; Rafter, 1983; Sheldon, 2008). Increasing numbers of privileged classed, White women capitalized on society's belief in maternal nature embedded in the ideal of true womanhood to gain work and assist in the war effort. 
Social feminism. Estelle Freedman (1979) describes the social feminism embedded in the Progressive Era as "an era of separate female organization and institution building" (p. 517). After the Civil War, middle and upper class women were increasingly being educated and seeking ways to use their newfound skills in a male dominated world that systematically excluded women from professions. Notably, women entered the field ${ }^{6}$ of social work in high numbers during this time (Abrams \& Curran, 2000). These women turned their attention, once again, to social reform efforts. They were "imbued with the mission of bringing their female values to bear on the entire society" (Freedman, 1979, p. 518). Unlike radical feminists of the time, social feminists sought to mitigate oppressive social conditions, not change them. They embraced and bolstered assumptions about gender and femininity by introducing sexist sentiments into public policy (Freedman, 1981; Rafter, 1983). Freedman states,

Like the separate but equal racial ideology, however, social feminist strategy rested on a contradictory definition of equality. The $19^{\text {th }}$ century prison reformers did seek to expand women's rights when they argued for greater authority over public policy and improved treatment for women prisoners. But at the heart of their program was the principle of innate sexual difference, not sexual equality (1981, p. 47).

Though perhaps well intended, these efforts shaped and continue to shape the gender norms that form the foundation of criminal justice and social work practice with criminalized women today.

\footnotetext{
${ }^{6}$ Field is a broader term than profession or discipline and is used throughout this document to account for those without formal training/education in social work, as well as both academics and practitioners.
} 
Social reformers, including social workers from Settlement Houses, focused their energies on many areas of reform targeted specifically at women, including women's prison reform efforts (Abrams \& Curran, 2000; Freedman, 1981; Sheldon, 2008).

Scholars note that the social reform movements of the time involved mostly middle class White women, who participated in a "variety of reforms aimed at improving the lot of the dependent and defective classes" (Rafter, 1983, p. 153). Reformers purported a belief in women's superior morality and saw the prison as a source of impurity. Their mission, then, was to protect and reform women. They advocated for complete segregation by age, gender, and degree of crime. Treatment/intervention was then dictated in accordance with women's "true nature" and was to be provided by feminine women. The reformatory model was deemed suitable for this purpose.

Rise of the Reformatories. In 1870 the American Prison Association held its first annual convention in Cincinnati and established the American Correctional Association's Initial Declaration of Principles, consisting of 37 principles, which lay the foundation of some of the disparate treatment in criminal justice that we see today. Among other things, these principles called for: separate institutions for women; indeterminate sentencing; and training and education for inmates (Colvin, 1997; Freedman, 1981; Friedman, 1993; Rafter, 1983; Sheldon, 2008). Historians note that these principles moved penology from taking an environmental approach, which looked at societal causes for crime, to a more medical approach, which attempted to correct flaws and rehabilitate the wayward (Colvin, 1997; Friedman, 1993; Rafter, 1983; Sheldon, 2008).

By melding the Declaration of Principles with ideas about what it means to be feminine (and a staunch belief regarding fundamental differences between the sexes), 
women reformers were instrumental in shifting the discourse about women's penology (Rafter, 1983). Indeterminate sentences dictated by this new approach to penology explicated a "three-year law" specifically for women, based not on the severity of a crime but on the need to "reform." The three-year law declared that women could serve up to three year sentences for misdemeanors such as "disorderly conduct, vagrancy, lewd behavior." These types of offenses were often used as a stand-in for suspected prostitution (Colvin, 1997, p. 157).

Meanwhile, men commonly served much shorter sentences or simply received a fine for similar offenses, continuing a longstanding gendered pattern of differential sentencing. Differential sentencing was upheld on the grounds that more time was needed for the reform of the "fallen" woman, while men's behavior was seen as "normal" and not in need of rehabilitation. In 1865 an annual report of the Indiana Reformatory Institution stated that they aimed to reform women so that they could "occupy the position assigned to them by God, viz., wives, mothers and educators of children" (Colvin, 1997, p. 163). Thus began a legacy of a double standard, which promoted and enforced stereotypes of femininity that did not and do not apply to men.

After the convention, widespread establishment of the female reformatory was set in motion. The reformatory was conceived by Elizabeth Fry as a "notion of prison exclusively for women, administered by women, in which inmates would receive moral and domestic training" (Rafter, 1983, p. 146). During this time there was also a societal shift in the discourse regarding "fallen" women; they came to be seen as childlike and led astray, not depraved and beyond redemption (Agonito, 1977; Freedman, 1979; Freedman, 1981; Rafter, 1983). Reformatories primarily housed White women convicted of 
misdemeanors, as they were thought to be capable of salvation and reform ${ }^{7}$ (Freedman, 1981; Rafter, 1983). Women of color, however, were excluded from reformatories as they were seen as less worthy of effort, not capable of "true femininity," and less capable of reform; consequently they were primarily sentenced to harsher custodial institutions (Colvin, 1997; Freedman, 1981; Pollock, 1995). Women reformers saw themselves as protectors of morality, and the goal of the reformatory was to create "good" women. In her historical analysis regarding the incarceration of women, Nicole Rafter (1983) notes that the reformatory model was primarily based on already established institutions for children. Women were governed in a maternal fashion and disciplined like children. A point system, in which women lost points for un-ladylike behavior (talking loudly, pouting) was utilized.

The reformatories were run by middle and upper class women and focused on training women for domestic duties (Colvin, 1997; Freedman, 1981; Pollock, 1995; Rafter, 1983). The "rehabilitation" consisted of training defined in "gender-specific" terms:

Instructions were tailored to what was considered the childlike, domestic, and asexual nature of the true woman. In the course of establishing prisons that would, proponents hoped, transform fallen women into true women, reformatory advocates institutionalized the double standard. From today's perspective, their efforts to save seemed to have condemned their charges both to narrow programs

\footnotetext{
${ }^{7}$ It is important to note that such offenses were either not recognized as offenses in men or men were simply fined and/or served brief sentences (Freedman, 1981; Pollock, 1995; Rafter, 1983).
} 
and to care which, because it assumed adult women were childlike, was often infantilizing (Rafter, 1983, p.150).

Reformers insisted on an all women staff for a variety of reasons: they sought to eliminate sexual exploitation by male guards; they assumed that middle/upper-class women could serve as positive role models for "fallen" women; and they believed women were more able to understand the needs and concerns of other women. Given the differences in class and social status between matrons and their charges, the idea of "understanding role models" is questionable (Freedman, 1981; Pollock, 1995; Rafter, 1983). Rafter states:

It is not clear that these administrators were well prepared to understand the inmates' problems, particularly those that related to social class, work and independence. On the contrary, it was in part the failure of the founders of reformatories to tolerate sexual and other mildly deviant behaviors of working class women, which led to the founding of reformatories in the first place (1983, pp. 159-160).

With an increase in antagonism toward the poor during the close of the $19^{\text {th }}$ century, reformatories were used to restore "true womanhood" and overcome what were thought of as inherent defects of the poor. While intended to protect women from harsh treatment in the custodial institutions, the invention of the reformatory also served as an expansion of the state's control over women. In line with a Foucauldian analysis, the reformatories' approach to rehabilitation and treatment represents new forms of punishment and governance, rather than alternatives to it. Social work's role in these reform efforts highlights an historical legacy of the profession that is firmly rooted in social control. As 
opposed to challenging the social oppression of women, the reformers, in fact, kept women in their "proper place" by encouraging "propriety but certainly not upward mobility" (Rafter, 1983, p. 160).

Reconstruction and the South. At the same time that White women in the north were being sentenced to reformatories, the racial composition of the prison population in the South underwent radical changes. After the Civil War, with the "official" end of slavery, the South was in shambles and in need of a new source of labor. Now that slavery was illegal and unconstitutional, the South sought to ensure a captive labor force by redefining crime. Black Codes, vagrancy laws, and the convict lease system were all used to ensure a system of forced labor (Chowdhry \& Beeman, 2007; Schneider, 2003). African Americans were no longer slaves but they were certainly not free. The Black Codes, which made unemployment for African Americans a crime, used the criminal justice system to restrict adult mobility and prevent African Americans from leaving the plantation (Chowdhry \& Beeman, 2007). This reintroduced involuntary servitude.

Further, felony laws began to change. During slavery, Black people were not readily imprisoned because they were treated as a commodity. Punishment was dealt with primarily by slave owners (Chowdhry \& Beeman, 2007; Rafter, 1983; Young \& Spencer, 2007). After reconstruction, Black people were imprisoned for minor offenses and the prison population began to swell. Convict leasing, a practice in which states leased prisoners through a contractor for work, was then deployed to provide the South with an involuntary workforce (Chowdhry \& Beeman, 2007). When convict leasing went out of fashion, forced labor laws remained intact through the implementation of prison/state run public works projects for prisoners. For example, during WWI and WWII the South 
implemented "fight or work" programs. These programs applied vagrancy laws to African American women in order to compensate for labor shortages. Black women, like White women, worked in their homes taking care of their families. However, despite working unpaid in their homes, Black women were forced to either get jobs or be charged with vagrancy laws and sentenced to work, while White women in similar circumstances were not held to the same expectation (Chowdhry \& Beeman, 2007). Herein lies another example of how Black women have historically not had access to the dominant norms established for femininity. Feminist analyses of "separate spheres"8 are not necessarily relevant to the lives of Black women (Crenshaw, 1991). Historically, Black women were not relegated to the realm of the home in the same way that White women were; in fact, they were forced into economic production outside the home. In this way, racism creates conflicts with their ability to access established dominant gender norms. The history of racism embedded in the criminal justice system continues to shape the lives of women of color and to justify the ways in which they are criminalized today.

Social purity crusades. Toward the end of the $19^{\text {th }}$ century, the discourse in penology began to include medicalized explanations, seeing the biology of offenders as the source of criminality. In this, offenders were seen as abnormal and defective. Immigrants and people of color were especially harmed by this atavistic approach. And as Zedner (1991) notes, the shift in relation to women was more vivid than that of men. Women "criminals" were seen as "more depraved and hardened than the male" (Rafter, 1983, p. 138) because, in order to offend, they must have strayed further from their "true"

\footnotetext{
${ }^{8}$ Feminist concerns with women's exclusion from the workplace excludes the racial issues present in the lives of Black women and essentializes the experiences of women.
} 
nature. It was thought that as the moral gatekeepers for society, women injured society more through their criminality than men through theirs. Moreover, they were seen as responsible for men's immoral behavior (Colvin, 1997; Freedman, 1981; Pollack, 1995; Rafter, 1983; Sheldon, 2008).

Historians note an overall increase in the criminal convictions of women during the latter part of the $19^{\text {th }}$ century (Freedman, 1981; Pollock, 1995; Rafter, 1983). Not unlike how the policy changes emerging out of neoliberalism and the war on drugs have caused increased incarceration rates in contemporary times, the increase in criminal convictions at the close of the $19^{\text {th }}$ century is largely attributed to emerging antiprostitution and anti-abortion laws. For much of the 1800 s, many states lacked laws that explicitly criminalized prostitution (Friedman, 1993, p. 224). However, by the late $19^{\text {th }}$ century, the Social Purity Crusades initiated changes in both policy and public opinion regarding prostitution (Wahab, 2002). The Social Purists consisted of female reform leaders, including social workers from a casework orientation, whose goals were overtly geared toward the social control of dangerous classes as opposed to the betterment of conditions for moral uplift (Abrams \& Curran, 2000; Rafter, 1983). The Social Purity Movement was driven by a newfound belief in the medical model and in scientific understanding as a way to propel the human race forward (Abrams \& Curran, 2000). "Impelled by anxieties about alcoholism, immigration, prostitution, urbanization, venereal disease, and the like, the social purity movement generally sought to reaffirm and bolster traditional Anglo-Saxon standards" (Rafter, 1983, p. 154). The Social Purity Crusades succeeded in condemning prostitution as a public health problem in addition to a moral one (Freedman, 1981; Friedman, 1993; Pollock, 1995; Sheldon, 2008). 
Abortion laws also changed drastically in the late $19^{\text {th }}$ century (Colvin, 1997; Freedman, 1981; Friedman, 1993). Prior to this time, many states did not regulate abortion and the legislation that did exist was loosely enforced. In the 1860 s abortion laws tightened and grew. More than 40 new abortion laws were passed in the latter half of the 1800s (Friedman, 1993). In 1864 Oregon law declared abortion manslaughter and sentenced women to 1-45 years for getting an abortion (Myers, 1995). Since marriage and motherhood were viewed as a woman's primary purpose and ultimate calling in life, abortion was seen as a crime against women's "true nature." The anti-abortion sentiment was also a reaction to anxieties around immigration and an attempt to bolster and purify the native born population (Friedman, 1993).

Further, the sexual double standard for criminality persisted. Women continued to be convicted of crimes against chastity (which included adultery, common night walkers, fornication, lewd co-habitation, or lewdness) and crimes against the public order (drunkenness, idle and disorderly behavior, and stubbornness). In 1895, of the 336 women incarcerated in a Massachusetts women's institution, 39 were for crimes against persons and property (26 of which were larceny); 83 were for crimes again chastity; and the rest were for crimes against public order (Friedman, 1993). During the same time period only three men were committed for crimes against chastity (Friedman, 1993). Women sent to reformatories during this time continued to be of a certain type: primarily white and convicted of misdemeanors rather than serious felonies. In addition, many of the women now being placed in the reformatories were of the "new woman" and 
“working girl” type ushered in by urbanization (Freedman, 1981; Pollock, 1995; Rafter, 1983).

The Mann Act, also known as the White Slavery Act, was passed in 1910, and stipulated "felony penalties for any person who in any way knowingly aided or enticed a woman or girl to travel in interstate commerce for the purpose of prostitution or debauchery, or for any other immoral purpose" (Colvin, 1997, p. 175). The ambiguous language of the act allowed for selective prosecutions and discrimination toward minorities and immigrants. The Mann Act also established special courts to detain and confine women on moral charges and, thus, brought many more women into contact with the criminal justice system (Colvin, 1997).

Around the same time that the Mann Act was passed, eugenics theories entered reformatories. Those who prescribed to eugenics argued that sentences in reformatories should be indefinite so that "genetically inferior women could be removed from sexual circulation" (Rafter, 1983, p. 162). Josephine Shaw Lowell was a prominent figure in women's prison reform and an early leader in eugenics. She thought that promiscuous women were depraved and immoral and therefore produced undesirables.

"Feebleminded" women, including poor, immigrant, and/or Black women and prostitutes, did not go to the "gentler" reformatories; instead, they were sent to custodial institutions because they were thought to be beyond reform (Colvin, 1997; Rafter, 1983). Lowell advocated for long term commitments for women under thirty who were convicted of misdemeanors and/or gave birth to illegitimate children. Notions of propriety became institutionalized in the reformatory and "fallen women were removed from sexual circulation" (Rafter, 1983, p. 154). 
As ideas of "White Slavery" came into vogue, the social purists sought to eradicate prostitution with renewed fervor (Colvin, 1997; Rafter, 1983). Eugenics gave reformatories a new purpose, to "segregate prostitutes and identify those who were mentally defective" (Colvin, 1997, p. 180). Eugenicists claimed a relationship between deviance and low IQ. Under the leadership of the likes of Lowell, reformatories began to routinely administer biased IQ tests, based on White middle class American norms, to all women who entered. Women with low scores were sent to custodial institutions and committed for life to keep them from breeding. They were often sterilized while in confinement (Colvin, 1997; Flavin, 2007; Rafter, 1983).

World War I marked another dramatic shift in the discourse on women's criminality, as prostitution became the scapegoat for dramatic outbreaks of venereal disease among soldiers (Colvin, 1997; Freedman, 1981). Prostitutes were blamed not only for venereal disease but also for drunkenness in soldiers, and were charged with threatening the war effort. This excited a lot of societal loathing for prostitutes and any woman even resembling a prostitute. Myers (1995) states that "the inseparable association of prostitutes with venereal disease caused the public to fear the fallen woman it had once seen as a victim" (p. 125). Society began to view men as pure and women as depraved seducers responsible for men's transgressions and ill health.

The Commission of Training Camp Activities (CTCA) implemented broad antiprostitution policies which resulted in a mass increase in arrests and incarceration of prostitutes (Colvin, 1997; Freedman, 1981). Additionally, venereal disease in women was seen as proof of prostitution and, thus, grounds for incarceration. Men with venereal disease were viewed as victims and thus educated and provided treatment. Colvin (1997) 
states that the "purpose of imprisoning women was no longer to provide for their protection and reformation, but to promote societal protection through punishment" (p. 181). The increasing numbers of female inmates brought about by CTCA policies necessitated expansion of women's reformatories and prisons. These new institutions were justified in terms of cost-benefit because it was cheaper to lock up women as a preventative measure than to treat a soldier for venereal disease (Freedman, 1981; Sheldon, 2008).

Driven by eugenics and an emerging disdain for women, the reformatories began to collapse during WWI and take on a more custodial model (Colvin, 1997; Freedman, 1981; Rafter, 1983). Reformatories now held all women prisoners for all offenses, instituted heightened surveillance and security, and practiced harsh punishments and sterilizations. By the 1920s, eugenics had successfully supplanted the idea of rehabilitation (Colvin, 1997). Largely due to a practical and economic need for the penitentiary, a series of policies that would eventually result in the complete demise of the reformatory took hold after the war. In 1919, State v. Heitman, a Kansas decision, "permitted separate sentencing policies for each sex" and legally recognized femininity as different from masculinity and in need of "special considerations" (Freedman, 1981, p. 148). These special considerations included longer sentences for reform, separate institutions, and increased training in domestic homemaking (Freedman, 1981, p. 149). Historians note that this decision marked the beginning of the centralization of hundreds of women into one institution (Colvin, 1997; Freedman, 1981; Rafter, 1983; Sheldon, 2008). The first federal prison for women, thus, emerged in 1927 (Colvin, 1997; Friedman, 1993): 
The initial impetus for the federal institution came in the years immediately after WWI, when the number of women imprisoned for federal offenses more than doubled as a result of the Harrison Act (1914), which outlawed narcotics; the Volstead Act (1919), which implemented prohibition; and the Jones-Miller Act (1922), which made automobile theft a federal offense (Freedman, 1981, p. 145).

These new punitive laws changed the composition of women in reformatories and created conditions of overcrowding and sub-par conditions. Reformatories were no longer utilized for their original purpose and no longer adequate to house the growing population of prisoners (Freedman, 1981; Rafter, 1983). The 1930s saw the almost complete demise of reformatories (Freedman, 1981; Rafter, 1983).

\section{Contemporary Institutional Responses}

During the middle decades of the $20^{\text {th }}$ century, attitudes regarding women's criminality still focused on individual deficiencies but with renewed interest in rehabilitation and treatment. Due to the focus on treatment and the availability of social services, the female "criminal" population was relatively stable during this time. Hostile attitudes and stereotypes remained and "treatments" were questionable. The 1950s brought with it a rise in psychiatric commitments for "deviancy" in which electroshock, psychotropic and experimental drugs, and lobotomies were all common (Chesney-Lind, 2002; Colvin, 1997; Sheldon, 2008). Out of these practices grew many current models for "treatment" of criminalized women today that emphasize the role of choice in their decision-making processes. Some refer to current day psychological interventions as "thera-punitive" (Pollack, 2008). 
Psy-professions take hold. Feminists once again entered the dialogue concerning the criminalization of women in the $70 \mathrm{~s}$ and $80 \mathrm{~s}$. By attending to life stories and narratives they began to see patterns of violence and victimization among women involved with the law. The larger social movement of the time, problematizing violence against women, allowed feminists to make links and draw attention to women's victimization and their contact with the law (Chesney-Lind, 1997; Comack, 2006). Although limited by a tendency to construct women solely as victims, these attempts began to locate women's "criminal" activity within a broader context and made claims that women's "choices" are largely influenced by the conditions that shape their lives. The victimization discourse led the way to a general "pathways" approach to looking at/explaining crime. Proponents of a pathways approach critiqued the "add women and stir" approach to criminological and therapeutic interventions that had been dominant for much of the $20^{\text {th }}$ century. Looking at pathways requires attending to difference. Many criminologists now recognize that women have different "pathways" into crime and subsequently different needs along the way.

From the pathways approach emerged a focus on "gender sensitivity" and "gender responsive" programming for criminalized women, a trend that has gained a lot of traction in Canadian and U.S. treatment contexts. Gender responsive programming echoes the ideology of the reformatory and has been critiqued for its tendency to focus on the psychological effects of gender oppression. The gender-responsive focus is troubling because it strips gender of its social, political, and economic significance and relies on essentialized notions of "women" (Pollack, 2006). As with the pathways approach, gender responsiveness is limited because it does not address how and why certain 
behaviors by certain people become constituted as crimes. The focus of gender responsivity remains on correcting individual flaws and managing risk, rather than ameliorating the social and economic underpinnings of crime. Furthermore, feminists have documented that the activities, expectations, and the implementation of gender responsive programming are premised heavily on stereotypical gendered and racialized notions of criminality and femininity (Goodkind \& Miller, 2006; McKim, 2008).

For instance, Goodkind and Miller's (2006) study of an art therapy program for young women involved in the criminal justice system reveals how the program's policies and practices reinforced gendered notions of appropriateness. While the young men in this residential facility engaged in other kinds of treatment and education programs, the art therapy was only for the females. The program also relied on traditionally feminized undertakings, such as crafting identity dolls, and centered activities on gendered themes, such as building self-esteem. When participants tried to exert agency and engage in activities that felt more meaningful to them, they were sanctioned for being inappropriate. Goodkind and Miller (2006) assert that "in this way, the art therapy program creates and enacts meanings of gender through determining what is, and what is not, appropriate" ( $\mathrm{p}$. 57). Gender responsive programming echoes sentiments about femininity embedded in the reformatory movement. Like the reformatories, the program described by Goodkind and Miller was arranged so as to mold the young women into idealized versions of femininity with little reference to race and class.

Much of the therapeutic programming for criminalized women in contemporary times is aimed at reducing substance use, alleviating mental health symptoms, and assuaging the negative impacts of trauma; all of which are assumed to lead to improved 
"functioning" and consequently decreased "criminal behavior." Subsequently, outcomes for criminalized women in treatment programs are typically measured in terms of psychological indicators and recidivism rates, and progress in treatment is largely monitored in relation to a woman's ability/willingness to internalize treatment discourses and thereby fulfill the function of self-governance.

Pollack (2013) asserts that the current "truth regime" guiding what can be known within human services and correctional practice is rooted in evidence-based research and practice. For instance, cognitive and dialectical behavioral therapies (CBT/DBT) are advocated for strongly as "evidence-based" policy options for reducing crime (Drake, Aos \& Miller, 2009; Tripodi, et. al., 2011). Similarly, risk assessments have become a dominant "evidence-based" tool in both criminal justice and human services. Both CBT and risk assessments (when used to identify appropriate interventions) have been found effective in reducing recidivism, particularly with female offenders (Andrews \& Dowden, 2006). However, feminist scholars (Goodkind \& Miller, 2006; Maidment, 2002; Pollack, 2004) dispute and trouble the claims regarding the "effectiveness" of such practices for a number of reasons.

First, dependence on recidivism rates, as a measure of success, neglects other possible and preferable outcomes, such as gainful employment, safe housing, and reunification with children, to name but a few. Further, reliance on recidivism rates as a measure of success ignores the reality that despite not "reoffending," many women who have been criminalized continue to live in conditions of abject poverty and social exclusion (Kendall, 2004). 
Second, as Shaw and Hannah-Moffat (2004) argue, the current use of risk/needs assessments has "resulted in the reconceptualization of needs and certain social structural barriers as risk factors" (p. 94). Thus, women in crisis are judged as "risky" rather than as vulnerable or in need. In order to manage the "risky," punitive strategies are deployed, funneling women deeper into the criminal justice system.

Last, individualizing treatment discourses pathologizes individual women's choices while neglecting the structural factors that lead to crime and criminalization. As discussed previously, factors such as poverty and violence play a large role in the nature and extent of women's involvement in crime. Therefore, such factors need to be addressed in order to provide women with a meaningful range of life choices that could potentially lead to a reduction in crime and recidivism rates. As Kendall (2004) states, when criminalization is seen as a structural problem, reliance on "what works" is "weak and problematic" (p. 77). This is because "what works" is typically rooted in "what works" for individual psychological change, not what works to provide more social/economic opportunity and mobility.

\section{Conclusion}

Current trends in the confinement and rehabilitation of women have developed out of a long history of shifting discourses related to crime and feminine morality. Although the past forty years have marked a stark increase in the criminalization of women in the United States, many feminist criminologists point out that, with the exception of drugs, the nature of women's "crime" has not changed (Chesney-Lind, 2006; Comack, 2006; Jacobsen, 2008). Women are still criminalized primarily for nonviolent crimes and crimes of poverty. What has changed is neoliberalism's intersection 
with criminalization through the increased evisceration of a social safety net, the increased use of punitive responses to deal with the social problems, which have been exacerbated by the erosion of social welfare ${ }^{9}$, and the ways in which social control/regulatory practices operate across institutions to punish/regulate women.

Historically, the female offender has been judged primarily as an "inappropriate" woman. Concepts of "appropriate" female behavior have been and are now known to construct definitions of female criminality. Societal responses to female "criminality" are largely based on gender norms, and a look at history illustrates that traditional roles and gender norms are not natural or innate, do not apply to all women, and emerged from the changes in economic production of the $18^{\text {th }}$ century. Bosworth $(2000)$ suggests that historically and currently, the incarceration of women has been central to more generalized strategies of social control. She states:

Ideas of gender are apparent in the reasons used to justify the confinement of many women, and in the tasks given to them during their incarceration. Both the early modern and the modern periods undertook to control and punish particular types of women though incarceration. Unwanted wives, pregnant or sexually active girls, prostitutes, thieves and others, were punished by confinement from the $17^{\text {th }}$ century on. Given the types of women incarcerated, it seems that the prison was used to control gender as often as it was used to control crime (p. 277).

\footnotetext{
${ }^{9}$ For instance, women are increasingly arrested when calling the police for help in domestic violence situations (Neve \& Pate, 2005; Jacobsen, 2008). Zero tolerance policies and domestic violence mandatory arrest policies that have emerged within the last 25 years with the passage of the Violence Against Women Act (VAWA) fail to consider the construction of women's violence. Thus, women are often criminalized "because of their efforts to resist victimization" (Ogle \& Batton, 2009, p. 162).
} 
Although the concept of true womanhood has been largely discarded, the gender norms established and certain laws based on them ${ }^{10}$ remain with us today. "True womanhood" is an ideology that has served to criminalize women and blame them for larger social problems (Abramovitz, 1997). As Zedner (1991) remarks, "moral concepts of 'normal' and 'deviant' women underpin modern analysis" (p. 309). Female deviance continues to be explained in terms of gendered stereotypes that are grounded in outdated and racialized understandings of women's "true" nature. This holds true beyond simply explaining and regulating "deviance." Moral concepts and essentialized notions of gender also underpin a broad range of social control mechanisms that play out in everyday and interpersonal interactions to shape the experience of women. History also reveals how criminality is defined largely based on the norms and political/economic context of the time. The preceding historical review gives stark examples of how "new" crimes are increasingly legislated into existence and, thus, reveals the social construction of crime. Still, few contemporary interventions call into question the problematic category of "crime" and, thus, they seek to intervene on the level of what to do about "crime" as opposed to what to do about policies that create crime.

A look at the nature and extent of women's involvement in "crime" begins to paint a picture of how gender, race, and class inequalities shape who is likely to be criminalized. This is important because it allows us to better locate criminalization within the context of systemic inequality, which is a major force contributing to women's

\footnotetext{
${ }^{10}$ Examples include public order offenses such as anti-prostitution laws that criminalize behavior that defies conventional social norms. However, the maintenance of social/public order is not relegated solely to the criminal justice system, and transcarceral control mechanisms are regularly deployed for such offenses in order to manage behavior and people that are deemed a threat to social stability.
} 
involvement in illegal behavior. However, mainstream attempts at explaining and dealing with women's "criminality" neglect attention to such contexts and rely primarily on the individualizing discourses of the "psy" professions (Pollack, 2008).

Indeed, much of the literature regarding interventions and institutional responses related to criminalized women is rooted in an individualistic, often pathologizing, analysis of women who are involved with the criminal justice system. Subsequently, many dominant interventions involving criminalized women are aimed solely at changing women's thoughts, attitudes, and behaviors, thereby locating the problem within the individual woman. McCorkel (2004) argues that such interventions form the basis for therapeutic governance in that they systematically attempt to create citizens who can police themselves so that the authorities do not have to. Because systems of governance function through discourse, it is important to consider the discourses that shape social work's understanding of criminalized women. Therefore, the next chapter presents Critical Discourse Analysis Methodology and the research design. It will illustrate my understanding of the heavy conceptual nature of Critical Discourse Analysis and will link the study's research questions and theoretical foundations to the chosen methodology. 


\section{Chapter 4: Research Design}

This chapter discusses Critical Discourse Analysis methodology (CDA) and the research design. My study is grounded in a feminist post-structural epistemology, thereby merging both critical and post-structural understanding of power and knowledge. Staller (2013) explains that a researcher's choice of methods makes sense only when firmly anchored in their understanding of what constitutes reality (ontology) and how they believe we can come to know that reality (epistemology), thus presenting an overarching philosophical positioning for the research, or methodology. In other words, it is necessary to discuss the theoretical considerations that serve as the basis for the development of methods. Accordingly, this chapter presents the methodology of the research and is divided into three primary sections: (1) ontology and epistemology; (2) Critical Discourse Analysis methodology; and (3) methods and analysis.

\section{Ontology and Epistemology}

To illustrate the ontological foundations grounding this research, I borrow the words of Susan Strega (2005): "Reality is about the meaning that people create in the course of their social interactions; the world is not about facts but about the meaning attached to facts, and people negotiate and create meaning" (p. 206). Though CDA does not present a unifying theoretical framework, it does have fundamental ontological and epistemological assumptions. Ontology raises questions about the nature of reality, the nature of human beings in the world, and what constitutes truth. To begin, discourse is seen not only as a part of reality, but also as what constitutes it. Reality is seen as 
subjective and contextual, changing in time and place. Truth and knowledge are not seen as existing outside the discontinuity of historical processes.

Social reality (practices, labels, knowledge) then exists only in a discursive sense: it exists and means something only because we attach meaning to it. As Potts and Brown (2005) say, “truth does not exist, it is made. Therefore, we are not looking for a 'truth'; we are looking for meaning, for understanding, for the power to change." (p. 261). Knowledge is tentative at best.

Epistemology is concerned with how we know what we know. Susan Strega (2005) makes the case that "the epistemological foundation of methodology prescribes what good research involves, justifies why research is done, gives a value base to research, and provides ethical principles for conducting research" (p. 211). Thus, all vital aspects of a research endeavor are forged from epistemological assumptions and commitments (Denzin \& Lincoln, 2005). My epistemological allegiances in this project rest in both feminisms and post-structuralism.

The theoretical foundations of feminist post-structuralism are transdisciplinary in origin and have relevant application to social work research and practice (Strega, 2005). Post-structuralism, as an umbrella theoretical perspective, has a variety of definitions and is informed by the work of many scholars. There exist a range of applications for poststructural analyses, from apolitical deconstructions to the examination of the discursive dimensions of power and inequality. A common element of post-structural analysis is language (Meyer \& Wodak, 2009). Language, in post-structuralism, is the place where reality is created and also the place where reality may be deconstructed and challenged. The deconstructive strategies associated with post-structuralism are helpful in naming 
power relations and debunking the taken-for-granted assumptions of dominant discourses. Foucault, for instance, explored discourses in order to unsettle disciplines and disciplinary knowledge and practices. In doing so he exposed the historical and discursive processes through which things come to be seen as normal and natural. Through such exploration, aspects of social life, which are typically seen as stable and enduring (that which is taken to be "truth"), can be disrupted.

Whereas post-structuralism may not necessarily be political, feminist epistemologies are explicitly political and have a specific agenda toward social change (Fonow \& Cook, 2005; Gringeri, Wahab, \& Anderson-Nathe, 2010; Olesen, 2005). Poststructural understandings of power as diffuse and discursive can complement and deepen feminist critiques of structural power and dominance. A feminist, post-structural epistemology therefore can be seen as "a mode of knowledge production which uses post-structuralist theories of language, subjectivity, social processes and institutions to understand existing power relations and to identify areas and strategies for change" (Weedon, 1997, p. 40-41). In other words, feminist post-structuralism provides a lens through which to problematize the taken-for-granted truths embedded in social work academic journals and the constructions of criminalized women within their pages. Additionally, in line with a feminist post-structural epistemology, CDA requires researchers to examine their own values, social locations, and subjectivities and to make those visible in the research (Wodak \& Meyer, 2009). I embrace subjectivity and do not strive for a bias free analysis (which I think is impossible) but rather a more "critical subjectivity" (Guba \& Lincoln, 2005) which aligns well with CDA as the researcher is required to bring their own knowledge and context to bear in analysis. 
These ontological and epistemological commitments are central to CDA for three reasons: (1) Notions of absolute truth and a quest for objectivity are irrelevant in any CDA research endeavor. With roots in both discourse theory and critical theory, CDA starts from the assumption that reality is socially constructed and changing; at the same time the impact of material conditions and how they shape people's lives is acknowledged. Therefore, while accepting subjectivity, issues concerning oppression, power, and social inequality are always central to any CDA endeavor (Fairclough et al., 2013). (2) The interpretation of texts stems from the theoretical assumption that social practices are discursive. In other words, discourse shapes the way people understand their experiences and the way they act in the world. This is important to keep in mind when considering question three ${ }^{11}$ of my research because much of the interpretative work toward highlighting implications stems from the assertion that discourse is both socially constitutive and socially conditioned ${ }^{12}$ (Wodak \& Meyer, 2009). It is also important to note that the researcher, who is constructed and shaped by discourses, does the interpretation of texts. Thus, interpretation is open to constant interrogation, as it does not sit outside the influence of discourse. (3) Unlike objectivist epistemologies, CDA does not require the researcher to erase herself from the process. Rather, CDA requires that researchers make their own positions and interests explicit and visible. Further, the

\footnotetext{
${ }^{11} \mathrm{Q}$ 3: What implications do these constructions and knowledge claims have for social work practice and research with criminalized women?

${ }^{12}$ It is constitutive in the sense that it constitutes (shapes or gives meaning to) people, situations, objects of knowledge, social identities and relationships, etc.
} 
theoretical assumptions CDA is premised on hold true for the research process as well ${ }^{13}$. Since it is theoretically understood that discourses are historical, discourses must then be analyzed with reference to context in order to be fully understood. Therefore, the historical and contextual knowledge I bring to bear regarding criminalized women and social work shaped the lens through which I approached analysis and served as an important analytic tool.

\section{Critical Discourse Analysis Methodology}

CDA has its roots in the humanities and was born out of a critique of Enlightenment epistemologies (Wodak, 2013). Within the literature there is much diversity regarding what constitutes the core aspects of CDA. Depending on conceptual and theoretical framework utilized, CDA can mean very different things. Here I outline how I conceptualize CDA within the framework of this research and elucidate some key concepts and the ways I draw on them in this study.

Unlike more traditional discourse analyses established in linguistics, CDA is not exclusively concerned with the minutiae of linguistic units or the structure of grammar, but rather with the construction of larger social phenomena. CDA has been described as the study of language as a social practice with an intention toward social critique and social change (Wodak \& Meyer, 2009). CDA starts from the assumption that reality is socially constructed through discourse. Concepts of discourse, power, and knowledge are central to CDA.

\footnotetext{
${ }^{13}$ The research process is recognized as a discursive social practice in and of itself; in other words, the process of interpretation and analysis are also subject to the rules of discourse.
} 
Discourse. Foucault used the concept of an episteme to refer to the structure of knowing that dominates and governs a certain period of time. An episteme differs from a thinker, theory, or concept because it is not isolated to one person, genre, or discipline. Rather, it cuts across disciplines and refers to how we collectively comprise the world. In other words, it is spread through society and constitutes what is normative for a given time period. An episteme constrains what can be known and creates the rules of formation and exclusion in society. Epistemes are made up of and defined by discourses, or practices that shape reality. Foucault saw language as a primary vehicle through which knowledge gets embodied, shaping an episteme. He believed that meaning and reality cannot be separated from how we classify things and that the ideas and attitudes we hold are shaped by the larger episteme in which they are situated.

For the purpose of this project, discourse is defined as "an institutionalized way of talking that regulates and reinforces action and thereby exerts power" (Link, 1983, as cited in Jäger \& Maier, 2009, p. 35). In other words, discourse refers to context specific frameworks of meaning-making that inform action and (re)create the limits of what can be known (Fairclough, 2009, p. 162). It is through discourse that we give the world meaning. Social practices constitute and are constituted by discourse. Therefore, discourse itself is understood as a social practice.

Discourse defines, allows, and limits what can be known, what can be done and said, and how people can behave. Discourses actually construct, not just reflect, reality (objects, people, and events). Therefore, discourse enables and constrains what can be known. Discourses are culturally and historically situated. Dominant discourses privilege certain subject positions and notions of social reality, and become "commonsense" 
notions of the world. Dominant discourses become so taken for granted that we can't see other ways of doing/thinking about things. Multiple dominant discourses of gender, race, crime, and poverty, to name a few, shape criminalized women. In turn, analyses that seek to unearth how/if these discourses are normalized, reinforced, or disrupted in social work are useful toward understanding how power relations play out within the field.

Power and knowledge. Theorists from post-structural traditions have explored the power of discourse in creating social reality. They stress the ways in which language and thought are tied together, thereby producing knowledge of social reality that in turn shapes our thinking and being (Arrigo, 1997). The relationship between discourse and social life is therefore a dialectical one. As previously discussed, discourses do not just reflect reality but also actively create it. Discourse constitutes and is constituted by subjects, social practices, and institutions. It is through discourse that meaning is applied to material and social reality. Therefore, written and spoken language can be seen as an act of meaning-making which contributes to "reproducing and/or transforming society and culture, including power relations" (Fairclough et al., 2011, p. 370). This highlights the way language, knowledge, and power are intertwined. Therein lies the power of texts to shape reality and reproduce or disrupt the reproduction of power and inequality. As Fairclough and Wodak (1997) state:

Discourse is socially constitutive as well as socially conditioned-it constitutes situations, objects of knowledge, and the social identities of and relationships between people and groups of people. It is constitutive both in the sense that it helps sustain and reproduce the status quo, and in the sense that it contributes to 
transforming it. Since discourse is so socially consequential, it gives rise to important issues of power. Discursive practices may have major ideological effects - that is they can help produce and reproduce unequal power relations between (for instance) social classes, women and men, and ethnic/cultural majorities and minorities through the ways in which they represent things and position people (as quoted in Wodak \& Meyer, 2009, p. 6).

Further, discourses are also entangled with institutional practices. For instance, becoming "the client" in a social work discourse means that one becomes an object of interest to social workers and may thus be identified and formed in the process of intervention as part of the practice of social work. In this sense, there are subject positions that are created out of these institutional practices, for both the worker and the client.

Subject positions. Discourse brings with it particular understandings which construct subjects. Therefore, in a Foucauldian sense, discourse defines and creates subjectivities. Subjects are then positioned in society in relation to these understandings and definitions. We position ourselves and come to understand ourselves within discourses. Through discourse we create our sense of ourselves as well as our sense of the "other." This is important because how subjects and problems are seen and defined shapes how they are interacted with in the world.

Under a CDA framework, discourse is explicitly related to power in a number of ways. First, the context of discourse (i.e. education, media, politics) can be a power resource. Second, discourse has the power to influence and shape people's minds. Further, it is believed that cognition and social representations influence action and 
behavior. Thus, discourse indirectly forms our actions and behavior through knowledge. Knowledge is therefore power because of its discursive effects. In other words, knowledge is power because it directly shapes behavior and action. Thus, the discursive nature of reality is typically seen as a starting assumption for studying social phenomena. Finally, those with access and control over the most contextually influential discourse will have the most power in terms of influencing the thoughts and actions of others. There are different ways to represent criminalized women. According to discourse theory (Wodak \& Meyer, 2009), those representations will shape how other people think of and interact with them. This includes social workers and their subsequent practice and research with criminalized women.

\section{Methods and Analysis}

This study draws on the framework proposed by Jäger and Maier (2009) for performing a Foucauldian inspired CDA. I emphasize inspired because although this approach draws on aspects of how Foucault conceptualized discourse and the workings of power (as outlined above), it is not in the strictest sense a Foucauldian discourse analysis (such as an in depth genealogy or archaeology of knowledge). Jäger and Maier's (2009) framework builds on the work of Jurgen Link (1982) and focuses on:

- Analysis of current discourses and their power effects;

- Uncovering collective symbolism (which has, of course, been guided by discourses themselves); and

- The function of discourse in legitimizing and securing dominance. 
I found this framework useful for my project as it draws on the theoretical propositions discussed thus far concerning discourse, power, and knowledge and offers a concrete platform for attending to their linguistic expressions (i.e. metaphors, references, symbolism, style, presuppositions, implied meaning, argumentation strategies). Further, it provided a practical structure and procedure to engage in complex theoretical analysis.

Structure of discourse. To begin the discussion of specific methods and analysis, Jäger and Maier (2009) offer a useful breakdown of the structure of discourse, which makes it amenable to analysis. In this section, I describe this structure and characterize each aspect in relation to the study. I then provide a more in-depth discussion offering justification for the chosen study material.

Special discourse and interdiscourse. Jäger and Maier (2009) differentiate between "special discourses" and "inter-discourse" whereas special discourses refer to discourses situated in the sciences that feed continuously into inter-discourse, which constitutes non-scientific discourses. From this position, social work as an academic field firmly rooted in the social sciences (at least in a North American context) would be considered a special discourse.

Discourse strands and discourse fragments. Simply stated, discourse strands are streams of discourse centered on a shared topic. Discourse strands can be thought of as the concrete manifestation of the more abstract concept of discourse. Jäger and Maier (2009) describe them as "performances located on the surface of texts" (p. 46). Put more simply, discourse strands can be thought of as general themes that one is exploring-for instance, criminalization. Discourse strands have diachronic (concerning elements 
through time and history) and synchronic (concerning a particular point in time) aspects. A synchronic analysis examines that which is said and sayable in any given moment. In order to analyze texts that represent the current socio-political and economic context, I conducted a synchronic analysis of the discourse strand of criminalized women in social work. Specifically, my analysis focused on articles that were published in the $21^{\text {st }}$ century $^{14}$. Furthermore, discourse strands are made up of multiple discourse fragments. Discourse fragments are texts, or parts of texts, that form a discourse strand. In my analysis, specific journal articles, or parts of articles, that deal with the topic of criminalized women constituted the discourse fragments.

Discourse planes and discourse sectors. Discourse planes are the "social locations from which speaking takes place” (Jäger \& Maier, 2009, p. 48). This study investigated how the discourse strand of criminalized women operates on/in the discourse plane of social work. Discourse planes do not operate in isolation; they influence and are influenced by, interact with, and sometimes merge with other discourse planes. For instance, within the social work plane, I found that discourse fragments from the special discourses of psychology and criminal justice were often taken up to influence the discourse on criminalized women in social work.

Discourse planes are composed of various discourse sectors. These sectors take up different angles and positions but, nonetheless, can be considered a major aspect of a discourse plane. For this project, I explored the discourse sector of the academic literature

\footnotetext{
${ }^{14}$ Further justification of the chosen texts under examination is provided in the later discussion of my sample selection.
} 
in the discourse plane of social work. Social work constitutes a unique discourse plane and the academic journals constitute an important sector therein.

\section{Sample: Academic literature and high impact social work journals.}

Fairclough (2009) defines texts as a "point of entry" into discourse analysis. According to Jäger and Maier (2009), it is necessary to provide justification for the chosen texts because from a Foucauldian perspective all texts have a discursive function. Therefore, it is essential to emphasize the explicit role and function of an analyst's chosen texts. As previously stated, the primary data used for this project came from the discourse sector of academic journals within the discourse plane of social work.

The importance of published academic literature in establishing professional discourse cannot be overstated. Indeed, journals serve as an authority guiding research, education, and practice (Barretti, 2015; Lindsey \& Kirk, 1992; Tsang, 2001). Thus, the discursive (re)constitution of subjects within the published literature is worthy of investigation because as Weiler (2006) states, "this is where power is exercised" (p.18). Therefore, I see the social work academic literature as an important site of engagement for this project.

A scholar's work is legitimized through the publication process and thus endowed with a level of "specialness" and authority; this gives published literature an undeniably influential position in the process of knowledge production. Indeed, the context of such authority and its persuasive power to shape mental representations and social practices is at the theoretical core of CDA, as it represents how discourse is involved in dominance (van Dijk, 2001). The published academic literature in social work not only drives the research agenda but also shapes policy and interventions in the field. Additionally, the 
published academic literature is used as primary learning material in academia, which then influences conceptualizations practitioners bring with them into the field. As Tsang (2001) states, the selection of academic literature, though "obviously not representative of the totality of the social work discourse, can be taken as reflective of some of its major structures" (p. 232).

Van Dijk (2001) underlines the relevance of "mind control" within a CDA framework. Critical Discourse Analysis rests on the assumption that discourse influences mental models and societal representations. Discursive influence is formed by the context as well as the structure and form of texts. For instance, people may be persuaded and influenced by argumentation (structure) in and of itself, but are more likely to be influenced by argumentation from sources they see as authoritative or credible, such as experts, professionals, and doctors (context). Van Dijk (2001) further highlights the powerful influence of academic contexts in the formation and shaping of mental models. Therefore, I see social work journals as an important context for exerting influence on the mental models of social workers and thus their research and practice behavior.

It is well accepted that the purpose of scientific inquiry/knowledge production in social work is to shape policy and practice in the field (Marsh \& Reed, 2016). Thus, journal articles are frequently the subject of research in social work. Humble et al. (2012) examined the framing of HIV/AIDS in social work journals to ascertain how/if the changing knowledge in the field of HIV/AIDS was reflected in the knowledge base of the profession. Hardy (2013) assessed social work journals for their coverage of the Black Church and African American Christianity. Tsang (2001) explored the role of social work journals in constructing ethnicity. All these studies started from the assumption that 
social work journals are an important and credible source of knowledge within the profession and serve a crucial role in shaping the thinking and behavior of practitioners. Therefore, the knowledge contained in journals may be representative of some of the larger trends in social work.

Academic journals contain both conceptual and instrumental knowledge. Conceptual knowledge shapes the ways problems are considered, solutions/interventions are formulated, and understandings of professional context emerge. Instrumental knowledge is related to interventions and effectiveness. Despite social work's increasing emphasis on instrumental knowledge, particularly in the form of evidence-based practice and competence-based education, a study conducted by Cha, Kuo, and Marsh (2006) found that practitioners reported both conceptual and instrumental knowledge as being equally useful in helping them make practice decisions. Therefore, both are included in my analysis.

Academic journals serve a primary role in the formation of disciplines and professions (Tsang, 2001); they both shape and reflect values, knowledge, and priorities. Editors and their selected reviewers serve a gatekeeping function in defining the boundaries of knowledge production of a given discipline/profession ${ }^{15}$. Though social workers obviously write in and draw from other (inter)disciplinary sources, it is also important to examine disciplinary boundaries themselves for what they signify. There may be distinct differences in what is reviewed and accepted in social work journals

\footnotetext{
${ }^{15}$ Though I recognize that social work's status as a discipline and/or profession is and has been debated due to its lack of a distinct and specialized body of knowledge, engagement with that debate is outside the scope of this dissertation. Despite where one comes down in relation to this debate, it may be amenable to both sides to say that social work is a field with discursive limits.
} 
versus what is reviewed and accepted in, for example, criminology journals, sociology journals, or counseling journals; despite coverage of similar topics, the discourses represented may vary. Though there may be shared elements, each discipline/profession has its own language, culture, value base, and general orientation to the social world, and their journals can be seen as representative of the major elements of a field's internal form and coherence. Therefore, an explicitly social work distinction in my selection of journals for this research is important because I am interested in the distinct discourse of social work.

For instance, a dominant theme in the criminological literature is "criminogenic need," which focuses on identifying risk factors for recidivism and tailoring intervention programs to address those risks (Latessa \& Lowenkamp, 2005). The language of “criminogenic need," though not entirely disregarded by social work, is deficit-based and largely neglectful of context with a focus on changing individual behavior. Though similar risk frameworks are certainly adopted by social work, one would expect that the profession's values around humanitarianism, strengths-based practice, self-determination, and social justice largely impel social work scholars to speak in a different (specific) way. Still, despite embracing these values, dominant cultural narratives are likely to seep into the work that social work performs. As Tsang (2001) states, "the profession is not totally immune to the influences of the dominant discourses of society" (p. 229). For example, in a Critical Discourse Analysis regarding social work's role in immigration, Park and Kemp (2006) show that social work discourse supports dominant ideology surrounding immigration while simultaneously attempting to redress the consequences of such ideology and discourses. This has profound consequences for how we work with 
people who inhabit liminal spaces, such as women on community supervision who dwell in a world between "free" and "not free."

Further, though critical analyses of the construction of criminalized women have been done in relation to criminological and penal literature, I am unaware of any in depth explorations as to how criminalized women are constructed in the social work literature. Indeed, compared to the larger body of work coming out of criminology, law, and psychology, social work appears to pay scant attention to criminalized women (Wheeler \& McClain, 2015).

I selected social work high impact journals (journals that are read and cited more frequently) because they represent an array of political and professional priorities and may possibly provide a spectrum of representations within the field. Additionally, the high citation rates of these journals illustrate their conferred legitimacy and acceptance as a source of information and knowledge within social work (Jäger \& Maier, 2009). Though imperfect, high impact journals have been recognized as serving an influential role in disseminating information and, over time, shaping practice behavior (Lindsey \& Kirk, 1992; Marsh \& Reed, 2015). Though many practitioners do not have easy access to these journals, I argue that the ideas and ways of thinking embedded in "high impact" research filter to practice both indirectly, through students who eventually become practitioners, and directly, through funding agencies which allot funding for "evidencebased practices" that are often tested and legitimized through academic scholarship. Though high impact journals represent only one tendril of academic scholarship, neoliberal forces and values influence researchers and organizations in such a way so as to elevate and hold high impact journals to a greater esteem. 
Further, high impact journals impart legitimacy and authority to social work researchers and scholars often regarded as "experts.” In this, I believe high impact journals can provide an understanding of the kind of scholarship that shapes social work discourse and vice versa. Still, I want to be clear that my choice of using high impact journals as my sample is not linked with assumptions regarding the quality of a journal or publication. Rather, it is linked to an assumption of influence.

Limitations of high impact journals. Despite the practical and theoretical reasons for using a sample consisting of high impact journals, it is worth noting some inherent limitations with this approach. Flaws and biases within citation indexing databases have been widely recognized (Bornmann et al., 2012; Kurmis, 2003). A range of factors other than quality or actual influence can influence impact scores, including ease of journal access, publication frequency, and type of material published by a journal. Impact scores for a journal are generally calculated by dividing the number of times articles published in a two-year period were cited by the total number of "citable" articles ${ }^{16}$. Therefore, only a small proportion of its articles may influence the impact factor of a journal. Furthermore, a large percentage of published articles never get cited, which could exclude articles from my sample that may be representative but not widely known.

Additionally, citation-indexing systems do not include all journals in any given field (regardless of number of times their articles have been cited) and the criteria for inclusion remains unclear. This can present problems when assuming influence. For

\footnotetext{
${ }^{16}$ Not all items published in journals (such as editorial and news articles) get factored into the impact factor.
} 
instance, it has been noted that publications not included in the Scientific Citation Index Database sometimes have more citations than those that are included (Kurmis, 2003).

Lastly, authors who are cited frequently are more likely to be known in a field and to publish work that is easily recognizable and sought after by other scholars. Therefore, the use of the impact factor in this research may have contributed to encountering the same authors and types of work again and again, which is more representative of institutionally reinforced popularity rather than the discourse of the field at large. In this sense, the use of high impact journals may have potentially made my sample more homogenous than desired. However, given that I drew my sample from a range of the listed high impact journals, rather than just the top five or ten, I found a good amount of variability within the sample.

Sample selection. I identified high impact social work journals using Eigenfactor. Eigenfactor is a project established through the University of Washington which evaluates the importance of scholarly journals and provides a searchable database of the most influential journals by ISI subject category ${ }^{17}$. Though Eigenfactor scores are calculated a bit differently than the more well-known ISI Impact Factor, Eigenfactor is freely available and is considered a good proxy for the Impact Factor (Davis, 2008). The journal citation data for Eigenfactor comes from the Journal Citation Reports (which is the proprietary database for ISI Impact Factors). Therefore, all of the journals that appear in Eigenfactor are also listed in Journal Citation Reports. Eigenfactor uses a five-year

\footnotetext{
${ }^{17}$ Institute for Scientific Information subject categories are generally interpreted as providing a disciplinary structure of science.
} 
citation average rather than the two-year period for ISI Impact Factors ${ }^{18}$. Eigenfactor also provides a weighted citation count, which takes into account the size of the journal, rather than just a raw citation count as provided by the ISI Impact Factor.

Eigenfactor helped me identify high impact journals that are categorized under the “social work" ISI subject category. However, not all of them were explicitly social work journals, so I did some elimination. Eigenfactor generated an initial list (latest calculation from 2015) of 41 journals. I excluded those that were not in English (2) and those that would not be expected to have articles of relevance to the North American context ${ }^{19}$. Of the remaining 37 journals, 13 were researched further to ensure that they were explicitly social work identified. I eliminated multi-disciplinary/interdisciplinary journals, unless their editorial board was made up of social workers, which resulted in the exclusion of 12 more journals, for a remaining total of 25 social work journals. Appendix A shows the remaining 25 journals from which the sample was drawn.

I utilized the list of journals generated by Eigenfactor and searched the Web of Science with topic/keywords AND [journal title] as publication name. I did separate searches for each journal in order to keep things organized. Key words included: criminal/ criminalization/ criminality/ prison/ incarceration/ criminal justice/ corrections/ reentry/ diversion/ offender / offense/ re-offense/ recidivism/ parole/ probation AND women/ woman/ female/ mother AND date range [2000-2017]. The above key words are those that are commonly found in the literature regarding women involved in the criminal

\footnotetext{
${ }^{18}$ Calculating averages over longer periods of time results in less variability and provides more of an enduring sense of the journal's influence.

${ }^{19}$ Though research could certainly look at the discourse generated in a larger global social work context, my project is explicitly framed within a U.S socio-political context. Therefore, I include articles only of relevance to or generated in relation to such a context.
} 
justice system and include women who may be currently and formerly incarcerated. Furthermore, because children of incarcerated parents are a growing topic of interest to social workers, mother/motherhood was included in addition to women/woman/female as keywords in the sample.

Only articles dealing explicitly with criminalized women were selected. To account for the diversity and difference among women necessitated by both multiracial feminism and post-structuralism, "woman" was defined broadly and included trans women. Initial selection was made mainly on the basis of abstracts; I scanned abstracts to ensure that a primary focus in the article included criminalized women (using the key words offered above). Searching journal articles through key words also allowed me to see and look for discursive entanglements with other discourse strands.

In order to conduct a synchronic analysis of texts that represent the current sociopolitical and economic context, my sample was comprised of articles that were published in the $21^{\text {st }}$ century. This time frame provided a lens through which to view the long-range impacts of punitive sentencing policies that emerged in the latter part of the $20^{\text {th }}$ century and early part of the $21^{\text {st }}$ century. As I previously discussed, such policies have caused an increase in criminalization and incarceration, and the effects are reverberating today. Further, because the topic of criminalized women is not always treated extensively, it made sense to evaluate journal articles from this longer period of time in order to ensure that the qualitative nature and variety of the discourse strand became apparent.

My initial search revealed 273 citations. Next, I reviewed article titles to eliminate those that clearly did not fit within the inclusion criteria of the study. Such eliminations included articles focused on issues such as juvenile justice, foster care, women as victims 
of crime, and other completely unrelated topics. Next, I reviewed abstracts and looked more closely (reviewing full texts when necessary) at articles focused on children of incarcerated parents, domestic violence, child abuse, and those about criminal justice but ambiguous about a gender focus to ensure that they fit parameters for the study. Applying exclusion criteria (e.g. outside of a U.S. context, book reviews, criminalized women not an explicit focus) resulted in 51 citations. I retrieved the full text for each of these citations. During the course of my initial read through of all the articles, two additional articles were removed from the sample because the focus was not ultimately on criminalized women. My final sample consisted of 49 articles from 12 journals, which I think is telling in and of itself; in almost two decades of scholarship in the context of mass incarceration, with women being the fastest growing correctional population, only 49 articles on this issue come out of the profession's quote un-quote most influential journals. Appendix B provides a list of the articles included in the dataset. It is also notable that of the 25 journals I searched, my final sample came from only half $(n=12)$ of the original list. The other half did not contain articles meeting inclusion criteria from the specified time period. Appendix $\mathrm{C}$ provides a breakdown of the number of articles per journal included in the dataset.

Analysis process. A synchronic analysis investigates what is sayable ${ }^{20}$ within any given context at a certain point in time. In other words, it identifies the current state of a particular discourse and the knowledge embedded therein. This study drew on an analysis plan offered by Jäger and Maier (2009). Analysis occurred on two levels consisting of 1)

\footnotetext{
${ }^{20}$ Different from what is said in that what is sayable refers to what is even possible to say or think within a given context.
} 
a structural analysis on the discourse strand; and 2) a detailed analysis on smaller text units. These two levels of analysis led to an overall synoptic analysis, or final assessment of the overall state of the discourse on criminalized women in social work. According to Jäger and Maier (2009), the researcher can expect to go through several cycles of analysis in order to discover connections and to develop and strengthen interpretations. As such, the articles in my sample were subjected to repeated analysis involving iterative “coding" ${ }^{21}$ utilizing Jäger and Maier's analytical guidelines described below. Ultimately, CDA requires a particular orientation when engaging with texts; for me, this meant that I was consistently looking at how meaning was constructed in the texts, questioning what was implied through the texts as well as what was missing or left out (Jäger \& Maier, 2009; Wood \& Kroger, 2000). Janks (1997) explains that CDA necessitates that analysts deliberately partake in an "estranged reader" position; that is, "reading against a text" in order to resist its "apparent naturalness" (p. 331). However, Janks warns that “estrangement without engagement is a refusal to leave the confines of one's own subjectivity, a refusal to allow otherness to enter" (p. 331). Therefore, it is important to also "read with a text" in order to decipher the intended meanings and dominant readings

\footnotetext{
${ }^{21}$ In CDA, traditional notions of 'coding' are not typically used. Rather, there is a close focus on how meaning is constructed in texts, which requires analysts to make sense of the function of various textual features. For instance, the discourse analyst may focus on lexical choices and the ways such choices mark particular assumptions or imply particular meanings. At times, I attempted to employ traditional coding strategies for ease of organization and extracting examples from the data. However, this proved challenging because coding in this manner pulled the data out of its larger context and thus interfered with interpreting its meaning. Instead, I annotated as I read, grouped articles according to particular discursive themes and patterns that emerged in the structural analysis, and worked with data analysis templates. When it came time to isolate examples during the writing process, I would then revisit a text in its entirety, along with its annotations and completed data analysis templates. This required me to think and re-think, analyze and reanalyze as I wrote. In this way, writing became an integral part of the inquiry process.
} 
of a text. For this reason, I considered the idealized reader perspective ${ }^{22}$ in my analysis. Huckin (1995) describes the idealized reader as one who is looking for the general picture of the text without trying to deconstruct it. An idealized reader framework considers the intended meanings of a text as well as aspects of the text that a "typical reader" would be likely to focus on. In relation to academic journal articles, the idealized reader might be a busy scholar, or perhaps student or practitioner, who reads for a gist or to support their own work; someone who may not have either the time to spend or the effort to exert on analyzing the text beyond skimming the title, abstract, introduction, and conclusions. As such, these aspects of the texts were given extra thought in my analysis due to the likelihood that many readers may be exposed only to them. The idealized reader perspective helped me consider the power of a text and its effect within the process of knowledge production and dissemination. I continued analysis until I reached “completeness” or saturation (Jäger \& Maier, 2009). Completeness was identified when themes and interpretations began to repeat themselves.

Structural analysis. The structural analysis included multiple readings which helped me identify broad discursive themes and specific pieces for detailed analysis (Wood \& Kroger, 2000). In the structural analysis, I essentially searched for what was typical within the sample and identified discourse positions. Jäger and Maier (2009) contend that within any discourse plane or sector, dominant discourses as well as counter-discourses may emerge. This proved true and served as a launching point for understanding the discursive limits of the discourse strand.

${ }^{22}$ Similar to Derrida's analytic strategy of 'double reading.' 
The structural analysis consisted of a broad overall analysis of the texts that made up the discourse strand and consisted of the following steps. First, I compiled a list of all relevant articles and their identifying characteristics. This included bibliographic information, information related to the journal, basic information on the authors, and general notes on what the articles covered. I began the structural analysis by reading all of the articles in alphabetical order. As I read, I annotated the articles and kept memos and notes in a reflexive audit trail. It soon became apparent that different authors and themes emerged from and coalesced in different journals. At this point, I created a detailed breakdown of articles per journal (see Appendix D). I then re-read all of the articles in a different order, this time based on journal. After this reading, I noted the major themes and trends coming from each journal.

Next, I worked with Jäger and Maier's (2009) outline for the structural analysis to capture the overall characteristics of each article. This included the topics and subtopics covered, use of collective symbols (cultural stereotypes or topoi), arguments that were made, vocabulary that was used, and attitudes that emerged. As I continued to read and re-read through the articles, I adapted this outline to capture other points of interest that emerged in the initial readings (these included reliance on risk, use of social justice values, binaries and contradictions, strategies for staying neutral, and textual silences) and created a structural analysis data template (See Appendix E). I then read through each article again, using the structural data analysis template. This process helped me identify what was typical in the sample (typical arguments, positions, vocabulary, etc.) and helped identify discourse fragments (i.e. articles and parts of articles) for detailed analysis. 
Moving through the structural analysis also helped me to refine which aspects of grammar would be most fruitful to examine more in depth in the detailed analysis. For example, I began to notice that the vocabulary and word choice identified throughout an article would often reveal the overall discourse position or discursive pattern of an article. So later in the detailed analysis, taking a closer look at nouns, verbs, and adjectives helped shed light on the sort of logic the text implied and what judgments the text passed on certain groups. For instance, risk emerged as a defining feature of the discourse strand. However, there were distinct ways that risk was portrayed and framed through the use of language. The strongest framing of risk occurred through the use of criminogenic language, which invoked images of criminal women. Riskiness was also portrayed through the language of psychology. Observing this distinction led me to wonder if there was a distinct psychologized construction of risk that is more about the "fallen" or pitiful women in need of help and treatment, rather than the dangerous or criminal woman in need of containment and surveillance (Rafter, 1983). At first, I did not make a distinction between different invocations of risk. However, upon closer examination of the lexical choices I saw that, though both constructions (psychologized and criminogenic) imply individualized notions of choice and individualized understandings of crime and women's involvement in the criminal justice system, they do so in different ways. The language of psychology focused on women's individual psyches and called for treatment in order to promote healing, whereas the use of criminogenic language focused on neoliberal notions of responsibility and called for treatment in order to reduce risk and increase surveillance. This led to the creation of distinct categories for the construction of risk: the risky woman and the vulnerable woman/object of pity. 
In the structural analysis I also identified discursive entanglements. Texts often reference various topics and discourse strands. An analysis of discursive entanglements looks at how different discourse strands are entangled, in other words, the associations between different concepts. For instance, I found that the discourse of child welfare was often entangled with the discourse of criminal justice, the discourse of social services was often entangled with discourses of psychology, and the discourse of trauma was often entangled with the discourse of attachment. Locating discursive entanglements allowed me to further discover the discourse position within a given text. A discourse position is "the ideological position from which subjects, including individuals, groups, and institutions, participate in and evaluate discourse” (Jäger \& Maier, 2009, p. 49). Discourse positions are essentially overarching worldviews that are developed from being immersed in various discourse strands.

Lastly, I summarized the topics and subtopics of the sample into groups. The frequency with which the subtopics appeared (those that were focused on more heavily and those that were marginal) was noted. Further, any subtopics/issues that were conspicuously absent were also noted. I kept memos to include descriptions of these groups, within-group trends, and the significance of each grouping within the context of the sample. This helped me further articulate discursive themes within the entire sample.

Detailed analysis of typical discourse fragments. To further analyze discourse positions and their effects, discourse fragments that were typical or representative of a specific discourse position were subjected to detailed analysis. Analysis at this level involved establishing connections between language form, function, and context. In my analysis, specific journal articles (and parts of articles) that embodied key discursive 
themes found in the structural analysis constituted the discourse fragments. Jäger and Maier (2009) organize the detailed analysis under the following headings:

1. Context of Text. Analysis of the context considers aspects regarding the text production such as who wrote it, the journal it was published in, and under what conditions. The context in which a text is produced gives many clues to its status, legitimacy, and degree of power (Jäger \& Maier, 2009). The surrounding sociopolitical context within which the text is written and framed should also be considered in order to more fully understand what is said or left out of the text. Here, I consistently kept in mind the overarching place high impact journals hold in the enterprise of knowledge production. I also thought about how the larger socio-political context was reflected in, or left out of, the texts and how it informed the arguments being made.

2. Surface of Text. An analysis of the surface of a text looks at what is actually present in the text. This includes the layout, graphs, how the text is organized into units of meaning, and the topics covered. Such factors frame the meaning of a text and are therefore considered in analysis. In terms of topics, I looked at the key themes that were communicated about a topic and the general statements that could be derived from these themes. In line with the expectations of the discourse sector of academic journal articles, the general structure of the articles in my sample was relatively stable, showing little variability in organization and layout. Therefore, what became fruitful for me in terms of examining the layout of these texts was considering the role that the tile, abstract, introduction, and conclusion had in the overall scheme of things. Given that these components of academic 
journal articles are more prominent in terms of usage, I spent extra time analyzing them as specific sites of power.

3. Rhetorical Means. Analysis of rhetorical means looks at the argumentation, collective symbolism, how subjects are constructed, use of lexical choices (choice of vocabulary), and other grammar features. Rhetoric, or rather how something is said, is important because it can signal certain value orientations and serves to shape the ideological implications and discourse positions present in a text. Here, I found that also looking at the use of evidentialities helped illuminate not only the overarching tone of an article, but also how the text would "naturalize" certain statements as common sense. I also spent time looking at intertextuality, or the references made to other sources, and the function and use that certain sources served in shaping the overall argument.

4. Content and Ideological Statements. An analysis of content and ideological statements attends to the overall worldview portrayed by a text. Here, I looked at how the ideology was framed and justified in the texts. For instance, depoliticized explanations for crime and criminal justice involvement were actively produced through a mode of reasoning that decontextualized representations of women's behaviors and situations. Another key aspect of this analysis included what was excluded, or only implied in the text.

5. Other peculiarities of the article and the overall discourse position and message. Jäger and Maier (2009) offer a detailed outline of specific questions to guide each aspect of the detailed analysis, which served as a useful heuristic device in my analysis (p. 55). As suggested by Jäger and Maier, I used their questions as "sensitizing concepts" 
rather than constructs that were applied mechanically. I adapted their outline to conceptually align with my study, and with what I was learning in the structural phase of analysis. Table 1 shows the adapted version of Jäger and Maier's framework for detailed analysis. Appendix F includes an illustration of both phases of analysis (structural and detailed) on the same article. Jäger and Maier (2009) highlight that meaning is always emergent and analysis will not always move directly from one level of analysis to the next. I found this to be true in my own process and sometimes found myself moving through detailed analysis while simultaneously engaged with structural analysis. 


\section{Table 1. Jäger and Maier’s (2009) Adapted Framework for Detailed Analysis}

1. Context

a. Why was the article selected for detailed analysis? Why is it typical?

b. Who is the author? What is their position and status within social work? What is their area of expertise, and so on?

c. In which section of the journal does the article appear? What kind of article is it? (empirical, conceptual?) Is the article a part of a special issue?

d. What year was the article written? Any significance of time?

e. What meaning does the text attribute to other sources? Does it imply knowledge of another subject matter?

2. Surface of the Text

a. What is emphasized in the title and abstract? Introduction/conclusion?

b. What are the headings and subheadings? How is the article structured into units of meaning?

c. What topics are touched upon in the article?

d. How do the topics relate to each other and overlap? (discursive entanglements)

3. Rhetorical Means ${ }^{23}$

a. What kind and form of argumentation does the article follow? What argumentation strategy is used? What logic underlies the composition of the article?

b. What implications and allusions does the article contain?

c. What collective symbolism is used?

d. What idioms, metaphors, sayings, and clichés are used?

e. What are the vocabulary and style? (lexical choices, coded language, modality, evidentialities, binaries)

f. What actors are mentioned, and how are they portrayed?

g. What references are made? (e.g. cultural references, references to other disciplines/professions, media or policy referenced, does the text imply knowledge from other sources?)

4. Content and Ideological Statements

a. What concepts of social work does the article presuppose and convey?

b. What concepts of "client" does the article presuppose and convey?

c. What concepts of crime, criminality, and punishment does the article presuppose and convey?

d. What explanations for criminalization are given? Where does the problem for a woman's crime/criminalization lie? (i.e. individual? structural? socially constructed? a pathology?) Who/what needs to change?

e. What concepts of practice and intervention does the article presuppose and convey? What is deemed as "effective" practice? How are outcomes defined?

f. What frameworks of thought/rationalities are these practices embedded in? (i.e. Risk? Welfare? Morality?)

g. How are gender, race, and class discussed, explained, and exposed?

h. What content or background is missing?

5. Discourse Position and Overall Message of the Article.

\footnotetext{
${ }^{23}$ To supplement these questions, I generated a list of categories during the structural analysis which served as a guide for things to be on the lookout for, at the level of language (see Appendix G)
} 
Synoptic analysis and final assessment. Synoptic analysis is typically the final step of CDA and consists of analyzing the structural analysis and detailed analysis in relation to each other and comparing and contrasting the findings to gain an overall assessment of the discourse position(s). Throughout their discussion of analysis, Jäger and Maier (2009) are clear that analysis is an iterative process with ongoing interpretations and revisions. I originally envisioned moving cleanly from one step of the analysis to the next. However, I found that, in line with the principles of CDA, I needed to be much more flexible and creative in building my project and in moving through and among the different levels of analysis and interpretation. Rather than the previously outlined stages of analysis being discrete, I found a lot of slippage between them. The phases of analysis often occurred simultaneously. As I moved back and forth between paper copies and electronic versions, oscillating between these different data artifacts, I was able to hone in on different details.

Though I began with some useful heuristic devices, CDA does not consist of specific formulas or methods that can be applied across the board to research projects (Fairclough, 2009; Jäger \& Maier, 2009; Wood \& Kroger, 2000). This was initially a point of contention for me. As a novice discourse analyst, I found myself wanting to find certainty and a procedure that I could follow which would allow me to do things the "right" way. This was an ironic anxiety given that the epistemological nature of this study lingers in the realms of uncertainty and provisional knowledge. Ultimately, I saw myself as experimenting with this methodology using Jäger and Maier's framework as a helpful 
starting point and adapting it as I progressed ${ }^{24}$. After all, as Jäger and Maier (2009) state, "the best way to learn CDA is to do CDA" (p. 56).

\section{Researcher Position}

I positioned myself in this research as a "transformative intellectual" (Guba \& Lincoln, 2005). I find the notion of transformative intellectual to be most in line with my goals and values. Still, I find this an uneasy alliance. Both words, transformative and intellectual, burst forth with such confident claims toward authority. As a first generation college student, I often feel displaced in an environment of academic politics and forced intellectualism. I struggle to "keep up" but more so to stay engaged and find inspiration. Further, as a woman, I have been adequately socialized into a more humble position of doubt and uncertainty. Instinctively, I wonder about my ability to do justice to the label of "transformative intellectual" and I ask "who am I to claim this role?" But then again, as a feminist scholar with a strong allegiance toward social justice claims and toward challenging entrenched beliefs about who can be a knower, I also have to ask, "who am I not to claim this role?" Therefore, I tentatively embraced the position of transformative intellectual within my research. In the next chapters, as I communicate my interpretations, I practice centering myself as legitimate while still recognizing the limits of my understanding.

The post-structural concepts I have discussed thus far-discourse, power, knowledge, and subject positions - apply to my position in this research as well. I, myself, am bound up in the larger discourses of society and the discourses of social work.

\footnotetext{
${ }^{24}$ Because of the emergent nature of my project, I kept detailed notes on the research protocol and how/why it evolved throughout the process.
} 
My own subject position and understandings of the world have been deeply shaped through these discourses. This, in part, may have helped me understand implicit meanings while engaged in analysis, but it also formed the boundaries of my interpretations.

\section{Evaluative Criteria and Ethical Considerations}

Within CDA there is a marked lack of conversation around quality criteria. Common markers of quality criteria in qualitative research include 1) Attention to "contexts of production"-including research relationships, the institutional, cultural, and historical settings; 2) Attention to representation-including questions related to selection of what to tell and what to leave out; 3) Attention to the construction of knowledgeincluding "questions of whose version of reality is privileged, who can tell a story and who can change it"; and 4) Attention to dissemination (Seale, 2002; Mertens \& Ginsberg, 2008; Gilgun \& Abrams, 2002).

Like others before me, I reject "standard notions of rigor or validity as evaluative criteria" (Strega, 2005, p. 228). Judgments of quality that are borne out of an Enlightenment epistemology are not useful in work that explicitly rejects notions of truth and objectivity (Strega, 2005). Strega (2005) outlines three standards for assessing feminist, post-structural research that I find compatible with CDA and with my expressed ontological and epistemological assumptions.

First, assessment is based on the goals of social justice. The research takes seriously its usefulness and political implications and should have the capacity to instigate progressive change for marginalized people and communities. This research 
puts the gaze on the profession of social work and seeks to activate a deeper, critical analysis of the ways in which we think and talk about the people with whom we work. Therefore, a critical analysis of the discourses surrounding criminalized women in social work journals has the potential to change the way social workers understand and apply academic knowledge in their research and practice and thereby improve the experience of criminalized women involved in social work research and services.

Secondly, the research should consider dissemination that is rooted in an "ethic of care and personal responsibility.” Along these lines, van Dijk (2009) proposes accessibility as a quality criterion for CDA. Thus, findings should be accessible and readable, particularly for those whom the research is "about." Gilgun and Abrams (2002) further highlight the ethical nature of dissemination. In their view, attention to audience includes considerations regarding who needs to hear the results as well as accessibility. In dissemination lies the potential for the research to "disrupt oppressive social processes" (Chase, 2005, p. 667) and reflects larger ethical commitments to social change. Here, I could comment on the importance of making sure my work gets published as a transgressive act. Certainly social work researchers, educators, and practitioners would fall into the category of who needs to hear the results. After all, scholarship that gets published is garnered with a certain level of legitimacy, and legitimacy for work that seeks to examine and disrupt the status quo propels that disruption forward. Still, there is an enormous tension for me here. In this project, I have written a dissertation for a specialized audience and I was thus compelled to adhere to the established criteria set for this endeavor-whether this is a situational excuse or a cop-out remains to be seen. From 
here, I will move forward into a career in academia. Though I will no longer be operating under the constraints of "student," my personal advancement will once again rely on my ability to meet certain metrics for success, publications being one of these. Academia privileges certain ways of speaking and writing. Scholar reputation is not unhinged from journal reputation. This raises question about (1) how much I will try to subvert the dominant talk of academia and risk not being published; and (2) how much I will attempt to bring my work into other venues, where it may have more practical applications, but less for career advancement.

Ultimately, I have many questions regarding the social justice claims that any of us in academia make. We are so deeply embedded in an elitist institution that has historically been exclusionary. By virtue of our participation, we are to a certain extent complicit in that exclusion. Further, for my specific project, I recognize the heady nature of much of what is involved in CDA. It is firmly grounded in inaccessible language and discussions that emerge out of academic theory and jargon, which is an ironic turn given that its goal is to unsettle dominant narratives. I don't have a good resolution for this tension. But every day I am acutely aware that I am participating in something that alienates me from my friends and family as well as from the people whom social work serves. Therein lies another layer of tension for me. The excitement of passionate inquiry is tinged with a shade of isolation and despair.

Lastly, evaluation can be determined through the extent of critical reflexivity. This impels researchers to make themselves, their biases, and their interpretations visible in the process as well as acknowledging and addressing the tensions that arise (Finlay, 2002; Strega, 2005). In other words, dealing with "the politics of reality" (Lal, 1996, p. 
207). Here, I will say more about power and reflexivity as it is central to ethical research as well as quality research. Strega (2005) asserts that "a critical measure by which our work needs to be assessed is the extent to which we are complicit with or challenging of dominant discourses” (p. 231). Daley (2010) distinguished reflexivity, as reflecting in action, from reflection, as reflection on action. In her assessment, the former considers power relations in the research process and the latter considers the effects of structural arrangements on the research. Thus, reflexivity, as I understand it, goes beyond reflection and simply locating oneself in their research. It stretches us to consider seriously the ways in which we are complicit in systems of oppression. As a social worker and academic myself, I am deeply implicated in (re)creating the power dynamics and relations which I seek to unsettle and critique. I do not sit outside of these institutions; indeed, I have been intimately shaped by their discourses, perhaps in ways outside of my conscious understanding. This is often a troubling space to inhabit and there is a need to guard against slippage into neoliberal thinking that is so prominent in both social work and academia. Reflexivity, then, was crucial throughout the research process in order to recognize and own my privileged position and how it played out in analysis, to either challenge or uphold dominant structures and power relations. This is particularly salient in work that critically pushes back on a profession with which I actively identify. Reflexivity, therefore, makes it known that subjective interpretation is taking place and gives the researcher space to not only situate themselves in their interpretations but to also put themselves in conversations with their interpretations, which I attempted to make visible in my writing. 
For this project I engaged with reflexivity primarily by keeping a reflexive audit trail. This audit trail served as a repository for my understandings and experiences with the data that I visited and revisited throughout the research process. In it, I documented my processes, thoughts, ideas, and questions, as well as my anxieties and uncertainties regarding the problematic of interpretation. These notes helped me track the research process and to record concepts and issues that needed further thought and exploration. Additionally, I found myself paying attention to places where resistance, existential quandaries, and epistemological tensions surfaced during the course of this research. I have found that engaging with these more intellectually and emotionally challenging aspects of the research allowed for deeper levels of meaning-making to occur-regarding both my interpretations of the data and of myself as a researcher and citizen of this world. This level of meaning-making is the terrain in which I negotiate my subjectivity as an academic who wants her work to be useful and noble. 


\section{Chapter 5: Findings and Analytical Discussion}

My overarching research question examined how criminalized women are constructed in social work high impact journals. There were also two other research questions related to knowledge and practice because the aim was to make visible the current constructions of criminalized women in social work, to understand the knowledge that is produced through those constructions, and to explore how that knowledge supports/shapes certain kinds of research and practice. The three research questions are shown below:

1) How do social work high impact journals construct and represent criminalized women?

2) What particular knowledge claims about criminalization and criminalized women are made through these constructions?

3) What implications do these constructions and knowledge claims have for social work practice and research with criminalized women?

The purpose of this chapter is to share the study findings and provide an analytical discussion to address the research questions. Attempting to articulate the results in this manner has been a challenging endeavor. There are certain threads from the data which can be neatly reviewed and discussed, but much else remains indistinct and incoherent, emerging only through immanent tension and apparent contradictions. I noted multiple competing discourses both among and within texts; about criminalized women as well as the nature and purpose of social work. What becomes clear through such contestation is that in constructing criminalized women, social work also constructs itself.

Throughout this project, I kept returning to Foucault's assertion that discourse analysis looks not just at what a text says, but also at what it does. This question of doing 
continually strikes me when examining the data. There's the doing of individual texts, and the doing between and among them. In this way, all of the individual texts, taken together, can be read as a larger text doing something different, something more substantial, than each individual part. Analyzed from this point of view, what emerges from the data is not just a contestation over the construction of criminalized women, but a discursive struggle over the very nature and meaning of social work itself. I observe this struggle as one of dualities; dualities regarding levels of practice (micro/macro), epistemological advantage (positivism/interpretativism), mission (social change/social control), and professional identity (professionalization/politicization). Of course, this tension is nothing new. Debates regarding the dichotomous nature of social work practice have been raging since its inception. As I watched this discursive struggle unfold in my analysis, I began to wonder if the contradictions I saw constituted a contradiction at all, or if this core tension actually constitutes what social work is. In other words, a struggle of dualities not only defines a singular aspect of social work, but also produces the very structure of social work and the discursive space in which it exists and is thereby recognizable.

However, thinking in terms of duality, or even the paradox of dualities, seems insufficient to explain social work. Derrida (1981) argues that dualisms are always already troubled. He invokes the undecidable, something that cannot conform to either side of an opposition. An example is the Greek word pharmakon, which means both poison and remedy; or a ghost, which is both present and absent. Undecidables contain "both contradiction and noncontradiction-and the contradiction and noncontradiction 
between contradiction and noncontradiction" (Derrida, 1981, p. 221). The undecidable disrupts binary logic, displacing either/or dualism with an ambiguity that occupies both sides of the dialectic while also destabilizing it from within. Derrida (1981) describes undecidables as 'the 'between', whether it names fusion or separation, that thus carries all the force of the operation" (p. 220). I argue that social work acts as such an undecidable.

Derrida (1981) stresses that undecidability contains the presence of an “inexhaustible ambivalence.” An ambivalence, which determines that the undecidable can always be defined in more than one way. The undecidable cannot be fully decided, and it is in this undecidability that the "conditions of possibility for acting and deciding" are actually created (Caputo, 1997, p. 137). As such, the dualistic debates that have framed social work practice for decades are part of the praxis of the undecidable. For instance, social work is neither driven toward micro or macro practice, but simultaneously both-each side of the dialectic mutually enabling the other. This links Derrida's work with Foucault's discussions of power. In Foucauldian terms, power is not only repressive, it is also productive. It operates in and through relations to produce knowledge and subjectivities. It is within a discursive struggle of dualities that social work as an undecidable comes into being, and that we as social workers claim our identities and priorities within the profession.

Undecidability also reveals paradoxes involved in the project of social work, where the profession's conditions of possibility are at the same time its conditions of impossibility. For instance, social work upholds aspirational values toward social justice 
while simultaneously functioning as an agent of social control. Throughout my analysis, I watched this specific paradox reveal itself time and time again. Authors in my dataset would simultaneously uphold the neoliberal mantel of individualism while clinging to the reclamation of a larger social obligation. I was often confused about what was happening in a text or where an author stood in relation to the carceral state. I found myself wondering about the intent of what I was reading and doubting my own analysis. Notwithstanding the problematic of interpretation that is always present, I was knee-deep in an ambiguity embedded in the texts related to how they embodied the competing interests of the profession. In one moment, I read a text as upholding social justice and in the next, undermining $i^{25}$. I couldn't decide. In Derridean terms, it is the "the ghost of undecidability" that marks and constitutes the profession, "for the undecidability is never set aside, never over and done with. It hovers over a situation before, during and after the decision, like a specter of justice, disturbing it from within, divesting it of absolute self assurance" (Caputo, 1997, p. 138). I have found this increasingly difficult to capture within the bounds of writing that necessarily needs to be defined and limited. Therefore, I foreground the undecidable as the discursive space in which to hold all subsequent discussions of results that unfold in the remainder of these pages.

The discussions in this chapter are organized around the research questions. However, while the three questions may appear to be discrete and linear, there is

\footnotetext{
${ }^{25}$ Because of the imperative within social work to perform some enactment of social justice (even if it is a performance without substance), one reading of this phenomenon could be that authors were simply giving lip service to the values of social justice (and, as you will see in the coming pages, it is a reading I have not entirely discarded). However, over time I became less and less convinced of this interpretation. It seemed like perhaps something less nefarious, less cynical was occurring in the data. I continually had/have to fight the urge to grasp at the certainty of the cynical reading, knowing my own subjectivity, being so firmly formed by and embedded in the macro side of the micro/macro ambivalence, predisposes me to such an analysis. An analysis that, I hold, is important, albeit constrained.
} 
considerable overlap in the assumed perspectives of each. The levels of organization and analysis are not always distinct and often draw on multiple discourses simultaneously. Though I have attempted to organize this chapter around each individual research question, they are also so deeply integrated, each operating beyond the confines of specific examples to produce knowledge, subjectivities, and social practice (Hook, 2001) that analysis should more accurately be viewed as a whole. I offer this as a caveat to the reader so they may read with an eye to the conceptual slippage between questions. As for comprehensibility, given the heavy theoretical nature of my project, I found it impossible (or perhaps incomprehensible) to discuss the findings outside of my sense-making process. While I recognize that, traditionally, results are discussed separately from the analytical discussion, in this chapter these elements are integrated so as to adhere to the epistemological integrity of my project.

Here, it may also be worth noting the slippery terrain of interpretation. I want to stress that this analysis is my own and it is but one reading of a very complicated landscape. Throughout my discussion of the results I draw on examples from the dataset. This is not to disparage or critique any individual author, but rather to highlight an overall trend in the larger discourse that we share. Putting the deepest preoccupations of our lives to paper is a vulnerable endeavor. As such, I felt a lot of hesitancy and unease in taking the words of other scholars down to the bare bones, making judgments, and naming specific authors in my analysis. What if I am wrong? What if they intended something totally different than what I think they accomplished? Why is my reading "better" or more right than any other? And here again, we revisit the problematic of interpretation: I am wrong; and I am not. I make no claims toward objectivity or to "truth." To do so 
would be an epistemic fallacy under the umbrella of CDA. My view is inherently partial and explicitly political. It is shaped by my own values and interests, by my relationship to the profession, and by my desire to more deeply understand how social work participates in processes of criminalization. I respect the efforts of the authors whose work has enabled my own. The eye of critique here is not on individual scholars; it is turned back on social work as a profession and a knowledge producing enterprise. Though it often felt like I was analyzing an Other-“those social work scholars"-my critique comes from within, from what Patti Lather (2003) calls a "critical intimacy." As such, I am deeply implicated in whatever accusations my critiques levy.

This chapter begins by identifying the constructions of criminalized women based on the vocabulary and framing choices within the dataset. Though I discuss a number of co-existing constructions present in the data, there is an overriding construction of criminalized women as risky. Embedded in this construction is a strong neoliberal discourse on knowing and changing the "responsibilized" self. I go on to provide a discussion of the implied knowledge claims that flow from these constructions, focusing deeply on the use of "objective" and often depoliticized explanations for crime and criminal justice involvement found in the data. I show how this depoliticization is accomplished through a variety of what I call neutralizing strategies. These neutralizing strategies ultimately serve to depoliticize social work itself. I highlight how by primarily constituting criminalized women as risky, social work necessarily responds to her with individualized service delivery aimed at regulating and changing the behavior of individuals. I argue that in its reliance on practices of risk management and a preference 
toward micro-level service delivery, social work deploys regulatory practices that further neoliberal governance (Parton, 1998; Webb, 2003).

Despite observing a very clear dominant discourse of risk and responsibility in the data, there was also a powerful counter-discourse, both embedded as a contradiction within the dominant discourse and encompassed outside of it, in distinct articles. The pieces in this counter-discursive thread firmly anchor their analysis in explanations of structural inequity, disrupt the underlying construction of crime, and question the logic of punishment. Accordingly, they move away from reliance on the criminal justice system as a means of dealing with social problems. Though just a small subset of my sample, I see these emergent counter-discourses as indicative of the larger discursive struggle within the profession and as critical to fostering spaces of hope and possibility. Dominant discourses have power because they naturalize their subject matter and make certain things seem self-evident (Foucault, 1972). Therefore, a look at the discourses that exist on the margins helps us disrupt what comes to be known as normal and natural. As Fadyl, Nicholls, and McPherson (2012) state:

...those practices on the boundaries, which occupy the areas of 'possible but outside the mainstream', allow an exploration of what could be. Exploring the boundaries between what is allowed and not allowed, between what makes sense and what seems absurd, highlights those things that are thinkable and doable but not self-evident, and thus helps to make current discourse and its material effects more visible. (p. 492).

In other words, by attending to the discursive, we can see how discourse is contested and contestable, productive in expanding possibilities for resistance. As such, I close this 
chapter with a discussion of an emergent counter-discourse. Please note that for purposes of clarity, all excerpts from the data that are longer than one line are displayed in single spaced block quotes.

\section{Constructing Criminalized Women}

Question \#1: How do social work high impact journals construct and represent criminalized women?

In this section, I outline the main constructions of criminalized women identified in the data. Though there are a number of representations found in the data, there is an overriding construction of risk. Through a variety of discursive mechanisms, criminalized women are framed most often as risky. A less pronounced, yet still significant construction is that of vulnerability (fragile/vulnerable/tragic). Though these two constructions (risk and vulnerability) may seem disparate, both ultimately mobilize the logic of risk management and can be seen as different sides of the same risk/needs coin. Through these constructions, criminalized women emerge as a subject of governance for social work. I outline how these constructions, rather than offering a unique social work construction, parallel the dominant and historical constructions of criminalized women.

The Construction of Risk. The construction of risk varies in its nature and articulation. It shows up both explicitly and implicitly in the dataset ${ }^{26}$. Explicitly, through the repeated use of the word as a descriptor for both women and interventions: "at risk," "risk assessment," "risk-reduction." And implicitly, through what has been dubbed risk thinking (Rose, 1998). According to Rose (2000), risk thinking is "concerned with

\footnotetext{
${ }^{26}$ Though there is a staggering amount of explicit discussion on risk and risk factors, appearing in 42 of the 49 articles, I also found myriad ways that authors invoke discourses of risk without actually naming it.
} 
bringing possible future undesired events into calculations in the present, making their avoidance the central object of decision-making processes, and administering individuals, institutions, expertise and resources in the service of that ambition" (pg. 332). He goes on to assert that risk thinking has become "central to the management of exclusion in postwelfare strategies of control" (pg. 332). Understood in this way, Green (2007) argues that the prediction and management of risk has become a central organizing principle of health and welfare programs in a neoliberal context. Based on my analysis of the literature in high impact social work journals, I would argue further that the prediction and management of risk has also become central to the process of knowledge production in social work.

Many scholars discuss the emergence of risk as a product of modernity (Giddens, 1990; Beck, 2002; Lupton, 1999). Lupton (1999) explains how with the onset of modernity, society moved from thinking about dangerousness to riskiness. Rather than attributing danger to fortune, fate, or the gods, as was common in pre-modern times, the concept of risk localizes danger in individual choices. As Beck (2002) states, risk “presumes decision making. As soon as we speak in terms of 'risk' we are talking about calculating the incalculable, colonizing the future" (p. 40).

Hannah-Moffat (2005) discusses risk thinking in relation to gendered strategies of control. She explains that risk thinking emerges through the conflation of women's needs and vulnerabilities with risks, and leads to the framing of women's involvement in the criminal justice system as a result of individual deficits or deviance that need to be managed or corrected. In other words, risk thinking is a "narrative that rejects social context and privileges attitudinal and psychological factors" (Pollack, 2010, p. 1273). 
Indeed, throughout the dataset, the individualization of structural concerns emerged as a key discursive practice. For example, in the introduction to an article advocating for the expansion of gender responsive programming in U.S. prisons, White (2012) states:

The number of women arrested and incarcerated is at an all-time high. As a result of two distinct arms of the War on Drugs (legislative changes and the social construction of the drug user as a criminal), women have become more vulnerable to arrest for drug crimes than they were in the past. Add to this a group of conspiracy laws used to prosecute women who are acquainted with a drug dealer, and the numbers escalate even more (Merolla, 2008). Poverty and a lack of education often lead women to make poor choices and engage in high-risk behavior [emphasis added] (pg. 284).

This is a typical discursive move made in the literature I examined. White clearly acknowledges the impact that social policy has on increasing the number of women in prison. However, the author immediately reframes it as an issue related to "poor choices" and "high-risk behavior." In this way, structural risks, such as poverty, are recast as personal risks. Despite naming "legislative changes and the social construction of the drug user as criminal" in the introduction, the author marginalizes these points throughout the remainder of the article in favor of a focus on individual choices and high risk behavior. Similarly, Salina et al. (2011) state:

....when they return home, most have not developed more positive coping skills, have not received training, and have not been offered referrals and/or other resources or the opportunity to make any positive changes. For example, poor housing status, limited social support, lack of drug treatment, and poor services utilization all are associated with post release relapse into drug or alcohol abuse (Healey, 1999). As a result, many return to the criminal justice system. Thus, programming must focus on developing the skills necessary to keep women from returning to high-risk behaviors after they leave the correctional system, but more importantly, [emphasis added] women need to learn to identify positive supports and resources that will help them avoid the drug-using or criminal networks that do not promote healthy living (pg. 368). 
In the above excerpt, the authors make multiple discursive moves in one paragraph. First, they name socio-economic issues that criminalized women face during reentry, such as lack of housing and lack of access to treatment, but rather than highlight a systemic lack of these resources, the authors reduce structural barriers to a lack of individual coping skills, lack of individual change, and poor service utilization on the part of individual women. The supposition being that services and resources are not only abundant but also accessible, and that women are not being proactive enough in their recovery to find and utilize them. Furthermore, the authors deploy notions of "positive supports" and "healthy living" which rely on normative understandings of what constitutes healthy behavior and positive relationships, thereby reinforcing notions of what constitutes risky behavior. Such strategies of normalization were consistently deployed throughout the dataset. O’Malley (1996) describes normalization as the method by which norms of behavior are identified. He argues that normalization is the primary technique of disciplinary power and that "normalization, in the disciplinary sense implies 'correction' of the individual, and the development of a causal knowledge of deviance and normalization" (pg. 189). Therefore, through processes of normalization, social work enables its function as a form of governance.

The previous excerpt from Salina et al. (2011) also exemplifies how risk-thinking manifests through the use of narrow and positivistic outcome measures that are primarily focused on recidivism as an indicator of success. The authors in the above statement associate recidivism solely with individual behaviors and assert that programming must focus on skill development. They go on to suggest that the more important thing is that women must learn to identify positive supports and resources to help them change and 
avoid a life of crime. The use of the phrase "more importantly" emphasizes individual responsibility in identifying resources and supports, and renders invisible the very real possibility that resources and support may not be readily available or equally accessible to all women. This type of individualizing related to the causes of recidivism was abundant in the dataset, with 24 of the 49 articles focusing on recidivism as the primary outcome for success. Overemphasis on recidivism as a marker for success fails to reflect the sociopolitical realities that women face and relies primarily on individualized understandings of how and why women get entangled and re-entangled with the criminal justice system. Further, an emphasis on recidivism neglects other outcomes that women may define as success for themselves, such as obtaining housing, regaining custody of their children, or gaining employment (Pollack, 2007).

Here, we see evidence of what Hannah-Moffat (2005) calls the "transformative risk subject." The transformative risk subject emerges when need is fused to risk. Unlike the static risk subject, the transformative risk subject has "intervenable needs" (i.e. substance abuse, attitudes, and behaviors), which are "amenable to targeted therapeutic interventions" that when addressed will lower the risk of recidivism (Hannah-Moffat 2005, pg. 31). The creation of intervenable needs is emblematic of a wider shift in governing; intervenable needs facilitate governing at a distance as women become regulated through their needs rather than direct repression (Hannah-Moffat, 2001). In the examples from the dataset listed above, the transformative risk subject is constructed by first translating women's gender specific socio-economic oppression into gender specific psychological deficits. In so doing, her criminal behavior is linked to her inability to reason and choose. An inability to make good choices is then interpreted as an essential 
part of her riskiness (Pollack, 2007). To take the argument further, I would highlight how the creation of intervenable needs may be inherently related to the neoliberal economy of knowledge production: intervenable need $=$ intervention $=\$ \$ \$($ i.e. funding $)=$ research $=$ publications $=$ tenure and recognition and all those prized accomplishments that go along with being an academic. Taken to this point, we can see how whole academic careers are built on the (re)construction of risk.

The use of value-laden and judgmental language to invoke images of risk and responsibility was littered throughout the data set. This raises a number of key concerns regarding the discriminate application of even basic social work values in the process of knowledge production. Social justice is a particularly thorny problem in the analysis and will be discussed more in depth later in this chapter. Of particular concern at this point are the social work values related to: dignity and worth of the individual; the importance of human relationships; and integrity. It seems as though authors apply these social work values discriminately (i.e. to children and not mothers, and unevenly among participants in their studies). This points to the active construction of worthiness in the social work discourse, in regards to not only who deserves services but also who deserves decency. Indeed, deservingness was constructed time and time again in the dataset through specific lexical choices.

Discourse analysts note that lexical choice is significant because it allows authors to lay out a lexical field which signals certain values, judgments, and identities (Mayr \& Machin, 2012). For example, the use of terms such as "female offender," "high risk group," "criminal behavior," or "deviant lifestyle" is common in some articles. Such terms are borrowed from the Corrections lexicon and load the text with particular kinds 
of meanings, which allow the authors to foreground an emphasis on individual behaviors and choices. Pollack (2006) states that "accepting normalized criminal justice concepts and categories and the widespread use of terms such as 'women's criminality' and 'female offenders' helps to consolidate the deficit based individualism characteristic of penal-welfare approaches" (p. 247). She goes on to argue that terms such as "offender" reify “women's identity as permanently criminal or offending....and can be used to rationalize unjust correctional practices" (p. 247).

By contrast, other articles set up an entirely different lexical field through the use of terms such as "criminalized women," "justice involved women," "vulnerable population," and "mothers who have an arrest history." This is not to imply that these terms are not also imperfect, but rather to illustrate the different orientations and judgments that can be made visible through the use of language. "Criminalized women" for example, alludes to the social construction of crime and allows for an analysis beyond the individual toward larger social and political processes that criminalize (Pollack, 2006). "Vulnerable population," on the other hand, reifies the individualist orientation of the "offender," yet it is void of the same sense of blame. Amongst data that is plagued with value-laden and judgmental language, the lexical field of vulnerability allows for a softening in the dataset. However, the discourse is once again focused on individual characteristics and individualized understandings of crime, which are then linked to practices aimed at reducing risk and bolstering resilience. It is to this framing of vulnerability that I now turn my attention.

Object of Pity. In general, the articles (or pieces of articles) in this group highlight women's vulnerabilities and/or draw on discourses of empathy or pity. The object of pity 
is constructed through a lexical field that describes criminalized women as "vulnerable," “weak," "invisible," and "voiceless." As women who struggle "fiercely with negative self perceptions" and "low self-esteem," who are "imprisoned by their own guilt and remorse." At the same time, they are "poorly served by systems that should be helping." Women's criminal justice involvement is seen as a product of "troubled life histories." They are observed as suffering from "unresolved trauma" which leads to substance abuse as a "means of self medication." The object of pity is, therefore, unable to escape from the "cycle of criminality." Above all, she is "powerless." The following excerpt from Allen, Flaherty and Ely (2010) illustrates the expression of powerlessness found in the data:

...these poor and incarcerated mothers also expressed feelings of profound powerlessness: powerless at being separated from their children, powerless to protect their children from sharing their same fate, powerless against the child welfare system, powerless against their addictions, and powerless against the society from which they have become so disenfranchised [emphasis added] (p. 165).

The authors' exaggerated use of the word powerless enhances a representation of criminalized women as tragic and vulnerable. It evokes feelings of empathy and pity. From the title of the article "Throwaway Moms: Maternal Incarceration and the Criminalization of Female Poverty," one could assume the authors are trying to humanize their participants and disrupt dominant narratives told about women in the criminal justice system. However, the article minimizes discussions of poverty and oppression by using emotive language and "feelings talk" as their main argumentation strategy. In so doing, they inadvertently demean their participants, strip them of agency, and distract the discussion away from larger structural issues. In many ways, it may be necessary to step 
back from this critique in order to see the political utility of conjuring up sympathy to build support for a highly stigmatized and marginalized population. However, the problematic of sentimentality remains: the authors changed the focus of the article from one concentrated on inequity and injustice to one that is driven exclusively by emotionality and misdirected sentiment, thereby depoliticizing the issue.

As is the case in the above excerpt from Allen, Flaherty, and Ely, the object of pity is similarly portrayed throughout the dataset as having very little agency. Agency is stripped in a variety of ways, but typically by making the case that a woman's "criminal behavior" is the result of an addiction, trauma, or mental health issue. The implication being that she does not actively choose her behavior. Substance use, for example, is often discussed as something used to self-medicate the untreated symptoms of trauma and abuse. Therefore, it is understood as something requiring treatment, rather than a bad or deviant choice the woman has made. In this way, women are constructed as passive rather than active participants in their criminalized behaviors. Paradoxically, treatment and intervention for the object of pity then centers on helping a woman heal so she can make better choices. So while she is framed as powerless, she can be saved. She is the “fallen woman” (Rafter, 1983; Zedner, 1991).

Note that criminalization or social structure is still not of concern here. The focus remains steady on behaviors. Though there is some recognition of constrained choice, it is recognized as being constrained by trauma or life circumstance that the individual, with treatment, can widen. For example, in their article on improving pregnancy outcomes during incarceration, Siefert and Pimlott (2001) state: 
Issues that trigger substance abuse and criminal conduct, including physical and sexual abuse and their sequelae, such as low self-esteem, depression, anxiety, and self-destructive behavior, must be addressed (p. 129).

As was the case with much of the data, these and similar claims allow authors to construct women as vulnerable. In so doing, they distract attention away from the "criminal conduct" and onto an underlying psychological issue the authors believe to be at play. However, her vulnerabilities (i.e. trauma and mental health issues) are simultaneously turned into risks for "substance abuse" and "criminal conduct." Women's trauma and lack of self-esteem then become the focal point of intervention: the intervenable need. The construction of vulnerability in the data is also highly genderedlack of self-esteem and lack of skills (e.g. parenting, decision making, etc.) are typically linked to experiences of trauma and gendered socio-economic issues (Hannah-Moffat, 2010). This is demonstrated in the following excerpt from an article by Mignon and Ransford (2012), advocating for the maintenance of parent-child relationships while incarcerated:

The difficult early life of many incarcerated mothers, coupled with their current circumstances, can often have a negative impact on a woman's self-esteem (Houck \& Loper, 2002; van Wormer \& Kaplan, 2006) [emphasis added] (p. 70).

From this excerpt, "difficult early life" is understood to be code for abuse and neglect; and "current circumstances" stands in for poverty, incarceration, and child welfare involvement. Pollack (2007) argues that

When incorporated into corrections logics and discourses, the victimization narrative becomes psychologized; that is, there tends to be a focus on the psychological and emotional impact of such experiences and how impaired 
thinking, decision-making, and lack of emotional control lead women to commit crimes. The psyche of the criminalized woman is the site at which reformation occurs (p. 160).

Indeed, explicit recognition of victimization and trauma was used to construct vulnerability in many of the articles in the dataset. However, it was highlighted in different ways. In the articles that take a more transparent risk focus, trauma is generally named as a characteristic when describing the population and then sidelined or not discussed at all. Vulnerability, in these cases, is established by comparing criminalized women to their counterparts including, for example, incarcerated men, non-incarcerated women, and incarcerated women without children. For instance, Horton (2011) describes incarcerated women as "a particularly vulnerable population" (p. 184) and strengthens the case for vulnerability by reporting on the differential rates of childhood abuse among incarcerated women, men, and the general population:

A greater percentage of incarcerated women report being physically or sexually victimized before the age of 18 (37\%) compared to their incarcerated male peers (14\%), as well as the general population ( $8 \%$ for men, $17 \%$ for women; Harlow, 1999) In addition, on every measure of drug use, female inmates report higher use than their male peers (Greenfeld \& Snell, 2000) (p. 184).

Here the meaning of "particularly vulnerable" is established through difference; thus, it is through opposition to their "incarcerated male peers" and "the general population" that the author is able to make incarcerated women's vulnerability visible.

The articles that vigorously emphasize vulnerability over deviance tend to locate victimization in the interpersonal violence of spousal or family abuse/neglect. Here, trauma is understood as an underlying cause of "criminal" behaviors. These articles make 
a direct link between women's trauma and her engagement in "crime." For example, Kubiak (2004) asserts that:

Attention to trauma-related disorders among incarcerated women may be pivotal in preventing relapse and as a consequence, recidivism (p. 430).

By contrast, in the articles that I identified as part of a counter-discourse (more on this later) the authors discuss victimization but they characterize it as a gendered social issue rather than a personal one; in this way, they focus less on a woman's victimization and more on her marginalization. Further, while the general assumption in most of the articles appears to be that trauma and mental health issues can be effectively treated in prisons ${ }^{27}$, the articles that comprised the counter-discourse ardently disavowed such a stance while also calling attention to the state sanctioned violence women experience through interactions with penal-welfare systems.

As I have demonstrated, while most articles in the dataset deploy notions of risk by emphasizing choice and responsibility, others emphasize vulnerability. Some do both. An example may help illuminate this phenomenon. In their article on developing a parenting program for jailed mothers, Miller et al. (2014) foreground the challenges incarcerated mothers face that make it difficult for them to maintain their parenting roles both in jail and upon release. The authors identify histories of trauma, abuse, and a subsequent loss of confidence as things that interfere with a woman's ability to parent. The authors also emphasize the distress mothers feel upon being separated from their children. In this way, they highlight criminalized women's vulnerabilities. She is not constructed as "deviant," but rather a woman who cares and is up against uniquely

\footnotetext{
${ }^{27}$ Indeed, with few exceptions, the violence of prison was left unexamined in the dataset.
} 
gendered challenges. Later in the same article, while advocating for the effectiveness of jail-based parenting interventions, the authors assert that:

A jail stay may function as a "wake up call" for some mothers, offering a chance to prevent them from falling deeper into the system (p. 164).

Though the authors first position the mothers within powerlessness, the symbolism of a "wake up call" indicates the need and ability for women to take responsibility for themselves and their actions; through this symbolism, crime is firmly re-established as a fact rather than a social construction (Pollack, 2006). Miller et al. (2014) end their article by pulling both of these constructions (risky and vulnerable) together:

Although challenging, implementing parenting programs in jail settings represents an opportunity for high-risk mothers to focus on and develop their parenting skills. Although the setting may prevent practicing new skills with children, offering parenting sessions in jail may be an effective way to reach this vulnerable population of women [emphasis added] (p.169).

Whether deployed exclusively or simultaneously, the language of both risk and vulnerability accomplish similar things. They individualize the reasons for committing crime and divert attention away from a woman's social context, locating both the problem and solution within the individual (Hannah-Moffat 2010; Maidment 2006). Indeed, throughout the dataset, the redefinition of the structural into the individual has the effect of constructing women as both the cause of and solution to not only crime, but also the increasing rates of women's incarceration. The supposition being that to decrease incarceration rates, you have to deal with problematic individual behaviors, not problematic policies or the conditions of inequality that facilitate "crime." This will be discussed more in depth in relation to research question $\# 2$. 
The Unfit Mother. The representation of the unfit mother is another way the construction of risk plays out in the dataset. Many women in the criminal justice system, about two-thirds, are mothers (Kajstura, 2018). Not surprisingly then, my sample included a number of articles with an emphasis on children and motherhood. Specifically, such articles focused on either incarcerated/criminalized mothers/pregnant women or children with incarcerated/criminalized mothers. This category is significant for analysis because over half $(n=25)$ of the sample is comprised of articles with a focus on children and mothers. Indeed, if I had not used the word "mother" in my keyword search, my sample would have been reduced by about half.

In a significant proportion of these articles, the welfare for children is framed as the primary concern and is bolstered through the construction of the unfit mother, and through a strong focus on negative outcomes for children and an infant determinism for such negative outcomes-children are framed as being "at risk" and bound for problematic life trajectories. These outcomes are further attributed to the mother, not the larger social context. The mother herself is then framed as risky because she is responsible for the creation of damaged children, or worse, future criminals. This plays out in a number of ways.

Attachment. 11 of the 25 of articles in this part of the sample (i.e., those focused on children and mothers) deploy narrowly defined conceptualizations of attachment that emphasize the mother-child relationship, and exclude an analysis of contextual issues, such as poverty, that may lead to poor outcomes for children. For instance, in an attachment-based study on the relational health of infants who live in a prison-based 
residential parenting program with their incarcerated mothers, Condon (2017) introduces their ${ }^{28}$ article by stating:

Many infants in the United States have incarcerated parents (Pattillo, Weiman, \& Western, 2004; Rebecca Project, 2010; Villanueva, 2009) and are at risk for poor social outcomes, partially as a result of disrupted attachment relationships (Cassidy, Poehlmann, \& Shaver, 2010; Kjellstrand \& Eddy, 2011; Lange, 2008; Myerson, Otteson, \& Ryba, 2010) [emphasis added] (p. 5).

Here, the author links poor outcomes for children (at least partially) to the only named variable of "disrupted attachment relationships." Through the remainder of the article Condon hints at how social context could lead to "disrupted attachments," but remains squarely focused on the mother child-attachment as the site of intervention and asserts a very clear idea of what a "normal" and "healthy" relationship between mother and infant should be. Failure of the dyads in this study to achieve normative standards for bonding and attachment is then attributed to the mother's individual characteristics, not the prison environment or other possible factors. For instance, while listing the constructs under study, Condon looked for:

(d) moments in which mothers showed awareness of their own and their child's inner worlds (reflective capacity); and (e) high-stress moments during which it was very difficult for mothers to be anything but self-centered, reactive, selfprotective, or dismissive of their children's experiences (pg. 12).

To begin, "high stress" is not defined, but given the context of the prison environment one can assume it may involve experiences that trigger a mother's trauma ${ }^{29}$. Next, the use of such value-laden language regarding a mother's response to these "high stress moments" implies judgment and implicitly asserts a norm for mothering that involves not

\footnotetext{
${ }^{28}$ Gender-neutral pronouns are used when an author's pronoun is unknown.

${ }^{29}$ It is interesting to note how in this article and others like it, the discourse of attachment becomes entangled with the discourse of trauma. I wonder in some ways if trauma is the new shiny thing that has come in to replace attachment. But that's another paper.
} 
only awareness and engagement (as in point d) but also selflessness. These types of lexical choices implicitly assert universal norms for parenting and were prevalent throughout the data set. In juxtaposition, it could have been just as easy to look for "high stress moments during which it was difficult for mothers to be present."

Later in this same article, Condon (2017) doubles down on the implications of the mother-child relationship for a child's future:

Over time, their experiences during interactions with their parents become a blueprint or inner working model for their developing sense of self, and set the stage for later relationship patterns [emphasis added] (pg. 19).

The imagery of a blueprint harkens back to Beck's notion of "colonizing the future." Similar to Condon's article, it was common among the other articles that drew on notions of attachment to include little to no discussion of how culture, socio-economic status, or the prison environment itself may impact a child or the context of parenting. Ghenie and Wellenstein (2009) refer to this as a "context stripping view of attachment" and assert,

Larger issues of poverty, racism, social exclusion, and violence become reduced to blaming birth parents who fail the test of proper parent-child bonding. Through diagnosis and treatment of their children in care, the problem is further reduced to one located in the "detached" child, who has one therapeutic shot at connection before being written off as a future sociopath (pg. 161).

Ghenie and Wellenstein contend that such an application of attachment theory moves the focus away from the larger social context that plays a role in child development, and lends itself to a form of infant determinism - the assumption that problems in childhood 
will inescapably lead to poor outcomes across the lifespan ${ }^{30}$. Indeed, throughout the data, there is a strong focus on problems predetermined for children of criminalized mothers and an emphasis on women's deficits as mothers, which constructs them as a deviant risk group because she is seen as being at risk of (or responsible for) causing her children future harm or creating "risky" children and future criminals. Similar to Cruikshank's (1999) argument regarding self-esteem discourses, I argue that by linking the motherchild bond to larger societal goals of eliminating crime and reducing incarceration, attachment becomes both a normalization strategy and a "political obligation." Through the discourse of attachment, the mother-child bond becomes a relationship that is governable. "Here the social sciences can be seen as productive sciences; the knowledges, measurements, and data they produce are constitutive of relations of governance as well as the subjectivity of citizens" (Cruikshank, 1996, p. 237).

Intergenerational Risk. The construction of the unfit mother was also evident in the way many of the articles on maternal incarceration drew on assumptions of "intergenerational crime" ( $\mathrm{n}=14)$. Typical statements in this regard include the following by Miller et al. (2014):

\footnotetext{
${ }^{30}$ Traditional developmental models, such as attachment theory, take inherent biological and psychological processes as a starting point for analysis of people and provide a rationale for notions of "normative" to which all others are deviant or "at risk." They work off of a foundational assumption of human development based on the idea that all people go through a series of universal and natural developmental stages, and if the developmental tasks of one of those stages are compromised, the window of opportunity closes and it is difficult, if not impossible, to recover. However, at this point in time a large body of interdisciplinary literature integrating the discovery of neuroplasticity has complicated, if not refuted, the foundation of developmental models. It is interesting to me that social work still persists in centering traditional and outdated developmental theories in both research and education. I would argue that by now, rather than being scientific, the discourse around attachment is largely symbolic. In so being, it can be deployed in a resistive manner.
} 
Parents, particularly mothers, in the correctional system have also often experienced poor parenting role models and experience multiple associated challenges that make it difficult to break the intergenerational cycle of incarceration [emphasis added] (p. 163).

Similarly, Hanlon et al. (2005) state:

Noting that children of mothers in prison are vulnerable to the adoption of a deviant lifestyle because of the risk factors to which their families' difficult life circumstances have exposed them, Greene, Haney, and Hurtago (2002) point out that many of these children experience the very same criminogenic conditions that contributed to their mothers' incarceration - ultimately giving rise to an intergenerational cycle of criminality [emphasis added] (p. 68).

Not only do statements such as these impose an inevitable "cycle" of generational incarceration (or criminality), but the language around "poor parenting role models" and "adoption of a deviant lifestyle" strips away all social context and locates the problem of incarceration solely in the behavior of individuals. In this way, incarceration is implicitly linked to problematic behaviors rather than problematic sentencing policies and/or unequal application of the law. The logic of this link relies on an assumption that when people are incarcerated, 1) they are guilty, and 2) they have violated some universal (i.e. normal) standard for behavior, and 3) they deserve to be incarcerated. The underlying notion of "criminal behavior" and the logic of punishment goes unquestioned; and deservingness remains firmly embedded in the discourse around criminalization.

These types of arguments rely on cultural ideologies about crime that take crime to be a stagnant, fixed category. However, as has been discussed previously in this dissertation, plenty of research shows that crime is a social and historical construct, which arises through discourse and is applied differentially across lines of gender, race, and class (Boyd, 2006; Comack \& Balfour, 2004; Faith, 1993; Laberge, 1991; Pollack, 2007). Cultural myths about crime and criminality are deeply embedded in the dataset, 
conflicting with and constraining the profession's most aspirational values toward social justice. A risk framework that pre-determines future criminal justice involvement leads to responses that always include more surveillance and intrusion into the lives of those under its gaze.

Relatedly, in an attempt to establish relevance for a study on the relationship between maternal incarceration and school dropout rates for children, Cho (2010) introduces their paper by discussing the limitations of previous research on children of incarcerated mothers and states:

...such studies are not able to examine the cumulative process of intergenerational disadvantage [emphasis added] triggered by a mother's incarceration, and this process may eventually lead to the social exclusion of their children as adults (Foster and Hagan 2007) (p. 258).

The notion of "intergenerational disadvantage" is reminiscent of the "culture of poverty" theory, which suggests that poor people have certain innate characteristics (psychological and behavioral) and values that perpetuate poverty. The culture of poverty rhetoric is often invoked in media and political debates on the welfare state, but has been largely cast aside in the social sciences. ${ }^{31}$ This type of rationality sidelines the major economic and political systems that place various groups at risk for poverty and disadvantage, in favor of individual level explanations. Similarly, by proposing that "intergenerational disadvantage" is "triggered by a mother's incarceration," the author is ignoring a large body of research which shows that many families are disadvantaged prior to the mother's incarceration, and that such disadvantage is likely to shape one's entry into the criminal justice system. Certainly, incarceration exacerbates disadvantage, but it is notable that

\footnotetext{
${ }^{31}$ Its explanatory power, in the social scientific sense, is both problematic and weak because it centers culture, rather than poverty, as the explanatory variable.
} 
Cho frames incarceration as the cause of disadvantage and social exclusion and not the other way around. Despite nodding to structural factors throughout the paper, this initial framing exposes the underlying neoliberal logic embedded in Cho's research.

Cho (2010) further establishes relevance for this study by discussing concerns related to the "intergenerational transmission of crime" (p. 267). Transmission, like a message from space or the plague. Cho cites research that:

finds that maternal incarceration is associated with high rates of incarceration among those mothers' children when they reach adulthood (p.267).

Cho's study then examines school dropout rates among children in relation to length of a mother's "incarceration spell" ("dosage") and the "developmental stage" of the child during the mother's incarceration ("timing"). Cho asserts that dosage matters because as dosage increases so do disruption and stigma. The author then attributes greater disruption and stigma to prison stays by stating:

About half of the inmates sentenced to jail are convicted of a crime and usually receive a sentence of a year or less. They are admitted for light felonies, misdemeanors, and probation violations....prison inmates generally have longer sentences than jail inmates do and are convicted for more serious crimes" ( $p$. 262).

Despite this being wildly inaccurate-mandatory sentencing policies send people to prison for many of the same reasons people end up in jail, including violations of probation $^{32}$ - by positioning severity of behavior as the factor for imprisonment this statement inadvertently positions the mother as the sole explanatory variable for child outcomes, despite all other obvious issues such as poverty, racism, or other contextual

\footnotetext{
${ }^{32}$ In fact it has been widely recognized that probation often serves as a back door to incarceration. Probation increases surveillance and monitoring on a person's life. Therefore many probationers are sent to prison for technical violations in regards to the terms of their probation, rather than re-offense.
} 
disadvantages empirically associated with incarceration. In the context of Cho's study, school dropout rates could likely have something to do with the type of school a child attends. Further, the link between school dropout rates and a child's own incarceration could have something to do with zero tolerance policies and the school-to-prison pipeline. When viewed through this wider lens, the association between a mother's incarceration and her child's incarceration has less to do with the severity of a mother's crime and more to do with systems of inequity that perpetuate social exclusion.

Manufactured Risk. Like many of the studies in my sample, Cho's found, at best, mixed results and was ultimately unable to confirm their hypothesis (i.e. maternal incarceration $=$ destined detrimental outcomes for children $)^{33}$. Still, by foregrounding the paper with arguments related to the mother at the expense of a discussion on structural issues, the article paints a misleading picture regarding correlation. It is as though the researchers forget the most basic rule of statistics: correlation does not equal causation. By conflating correlation with causation, authors are able draw on the symbolism of “intergenerational crime," which conjures up fears and insecurities regarding a child's "risk." This then becomes a catalyst for perpetuating messages regarding the need for increased surveillance.

I emphasize this, not to negate the correlation, but to suggest that perhaps the focus is misplaced. Invoking a discourse of intergenerational crime narrows the profession's focus to that of assessment and monitoring of a child's risk. A focus on risk

\footnotetext{
${ }^{33}$ It is perhaps also notable that when this same study found better outcomes for children if their mothers had longer stays in jail or prison, the researcher concluded that children (especially girls) might benefit from being separated from their mothers via incarceration-a prime example of the active construction of the unfit mother.
} 
loses sight of a child's agency and potential. Scholars studying the "cultural politics of childhood" call attention to the ways in which political and economic factors shape the lives of children and youth (Nybell, Shook, \& Finn, 2009; Qvortrup, 2005). They connect their understandings of children and youth to shifting social, political, and economic conditions rather than just biology and family of origin factors. Social work can take lessons from such scholarship in order to shift the discourse on how we support children from one defined primarily by the assessment and management of risk to one that acknowledges agency and focuses on providing economic support to families in order to support a less constrained form of agency.

Similar to Cho's, many of the other studies on children in my dataset were framed around the expectation of dysfunction. However, results did not always compellingly support such expectations. At times, authors rationalized their unexpected results in ways that reinforced their original expectations. For example, Hanlon et al. (2005) conducted a study on 9-14-year-old children of incarcerated mothers in order to inform prevention programming. The study was premised on the assumption that these children would be "at-risk" for a variety of negative outcomes and, therefore, in need of targeted prevention:

We anticipated that most, if not all, of the children of mothers who have been incarcerated, particularly substance-abusing mothers, would be highly vulnerable to the development of a deviant lifestyle (p.80).

In the end, their results did not support these claims and the authors acknowledge that the children in their study "were neither especially deviant nor maladjusted" (p. 79). They go on to subtly qualify the disconfirmation of their expectations by stating:

The majority of the children had been able to avoid the adoption of a deviant lifestyle at this point in their lives [emphasis added] (p. 79). 
The use of the phrase at "this this point" indicates an inherent predication that at some point these children will indeed adopt a deviant lifestyle. Indeed, the authors then return to the larger body of literature to support this predication:

In view of the positive relationship between age and delinquency noted in the literature (Elliott, 1994; Moffett, Caspi, Dickson, Silva, \& Stanton, 1997), the vulnerability of all of the children is likely to increase during their teenage years (p.79).

The authors then go on to disqualify their findings ${ }^{34}$ by emphasizing the smaller portion of their sample that displayed "disquieting characteristics" (p.79) related to peer associations and school performance, and state:

Along with family support services, these two problem areas, both of which have an impact on the subsequent development of a deviant lifestyle, need to be promptly and aggressively [emphasis added] addressed in interventions targeting these and similarly disposed children (p.79-80).

This example illustrates a trend in the larger dataset wherein authors persist in emphasizing deficits and calling for interventions related to risk despite not finding particularly problematic patterns of behavior ${ }^{35}$. I argue that an investment in the logic of risk is evidenced by such practices. Despite refuting their own expectations for riskiness, Hanlon et al., like other authors in my sample, cling to their predictive powers and try to re-invent risk. They legitimize their work by drumming up problems (i.e. risks) where none are indicated. In this sense not only are they displaying an investment in the

\footnotetext{
${ }^{34}$ Another way these authors, and others in the dataset, rationalized similar unexpected findings was through a post facto analysis regarding the limitations of their study or sample.

${ }^{35}$ This trend was also found in the articles on intervention research. When interventions were found to be ineffective or inconclusive, authors rationalized the results by focusing on negative qualities of the participants (e.g. lack of motivation, lack of insight, etc.) rather than the qualities of the intervention. A prime example of this can be found in Buttell (2002) wherein the author attributes the ineffectiveness of the intervention under study (treatment for "female domestic violence offenders") to a low level of "morality" among participants.
} 
discourse of risk, but they are also creating risk. They are manufacturing risk. This speaks to the productive nature of social work research. Scholars produce a risky or "atrisk" subject, generate knowledge or truths regarding that subject, and then establish expert interventions to regulate that subject (Cruikshank, 1996). In other words, we create subjects that need us and our interventions.

Symbolic Use of Childhood. While some writers rely on symbolism around intergenerational crime and attachment to propel a discourse on risk, others invoke symbolism around childhood, and childhood lost, to tug at the heartstrings of readers. Common sentiments include those extorted by Harris (2017):

Children are innocent and have not committed a crime (p. 39);

Miller et al. (2013):

Implementing such practices and policies takes time, and the resources for implementation are not always readily available; nevertheless, the cost to children is too significant to delay action (p. 412); and

Schlager and Moore (2014):

Ultimately, the brunt of the impact of incarcerating mothers is acutely felt by children with both significant short and long-term consequences (p. 100).

In these statements (and others like them), symbolism around innocence and "an endangered child" are used to conjure up images of subjects who are worthy of our attention, our efforts, and our care. Such argumentation strategies are powerful because they invoke symbolic consequences for children. As Sherr (1999) states, "Children are the quintessential example of individuals placed in circumstances beyond their control. The consummate victims, children are unable to overcome difficult circumstances without the assistance of caring adults" (p. 52). 
Arguments that invoke the symbolism of childhood draw on larger cultural debates about deservingness (Cousins, 2013) and legitimize calls for advocacy and intervention on behalf of children. In this way, such argumentation can be seen as strategic and productive in the sense that it broadens the perspective regarding who is harmed by the carceral state and opens up spaces for resistance. However, I would argue that it also conceals larger questions regarding the underlying moral justifications that uphold the carceral state which ultimately deem it acceptable to lock those Other people (i.e. not innocent) in cages. The harms of incarceration are reduced to the level of platitude. Furthermore, I would argue that positioning children as symbolic victims justifies the continued regulation of their mothers. In over-emphasizing the welfare and worth of children, mothers are inadvertently positioned as undeserving (i.e. not innocent but guilty) and there is concurrently a persistent disregard for her traumas and needs, as well as her ability to be a loving parent. Social workers are, in turn, positioned as the caring adults, the guardians of the vulnerable.

The Idealized Mother. In a smaller portion of the articles related to children and motherhood, the welfare, experiences, and opinions of mothers are discussed, and women are framed as being good or capable mothers. Typically, however, this is accomplished by using the binary of the good/bad mother which positions criminalized mothers in opposition or comparison to an idealized mother. For example, in their results section, under a theme labeled "Parenting: The Shame of Maternal Failure," Allen, Flaherty, and Ely (2010) summarize their results by stating:

Perhaps, the most outstanding quality of these interviews was how deeply reflective - often philosophical - these women were about all the subjects they covered but particularly with regard to the topic of motherhood. Many of the 
women also struggled fiercely with their negative self-perceptions as parents. In many ways, the women expressed the same themes one would expect from any mother, including the aforementioned idealized mother. These themes included love for their children, pride in their children's accomplishments, and worry about their children's circumstances and future challenges. However, unlike idealized mothers, these poor and incarcerated mothers also expressed feelings of profound powerlessness: powerless at being separated from their children, powerless to protect their children from sharing their same fate, powerless against the child welfare system, powerless against their addictions, and powerless against the society from which they have become so disenfranchised [emphasis added] (p. 165).

Notice how the authors frame the first sentence in a way that presupposes the expectation that criminalized mothers would not be reflective and philosophical in regards to motherhood. The use of the phrase "most outstanding" rather than an evidentiality ${ }^{36}$ such as "of course" propels certain assumptions about the women and has the effect of denaturalizing their participants as good mothers. A question to ask ourselves is: if these participants were middle class women (or non-criminalized women), would this even be considered a finding? Further, the authors work from an assumption that "idealized" mothers do not feel powerless. This again speaks to the normative constructions/expectations around motherhood. Though the authors appear to set the women up in this dichotomy so as to challenge the construction of criminalized mothers as unfit, it ultimately ends up reinforcing the bad/good mother dichotomy and the construct of an idealized mother as legitimate and achievable. Similar normative gendered expectations around mothering were deployed throughout the dataset. Rarely

\footnotetext{
${ }^{36}$ Evidentialities are phrases that suggest factuality (e.g. "of course"). Such discursive moves have the effect of naturalizing certain statements as common sense. It is notable that the authors use of "most outstanding" in effect worked off of a "commonsense" notion that women in the criminal justice system could not possibly be thoughtful, engaged mothers. In trying to dispel such narratives they make space for their sample to be considered "exceptional." And though I would love it if the adage were that the exception complicates the rule, it is generally understood that the exception proves the rule.
} 
was the criminalized mother discussed as being a complicated mother, who is neither idealized nor demonized (see Vandermause, Seversten, and Roll (2013) for an important exception $\left.^{37}\right)$. Throughout the data there was a heavy emphasis on how one's ability to meet (or not) these expectations is shaped by substance use and mental health issues and the subsequent lack of mental health and addictions treatment. In honing in on the lack of services and treatment, I believe the authors think they are looking at social justice and structural issues; however, without including a discussion related to how a woman's ability to meet expectations for parenting is shaped by things such as poverty and racism, it ultimately reifies the focus on individual deficit and fault and holds steady the underlying logic of punishment and control.

Similar to the use of normative constructions of motherhood, guilt was deployed as a gendered strategy of responsibilization. The articles on incarcerated mothers pull on guilt in different ways. For instance Allen, Flaherty, and Ely (2010) emphasize the guilt and shame mothers $d o$ feel in statements such as the following:

Perhaps, the most powerful and heartbreaking themes were those of the maternal love that these women consistently expressed for their children and the profound sense of guilt and staggering remorse they were all struggling with when they discussed the impact of their actions on their children. It became abundantly clear that their substance abuse problems and criminal justice involvement were symptomatic of extremely troubled life histories (p. 170).

\footnotetext{
${ }^{37}$ It is perhaps noteworthy that these authors are nursing scholars rather than social work scholars. I debated whether this constituted a discourse outside of social work, but in the end because it was published in an explicitly named social work journal (QSW), with an editorial board consisting of mostly social work scholars, I decided that it contained something important related to how social work discourse is/can be shaped by interdisciplinary scholarship.
} 
Here, the focus on guilt emphasizes the action of taking responsibility and renders the women worthy of our empathy and understanding. In contrast, Gilham (2012) also deploys guilt but emphasizes the lack of remorse mothers feel.

It seemed clear that these mothers were attempting to protect their children, but by denying their incarceration, they were able to save themselves from further embarrassment and shame. When asked whether their children had experienced negative consequences related to their incarceration, all of the women expressed that their children had indeed experienced at least some negative consequences. Many of the women seemed to minimize the impact of their behavior on their children, and several stated that they had not done drugs or committed any illegal activity in the company of their children. Three women in particular spoke at some length about their positive parenting skills and concern for their children despite their other actions. One mother was quoted as saying, "My kids are my life. I'm not a bad mom.' Incidentally, this participant was separated from her two children and two step-children, and her two sons had entered mental health counseling since she was jailed. Another mom, a newly admitted heroin and crack addict, spoke at length about the positive relationship she shared with her 6-yearold daughter even though she had not seen her in more than a year. It is noteworthy that these three women were more recent admissions to the facility and had not had the benefit of the treatment the other women had received, which may account for their responses (p.94).

Now, the focus on guilt emphasizes the absence of taking responsibility and renders the mothers unfit and no good for their children. However, in the last sentence readers are reassured that therapy can fix them right up. Indeed, Gilham goes on to say:

From the women who had been in the facility for longer periods, we found that releasing them from their denial enabled them to have a somewhat different understanding of their family situation. The women who had served more of the typical 6-month sentence at the facility when interviewed made us aware that once a woman was able to admit to and begin to address her personal issues, including her addiction, she was able to re-examine her parenting behavior and how her problems affected her children (p. 96).

In many ways, these two examples highlight the two primary constructions of criminalized women found in this study, the former being the vulnerable woman (object of pity) and the latter being the straight up risky woman. Despite the distinction, I don't 
necessarily see these two constructions as being completely oppositional, in that they both draw on neoliberal notions of responsibilization (for changing the self) and exert a reliance on the needs/risk paradigm (Hannah-Moffat, 2005). One portrays riskiness through the use of psychological language, which emphasizes a "fallen" or pitiful woman in need of help and treatment. The other frames a pattern of riskiness through the use of criminogenic language and needs, which ultimately paints a picture that emphasizes deviance and criminality. Though one highlights a woman's vulnerability and the other her culpability, they both expose the underlying neoliberal ideology that is at work across constructions. Juxtaposed to one another, we can see that they come from different sides of the same needs/risk coin. Further, the distinction between risk and need is reminiscent of the historical binary of criminal woman/fallen woman, which is not only gendered, but also highly raced (Colvin, 1997).

Concluding Thoughts. Throughout this section I have shown how the construction of risk operates through processes of normalization. In this way, risk becomes self-evident and taken for granted as an appropriate conceptual framework through which to view criminalized women and their children. Garrett (2016) discussed how dominant texts and popular ideas within social work "are frequently riddled with take-it-for-granted assumptions reflective of a particular historical and economical conjuncture" that show up in the "verbal categories that social workers are apt to use, promote, and reify" (p. 1912). I argue here that risk is one such verbal category. Risk saturates the discourse in this dataset in a manner that is reflective of (and reinstates) a neoliberal hegemonic order. The unquestioned reliance on risk is so strong that it is frequently hard to distinguish what constitutes a need from what constitutes a 
risk. The persistence of risk as a totalizing discourse cannot be denied. Its subjects are caught up in a form of discursive capture and risk is turned into a scholarly platform and a profession. A closer look at the knowledge claims underlying and enabling the rampant use of risk helps to expose and rupture the places where neoliberalism hides out in the discursive production of risk. These knowledge claims are the focal point of the next section.

\section{Knowledge Claims}

Question \#2: What particular knowledge claims about criminalization and criminalized women are made through these constructions?

The following analysis is heavily influenced by Foucault's concern with the production of knowledge through discourse. For Foucault, power does not exist outside of the production of knowledge (1995). He theorized the connection between power and knowledge in terms of not simply producing certain understandings of social reality but actively shaping reality. In other words, discourse produces knowledge claims that, in turn, shape what can be said and known about any topic. Jäger and Maier (2009) explain, "Discourses exert power because they transport knowledge on which collective and individual consciousness feeds. This knowledge is the basis for individual and collective action, which in turn shapes reality" (p. 39). In this way, discourses are tied up with power because they are ultimately capable of inducing ways of thinking and behaving. As modes of power, discourses not only construct reality but do so in unequal ways, privileging some as legitimate and normative while rendering others illegitimate and abnormal. Which, of course, circles us back around to Foucault's (1991) idea of 
governmentality and the importance of examining knowledge claims for how they produce objects of governance.

My examination of knowledge claims in the dataset revealed a consistent use of depoliticized explanations for crime and criminal justice involvement throughout the data. From a Foucauldian perspective, such knowledge claims serve as normalizing technologies through which the discursive production of "criminal behavior" and a “criminal self" emerge. Being productive of neoliberal ideology rooted in selfdetermination and responsibilization, depoliticized knowledge claims promote individualized discourses which then serve as the basis for governing through the regulation of conduct. More broadly, depoliticized explanations for crime and criminal justice involvement can be seen as a way of legitimizing the logic of punishment and control. As I outlined in the previous section, when it comes to social work, depoliticized knowledge claims emerge from a preoccupation with vulnerability and risk. In this section, I outline how depoliticized explanations for crime and criminal justice involvement are made through three primary neutralizing mechanisms: 1) an overriding emphasis on women's individual choices; 2) an absence, or relegation, of issues related to structural context (decontextualization); and 3) a strong reliance on the language of the “psy” professions.

Emphasis on Individual Choices. Depoliticized knowledge claims were exerted through a strong emphasis on choice and responsibility present throughout the dataset. Notions of choice and responsibility reflect neoliberal assumptions about individual autonomy and presuppose an "empire of choice" (Rose, 2000) in which all people have access to the same choices and opportunities. Like risk, choice rhetoric was deployed in 
both implicit and explicit ways throughout the data. For example, in their article on the challenges of conducting research with women in prison, O'Brien and Bates (2003) state:

And most important, how can we make use of these women's experiences to help us construct better alternatives for holding women accountable for the crimes they commit while recognizing their potential to make different choices and enhance opportunities to make these positive choices? [emphasis added] (p. 223).

In the above excerpt, we can see that the authors are being critical in that they are suggesting "alternatives" to prison. Their use of the modality "most important" even suggests a sense of urgency and serves as a call to action. Yet the suggestion for alternatives is not premised on questioning the underlying logic of criminalization; rather, alternatives are suggested in order to "hold women accountable." The authors thus frame crime as a problem of the self. However, a strengths-based rhetoric also shines through in the authors' desire to "recognize the potential" for women to make better "choices." For Foucault, reformation of the self is a key aspect of governance. In this way, the authors' utilization of a strengths-based position can be seen as upholding the mantel of neoliberalism. The above excerpt provides an exemplar of the sneaky ways in which neoliberal ideology is embedded in social work discourses and how it undercuts claims toward social justice. The authors clearly recognize that all women do not have access to the same choices, hence the need to "enhance opportunities." However, despite this acknowledgement, their focus on individual choice still locates the cause of crime and criminal justice involvement in individuals and their intrapersonal concerns related to substance use, mental illness, poor self-esteem, and poor decision-making (i.e. choices). In so doing, the authors' calls for "alternatives" fall short. Because the discursive production of the individual as the problem remains intact, "alternatives" simply relocate 
punishment and control to the community. Similar assumptions of choice show up consistently throughout the data. Typically, they are explicitly gendered. I understand this as a strategy of gendered responsibilization.

Decontextualization. Similar to the emphasis on individual choice, depoliticized explanations for crime and criminal justice involvement were further developed through various methods of decontextualizing the content. Decontextualization is a process whereby women's actions, choices, and circumstances are predominantly represented as disconnected from larger social, institutional, and historical contexts. Such representations act as a mode of reasoning which legitimates research and interventions fixated on naming and changing personal and behavioral characteristics of individuals at the expense of those aimed at understanding and unsettling the discourses of the penalwelfare state. Analyses of criminalization that do not engage with the political economy not only are incomplete, but function to promote discourses of individualization. Decontextualization, then, overlaps with a discussion on normalization in that individuals who are unable, or unwilling, to meet socially prescribed (read: normative) rules and expectations are understood as individuals who fall outside the bounds of what is considered normal and natural, and thus are in need of fixing. Within social work, this is enacted through processes of responsibilization (Rose, 2000). Therefore, I understand decontextualization as an enactment of neoliberal ideology: it discounts the social, political, and economic factors that account for women's involvement in the criminal justice system in favor of explanations focused on individual deficit and choice.

Women are the fastest growing segment of the correctional population, and this fact appeared to be widely acknowledged within the data. Consequently, most of the 
articles in the dataset touch on the causes for the increasing rates of

incarceration/criminalization; however, they do so in different and often conflicting ways. While some articles recognize sentencing policies as playing a part in the growing rates of incarceration, many others do not. For example, Gilham (2012) opens their article by acknowledging women's growing rates of incarceration and then states:

This ballooning incarceration rate for women has been associated with drug and alcohol addiction (Alleyne, 2006; Arditti \& Few, 2008) (p. 89).

What Gilham's discussion lacks is any acknowledgement of the social and sentencing policies related to the war on drugs that lead to the criminalization of substance use. Instead, the author focuses solely on addiction as the driving factor for the mass incarceration of women. This was a common discursive strategy within the dataset whereby the larger context of mass incarceration is highlighted only to establish significance for research, which, conversely, explains rising incarceration rates through the lens of addiction or other individualized discourses. In this way, substance use and addiction become understood as the cause not only of individual crime, but also of mass incarceration. Such discursive framings obscure the fact that drugs (use, possession, proximity to) are in fact the crime, and not the cause of crime; and presuppose that crime, rather than policy, is the causal factor leading to punishment and incarceration, an assumption that has been effectively disputed by sentencing experts (Tonry, 2007).

To take the discussion further, it is prudent to hone in on the word addiction. Gilham, like other authors in the dataset, associates increasing rates of women's incarceration with addiction rather than drug use or involvement in the drug trade. However, as I demonstrated in Chapter 3, the criminalization of drugs has less to do with actual addiction than it does with systemic racism and how that racism plays out on a 
national stage. Certainly, many individuals involved in the criminal justice system are managing issues related to addiction, but many have also been arrested and prosecuted for recreational and periodic use and/or their proximity to drugs. Conversely, many people with addictions (depending on their classed and raced social locations) never become criminalized. To characterize women who are caught up in the drug war as "addicts" is a gross misrepresentation of the actual political and economic forces at play in the carceral state. The focus on addiction = mass incarceration is a discursive strategy that obscures the social and historical production of crime, and thereby reconstructs gendered, raced, and classed social exclusion as being the result of individual behaviors and deficits. By now, there is a large body of research that challenges the notion that drugs cause crime. Rather, it is recognized that the link between drugs and crime is part of a broader problem generated by poverty and racism. Further, Taylor (2016) notes the othering effect that the drugs $=$ crime discourse has in purporting dominant notions of criminality and simplifies understandings of drug use as dangerous.

In general, I am concerned about the overall lack of engagement with the political economy that I saw in the data. Lack of awareness regarding the political economy leads to incomplete understandings and overreached knowledge claims. For instance, in their study on the role of gender in post-jail homelessness, Fries, Fedock and Kubiak (2014) state:

Screening for CODs upon jail intake is perhaps the first and most crucial step social workers can take to reduce homelessness among the incarcerated population (p. 113).

When reading this statement, and others like it that are strewn throughout the dataset, I wonder: how far away from any understanding of the political economy does one need to 
get to not only make this statement, but also make it intelligible? And it is not just a problem related to the authors. This article passed the editor's desk, went through the process of peer review, and was ultimately published. According to Google Scholar, it has been cited 27 times. The authors, the gatekeepers, and other scholars have deemed the above excerpt a reasonable and logical assertion. I take this to be indicative of a broader lack of engagement with both gender and the political economy in social work at large.

Leaving behind the articles that completely exclude contextual and policy factors related to women's involvement in the criminal justice system, at least $40 \%$ of the articles in the dataset acknowledge systemic issues, such as punitive sentencing policies and the war on drugs, as the cause of women's mass incarceration. However, a contradiction emerges whereby despite acknowledging systemic issues, most of these articles ultimately fall back on individualized understandings of crime and/or scale their suggested intervention down to the level of the individual. For example, in a study testing an intervention for "female batterers," Buttell (2002) explains that:

Women are increasingly being arrested and prosecuted for domestic violence offenses under mandatory arrest statues (p. 349).

Buttell then goes on to use that as evidence for the existence of, and increasing rates of, women's violence, which the author explicitly links to morality. Buttell's project then studies the relationship between moral reasoning and recidivism. To establish relevance for this investigation, the author asserts:

In summary, there is an abundance of empirical support indicating that (a) the structure of moral development is universal (e.g., equally applicable to men and women) (Kohlberg, 1984; Nisan \& Kohlberg, 1982; Rest, 1993; Snarey, 1985; Snarey, Reimer, \& Kohlberg, 1985; Walker, 1994); (b) offenders most often employ 
a preconventional level of moral reasoning (Blasi, 1980; DeWolfe, Jackson, \& Winterberger, 1988; Jennings, Kilkenny, \& Kohlberg, 1983; Jurkovic, 1980); (c) moral education programs are effective in raising the level of moral reasoning (Blasi, 1980; MacPhail, 1989; Rest, 1986; Rest \& Navarez, 1994; Thoma, 1984); and (d) enhancing moral reasoning results in decreased criminal activity (Blasi, 1980; Kohlberg \& Candee, 1984; Ma, 1989; MacPhail, 1989) (p. 350).

Notwithstanding the many normalizing knowledge claims based on dated and limited data, Buttell effectively de-genders women's use of violence by defining such violence as an issue related to individual morality. Further, linking the use of violence to immorality in such broad strokes creates (ironically) moralistic claims that violence is never warranted, even in the case of self-defense. Though this is a somewhat extreme example, it was a common practice in the dataset. Few of the articles in the dataset locate the cause of crime as rooted in issues of inequity and oppression, and fewer problematize the category of crime at all.

When policy and structural issues were acknowledged by authors, they were commonly relegated to the margins of the texts, given a nod in the introduction, literature review, or conclusion, and then ignored in the substance of the article in favor of a focus on individual level factors such as feelings, behaviors, and relationships. For example, in their introduction, Berry et al. (2009) introduce a number of structural issues that impact criminalized women, such as:

punitive public welfare structures, low-paying and unstable jobs, husbands and boyfriends who cannot or will not provide adequate financial support, and the absence of community-based supports (p. 294).

However, the authors immediately frame these as,

factors that can push women into lifestyles that bring them in contact with the criminal justice system [emphasis added] (p.294). 
Here we see a key responsibilization strategy in what Rose (2000) calls the politics of conduct, where the "problems of problematic persons are reformulated as moral or ethical problems, that is to say, problems in the ways in which such persons understand and conduct themselves and their existence" (p. 334). In this way, women are understood as not just making one bad choice or engaging in a specific crime, but rather living a criminal lifestyle. This provides an exemplar of how power is exercised throughout the data. The discursive shift to lifestyle produces a "truth" in which a woman's whole identity (i.e., existence) is constituted through the notion of criminal lifestyle.

The discursive reformulation of choice into lifestyle "opens the possibility for a whole range of psychological techniques to be recycled in programmes for governing the excluded" (Rose, 2010, p. 334). Through the remainder of Berry et al.'s (2009) article, the aspects that make up this lifestyle are then identified and targeted for intervention. The authors specifically implicate women's personal relationships for interfering with "self sufficiency" and invoke a dependency discourse which renders political and economic impacts on women's "lifestyles" and law-breaking obsolete. In their conclusion Berry et al. make several suggestions for programs that could improve women's selfsufficiency, including education, job training, pregnancy prevention programs, and substance abuse treatment. At the very end, they tag on the need for "changes in the laws mandating prison sentences for drug-related crimes" (p. 299).

Such nods to social, political, and economic factors give an illusion of invoking social justice. And perhaps they do. My students often argue that providing individual level services is indeed linked to social justice. They assert that systems level change takes time and, while we wait, it is important that people receive services in order to meet 
their needs. I am drawn to the openness and certainty of such argumentation. And I would say they it is without merit. Still, I argue that for social justice to be social justice, a practice/analysis needs to be firmly rooted in a scrutiny of power. Perhaps this brings us to a larger ambiguity within social work: what exactly constitutes social justice and who gets to decide? Relatedly, there is lack of consensus in social work regarding what constitutes power and how it is exercised in practice. Which, of course, leads us back to the ambiguous nature of the undecidable. The space of undecidability is where Foucault's conceptions of power may have particular significance for social work. Foucault invites us to think about power as diffuse, not in terms of who possesses it and who does not, but rather in terms of how it is exercised in context specific situations (Foucault, 1991). In this sense, power is discursive and produced in multiple, conflicting ways. Power then functions through the production of knowledge, or regimes of truth, which shape subject positions and dominant ways of knowing and seeing.

For my analysis, then, rather than thinking in terms of social justice as being either present or absent, it seemed more helpful to think in terms of shades of social justice. Along these lines, I would argue that many of the articles in the sample exercised power through engagement in apolitical invocations of social justice, which can be just as dangerous as apolitical deployments of empathy and love. Just as a discourse of empathy and love can mask the power involved in the helping relationship (Margolin, 1997), so too can the discourse of social justice (Badwall, 2015), thereby allowing social work to function under a veil of innocence.

Textual Silence: Racism. A stark example of decontextualization can be found in the textual silence around racism. Huckin (2002) describes textual silence as being "the 
omission of some piece of evidence that is pertinent to the topic at hand" and by its omission provides or inhibits certain views (p. 348). As I read and re-read through the data, I started to notice that a conversation about racism was starkly absent. To confirm this observation, I counted the occurrences of the word racism using the word cruncher in ATLAS.ti. As a comparison, the word risk (and its derivatives risks, risky, etc.) appears 783 times in the dataset; the word racism appears only eight. The concept of risk shows up in virtually every article, whereas racism is discussed in only four. In Chapters 2 and 3, I reviewed the profound racial disparities that plague corrections and argued that we cannot talk about the criminal justice system without talking about and centering race and the historical legacy of racism through which it emerged. As I have illuminated previously, racism is one of the largest structural issues causing and impacting high incarceration rates in the United States, yet the discursive practices of scholars in the dataset enable racism to be disregarded or completely silenced. The question remains, when racism goes unacknowledged and unchallenged, what is enabled and what is constrained? First, inattention to racism inherently limits any analysis of the criminal justice system. Second, it also serves as a powerful neutralizing technology allowing authors to claim objectivity. Deployment of objective, apolitical analyses allow authors to bolster their legitimacy in a knowledge production enterprise that privileges the value neutral objectivity of positivism. Further, the erasure of racism reinscribes individualizing discourses and reveals how neoliberalism and whiteness remain at the heart of knowledge production and social work praxis.

Bonilla-Silva (2014) describes the racial ideology of the post-civil rights era as one marked by colorblindness and "apparent non-racialism." He explains how under an 
ideology of colorblind racism, racial inequalities are rationalized through cultural rather than biological explanations. From this understanding, the overwhelming explanations for criminal justice involvement related to individual and familial traits, found in the dataset, can be seen as naturalizing the racial inequities embedded in the criminal justice system. Bonilla-Silva (2014) asserts that this "is the central way in which contemporary scholars contribute to the propagation of racist interpretations of racial inequality. By failing to highlight the social dynamics that produce these racial differences, these scholars help reinforce the racial order" (p. 8).

Scholars have also examined the production and erasure of racism in social work education and practice settings (Badwall, 2015; Jeffery, 2005). Badwall (2015), for example, examines how the historical production of the kind, charitable helper intersects with neoliberalism to shape contemporary practice. Badwall shows how the social work as "helper" identity is built upon colonial scripts of whiteness and argues that whiteness then serves as a centralizing organizing principle for practice. Badwall further argues that acknowledging the function of racism and social work's participation in perpetuating racist systems requires disrupting a professional identity defined by "goodness." Therefore, under discourses of helping and empathy, racism necessarily disappears so that social work may maintain an image of itself as a "good helper," a place of innocence in processes that perpetuate racialized exclusion and oppression. Badwall states, "The very naming of racism disrupts both the ideals of the profession and the neoliberal underpinnings of the state. Being seen as moral subjects requires an erasure of race" ( $p$. 19). If knowledge production is the site in which such helping practices are legitimized, whiteness can be seen as operating through the erasure of racism in my data as well. 
There are three primary types of articles in which this textual silence manifests: 1) articles that make no mention of racialized issues, by either avoiding it entirely or implicitly disavowing it as an explanatory variable related to criminal justice involvement; 2) articles that make note of racial disproportionality in the criminal justice system, but include no further mention or analysis around racism; and 3) articles that focus on a specific racial group but include no analysis around racism. I will address each of these in turn.

Complete Silence. 26 articles include no analysis of criminal justice involvement as a racialized issue, and mention race only when describing sample demographics. This omission of race and racism is explicit in the following excerpt from Allen, Flaherty, and Ely (2010):

These women are already marginalized by their gender, class, and victimization status and the systemic barriers they consistently face (p. 162).

Note the missing category of race. Throughout this article, the authors name gender and poverty as axes that are pivotal to understanding the criminalization of women, but they remain silent on race. Despite almost half of their sample being composed of women of color, neither race nor racism is discussed. The only time the authors mention anything related to race is when they name the White racial identity of participants in their study, as in the following statement:

Margie, a 24-year-old White woman, has a 14-month-old son who is in state custody [emphasis added] (p.168).

Moreover, phrases such as “crack subculture" and "America's poor struggling communities" (p. 166) appear to operate as proxies for race in this study. The effect this has is to whitewash the study and its participants and subsequently neutralize (i.e., 
depoliticize) the analysis. By not considering race as a factor that shapes gendered experiences and women's interactions with the various systems that impact their lives, women are then homogenized. Historically this has meant women $=$ white women.

The silence on race and racism is so stark in this article that it is hard to believe it is unintentional. The blatant omission of race and the use of coded language throughout make me think there was some effort involved in this process. But the question remains, why? Are the authors drawing on colorblind ideology of "goodness" and in so doing making their expressed feminist intentions more appealing to a broader (i.e., racist) audience? If so, what good does this do given that racism is so firmly embedded in the criminal justice system? Here, it is interesting to note that this article draws heavily on the construction of vulnerability discussed earlier in this chapter. This article and many others that also draw on the construction of vulnerability are similarly silent on this issue of racism. "Vulnerability," then, can also be read as white. Vulnerable (i.e. white) women are worthy of our empathy and can be redeemed. In this we see social work drawing on an historical discourse regarding the "fallen" woman. While in the time of the reformatories the fallen woman was constructed as childlike and led astray, in the $21^{\text {st }}$ century she is recast as vulnerable. However, as has historically been the case, women of color are excluded from this construction and consequently deemed more "criminal," further justifying their imprisonment.

Racial Statistics. The issue of racial disproportionality is mentioned as a matter of fact, but is left unproblematized and not linked to processes of racism in 15 articles. For example, in the introduction to an article on gender responsive programming in prisons, White (2012) states: 
The number of women arrested and incarcerated is at an all-time high. As a result of two distinct arms of the War on Drugs (legislative changes and the social construction of the drug user as a criminal), women have become more vulnerable to arrest for drug crimes than they were in the past. Add to this a group of conspiracy laws used to prosecute women who are acquainted with a drug dealer, and the numbers escalate even more (Merolla, 2008). Poverty and a lack of education often lead women to make poor choices and engage in high-risk behavior; it happens that the majority of these women are Black and Latina. The number of women admitted annually to the Illinois Department of Corrections quadrupled between 1990 and 2005, and women of color make up $90 \%$ of that number (CLAIM, 2006) [emphasis added] (p. 284).

A number of neutralizing strategies merge in the above excerpt. First, the author frames the high rates of criminalization as a direct result of sentencing policy and the war on drugs. However, White immediately casts that aside in favor of a discussion on individual "high-risk behaviors" and "poor choices," which the author then links to women of color. The use of the phrase "it happens" allows her to treat racial disparities as a matter of fact, as a somewhat natural occurrence for which there is no responsibility to be had. Finally, White calls attention to racial disproportionality in the criminal justice system, but never once throughout the entire article does she mention racism. Racism is effectively disregarded as a factor contributing to high rates of incarceration, poverty, and lack of opportunity, or "high-risk behavior."

Ferraro (2008) argues that presenting racial statistics without reference to the historical, social, and political context from which they emerged has the potential to reify "racial realist" notions about the deficiencies and pathologies of people of color. She astutely notes, "Without careful contextualization of data, these analyses can obscure the social processes of domination and lead to spurious conclusion about race as a cause" ( $p$. 194). Ferraro (2008) asserts that within a neoliberal context where widespread "individualistic and moralistic interpretations of social problems" is common, it is 
important not only to present racial statistics, but to also consider how they will be received. Therefore, the concern with discussing racial disparities in the criminal justice system but leaving them unexamined is that it reinforces dominant notions of people of color as being inherently more "criminal" and uses the power of positivity to undercut, rather than promote, racial justice. In so doing women of color are, once again, framed as "criminal" while white women are framed as "fallen."

Race without Racism. Race was the explicit factor of analysis in four articles. However, even when this was the case, the naming and analysis of racism was still bypassed (with the exception of Epperson et al., 2009). For example, in their study on the moderating effects of race on the behaviors of children with criminal justice involved mothers, Miller and Bank (2013) explicitly compare the effects of maternal criminal justice involvement on "Black" and "non-Black" children. Though the main point of analysis is clearly centered on the racial category of Black, and it could be assumed that this choice was made based on the gross overrepresentation of Black women in the criminal justice system, the authors include no discussion of the role that racism plays in shaping these racial disparities or the results of their study. Rather, the authors draw on culture as a protective factor in shaping Black children's outcomes. Thereby, a discussion of racism is circumvented through a discussion of culture. Given women of color's disproportionate representation in the criminal justice system, the absence of a discussion and analysis around racism feeds into depoliticized explanations for crime and criminal justice involvement, thereby producing a limited vision regarding the space for social work intervention. Engagement with racism as a cause for mass incarceration would render incoherent rationales for individual level interventions and the program 
evaluations that ensue. At the very least, engagement with racism would require scholars to admit to the limits of individual level interventions and evidence-based practice knowledge. Silence around racism, therefore, depoliticizes the issue and helps to not only secure a place of innocence, but also legitimize a fundable research enterprise in social work.

We need to talk about gender. I'm deeply unsatisfied with the way gender is dealt with in the data set. I will start by noting the simplistic analysis of gender that was prevalent throughout the data. It is actually quite remarkable how little gender is dealt with in the dataset. In fact, there was a striking un-discussion of gender. In most of the articles, gender is only discussed or explained in relation to naming demographic characteristics that criminalized women share as a group. For instance, women were typically defined in relation to men; as not men. Specifically, women were most often described as distinct from men in three primary ways: they are mothers, they have more extreme experiences of victimization and trauma, and they have higher levels of substance abuse. It appears then that gender is operationalized along the lines of trauma, substance abuse, and motherhood. In this way, gender is privileged as an analytic category and the differences that exist between women are largely ignored. It is presupposed that criminalized women have more in common with other women than with criminalized men. Issues of race, class, sexuality, disability, age, nationality, etc. ${ }^{38}$ are subsequently erased or ignored.

\footnotetext{
${ }^{38}$ Notably, the data marginalizes women who do not have children (or in some cases pathologizes them), and completely ignores older women, trans women in men's prisons, and women with disabilities.

Furthermore, there is an assumed heterosexuality inherent in the discussions of gender, particularly in the ways in which women's intimate relationships are pivoted around men.
} 
Vis-à-vis a simplistic framing of gender, many articles in the dataset deployed the notion of "gendered pathways" as an explanatory framework for understanding women's crime and criminal justice involvement. The discourse on gendered pathways came about in the 90 s as feminist criminologists sought to explain the gendered nature of women's trajectories into crime (Comack, 2006). The pathways discourse looks at specific factors that put women "at risk" for ongoing criminal involvement. Trauma and victimization are central concerns under a pathways umbrella; victimization is understood as leading to mental health concerns, which lead to substance use as a self medicating strategy, and ultimately living in poverty-factors that are all assumed to lead to criminal activity. The pathways approach was successful in drawing attention to the violence women face before, during, and after contact with the criminal justice system, and thus complicating presumed knowledge regarding criminalized women. In other words, by turning trauma into a risk factor, the pathways discourse essentially reframed women as victims instead of criminals. However, as some feminist criminologists have since pointed out, when women are equated with trauma, and trauma is equated with crime, risk is uniquely gendered (Hannah-Moffat, 2004). As I have already demonstrated, this discursive chain of logic (trauma $=$ substance abuse $=$ crime) was common throughout the dataset.

Furthermore, the pathways approach was deployed throughout the data in such a way as to highlight pathways to individual acts of crime, not pathways to criminal justice involvement. For example, in a study on the effect of maternal criminal justice involvement on children, Miller (2014) states:

While the purpose of the current study was not to examine the association between children's outcomes and risks for intergenerational criminal justice 
involvement, these findings speak to the literature on the link between female traumatic life experiences and pathways of delinquency and crime [emphasis added] (p. 76).

Similarly, in a systematic review of the effects of correctional-based programs for "female offenders," Tripodi et al. (2011) state:

Substance abuse, a criminogenic factor, is one of the most prevalent pathways to crime for female offenders [emphasis added] (Chesney-Lind, 1998; Covington, 1998).

Such discursive framings naturalize crime as a fact rather than a social construct (Pollack, 2006). Indeed, except for the counter-discourses (which I will discuss later in this chapter), the underlying construct of "crime" is rarely questioned in the data. This clearly circles us back around to the emphasis on choice and the ways in which choice is bound up with gender and neoliberalism. Within a neoliberal framework, concepts such as choice, gendered pathways, and the gender-responsive strategies that flow from them are depoliticized and deployed as regulatory strategies of self-governance.

At this point, I have reviewed two reasons for why a pathways framing is inadequate. First, it genders risk; and second, it takes crime to be a stagnant category located within individual behaviors. This brings me to a third reason. In an era of mass incarceration and "new penology," dominant narratives of gendered pathways are no longer logical. Let me elucidate. The pathways approach emerged prior to the passage of welfare reform and Clinton's crime bill, two pieces of legislation that collided to exacerbate mass incarceration and to propel an unprecedented growth in the female correctional population. As such, pathways rationality is notably void of any analysis regarding the impacts of the neoliberal political economy on women's lives. 
As I discussed in Chapter 2, the context of neoliberalism produces a rolling back of the welfare state and the rolling out of the carceral state. This simultaneous "rolling back and rolling out" has been documented as a key dynamic in bringing increasing numbers of women into contact with the law (Sudbury, 2000). While I do not disagree with the fact that violence is a gendered issue and that women face a disproportionate amount of violence, pathways analytics, which center on experiences of trauma and victimization, do not adequately explain the current levels of women's criminalization and incarceration under a rubric of neoliberal globalization.

A brief discussion on the concept of "new penology" is warranted here. Feely and Simon (1992) introduced the term new penology to describe a distinct shift in the apparatus of corrections that occurred in the late $20^{\text {th }}$ century. This time period marked a shift away from a focus on the individual in criminal justice toward an overwhelming concern with aggregates. The rationalities undergirding the new penology have brought forth a conglomeration of actuarial policies concerned not with the rehabilitation of individual offenders, but rather with the identification, classification, and management of selected risk groups. The logic of new penology relies on discourses of risk, which seek to assess and predict probability of offense and re-offense. Such logic is apparent in sentencing policies, such as three strikes you're out and mandatory minimums, which allocate punishment indiscriminately rather than on a case-by-case basis. The logic of new penology is also evident in an overreliance on a number of other practices that entail targeted policing and surveillance. As such, scholars have identified the emergence of new penology as the fuel for mass incarceration. 
The data suggest that social work appears to draw on notions of individual choice and responsibility, indicative of the old penology, while simultaneously deploying the discourses of risk prevalent in new penology. It is as though social work is attempting to hold on to the rehabilitative ideals of the previous penal ideology (which is perhaps better aligned to the ideals of social work) while also clinging to the promise of the evidencebased movement. The contradiction produces a paradox in which social work continues to individualize and responsibilize under a 'new' penal regime which classifies, targets, and criminalizes entire groups of people based not on their individual behaviors and choices, but on the characteristics they share: for having black and brown bodies; for being poor, homeless, unemployed, uneducated; for experiencing violence or mental illness; the list goes on.

There are two problems I see here. First, the logic does not hold. If gone are the days when individuals were criminalized for their individual acts alone, and not because they were caught up in a system of surveillance and regulation (though it is contestable whether this was ever the case), then to continue to focus on individual choices and behaviors is clearly misguided. Second, and following the same line of reasoning, the focal point of intervention should not be the individual behavior of so called "criminals," but rather the systems levying their powers of prediction and surveillance and the discourses that enable them. Even if we were to agree that crime is a real thing, and that trauma leads women (for whatever reason) to engage in such crime, and even if we agreed that treatment for trauma could then prevent criminal behavior, trauma treatment is not going to keep women from being classified in a risk category and subsequently regulated because of that classification; it is not going to stop mass incarceration, or even 
put a small bandage on the gaping wounds caused by mass incarceration. Under the logic of new penology, the purpose of punishment is not rehabilitation; the purpose of punishment is deterrence, incapacitation, and retribution. Social work's continued discursive framing of punishment as rehabilitation is ultimately dehumanizing to those caught in the apparatus of new penology. New penology also parallels broader trends in the professionalization of social work. Like social work, corrections is caught up in the rise of managerialism and the scurry toward "evidence-based" practice (EBP) and research. Both managerialism and EBP prize objectivity and emphasize a reliance on economic efficiency. Privileged then are research and practice activities that advance predictability, consistency, and effectiveness. Scholars highlight the danger this holds in terms of shifting the focus of criminal justice from retrospective penalty to prospective regulation and control, thus widening the carceral net of control (Balfour, 2006; Carlton \& Segrave, 2016; Maidment, 2006). Social welfare systems are intimately caught up in such prospective processes of regulation and control.

Language of the Psy-Professions. Depoliticization is further enhanced through a reliance on the language of the "psy-professions." Rose (1998b) refers to the discourses of the "psy-complex" as "ways of understanding and responding to human concerns using psychiatric terms, logics, and practices" (p. 101). Drawing on Rose, feminist scholars analyze how psychiatric and psychological discourses play out in correctional systems to organize how criminalized women are constructed, understood, and therefore managed (Hannah-Moffat, 2001; Kendall, 2000; Pollack, 2006). These discourses play out in my study's data as well, and can be understood as ideological narratives that depend on psychological understandings of criminalized women and their behaviors. Psy- 
discourses establish a discrepancy between a normative or "ideal" and the person/behavior under analysis, which then prompts individuals to adjust their behavior in order to achieve the ideal. In this way, the narratives of the psy-professions can be seen as a governing through self-determination. Foucault would describe this as a productive rather than repressive power; a power that induces behavioral change and pre-supposes unconstrained agency and flexibility of "choice."

When used to explain the behavior of women involved in the criminal justice system, psychological discourses presuppose that errant behavior causes criminal justice involvement. Similar to risk thinking, the ideology of the psy-professions works on the assumption that criminalized women have psychological, emotional, or thinking deficits that lead them to engage in "criminal behavior." Therefore, interventions are aimed at reorienting one's thinking in order to promote emotional regulation and, thereby, change behavior. These techniques rely on notions of individual responsibility and thus allow women to be governed in ways that are aligned with neoliberalism. Psy-based interventions play nicely with the demands of funders for measureable outcomes, such as improved self-esteem, decreased depression, and, ultimately, lowered rates of recidivism. When deployed in a carceral context, psy-based interventions presuppose that the purpose of corrections is rehabilitation rather than incapacitation and retribution. The narratives of the psy-discourse effectively elide attention to the broader social context within which criminalization flourishes and allow social work to do the control work of the state (what in many ways it has always done) under the guise of treatment instead of punishment. As such, psy-based interventions are steered by social work's investment in professionalization. 
Though the discourses of the psy-professions were evident in most of the data, I focus the majority of the following discussion on one specific article that represents an exemplar of typicality in deployment of the psy-discourses. In an article titled, "Women's Psychological Adjustment to Prison: A Review for Future Social Work Directions," Fedock (2017) reviews research findings from the perspectives of deprivation theory (the effects of the prison environment on a prisoner's well being) and importation theory (the effects of a prisoner's history and personal characteristics on their well being while incarcerated) in order to build a case for a research agenda that integrates both perspectives. The author claims that such a research agenda is important because:

Psychological adjustment has been understudied...however, psychological adjustment is a core issue for determining the mental health needs of prisoners, preventing worsening mental health, and promoting lowered recidivism [emphasis added] (p. 33).

The sneaky issue of recidivism rears its head once again. Linking psychological adjustment, or lack thereof, to risk for recidivism once again assumes an individualized understanding of the factors that lead to recidivism and (re)entanglement with the criminal justice system and keeps the discussion located at the site of individual choices and feelings. The individual, rather than the prison, is centralized as the explanatory variable for recidivism. Such explanations ignore the research that shows that incarceration itself actually works to increase recidivism (Lipsey \& Cullen, 2007). The author proceeds to define and discuss psychological adjustment in prison:

Initial psychological distress on entry into prison is considered normal and typically decreases after the first few weeks (Islam-Zwart, Vik, \& Rawlins, 2007). However, persistent psychological distress is viewed as abnormal and indicative of a potentially long-term, chronic concern labeled "prison adjustment depression” (Reitzel \& Harju, 2000) [emphasis added] (p. 34). 
Here, the discourse invokes normalizations regarding how a prisoner should adjust to prison, which presupposes that prison is a place one should adjust to, or that one would naturally adjust to. What's left out of such conjecture is the possibility that prison may actually be an impossible place for healthy adjustment or that not adjusting to such a violent atmosphere might actually be a healthy response. What is also left out is the possibility that depression may actually be the only normal response to being locked in a cage. What this author calls "prison adjustment depression," others might call posttraumatic stress disorder.

After discussing deprivation theory, which does indeed connect inmate distress and mental health issues to the prison environment, Fedock presents critiques of the perspective and states:

Also, in regard to social work practice models, this perspective ignores active ways that individuals cope with difficult environments. There is limited research about prison-specific ways that women cope in prison (for example, Negy, Woods, \& Carlson, 1997), and research has not examined resiliency within prison life for women and a potential mediating role of individual-level coping with deprivation factors [emphasis added] (p. 36).

In this excerpt, the author effectively disavows concerns with the prison and returns to typical social work focus on an individual's ability/responsibility to "cope" with the deprivation of prison. Here, resiliency is aligned with coping, rather than resistance or even survival. Coping thus becomes a moral imperative and personal resilience is positioned as the remedy for "difficult environments." Garrett (2016) argues that with its overemphasis on individual adaptation, resilience operates as a "keyword" of neoliberalism. From this perspective, a resiliency discourse, when deployed in the manner illustrated above, can be seen as complicit with the demands of neoliberalism as 
women are charged to take responsibility for the impact of prison through the use of coping skills. Simultaneously, the role of social work is reduced to one of fostering or facilitating the capacity for coping and becoming resilient. The author then moves on to talk about importation theory, which

posits that an inmate's demographics and past experiences determine his or her psychological adjustment to prison (p. 37).

When linked to the previous critique of deprivation theory, the inmate's personal characteristics and past experiences become an important focal point in assessment and intervention because such factors determine an individual's ability to be resilient and cope. In Foucauldian terms, resiliency, then, works as a "technology of the self."

Fedock makes various critical, seemingly social justice oriented, points throughout the article while also relying on the logic of positivism to erase a point of view. The author appears to be utilizing normalizations (perhaps strategically) to make a case for improving prison conditions, without ever actually claiming an advocacy position. Though a neutral, apolitical stance was not exclusive to this author, or rare in the data set, I had to spend a lot of time with this specific article trying to unpack it in order to understand its purpose and what it accomplished. The article exerts a veil of objectivity that I find confusing but not at all compelling. Driven by the logic of positivism, objectivity requires measurable outcomes which, I argue, drive the creation of intervenable needs. This raises concerns for me regarding how success is conceptualized and what is expected from humane treatment. I am of the mind that people should be provided humane treatment regardless of how they respond to it. Arguments such those provided in Fedock's article, though in some ways strategic, inadvertently imply that 
humane treatment is valuable only if it produces certain outcomes (i.e., healthy psychological adjustment). These outcomes may be unrealistic and overly demanding of individuals, given the inherent violence of the prison. The danger, then, lies in the possibility that politicians and funders will discredit the need for humane treatment if the externally defined outcomes for success are not met. The question remains: what use and whose interests does objectivity actually serve in this article?

The discourse deployed throughout the dataset was one that allowed authors to appear progressive in intent while ultimately remaining neutral. Through the use of subtle contradictions, detached descriptions, and passive language, authors manage to not claim any perspective at all, and to stay politically neutral. For instance, when presenting common critiques of importation theory, Fedock (2017) states:

Importation factors are often described as prisoner risk factors, and the conflation of needs into risk factors has shifted the responsibility from system solutions to individual-level factors (Hannah-Moffat, 1999; O’Malley, 1996) (p. 38).

In the above excerpt, the author cites feminist (Hannah-Moffat) and post-structural (O’Malley) scholarship in order to provide a critique of risk thinking. However, a reliance on risk is simultaneously re-inscribed throughout the article, demonstrating a subtle contradiction as well as a lack of sophisticated engagement with the feminist and post-structural perspectives she invokes. For instance, Fedock explicitly names a range of risk factors (for poor psychological adjustment and recidivism) throughout the article, including: "chronic mental health distress," "poor psychological health," and being a "woman of color." Despite presenting a discussion of how deprivation theory accounts for emotional distress, the author never once names the prison itself as a risk factor (a feminist critique); nor does she ever question the notion that women should adjust to 
prison (a post-structural critique). Nor does the author acknowledge the very real possibility that one might be depressed precisely because they are in prison. In fact, despite calling for an integration of importation and deprivation theories, the author uses the discourses of the psy-professions to reconfigure disciplinary control through a lens of rehabilitation. Such discursive sleights of hand were a common way that the authors in my dataset remained neutral and undermined their professed alignments with social justice.

Fedock also maintain neutrality through the use of objective description:

The prison environment is a physically, socially, and psychologically distinct location with intentional deprivations (such as loss of privacy), with adjusting and adapting to this environment as challenges [sic] for inmates (Owen, 1998). Prisons are total institutions in that they operate within a contained space, dictated by their own set of rules, regulations, surveillance, and consequences and maintained by authoritative custodial staff (Goffman, 1961) [emphasis added](p. $32)$.

As in other discussions in this article, the author provides no critique or commentary of prisons as a "total institution." Rather, she presents a detached, matter-of-fact description. Further, when discussing the "dynamics of women's prisons" the author gives a brief historical overview and then states:

It has been argued that gendered ideas of corrections persist in how women's prisons function [emphasis added] (p. 32).

The use of the passive phrase "it has been argued" allows the author to remain neutral, to not take a stance. While the use of depersonalized, passive language may be in line with the norms of the genre of academic literature, such tactics are also indicative of a positivist epistemology that privileges objectivity in revealing "truth." Why, you might ask, is a critique of the prison necessary when examining psychological adjustment? 
Precisely because the concepts this discourse invokes to describe adjustment (i.e. coping, resilience) presuppose a certain level of control and flexibility of choices, which in prison do not exist (Hannah-Moffat, 2000). The effect of such neutralized discourses on and about the prison reduces the purpose of social work to one in which our mandate is to simply teach people to cope with mechanisms of oppression so they can be better managers of their own risk.

Furthermore, throughout the article, Fedock establishes a need for a future research agenda by emphasizing the lack of research on a number of issues related to how women respond to and cope with prison. ${ }^{39}$ However, there is in fact significant feminist engagement on a number of fronts that the author purports as lacking. For instance, there is thoughtful scholarship on how women form relationships, navigate power, and resist oppression and loss of personhood while incarcerated (e.g. Bosworth \& Carribine, 2001; Rowe, 2015; Smoyer, 2015). Likewise, there is substantial research on the violence of prison and the inhumane conditions/treatment women experience in prison (e.g. Law, 2012; Rafter, 2017). There is also research documenting how the era of 'new penology' impacts women and how it is taken up in women's prisons (e.g. Hannah-Moffat, 2001; McCorkel, 2013). Emphasizing a lack of research when there is indeed research was common throughout the data.

Perhaps by "lack of research," authors really mean lack of quantitative, positivist research. Or perhaps the overarching point of this particular article is that the research that is done is not explicitly linked to mental health outcomes. However, the harms of

\footnotetext{
${ }^{39}$ The criminalization and mass incarceration of women has gained substantial scholarly attention over the last decade. Fedock's claim regarding the lack of research in this area may be attributable to the fact that most of the research she cites is from the late $20^{\text {th }}$ century and the first decade of the $21^{\text {st }}$.
} 
prison are, in fact, well documented, which begs the question: why are scholars investing their time in making a case for more research on what we already know, rather than advocating hard for policy change and alternatives to prison? After all, wouldn't not going to prison in the first place better support the goal of improving women's mental health? Whose interests are actually served through scholarship of this sort? Pollack and Rossiter (2010) argue that under neoliberalism, the academy, and by consequence individual scholarly agendas become instruments of the state; in social work, a profession that has been historically aligned with the public good, the position of scholars thus changes to "one of self-interest rather than contribution to the common good" (p. 160). I would argue that scholarship of the sort that is advocated for throughout the dataset supports a fundable research agenda more than it supports criminalized women's actual needs, and leaves the fundamental machinery of the carceral state untouched.

I also find it notable that a couple of the authors in the dataset hold positions of leadership on social work's national Smart Decarceration Initiative. Though intentions may be pure-after all, many authors present a case for either improving prison conditions or attending to women's complex needs, which is both necessary and nobleit is important to remember that the powerful function of discourse lies outside of intention. Individual intention has little bearing on the operation of disciplinary power which "works through and upon the individual and constitutes the individual as an object of knowledge" (O’Malley, 1996, p. 189). Therefore, advocating for improvements to prison so that women can better "adjust" invokes a strategy of normalization and engages a logic that fortifies the existence of the prison. In essence, it is calling for "kinder, 
gentler cages," which can be likened to rearranging the furniture on the Titanic. Yet, as Hannah-Moffat (2006) reminds us, "prisons, by any name, or in any form, are limited in their ability to respond to the needs of women offenders or to appreciate the context of their offenses" (p. 30). Fedock's discussion then ultimately supports the logic of punishment, and her neutrality puts her out of alignment with the goals of Smart Decarceration, a discursive tendency within the dataset that is by no means exclusive to this author. I argue that neutrality on issues related to the carceral state allows social work scholars to shirk ethical and moral responsibility for promoting social justice and aligns social work with carceral systems in troubling ways. It seems that, in line with a neoliberal agenda, social work has engaged a depoliticized mandate for Smart Decarceration that operates through discourses of risk and psychological treatment rather than engaging ways of thinking and speaking that could enable solutions geared toward systems responsibility and change. Indeed, within the discourses of the psy-professions ${ }^{40}$, social justice and social change are rendered irrelevant and obsolete.

Concluding Thoughts. De-politicized explanations for crime are dominant in social work discourse. As such, women's involvement in crime and the criminal justice

\footnotetext{
${ }^{40}$ On a final point regarding the overreliance on the "psy" discourses, I feel as though it is important to draw attention to the way in which an escalated focus on the psychological and emotional has led to what appears to be an abandonment of physical bodies. If we are talking about prisons and jails, I would argue that we also need to talk about the bodies that inhabit them. Bodies matter. However, while psychological interventions are advocated for because of their perceived ability to reduce and prevent recidivism, I found little to no concern for incarcerated bodies in the data set. For all the talk about substance abuse and addictions treatment, there is no discussion of what it might be like to detox in prison or jail. For all the talk of motherhood and parenting programs, there is very little about the physical experience of being pregnant and giving birth in a prison (the pregnancy pieces are primarily focused on the emotional aspects of having one's child taken away after giving birth). Similarly, there is nothing said about managing menstruation or going through menopause while incarcerated. And there is not even a slight acknowledgement of bodies (or gender for that matter) outside of the binary-what happens to the physical bodies of trans women in men's prisons (or trans men in women's prisons). Through the use of the discourses of the psy-professions, it seems that social work has abandoned bodies in order to colonize minds. I see this as another place in which neoliberal ideology hides out.
} 
system becomes framed as pathological rather than a product of discursive systems of oppression and disadvantage. The effect this has is to erase the link between inequality and criminality. Further, a reliance on individualized understandings of crime and criminal justice involvement has the effect of destabilizing any attention given to social/political issues in an article and undermining an author's social justice claims.

Though my analysis was confined to social work high impact journals, referring to high impact journals as producing social work discourse is not without grounding. Foucault (1972) recognized that the power of discourse is reinforced through institutional support, thereby producing systems that enable, constrain, and govern discourse. Ultimately, what comes to be seen as legitimate knowledge or "truth" is a product of both discourse and power. Thus, with their conferred status and legitimacy, academic journals, and high impact journals in particular, can be understood as governing social work discourse. The institutional support behind high impact journals merges with the totalizing power of "the scientific" to (re)produce and reinforce specific knowledge claims which in turn shape social work practice. In other words, the knowledge claims made in academic journals become naturalized through the use of scientific discourse and cemented in practice.

That being said, I would be epistemologically remiss if I grounded my analysis of social work discourse solely in the texts themselves. While it is necessary to consider the structures and practices underlying the production of knowledge, it is also necessary to account for the larger context of social work discourse in order to properly assess the power it holds. In that, my analysis is not without reference to the larger trends in the profession. The discursive patterns I see unfolding in the profession at large (and which 
others have astutely traced) are similar to the neutralizing mechanisms I have outlined above. The dominance of individualized and depoliticized discourses on crime and criminal justice involvement looms large in social work. Such dominance marginalizes and constrains other ways of knowing and alternative possibilities for addressing the carceral state. From my analysis, it appears that the privileging of positivism and evidence-based practices accounts, in part, for the depoliticized engagement with the carceral state throughout the data. In the economy of knowledge production, neoliberalism has resulted in a competitive drive toward funding, proliferation of evidence-based practices, and professionalization (Pollack \& Rossiter, 2010). Under this rubric, scholarship that questions and seeks to alter the fundamental structure of institutions is not recognized as valuable because, often, it is not fundable ${ }^{41}$. While counter-discourses and ways of understanding are certainly evident, both in my data and in the profession at large, the forms of knowledge and the practices that emerge from them are not institutionally supported through publishing and funding mechanisms. The dominant knowledge claims that flow from social work discourse are connected to power because, through dominance, they gain a discursive advantage and, thereby, inform how the profession addresses issues related to criminalization and mass incarceration. It is to the specific impact on practice and research that I now turn my attention. Though much of this has already been reviewed, in the following section, I will attempt to synthesize key points of my analysis.

\footnotetext{
${ }^{41}$ There is much to be said regarding the conflation of funding and worth in the academy. Here, I will simply say that when it comes to high quality, intellectual endeavors, just because something is not fundable does not mean it is not worthwhile.
} 


\section{Governance and Resistance}

Research Question \#3: How have these constructions and knowledge claims impacted social work practice and research with criminalized women?

This section brings the analysis together and examines the implications for social work practice and research with criminalized women. I outline the various interventions and practice modalities offered in the data. With the exception of the systems and multilevel interventions offered by the counter-discourses, I've noted a clear preference for individual level service delivery. Through analysis of the interventions called for and the specific outcomes they privilege, I argue that social work functions as a form of government at a distance. As such, there are very obvious ways in which dominant societal discourses and practices are reproduced. However, a close examination of the ways in which the data construct criminalized women and the implications for social work also show that the discursive limits of social work can be, and are currently being, stretched to embody a site of possibility and resistance. I begin this section by reviewing social work as a site of governance and end by considering social work as a site of resistance.

Social Work as Governance. There are two primary ways in which the discourse in the dataset approach criminalized women. One is focused explicitly on risk and risk reduction and the other is focused on the enhancement of a psychological self (selfesteem, skill development, parenting, etc.). As I have previously elucidated, these two approaches are distinct in some ways and overlap in others. Additionally, authors do not always draw on one or the other exclusively, but often pull on both. I do not see this as contradictory in that they both rely on depoliticized understandings of the nature of 
women's crime, which creates the conditions of possibility for individualized discourses and interventions rather than efforts aimed at addressing policy issues and structural inequity to emerge as the "natural" and logical response. As such, the data call for a variety of such practices that monitor and surveil criminalized women while simultaneously encouraging them to become experts on themselves and work to change themselves. Alongside this, however, is a clear discourse of empathy and what some might call an ethic of care. These discourses interact in a contradictory manner, in some ways reinforcing neoliberal discourses and in other ways challenging them. As such, social work emerges as a form of governance and therapeutic surveillance.

In an examination of drug treatment courts, Moore (2011) presents the concept of "therapeutic surveillance" and describes it as a "seemingly benevolent form of monitoring which also troubles the 'care/control' dichotomy" (p. 255). Throughout Moore's discussion we are introduced to the ways in which practices of care and discourses of empathy exist alongside practices of regulation and control. Surveillance is typically thought of as oriented explicitly toward disciplinary purposes. The concept of therapeutic surveillance provides us with a more nuanced view of surveillance, of what it means to watch and be watched, and, I believe, accurately reflects what I see in the data. Like Moore's, my analysis shows that strategies aimed at control and those aimed at care do not sit in opposition to one another. For instance, earlier in this chapter I distinguished the varying ways social work constructs risk. This helped illuminate the less obvious ways that social work is implicated in surveillance and control and how this involvement is not always antithetical to elements of care. Therapeutic surveillance, then, can be seen 
as a manifestation of Foucault's conceptualization of governance, which accounts for the multifaceted, discursive nature of power.

Risk Management Practices. Flowing seamlessly from the construction of risk, the majority of articles include a strong reliance on risk frameworks, with a focus on risk assessment and risk reduction as the intervention, and reduced recidivism as the preferable outcome. The logic of risk management rests in a framework of assessment and prediction that determines future criminal justice involvement (i.e., recidivism). Such determinations then lead to responses that always require more intrusion into the lives of those who are marginalized. In this we see a positivist, neoliberal rationality that defines social work's role as that of assessor and manager of risk. In so doing, such articles often call for expansion of programs and services both in and out of the criminal justice system to act as surveillance mechanism for criminalized women and their families. Such surveillance is often coded through the language of helping. For example, Jung and LaLonde (2016) state:

We conclude that incarcerated women with foster care experiences need more attention and extra support [emphasis added] from the appropriate institutions upon their release (p. 41).

The discourse throughout the data often identifies risks women face and then, like Jung and LaLonde, proceeds to call for increased "attention and support." Such calls presuppose benevolence in attention and support rather than an element of intrusion and surveillance. Increased surveillance of any sort, even the professed benevolent type, paves the way for more criminal justice interventions and sanctions. Indeed, technical violations while on parole and probations account for the largest proportion of recidivism rates (Sawyer \& Wagner, 2019). 
Jill McCorkel (2017) writes about profiteering in relation to for-profit carceral drug treatment. "Alternatives" to incarceration are implemented under the guise of treatment, yet they work by inserting constant surveillance into the lives of those convicted, and are backed up by the looming threat of incarceration for technical violations. In this way, community based alternatives can be said to expand rather than displace the carceral net of control. When social work blindly advocates for and implements such interventions, they are effectively supporting the expansion of carceral institutions into the community, rendering social work a transcarceral agent of control.

The issue of working with and for the criminal justice system was present throughout the dataset. Authors in the data accomplish this in a number of ways, primarily by: calling for collaboration of various sorts between criminal justice and social work; emphasizing what social work can offer the criminal justice system; and discussing the "opportunities" for practice and research that are available in carceral systems. For example, Fedock (2017) advocates for the increase of social workers in carceral settings and states:

Given the inherent tension between prison goals of security and the mental health needs of prisoners, social work may serve as a field for mediating this tension ( $\mathrm{p}$. 39).

These and similar statements throughout the data assume that social work will, or can, exert a therapeutic, perhaps humanizing quality on the criminal justice system. Such statements do not account for the danger that the influence will work in the inverse direction and that the goals and values of social work will be consumed under correctional logic. Fedock's sentiment functions to align social work with the interests and goals of carceral institutions. 
Discourses of Empathy. As I moved through the various phases and layers of analysis, it was interesting to see how I began to read into the depth of the discourse(s). For instance, there is a group of articles which I initially labeled "social justice light." These articles named, and provided more than a simple nod to, policy and structural inequality. Many also claimed social justice values, albeit often in an apolitical way, usually falling back on individualized understandings and interventions. The "social justice light" articles were, in my mind, what one would expect from a "typical" social work discourse. They emphasized a preference for micro-level service delivery while also claiming a space, through discourses of empathy and social justice, for social work to perform the identity of "helper." An article by Epperson et al. (2009) investigating HIV risks for Black female defendants provides a good example of this type of article. The following excerpt illuminates the discursive trends of such an article:

Investigating policies that support alternatives to standard criminal justice practices in reducing recidivism is a key element of social work with this population. The empowerment of Black criminal justice-involved women through HIV prevention and other culturally sensitive social work interventions is greatly needed (p. 269).

This was the kind of statement and article I expected to see more of when I began this project. Though there are some obvious places of critique that align with discussions presented previously in this dissertation (specifically in regard to the use of correctional outcomes [i.e., recidivism] and the flaccid use of terms such as "empowerment" and "culturally sensitive" that imply a politics of social justice), I initially thought of these articles as being relatively benign, and as "on board" with social work's mandate toward social justice. However, upon deeper inspection of this type of article, I began to see how deployment of social justice, despite being politically infused, at times operates as a 
screen and a mechanism of innocence. For instance, authors claim good intentions and social justice values while simultaneously eliding the profession's responsibility toward enacting those goals through textual silence. Here I began to see how deeply intertwined the textual silence on racism is to the project of innocence; whiteness as goodness becomes re-inscribed through depoliticized discourses of empathy.

The various grammar elements utilized in texts, such as the use of passivity and agentivity, also helped illuminate the maintenance of innocence. For example, many articles discuss child welfare policies that are linked to the increase in termination of parental rights for incarcerated mothers, but never acknowledge who is responsible for policy implementation or the role of the social worker in perpetuating disparate outcomes in child welfare. Similarly, many authors do not claim their arguments in their pronoun use. They often say "it," as in "it can be argued," rather than "we," as in "we argue." Authors are thereby able to remain relatively neutral on the topic at hand despite bringing up the issue for inspection.

Other articles drew on empathy discourses in a more overt way to propel an image of goodness. The typical "social work as savior" or good helper narrative was propelled through empathy in a number of ways. Stark examples are found when researchers defined themselves as on a "mission" to help the powerless, or "give voice to this invisible population." The positive qualities of the researchers (and social work) were also emphasized through the use of participants' quotes. For example, in an article on group therapy in a prison for women, Harris (2014) stated:

I was constantly reminded each week by the women of what the group meant to them. For example, one woman in the group stated, "This group has been something sent from God himself. I never thought I had a chance for any program 
from the prison. You gave me the skills to go through with my Family \& Offender Sentencing Alternative Program application" (p. 50).

The excerpt above provides an example of how authors can draw on a discourse of empathy and compassion by specifically choosing words from participants that emphasize gratefulness. This is a discursive strategy which propels the image and narrative of helping as a place of innocence. This article, and many like it, is strengthsbased and respectful. Throughout such articles the authors make it clear that they are on the women's side. Yet, they simultaneously obscure power relations. The tensions that exist between the goals of social work and the goals of criminal justice are, thus, minimized or ignored under a depoliticized discourse of empathy.

Gender Responsive Strategies. Discourses of empathy also emerged through the promiscuous use of "gender responsive/specific" interventions found throughout the data. Drawing on the "pathways" discourse discussed in earlier in this chapter, most of the articles in my sample called for gender specific/responsive interventions in some way. However, what is meant by gender responsive or gender specific is often vague and left undefined. One is generally left to assume what it means through the context of the text. Revisiting the way gender is dealt with in the data helps illuminate the key assumptions guiding the use of gender responsiveness in the data set. Primarily, gender responsiveness appears to parallel understandings of gender embedded in the pathways approach, which relies on a binary of men/women, and is focused on trauma, mental health, parenting, substance use, self-esteem, choice, and decision making.

"Gender specific" interventions, then, appear to be primarily focused on therapeutic strategies for bolstering self-esteem as well as skill building around decision 
making and parenting. When deployed in this way, gender specific strategies can be seen as an exemplar of practices that work with the "transformative risk subject" (HannahMoffat, 2005). The transformative risk subject relies on creation of intervenable needsthe process through which needs are constituted as intervenable by way of a risk management framework and then targeted for intervention-interventions which draw on the "psy" discourses and, ultimately, perpetuate depoliticization. As Nikolas Rose (2000) notes, interventions focused on personal fulfillment and personal development are closely aligned with risk management, and in their reliance on "self-surveillance" and "selfregulation" also serve as another form of governmentality.

It appears as though the discourse on gender responsiveness has largely escaped critical scrutiny in the social work discourse. As such, it has been ubiquitously taken up as a "commonsense" framework for thinking about social work interventions with criminalized women. Given the concerns I have outlined earlier in this chapter regarding the discourse on gender that is deployed in the data, as well as the almost universally accepted framework of risk, there is reason for alarm. Essentialized and psychologized notions of gender function in tandem with risk discourses to reduce gendered sociopolitical realities as a problem of the self. I argue that the notion of gender responsiveness in this data operates as a "screen discourse" (Garrett, 2016) to provide a veneer of progressiveness/social justice, while simultaneously minimizing or erasing the importance of economic oppression and racism. Further, when deployed in this way, it ultimately justifies the existence, and expansion, of carceral institutions. 
Prison as Opportunity. There are many ways in which the existence of the prison is bolstered throughout the data. I have spoken to some of these already, but the most troubling trend I observed in the data is the explicit framing of prison, or criminal justice involvement, as an opportunity $(\mathrm{n}=17)$. Flowing from the construction of women as "risky" and de-politicized explanations of crime, prison and supervision are subsequently constituted as an opportunity for growth, reflection, and skill building. For example, after discussing the challenging life experiences many incarcerated women face, Miller et al. (2014) assert that:

Jail may at some level provide-if not a respite-an opportunity to reflect [emphasis added] (p. 168).

Similarly in an article on substance use, Hepatitis C, and service availability among rural incarcerated women, Staton-Tindall et al. (2015) discuss the dearth of substance abuse treatment facilities in rural areas and state:

In the absence of these available and accessible services, the rural jail may provide an opportunity to "sober up" and return to the street where relapse and/or overdose is a significant risk. Thus, jails provide a valuable and often untapped opportunity to provide drug abuse and related health interventions to this highrisk population [emphasis added] (p. 393).

In the above excerpt, the authors not only frame jail as an opportunity for women to "sober up," but they also frame it as an opportunity for service providers. They reinforce the use of incarceration as a way to accommodate for neoliberal eviscerations to the welfare state. Through the assertion that jail is an appropriate venue for providing treatment, the authors implicitly affirm that it is also an appropriate way to compensate for the lack of treatment and services in the community. This statement highlights the very real ways in which jails and prisons are used to manage the social issues that 
manifest as a consequence of social exclusion under neoliberalism. Furthermore, the research that is conducted to support such statements effectively constrains social work's advocacy efforts. Rather than advocating for appropriate treatment availability in the community, Staton-Tindall et al. activate a logic that works to sustain the use of incarceration as a means for dealing with substance use. Through the propagation of social service/criminal justice alignment, they also ensure their own (i.e., social work's) legitimacy in a rapidly disintegrating welfare state. The question remains: what happens when services that are designed to "help" are dictated in and through (and perhaps depend on) the carceral system?

In another explicit framing of incarceration as opportunity, Gilham (2012) states:

Preparation for and return to life beyond the institution requires a corrective treatment experience that is based on exploration of past behaviors, skill development, and enhancement of the individual's self-confidence and selfefficacy to meet the demands of the future. These women must capitalize on the opportunity they have while incarcerated [emphasis added] (p. 100-101).

There are obvious ways in which the above statement reflects the ideological positioning of the psy-discourses and activates technologies of the self to initiate self-governance. As with other examples I have provided throughout this dissertation, the authors presuppose that the purpose of incarceration is treatment and rehabilitation rather than incapacitation and punishment. As I have previously discussed, with the advent of new penology, this assumption has been widely discredited. This discussion dovetails onto previous conversations presented in this dissertation questioning the purpose and ethics of prison. In a less explicit framing of incarceration as opportunity, Schlager and Moore (2014) state: 
Mothers who use incarceration constructively as a time of self-reflection can have more successful reunification with their children [emphasis added] (p. 100).

In this statement, the authors implicitly assert that there is a right way and a wrong way to "use incarceration." For them, the correct way involves "self-reflection." It leaves one to wonder if self-reflection is really all that is needed to support reunification with children? There is a inherent responsibilizing quality to their assertion. Women are held responsible not only for the behavior that fostered their incarceration, the behavior for which they presumably need to "self-reflect" (sit in the corner and think about yourself), but they are also held responsible for what reunification looks like. If reunification does not go well, it can then be reduced to a problem of the self-an individual woman's lack of effort or inadequate self-reflection.

My discussion here is not meant to diminish a woman's agency, but to point to the factors that constrain agency and therefore limit the logic of the author's assertion. The reality is that there are many reasons that reunification is challenging post-incarceration, and many fall outside of the control of individual women. Child welfare requirements for employment, housing, and childcare all interact with policies that disenfranchise and restrict the upward mobility of "offenders." There are also factors related to gender, class, and racial biases embedded in the child welfare system, as well as assumptions regarding "criminals" and the danger they pose to children, that influence worker discretion in promoting or inhibiting reunification. Workers are not just influenced by dominant cultural ideology in this regard. As I have shown throughout this dissertation, dominant discourses regarding crime and the welfare of children are actively reproduced in social 
work. This speaks loudly to the need to shift the discourse around crime and criminal justice involvement in social work knowledge production.

The framing of incarceration as an opportunity is troubling for many reasons. First, it requires infusing the discourses of treatment and "helping" with those of punishment and control, a process Carlen and Tombs (2006) dub “thera-punitive." Second, thera-punitive rationality assumes that women are getting effective treatment and support in carceral settings, which has been widely critiqued as a contradiction in terms given the violent and often traumatizing nature of correctional involvement (HannahMoffat, 2001; Pollack, 2010). Third, a discursive framing of incarceration as a therapeutic "opportunity" elides moral and political concerns regarding the carceral state, and upholds the use of prisons and jails as an appropriate response to social exclusion. Further, it passively accepts the logic of punishment and aligns social work with carceral institutions in concerning ways. The effect this has is to ultimately depoliticize social work itself.

Social Work as Resistance. Though not dominant by any means, there was a small subset $(n=4)$ of my sample that I would consider as offering a counter-discourse (i.e., Heidemann et al., 2016; O’Brien \& Ortega, 2015; Smith \& Young, 2003; Willison \& O'Brien, 2017). Counter-discourses are examples of resistance that contest prevailing representations and ways of knowing (Hall, 1997). In that, lies the possibility of multiple identifications and interpretations of both dominant and counter-discourses. My discussion of counter-discourses here is gleaned from my analysis of the major discursive themes and strategies that I have problematized so far throughout this dissertation. As I moved through analysis, it was sometimes difficult to distinguish between what 
constituted a true contestation to the dominant discursive patterns found in the data and what simply stretched them. In other words, I made an effort to distinguish between what served simply as a "less problematic" enactment of the dominant discourse and the truly counter-discursive. In so doing, I identified, and discuss here, pieces that present a significant challenge to the dominant ways of constructing, knowing, and working with criminalized women that were prevalent in the dataset. The meaning of a counterdiscourse is revealed only in juxtaposition to the dominant discourse. Therefore, the counter-discourse does not seek to simply supplant the dominant discourse; it exists in the same discursive space and by virtue of that existence exposes and questions the logic and strategies of the dominant discourse, and thereby undermines it.

In contrast to the discursive themes and strategies that are dominant in the data (and which have been discussed thus far), the articles that form the counter-discourse firmly anchor their analysis in explanations of structural inequity and construct criminalized women as subjects of structural oppression and disadvantage. As such, they rely on explicitly politicized explanations of crime and criminal justice involvement and expand the discursive limits within which social work operates and, thus, the possibilities for resistance. Unlike the majority of articles in my sample, the pieces I identify as a counter-discourse disrupt the underlying construction of crime and question the logic of punishment. Accordingly, they move away from reliance on the criminal justice system as a means of dealing with social problems. They call on social workers to engage in policy advocacy, utilize anti-oppressive practice frameworks, and consider prison abolition as a viable option. In this counter-discourse, social work defines itself politically, as an advocate and an agent of social change. 
There is very little behavior talk in the counter-discourse. When a discussion of individual level issues or behaviors is presented, the articles of the counter-discourse tend to situate behaviors within a sociopolitical context and examine them as manifestations of larger structural issues related to inequality. For example, in a discussion regarding the impact of the passage of the Personal Responsibility and Work Opportunity Reconciliation Act of 1996 on women, Willison and O'Brien (2017) state:

When women turn to survival behaviors, these are criminalized, stripping the contextual factors of poverty and institutional racism from the analysis (p.41).

This short sentence gives you a sense for how the flavor of the counter-discourse differs from the majority of what has been reviewed thus far in this dissertation. There are a number of factors worth noting. First, behaviors are discussed as being criminalized, not inherently criminal. Second, behaviors are also contextualized within, and as an inevitable product of, the political economy. The use of the adjective survival also depathologizes women without stripping them of their agency; it alerts us to the fact that in a neoliberal political economy, not everyone has the same choices, and the choices that people make may be among the best that are available to them. In other words, the term "survival behaviors" creates space to conceptualize behavior that is criminalized as a form of resistance to poverty and oppression. Third, sociopolitical factors are emphasized and racism is explicitly named. And finally, because the sentence was linked to a discussion of the impact of welfare reform, the authors attend to the nuanced ways in which seemingly disparate policies (i.e., social welfare and criminal justice) intersect in complex ways to impact the lives and criminalization of women. As you can see, this little sentence packs quite a punch and provides an excellent example of how, in the 
counter-discourse, women are constructed as criminalized and marginalized rather than risky.

Though the term risk is used very little in this portion of the data, when it is utilized, the locus of risk as well as the site of intervention is firmly grounded in systemic issues and the need for systemic change. Smith and Young (2003), for example, do a deep dive policy analysis on "The Multiple Impacts of TANF, ASFA, and Mandatory Drug Sentencing for Families Affected by Maternal Incarceration.” After providing an overview of the intention and impact of the Adoption and Safe Families Act, they state:

There is a societal obligation to address risk factors related to poverty, and concurrent planning does not address this reality [emphasis added] (p. 544).

In this statement they not only name poverty as the problem (i.e., risk), they also address the failures of policies such as ASFA when they are decontextualized. The authors often move beyond description to call for action, with intervention situated at the site of poverty. Further, the use of the term "societal obligation" creates a sense of urgency and responsibility. In this way, the authors are taking an explicit political stance.

Similarly, recidivism is not framed as the definition of "success" in the counterdiscourse. When recidivism is discussed, it is linked directly to structural barriers. By way of example, Heidemann, Cederbaum, and Martinez (2016) state:

The vast majority of women incarcerated in the United States will eventually be released (Visher \& Travis, 2003). Hoping to build a new life for themselves and their children when they come home, formerly incarcerated women (FIW) instead return to their communities to face an array of barriers to successful reentry, including barriers to employment, housing, education, civic participation, and income assistance, and difficulties reuniting with children and families. These barriers contribute to a staggering rate of recidivism (p.24). 
Rather than framing recidivism as a result of individual deficit or deviance, as is typical of the discourse on recidivism that runs through most of the dataset, the focus here is squarely on political and economic barriers. What is particularly notable about this article (as with the others in this subset) is that the authors do not move on from here to simply relocate the solution for recidivism in individual level interventions. In fact, this article is specifically about redefining outcomes and indicators of success for formerly incarcerated women, beyond that of recidivism. This type of scholarship creates space for the nuanced ways in which success can be conceptualized. Rather than attaching the label “criminal," "offender," or "at-risk," this work opens space for a variety of subject positions and in so doing is deeply humanizing.

Generally, interventions and outcomes in this subset of the data are aimed at the systems level. Smith and Young (2003), for example, call for changes in sentencing policies, and also target TANF and ASFA as the site of intervention. They call for administering financial assistance (i.e., money) to women and their families, rather than skill building, in order to promote reunification, reduce recidivism, and foster well-being. Smith and Young, like the others in the counter-discourse also stress that "substance abuse should not be considered primarily a criminal justice problem” (p. 549). Such statements shift the discourse on substance use and urge for a public health approach rather than a criminal justice response to substance use.

O'Brien and Ortega (2015) call for a complete dismantling of the criminal justice system and emphasize the politics of prison abolition:

Decarceration and/or prison abolition requires an emphasis on building community accountability for responding to harm rather than reliance upon policing, surveillance, and the criminal processing system. Prison abolition 
exposes the racism and institutionalized oppression inherent to the prison system and challenges the ideological 'need' for prisons. Advocates and activists within the prison abolition movement recognize that prison does not make us safer and calls for shifting resources to reinvestment in community-based empowerment, community-led education, and radical activism as alternatives to the prison system (p. 143).

Similarly, Willison and O'Brien (2017) call for a number of changes at the economic and policy level:

Durable change to the mechanisms of the Prison Nation and its resulting mass incarceration requires that we address the early criminalization of girls and women by rebuilding the safety net of economic supports that can provide quality education, fair wages employment, and the structural supports for health and wellbeing. In addition, we must advocate for the retooling of sentencing policies in response to women's criminalized behaviors to incorporate treatment and supports for recovery and for the expansion of in-prison programs available to currently jailed and incarcerated women. Finally, we argue for the creation of realistic pathways to citizenship after release from prison. Feminist social work practice requires that we address the outcomes of institutional sexism, racism, and class injustice in the lives of marginalized women who are impacted by the Prison Nation (p.46).

The above excerpts are both from articles co-authored by Patricia O'Brien. O'Brien's body of work in this dataset includes articles from various projects spread throughout the sample timeframe; the first was published in 2003 and the last in 2017. This provides the opportunity to examine the work of a single scholar over the course of almost two decades. What stands out from this analysis is how deeply politicized O'Brien's scholarship has become over the years. If you contrast the two excerpts above, from 2015 and 2017, to the one analyzed on page 153 from 2003, you can see a stark difference in the flavor of the scholar's work. Whereas I placed the piece from 2003 in the "social justice light" category because it simultaneously drew on notions of choice and responsibility as well as discourses of empathy and social justice, I included the later pieces as part of the counter-discourse as they are explicitly critical and political. I 
believe this illustrates a stretching of discursive limits. In this way, I find O'Brien's work to be amongst the most exciting in the dataset. It shattered my preconceptions and draws my attention to a genuine capacity for change in the social work discourse. It also raises many questions regarding the mechanisms that politicize social work scholars and, thereby, allow us to re-think the discourse on criminalization.

The articles in the counter-discourse all, in some way, actively undermine, rather than bolster the use of the prison and criminal justice system. For example, Heidemann, Cederbaum, and Martinez's (2016) interviews with formerly incarcerated women highlight the dehumanizing nature of interactions with criminal justice authorities:

Tina went on to describe the humiliation she feels when her female parole officer stands in the door of the bathroom and actually watches her urinate when she is drug tested. The feeling of being under constant surveillance-which has been an increasing function of parole in recent decades (Solomon, Kachinowski, \& Bhati, 2006) - and the constant fear of 'messing up' and violating strict parole conditions, which were often arbitrarily enforced, greatly hamper FIW's ability to feel free and to fully live their lives. For those still on probation/parole, success was defined not solely as the desire to discharge but more as an opportunity to fully live their lives no longer under the oppressive surveillance and control of criminal justice authorities (p. 32).

In their description and analysis of Tina's predicament, the authors address the problematic nature of surveillance, and thereby subtly interrogate the benevolence of community. The counter-discourse carries not just a critique of the criminal justice system, but also of social work and the ways in which social work research, policy, and practice perpetuate mass incarceration. The counter-discourse actively implicates social work in processes of criminalization and demands that social workers engage morally and politically. In short, all of the articles in the counter-discourse have goals related to 
building social justice. Though just a small subset of my sample, I see these emergent counter-discourses as critical to fostering spaces of hope and possibility.

\section{Concluding Thoughts.}

Throughout the data, there is a strong focus on "what works," with what works defined primarily in terms of managing risks and reducing recidivism. Indeed, risk assessment and risk management strategies as well as individualized interventions which focus on individual choice and therapeutic treatment appear to be the dominant model of service delivery in social work with criminalized women. The legitimacy for such interventions is bolstered through a discourse of neutrality. Neutrality surfaces when a stance is not taken on the issue of incarceration, when the issue of incarceration and criminalization is discussed in neutral or psychological terms, and when interventions are focused solely on individuals.

Furthermore, very little explicitly political language is used in the data. For example, despite being a large-scale issue that is recognized by our national professional organizations as an urgent social justice issue, mass incarceration is named in only two articles. This is the primary tension in the data whereby many authors invoke yet, ultimately, undermine social justice values. When terms such as social justice, empowerment, and oppression are used, they are immediately undermined by the suggested use of individual treatment, which effectively drains these words of their political and ideological meanings. Though I did not find any of this particularly surprising, I was caught off guard and deeply troubled by the calls, both explicit and implicit, for social service and criminal justice alignment that I found in the data. Through the acceptance of risk discourses and eager alignment with carceral systems, the 
profession functions as a instrument of state sanctioned governance and is depoliticized far too easily. Social work's imbrication in the carceral state brings into stark relief the profound ethical ramifications of doing business as usual. Our ability to contribute to the common good is thwarted by reckless engagement with neoliberal rationalities. I worry that we are too far removed from the moral and political discourses that are necessary for promoting social justice and social change.

By contrast, the articles of the counter-discourse provide an alternative way of seeing criminalization and social work's role. They also helped deepen my own analysis and lift my spirit of generosity. As I saw scholars become increasingly politicized in their scholarship over time, I thought about the notion of discursive limits: how they constrain, but also, how they can be stretched. I began to rethink how I was viewing the use of (or lack of) social justice in the data. Social justice may not be an all or nothing concept; like most things, it may be more usefully conceptualized as existing in shades. In this, the tension of the undecidable might also include a struggle to define social justice. Perhaps social work's inclination toward the individual and individual level treatment serves as a way of (re)defining social justice in neoliberal terms.

Though it is beyond the scope and epistemological assumptions of this study to speculate different interpretations, throughout this project, I often wondered how the interpretations of those with more clinical/micro orientations in the profession might differ from mine. I believe many clinicians would say, without a doubt, that they support and uphold social justice values, just as I do. Similarly, I believe many of the authors in my dataset would also claim social justice values, and perhaps ardently so. Which begs 
the question: within social work, is "helping talk" synonymous with social justice talk? If so, what are the implications for the profession's ability to effect social change? 


\section{Chapter 6: Conclusion}

This project examined social work's engagement with criminalized women. Using a Critical Discourse Analysis (CDA) I looked at how criminalized women are constructed in social work high impact journals and the implications this has for research and practice. In line with what Laura Nader calls "studying up," this project puts the gaze on a governing technology of social work in order to examine how the profession participates in maintaining and/or resisting the carceral state. Critical Discourse Analysis, informed by critical and post-structural frameworks, is premised on the notion that analysis and meaning making are both political and subject to multiple interpretations. As such, the interpretations and analyses in this dissertation are shaped by my subjectivity as a social work scholar who holds a pointed social justice perspective and strong commitments to advancing and strengthening macro thinking/practice in social work. In this chapter, I summarize the analysis and arguments of the dissertation and speak to what I see as some of its most pressing implications.

The overarching finding is that social work privileges a psychological discourse, and that the assessment and management of risk has supplanted a holistic approach to meeting client needs and addressing mass incarceration. There is a substantial emphasis on framing criminalized women and their children as "at risk" individuals who can be helped by social service and criminal justice alignment. I argue that social work's growing dedication to practices that seek to adjust the psychological fortitude of criminalized women relies on broader cultural discourses of responsibilization, which reproduce rather than interrupt criminalization, and divert attention away from the need for social and economic change, leading ultimately to the profession's depoliticization. 
My results show that approaches to practice which fail to address historical and structural contexts are dominant in the social work scholarship. This is achieved through a variety of what I have termed "neutralizing strategies," including decontextualization, the erasure of racism, and an overreliance on the languages of the psy-professions. These neutralizing strategies actively produce depoliticized understandings of gender, crime, and social justice. Depoliticized understandings shape social work practices that center on risk and responsibility, which undermine (or perhaps redefine) social work's professed commitments to social justice and to addressing mass incarceration. I have specifically begun to refine my understanding of and stance on gender specific/responsive interventions. My analysis shows that social work draws upon essentialized notions of gender to demarcate women from men, identify lifestyles, and produce ideas about risk, all of which drive the implementation of gender responsive assessment and intervention. I have thus become more skeptical of "gender responsive" approaches since completing this research. As other feminists have noted, gender responsive approaches tend to prescribe, rather than respond to, gendered notions of risk (Hannah-Moffat, 2010). If gender is going to be operationalized in this manner, then perhaps gender needs to be abandoned, or at the very least reworked as an analytic category.

Further, if our larger attempts as a profession toward addressing mass incarceration, such as the Grand Challenge of Smart Decarceration, are built upon discourses of risk and responsibilization, then we risk simply relocating the punishment and control of marginalized populations into the community. Social work's alignment with carceral systems and the subsequent call for prison based treatment programs and community "alternatives" leaves out a critical analysis of the underlying culture of 
punishment. Indeed, as critical and feminist criminologists have argued, many "alternative" programs often reproduce rather than displace the reach of the criminal justice system and create countless new spaces of governance.

My analysis therefore exposes how social work is implicated in processes of criminalization, and propels a shift in emphasis from individualized service delivery, aimed at changing the behavior of individuals, to launching interventions that tackle structural injustice and inequity. I do not intend to imply that social work cannot or should not provide individual level supports and treatment, but there are some serious questions our profession must grapple with regarding: 1) how we can provide effective support when aligned with carceral institutions and 2) how we sustain our values and ethical imperatives for social justice if some of the most influential scholarship coming out of our field is bound up in individualizing and pathologizing discourses.

The implications of this analysis are many. First, this work has sought to provide an account of social work discourse in relation to criminalized women. I explored and exposed the power function in social work knowledge production to produce subjects of governance and fortify the carceral state. Because power is beyond individual intention, we need to pay close attention to the ways in which it manifests and reproduces itself in the specific discourses and knowledge claims that form the foundation of our professional practices and knowledge. Neutralizing strategies make it difficult to identify responsibility for the continued existence of the carceral state and inspire doubts about the possibilities for change. Understanding the subtle and productive work of power to undermine our "good intentions" and aspirations for social justice requires us to rethink 
explanations for crime and our understandings regarding the purpose and necessity of the criminal justice system.

It is here that I discovered a profound ethical dissonance between social work's engagement with criminalized women and social work values. Specifically, I found that social work discourse passively accepts the logic of punishment and supports dominant ideology surrounding gender and crime, while concurrently attempting to redress the consequences of such constructions through social justice values. I conceptualize this as discursive struggle over the meaning and purpose of social work; a struggle that embodies some of the most salient historical and contemporary tensions in our field related to our professional identity and an increasing drive toward professionalization.

Though I knew upon setting out that I was studying the entwined aspects of criminalization and social work, I did not quite see that what I was examining was much bigger than that specific interaction. As I moved through this project, I found that my project felt less and less about criminalization, and more about confronting the soul of social work. And I am left wondering, what is the actual promise of social work? If it does indeed include visions for social justice and social change, can those visions be adequately met under an apparatus of neoliberalism, or only performed? Ethically speaking, I see this as a fundamental crisis in contemporary social work. Neoliberal discourses of individuality and responsibility are ill suited for addressing the harms caused by the carceral state, and when deployed through the process of knowledge production serve only to deepen our participation in it. In this sense, I believe ethics may be at the crux of my work. 
In examining the need for an ethics that accounts for trespass as an inevitable consequence of being, Orlie (1997) tells us that:

"Ordinary evil is the product of trespass, not sin; of thoughtlessness, not wickedness. Prevalent notions of ethical conduct-performing contracts, being reasonable, behaving predictably - do not necessarily diminish ordinary evil, but in fact often reinforce and extend it. Moreover, predominant rationalities often make us thoughtless rather than thoughtful agents of the governing powers that multiply trespasses" (p. 11).

Consequently, we face a crisis of the undecidable borne out by our difficulty in living up to our aspirational values while justifying our profession's continued existence. This raises serious questions worth our consideration: What does it mean to engage in responsible social work practice and research in the context of neoliberal globalization and mass incarceration? How do we proceed in ethical decision making within the discursive space of undecidability? Is the enactment of hegemonic discourses the inevitable consequence of the undecidable? Perhaps, but I think it is also within the terrain of undecidability that possibility emerges. Orlie (1997) calls for "transgressive thinking." Like Foucault, she argues that discursive limits cannot be transcended, but they can be transgressed. She asserts that "judgment is an insufficient way to care for the world. Rather, thinking (in contrast to judgment) cares for the world by attending to the effects of the limits through which we constitute the world" (p. 7). Thinking that questions the inevitability of crime and the carceral state expands our vision of the possible and re-centers social work as a political profession. 
Throughout this project, I kept returning to the same questions: Why has the prison and carceral state become such an inevitable, or necessary, feature in the social imagination of our profession? And why does social work seem to continuously fall back on individual level skill development as the answer for systemic issues? Do we simply lack imagination? Foucault reminds us that wherever there is power, there is resistance. In fact, the sustenance of power, in part, relies on the tension produced through resistance. Resistive ideas, then, are not suppressed but remain marginal, because in comparison to what passes for "truth" or common sense, they often seem illogical and irrational. Indeed, under a rationality of neoliberalism, resistance to the carceral state seems not only illogical, but also untenable.

Although the discourse of risk seems to be firmly entrenched in the contemporary social work lexicon, it should not be treated as infallible or inevitable. Neither should the use of punishment as a means of dealing with social problems. As the articles comprising the counter-discourse in my sample illustrate, it is possible to push beyond dominant narratives toward abolition. Just because what is, is, does not mean it must be. I argue here that the project of social work may benefit from claiming space for imagination: a stance of radical imagination. When we begin to imagine what is possible, even if it appears improbable, we also begin to create the conditions for its existence. In other words, only through radical acts of imagination can the improbable become possible.

The question remains, what does this analysis mean in terms of better understanding and responding to criminalized women? In thinking about how to shift the decontextualized and depoliticized approaches to understanding and working with criminalized women that emerged in my analysis, one place we can look is to education. 
However, as recent research shows, issues related to the criminal justice system are scantly covered in the literature and inadequately addressed in schools of social work (Epperson et al., 2013; Jemal \& Graham, 2017; Wheeler \& McClain, 2015). This has serious implications for the education of future social workers who are quite likely at some point to come into contact with criminalized populations (Wilson, 2010).

With what seems like an ever-increasing emphasis on professionalization and licensure in social work, it's crucial that we retain a focus on the historical and structural processes and discourses that contribute to production and reproduction of the carceral state. It is not enough to simply integrate material related to criminal justice issues in social work education, research, and training; I argue that in order to adequately respond to the "ordinary evil" in which Orlie implicates us we must also engage ethical and political discourses - the forms of thinking and speaking that cannot accommodate neutrality and which shatter certainty.

In her book Getting Lost, Patti Lather (2007) talks about the difference between "lovely knowledge" and "difficult knowledge." She tells us that lovely knowledge comes easy and "reinforces what we think we want from what we find" (p.13). Difficult knowledge, in comparison, works against affirming claims through data and "induces breakdowns in representing experience" (p.13). Throughout this project, lovely knowledge flourished in the data as social work confirmed, over and over again, what it thinks it knows, thereby limiting what can be known. Meanwhile, I found myself buried in difficult knowledge, burning with confusion, lost in paradox; working within and against my own (in)competence. This project forced me to re-think aspects of my 
intellect that I thought I had figured out: gender, social justice, the box I put all "those" social workers in, where I thought this research would lead me and where it did lead me, and ultimately my own identity within the profession. Through this, I have learned to be less strident, and in many ways I am left with more questions than answers. Questions that I suspect, if I am brave enough and strong enough, will pave the road for the difficult knowledge that is to come. It is a humble, yet hopeful position.

The temptation of lovely knowledge is strong, but the intellectual rapture that emerges from the depths of difficult knowledge is the very force of ethical scholarship. It is from the rigor of difficult knowledge that possibilities for change arise. As Lather says, "what one loves when lovely knowledge is lost is the promise of thinking and doing otherwise" (p.13). I believe it is here, in the abandonment of lovely knowledge, that we may begin to reimagine the carceral state. My challenge to social work is this: resist the seductions of the lovely knowledge found in the tools of assessment and prediction and on well-worn paths to funding and tenure. Engage the questions and conundrums found in the places where difficult knowledge dwells. It is here that we might begin to think what hasn't been thought and do what hasn't been done. It is here that we may begin to engage in what Ferguson and Lavalette (2006) call a "social work of resistance." 


\section{References}

Abramovitz, M. (1994). Challenging the myths of welfare reform from a woman's perspective. Social Justice, 1(55), 17-21.

Abramovitz, M. (1997). From the tenement class to the dangerous class to the underclass: Blaming women for social problems. In A.J. Katz \& A. Lurie (Eds.), Critical social welfare issues: Tools for social work and health care professionals (pp. 95-110). Binghamton, NY: The Haworth Press.

Abrams, L., \& Curran, L. (2000). Wayward girls and virtuous women: Social workers and female delinquency in the progressive era. Affilia, 15(1), 49-63.

Agonito, R. (1977). History of ideas on woman: A source book. New York, NY: Perigee Books.

Aguilar, G. D., \& Brown-Standridge, M. (2004). Elderly racial and ethnic groups: A content analysis of mainstream social work journals, 1995-2002. Journal of Baccalaureate Social Work, 10(1), 118-135.

Alexander, M. (2012). The new Jim Crow: Mass incarceration in the age of colorblindness. New York, NY: The New Press.

Allen, S., Flaherty, C., \& Ely, G. (2010). Throwaway moms: Maternal incarceration and the criminalization of female poverty. Affilia, 25(2), 160-172.

Andrews, D. A., \& Dowden, C. (2006). Risk principle of case classification in correctional treatment: A meta-analytic investigation. International Journal of Offender Therapy and Comparative Criminology, 50(1), 88-100. 
Arrigo, B. A. (1997). Transcarceration: Notes on a psychoanalytically-informed theory of social practice in the criminal justice and mental health systems. Crime, Law and Social Change, 27, 31-48.

Badwall, H. K. (2015). Colonial encounters: Racialized social workers negotiating professional scripts of whiteness. Intersectionalities: A Global Journal of Social Work Analysis, Research, Polity, and Practice, 3(1), 1-23.

Bagley, K., \& Merlo, A. V. (1995). Controlling women's bodies. In A.V. Merlo \& J.M. Pollack (Eds.), Women, law, and social control (pp. 135-154). Boston: Allyn and Bacon.

Balfour, G. (2000). Feminist therapy with women in prison: Working under the hegemony of correctionalism. In K. Hannah-Moffat \& M. Shaw (Eds.), An ideal prison (pp.94-102). Black Point, NS: Fernwood Publishing.

Balfour, G. (2006). Introduction: Regulating women and girls. In G. Balfour \& E. Comack (Eds.), Criminalizing women (pp. 154-170). Halifax, NS: Fernwood Publishing.

Balfour, G., \& Comack, E. (2006). Criminalizing women. Halifax, NS: Fernwood Publishing.

Barak, G. (2004). Class, race, and gender in criminology and criminal justice: Ways of seeing difference. Race, Gender \& Class, 11(4), 80-97.

Barretti, M. A. (2015). In search of women of color in the social work journal literature (1998-2007). Affilia, 30(4), 427-446.

Barton, A. (2005). Fragile moralities and dangerous sexualities: Two centuries of semipenal institutionalization for women. Aldershot, UK: Ashgate Publishing. 
Beck, U. (2002). The terrorist threat: World risk society revisited. Theory, Culture \& Society, 19(4), 39-55.

Bhattacharjee, A. (2002). Private fists and public force: Gender, race, and surveillance. In J. Silliman \& A. Bhattacharjee (Eds.), Policing the national body: Sex, race, and criminalization (pp. 1-54). Cambridge, MA: South End Press.

Bonilla-Silva, E. (2014). Racism without racists: Color-blind racism and the persistence of racial inequality in America. Lanham, MD: Rowman \& Littlefield Publishers, Inc.

Bornmann, L., Marx, W., Gasparyan, A. Y., \& Kitas, G. D. (2012). Diversity, value and limitations of the journal impact factor and alternative metrics. Rheumatology International, 32(7), 1861-1867.

Bortner, M. A. (2002). Controlled and excluded: Reproduction and motherhood among poor and imprisoned women. In J. Figueira-McDonough and R.C. Sarri (Eds.), Women at the margins, (pp. 253-266). New York, NY: The Haworth Press.

Bosworth, M. (2000). Confining femininity: A history of gender, power and imprisonment. Theoretical Criminology, 4(3), 265-284.

Bosworth, M. (2007). Identity, citizenship, and punishment. In M. Bosworth \& J. Flavin (Eds.), Race, gender, \& punishment: From colonialism to the War on Terror (pp. 143-148). Piscataway, NJ: Rutgers University Press.

Bosworth, M., \& Carrabine, E. (2001). Reassessing resistance: Race, gender and sexuality in prison. Punishment \& Society, 3(4), 501-515. 
Boyd, S. (2006). Representations of women in the drug trade. In Balfour, G. \& Comack, E. (Eds.), Criminalizing women, 131-151. Halifax, NS: Fernwood Publishing.

Brewer, R. M., \& Heitzeg, N.A. (2008). The racialization of crime and punishment: Criminal justice, color-blind racism, and the political economy of the prison industrial complex. American Behavioral Scientist, 51(5), 625-644.

Burford, E. J., \& Shulman, S. (1992). Of bridles and burnings: The punishment of women. New York, NY: St. Martin's Press.

Burgess-Proctor, A. (2006). Intersections of race, class, gender, and crime: Future directions for feminist criminology. Feminist Criminology, 1(1), 27-47.

Caputo, J.D. (1997). Deconstruction in a nutshell: A conversation with Jacques Derrida. New York, NY: Fordham University Press.

Carlen, P., \& Tombs, J. (2006). Reconfigurations of penality: The ongoing case of the women's imprisonment and reintegration industries. Theoretical Criminology, 10(3), 337-360.

Carlton, B., \& Segrave, M. (2016). Rethinking women's post-release reintegration and 'success'. Australian \& New Zealand Journal of Criminology, 49(2), 281-299.

Carson, E.A. (2018). Prisoners in 2016. Washington, DC: Bureau of Justice Statistics.

Carton, T. (2014). The spirit of motivational interviewing as an apparatus of governmentality: An analysis of reading materials used in the training of substance abuse clinicians. Sociology Mind, 4(02), 192-205.

Cha, T., Kuo, E., \& Marsh, J. C. (2006). Useful knowledge for social work practice. Social Work and Society, 4, 111-121. 
Chandler, C. (2003). Death and dying in America: The prison industrial complex's impact on women's health. Berkeley Women's Law Journal, 18, 40-60.

Chase, S. E. (2005). Narrative inquiry: Multiple lenses, approaches, voices. In N. K. Denzin \& Y. S. Lincoln (Eds.), The Sage handbook of qualitative research (pp. 651-680). Thousand Oaks, CA: Sage Publications.

Chesney-Lind, M. (1997). Patriarchy, prisons, and jails: A critical look at trends in women's incarceration. The Prison Journal, 71(1), 51-67.

Chesney-Lind, M. (2002). Imprisoning women: The unintended victims of mass imprisonment. In M. Mauer \& M. Chesney-Lind (Eds.), Invisible punishment: The collateral consequences of mass imprisonment (pp.79-94). New York, NY: The New York Press.

Chesney-Lind, M. (2006). Patriarchy, crime and justice: Feminist criminology in the era of backlash. Feminist Criminology, 1(6), 6-26.

Chouliaraki, L., \& Fairclough, N. (1999). Discourse in late modernity: Rethinking Critical Discourse Analysis. Edinburgh, UK: Edinburgh University Press.

Chowdhry, G., \& Beeman, M. (2007). Situating colonialism, race, and punishment. In M. Bosworth \& J. Flavin (Eds.) Race, gender, and punishment: From colonialism to the War on Terror (pp. 13-31). Piscataway, NJ: Rutgers University Press.

Cohen, S. (1985). Visions of social control: Crime, punishment and classification (pp. 127-143). Cambridge, MA: Polity Press.

Collins, P. H. (1990). Black feminist thought: Knowledge, power and the politics of empowerment. New York, NY: Routledge. 
Colvin, M. (1997). Penitentiaries, reformatories, and chain gangs: Social theory and the history of punishment in nineteenth-century America. New York, NY: St. Martin's Press.

Comack, E. (2006). Feminist engagement with criminology. In G. Balfour \& E. Comack (Eds.), Criminalizing women (pp. 22-54). Halifax, NS: Fernwood Publishing. Comack, E. (2014). Part II: Introduction. In G. Balfour \& E. Comack (Eds.), Criminalizing women (pp. 48-72). Halifax, NS: Fernwood Publishing.

Comack, E. \& Balfour, G. (2004). The power to criminalize: Violence, inequality and the law. Halifax, NS: Fernwood Publishing.

Cousins, L. H. (2013). Deservingness, children in poverty, and collective well being. Children and Youth Services Review, 35(8), 1252-1259.

Crenshaw, K. (1989). Demarginalizing the intersection of race and sex: A black feminist critique of antidiscrimination doctrine, feminist theory and antiracist politics. University of Chicago Legal Forum 1(8), 139-167.

Crenshaw, K. (1991). Mapping the margins: Intersectionality, identity politics, and violence against women of color. Stanford Law Review, 43(6),1241-1299.

Cruikshank, B. (1993). The will to empower: Technologies of citizenship and the war on poverty. Socialist Review, 23(4), 29-55.

Cruikshank, B. (1996). Revolutions within: Self-government and self-esteem. In A. Barry, T. Osborne, \& N. Rose, Foucault and political reason: Liberalism, neoliberalism and rationalities of government (pp. 231-252). Chicago: University of Chicago Press. 
Daley, A. (2010). Reflections on reflexivity and critical reflection as critical research practices. Affilia, 25(1), 68-82.

Daly, K. (1997). Different ways of conceptualizing sex/gender in feminist theory and their implications for criminology. Theoretical Criminology, 1(1), 25-51.

Danner, M. J. E. (1996). Gender inequality and criminalization: A socialist feminist perspective on the legal social control of women. In M. D. Schwartz \& D. Milovanovic (Eds.), Race, gender, and class in criminology: The intersections (pp. 29-48). New York, NY: Garland Publishing, Inc.

Davis, A. Y., \& Shaylor, C. (2001). Race, gender, and the prison industrial complex: California and beyond. Meridians, 2(1), 1-25.

Davis, J., \& Faith, K. (1987). Women and state: Changing models of social control. In J. Lowman, R. J. Menzies, \& T. S. Palys (Eds.), Transcarceration: Essays in the sociology of social control (pp. 170-187). Brookfield, VT: Grower Publishing Company.

Davis, P. M. (2008). Eigenfactor: Does the principle of repeated improvement result in better estimates than raw citation counts? Journal of the Association for Information Science and Technology, 59(13), 2186-2188.

Denzin, N. K. (2002). Social work in the seventh moment. Qualitative Social Work, 1(1), $25-38$.

Denzin, N. K., \& Lincoln, Y. S. (2005). Introduction. In N. K. Denzin \& Y. S. Lincoln (Eds.), Handbook of qualitative research (3rd ed.) (pp. 1-32). Thousand Oaks, CA: Sage Publications.

Derrida, J. (1981). Dissemination. London: Athlone Press. 
Donohue, E., \& Moore, D. (2009). When is an offender not an offender?: Power, the client and shifting penal subjectivities. Punishment \& Society, 11(3), 319-336.

Drake, E. K., Aos, S., \& Miller, M. G. (2009). Evidence-based public policy options to reduce crime and criminal justice costs: Implications in Washington state. Victims and Offenders, 4(2), 170-196.

Epperson, M. W., Roberts, L. E., Ivanoff, A., Tripodi, S. J., \& Gilmer, C. N. (2013). To what extent is criminal justice content specifically addressed in MSW programs? Journal of Social Work Education, 49(1), 96-107.

Fadyl, J. K., Nicholls, D. A., \& McPherson, K. M. (2012). Interrogating discourse: The application of Foucault's methodological discussion to specific inquiry. Health 17(5), 478-494.

Fairclough, N. (2009) A dialectical-relational approach to Critical Discourse Analysis in social research. In R. Wodak \& M. Meyer (Eds.), Methods for Critical Discourse Analysis (pp. 162-186). Thousand Oaks, CA: Sage Publications.

Fairclough, N., Mulderrig, J., \& Wodak, R. (2011). Critical Discourse Analysis. In T. A. van Dijk (Ed.), Discourse studies: A multidisciplinary introduction (pp. 357-378). Thousand Oaks, CA: Sage Publications.

Fairclough, N., Mulderrig, J., \& Wodak, R. (2013). Critical Discourse Analysis. In R. Wodak (Ed.), Critical Discourse Analysis, volume I: Concepts, history, and theory. Thousand Oaks, CA: Sage Publications.

Faith, K. (1993). Unruly women: The politics of confinement and resistance. Vancouver, BC: Press Gang Publisher. 
Feeley, M. M., \& Simon, J. (1992). The new penology: Notes on the emerging strategy of corrections and its implications. Criminology, 30(4), 449-474.

Ferguson, H. (1997). Protecting children in new times: Child protection and the risk society. Child \& Family Social Work, 2(4), 221-234.

Ferguson, I., \& Lavalette, M. (2006). Globalization and global justice: Towards a social work of resistance. International Social Work, 49(3), 309-318.

Ferraro, K. J. (2008). Invisible or pathologized? Racial statistics and violence against women of color. Critical Sociology, 34(2), 193-211.

Fine, M., \& Weis, L. (2000). Disappearing acts: The state and violence against women in the twentieth century. Signs, 25(4), 1139-1146.

Finlay, L. (2002). “Outing” the researcher: The provenance, process, and practice of reflexivity. Qualitative Health Research, 12(4), 531.

Fisher, T., \& Reese, E. (2010). The punitive turn in social politics: Critical race feminist reflections on the USA, Great Britain, and beyond. Critical Sociology, 8(16), 114.

Flavin, J. (2007). Slavery's legacy in contemporary attempts to regulate black women's reproduction. In M. Bosworth \& J. Flavin (Eds.), Race, gender, \& punishment: From colonialism to the War on Terror (pp. 95-116). Piscataway, NY: Rutgers University Press.

Fonow, M. M., \& Cook, J. A. (2005). Feminist methodology: New applications in the academy and public policy. Signs, 30, 2211-2236.

Foucault, M. (1972). The order of things: An archaeology of the human sciences. New York, NY: Random House. 
Foucault, M. (1991). Governmentality. In G. Burchell, C. Gordon, \& P. Miller (Eds.), The Foucault effect: Studies in governmentality (pp. 87-104). Chicago: University of Chicago Press.

Foucault, M. (1995). Discipline and punish ( $2^{\text {nd }}$ ed.). New York: Random House.

Franklin, C. (2008). Women offenders, disparate treatment, and criminal justice: A theoretical, historical, and contemporary overview. Criminal Justice Studies, 21(4), 341-360.

Freedman, E. B. (1979). Separatism as strategy: Female institution building and American feminism, 1870-1930. Feminist Studies, 5(3), 512-529.

Freedman, E. B. (1981). Their sisters' keepers: Women's prison reform in America, 1830-1930. Ann Arbor, MI: University of Michigan Press.

Freudenberg, N. (2001). Jails, prisons, and the health of urban populations: a review of the impact of the correctional system on community health. Journal of Urban Health, 78(2), 214-235.

Friedman, L. M. (1993). Crime and punishment in American history. New York, NY: Basic Books.

Garland, D. (2004). Beyond the culture of control. Critical Review of International Social and Political Philosophy, 7(2), 160-189.

Garrett, M. (2016). Questioning tales of 'ordinary magic': 'Resilience' and neo-liberal reasoning. British Journal of Social Work, 46(7), 1909-1925.

Ghenie, K., \& Wellenstein, C. (2009). The well-being of children and the question of Attachment. In L. M. Nybell, J. J. Shook, \& J. L. Finn (Eds.), Childhood, youth, and social work in transformation: Implications for policy and practice (pp. 145- 
168). New York, NY: Columbia University Press.

Giddens, A. (1990). The consequences of modernity. Palo Alto, CA: Stanford University Press.

Gilgun, J. F., \& Abrams, L. S. (2002). The nature and usefulness of qualitative social work research. Qualitative Social Work, 1(1), 39-55.

Gill, M. M. (2008). Correcting course: Lessons from the 1970 repeal of mandatory minimums. Federal Sentencing Reporter, 21(1), 55-67.

Golembeski, C., \& Fullilove, R. (2005). Criminal (in)justice in the city and its associated health consequences. American Journal of Public Health, 95(10), 1701-1707.

Goodkind, S., \& Miller, D. L. (2006). A widening of the net of social control? Journal of Progressive Human Services, 17(1), 45-70.

Gramsci, A. (1971). Selections from the prison notebooks. London: Lawrence and Wishart Publishing.

Gray, M., \& McDonald, C. (2006). Pursuing good practice? The limits of evidence-based practice. Journal of Social Work, 6(1), 7-20.

Green, D. (2007). Risk and social work practice. Australian Social Work, 60(4), 395-409.

Greene, J. A. (2004). Crime trends and incarceration rates in Oregon. Brooklyn, NY. Retrieved July 25, 2019, from https://static.prisonpolicy.org/scans/justicestrategies/Oregon_Crime_Reduction_R eport_June_2004.pdf

Gringeri, C. E., Wahab, S., \& Anderson-Nathe, B. (2010). What makes it feminist?: Mapping the landscape of feminist social work research. Affilia, 25, 390-405. 
Guba, E., \& Lincoln, Y. (2005). Paradigmatic controversies, contradictions and emerging confluences. In N. K. Denzin \& Y. S. Lincoln (Eds.), The Sage handbook of qualitative research (pp. 191-216). Thousand Oaks, CA: Sage Publications.

Gutierrez, L. M., Parsons, R. J., \& Cox, E. O. (1998). Empowerment in social work practice: A sourcebook. Pacific Grove, CA: Brooks-Cole Publishing.

Hall, S. (1997). Introduction. In S. Hall (Ed.), Representation: Cultural representations and signifying practices (pp. 1-12). Thousand Oaks, CA: Sage Publications.

Hannah-Moffat, K. (2000). Reforming the prison: Rethinking our ideals. In K. HannahMoffat \& M. Shaw (Eds.), An ideal prison (pp. 30-40). Black Point, NS: Fernwood Publishing.

Hannah-Moffat, K. (2001). Punishment in disguise: Penal governance and federal imprisonment of women in Canada. Toronto, ON: University of Toronto Press.

Hannah-Moffat, K. (2004). Losing ground: Gendered knowledges, parole risk, and responsibility. Social Politics 11(3): 363-85.

Hannah-Moffat, K. (2005). Criminogenic needs and the transformative risk subject: Hybridizations of risk/need in penality. Punishment \& Society, 7(1), 29-51.

Hannah-Moffat, K. (2006). Pandora's box: Risk/need and gender responsive corrections. Criminology \& Public Policy, 5(1), 183-192.

Hannah-Moffat, K. (2010). Sacrosanct or flawed: Risk, accountability and genderresponsive penal politics. Current Issues in Criminal Justice, 22(2), 193-215. Hardy, K. (2013). Searching for the spirit: A content analysis of the Black church in mainstream social work journals. Journal of Religion \& Spirituality in Social Work: Social Thought, 32(4), 373-396. 
Harlow, E. (2003). New managerialism, social service departments and social work practice today. Practice: Social Work in Action, 15(2), 29-44.

Hatton, D. C., Kleffel, D., \& Fisher, A. A. (2006). Prisoners' perspectives of health problems and healthcare in a U.S. women's jail. Women \& Health, 44(1), 119136.

Hedderman, C. (2010). Government policy on women offenders: Labour's legacy and the coalition's challenge. Punishment \& Society, 12(4), 485-500.

Hekman, S. (1999). The future of differences: Truth and method in feminist theory. Malden, MA: Blackwell Publishers, Inc.

Hook, D. (2001). The 'disorders of discourse.' Theoria, 48(97), 41-68.

Huckin, T. (1995). Critical Discourse Analysis. The Journal of TESOL, 2(3), 95-112.

Huckin, T. (2002). Textual silence and the discourse of homelessness. Discourse \& Society, 13(3), 347-372.

Humble, M. N., Bride, B. E., Kolomer, S. R., \& Reeves, P. M. (2012). Evolution of a virus: The framing of HIV/AIDS in social work journals. Social Work, 57(4), $371-376$.

Jacobsen, C. (2008). Creative politics and women's criminalization in the United States. Signs: Journal of Women in Culture and Society, 33(2), 462-470.

Jäger, S., \& Maier, F. (2009). Theoretical and methodological aspects of Foucauldian critical discourse and dispotive analysis. In R. Wodak \& M. Meyer (Eds.), Methods for Critical Discourse Analysis (pp. 34-61). Thousand Oaks, CA: Sage Publications. 
Janks, H. (1997). Critical Discourse Analysis as a research tool. Discourse: Studies in the Cultural Politics of Education, 18(3), 329-342.

Jefferson Smith, C., \& Young, D. S. (2003). The multiple impacts of TANF, ASFA, and mandatory drug sentencing for families affected by maternal incarceration. Children and Youth Services Review, 25(7), 535-552.

Jeffery, D. (2005). 'What good is anti-racist social work if you can't master it'?: Exploring a paradox in anti-racist social work education. Race Ethnicity and Education, 8(4), 409-425.

Jemal, A., \& Graham, W. K. (2017). Criminal injustice competency: A missing component of social work education to end mass incarceration. Intersections in Practice, 11(1), 9-11.

JFA Institute. (2007). Unlocking America: Why and how to reduce America's prison population. Washington, DC: JFA Institute. Retrieved July 25, 2019, from http://www.jfa-associates.com/publications/srs/UnlockingAmerica.pdf

Johnson, W. W. (1996). Transcarceration and social control policy: The 1980s and beyond. Crime \& Delinquency, 42(1), 114-126.

Johnston, L. B., \& Stewart, C. (2013). Still among the missing? A content analysis of LGBT articles in social work journals, 1998-2009. Journal of Gay \& Lesbian Social Services, 25(2), 232-243.

Johnston, N. (2009). Evolving function: Early use of imprisonment as punishment. The Prison Journal, 89(1), 10-34.

Juhila, K., Pösö, T., Hall, C., \& Parton, N. (2003). Constructing clienthood in social work and human services. New York, NY: Jessica Kingsley Publishers. 
Kajstura, A. (2018). Women's mass incarceration: The whole pie 2018. Retrieved July 25, 2019, from https://www.prisonpolicy.org/reports/pie2018women.html

Kemshall, H. (2002). Risk, social policy and welfare. Philadelphia: Open University Press.

Kendall, K. (2000). Psy-ence fiction: Inventing the mentally-disordered female prisoner. In K. Hannah-Moffat \& M. Shaw (Eds.), An ideal prison (pp.82-93). Black Point, NS: Fernwood Publishing.

Kendall, K. (2004). Dangerous thinking: A critical history of correctional cognitive behaviouralism. In G. Mair (Ed.), What matters in probation (pp.53-89). Cullompton, Devon: Willan Publishing.

Kurmis, A. P. (2003). Understanding the limitations of the journal impact factor. Journal of Bone and Joint Surgery, 85(12), 2449-2454.

Laberge, D. (1991). Women's criminality, criminal women, criminalized women?: Questions in and for a feminist perspective. The Journal of Human Justice, 2(2), $37-56$.

Lal, J. (1996). Situating locations: The politics of self, identity and "other" in living and writing the text. In D. Wolf (Ed.), Feminist dilemmas in fieldwork (pp. 185-214). Boulder, CO: Westview Press.

Larner, W. (2000). Neo-liberalism: Policy, ideology, governmentality. Studies in Political Economy, 63(Autumn), 5-25.

Latessa, E. J., \& Lowenkamp, C. (2005). What are criminogenic needs and why are they important. For the Record, $4^{\text {th }}$ Quarter, 15-16. 
Lather, P. (2003). Applied Derrida: (Mis)reading the work of mourning in educational research. Educational Philosophy and Theory (35)3, 257-267.

Lather, P. (2007). Getting lost: Feminist efforts toward a double(d) science. Albany, NY: SUNY Press.

Law, V. (2012). Resistance behind bars: The struggles of incarcerated women. Oakland, CA: PM Press.

Lindsey, D., \& Kirk, S. A. (1992). The role of social work journals in the development of a knowledge base for the profession. Social Service Review, 66(2), 295-310.

Lipsey, M. W., \& Cullen, F. T. (2007). The effectiveness of correctional rehabilitation: A review of systematic reviews. Annual Review of Law and Social Science, 3, 297320.

Lowman, J., \& Menzies, R. J. (1986). Out of the fiscal shadow: Carceral trends in Canada and the United States. Crime and Social Justice, 26, 95-115.

Lowman, J., Menzies, R. J., \& Palys, T. S. (1987). Introduction: Transcarceration and the modern state of penality. In J. Lowman, R.J. Menzies, \& T.S. Palys (Eds.), Transcarceration: Essays in the sociology of social control (pp. 1-15).

Brookfield, VT: Grower Publishing Company.

Lupton, D. (1999). Risk. New York, NY: Routledge.

Magee, C. G., Hult, J. R., Turalba, R., \& McMillan, S. (2005). Preventive care for women in prison: A qualitative community health assessment of the Papanicolaou test and follow-up treatment at a California women's state prison. American Journal of Public Health, 95(10), 1712-1717. 
Maidment, M. (2002). Toward a "woman-centered" approach to community-based corrections. Women \& Criminal Justice, 13(4), 47-68.

Maidment. M. (2006). Doing time on the outside: Deconstructing the benevolent community. Toronto, ON: University of Toronto Press.

Maidment, M. (2007). "We're not all that criminal": Getting beyond the pathologizing and individualizing of women's crime. Women \& Therapy, 29(3), 35-56.

Mallory, J. L. (2006). Globalization, prisons, and the philosophy of punishment. Women's Studies, 35, 529-543.

Margolin, L. (1997). Under the cover of kindness: The invention of social work. Charlottesville, VA: University of Virginia Press.

Marsh, J. C., \& Reed, M. (2015). Social work science and knowledge utilization. Research on Social Work Practice, 26(7), 742-750.

Mascharka, C. (2000). Mandatory minimum sentences: Exemplifying the law of unintended consequences. Florida State University Law Review, 28, 935.

Mauer, M. (2011). Sentencing reform amid mass incarcerations: Guarded optimism. Criminal Justice, 26(1).

Mauer, M., \& King, R. S. (2007). A 25-Year quagmire: The war on drugs and its impact on American society. Retrieved July 25, 2019, from https://www.sentencingproject.org/publications/a-25-year-quagmire-the-war-ondrugs-and-its-impact-on-american-society/

Mayr, A., \& Machin, D. (2012). The language of crime and deviance: An introduction to critical linguistic analysis in media and popular culture. New York: Bloomsbury Publishing. 
McCorkel, J. (2004). Criminally dependent? Gender, punishment, and the rhetoric of welfare reform. Social Politics: International Studies in Gender, State \& Society, $11(3), 386-410$.

McCorkel, J. (2013). Breaking women: Gender, race, and the new politics of imprisonment. New York: New York University Press.

McCorkel, J. (2017). The second coming: Gender, race, and the privatization of carceral drug treatment. Contemporary Drug Problems, 44(4), 286-300.

McKim, A. (2008). "Getting gut-level”: Punishment, gender, and therapeutic governance. Gender \& Society, 22(3), 303-323.

Mehrotra, G. (2010). Toward a continuum of intersectionality theorizing for feminist social work scholarship. Affilia, 25(4), 417-430.

Mertens, D. M., \& Ginsberg, P. E. (2008). Deep in ethical waters. Qualitative Social Work, 7(4), 484.

Meyer, M., \& Wodak, R. (2009). Critical Discourse Analysis: History, agenda, theory and methodology. In R. Wodak \& M. Meyer (Eds.), Methods for Critical Discourse Analysis (pp. 1-34). Thousand Oaks, CA: Sage Publications.

Moore, D. (2011). The benevolent watch: Therapeutic surveillance in drug treatment court. Theoretical Criminology, 15(3), 255-268.

Moosa-Mitha, M., \& Ross-Sheriff, F. (2010). Transnational social work and lessons learned from transnational feminism. Affilia, 25, 105-109.

Myers, G. E. (1995). A municipal mother: Portland's Lola Greene Baldwin, America's first policewoman. Corvallis, OR: Oregon State University Press. National Association of Social Workers. (2009). Social work speaks, $8^{\text {th }}$ edition: 
National Association of Social Workers policy statements, 2009-2012. Cary, NC: NASW Press.

Neve, L., \& Pate, K. (2005). Challenging the criminalization of women who resist. In J. Sudbury (Ed.), Global lockdown: Race, gender, and the prison industrial complex (pp. 19-33). New York: Routledge.

Nybell, L. M., Shook, J. J., \& Finn, J. L. (Eds.). (2009). Childhood, youth, and social work in transformation: Implications for policy and practice. New York, NY: Columbia University Press.

Ogle, R. S., \& Batton, C. (2009). Revisiting patriarchy: Its conceptualization and operationalization in criminology. Critical Criminology, 17, 159-182.

Olesen, V. (2005). Early millennial feminist qualitative research: Challenges and contours. In N. K. Denzin \& Y. S. Lincoln (Eds.), Handbook of qualitative research ( $3^{\text {rd }}$ ed.) (pp. 235-278). Thousand Oaks, CA: Sage Publications. O’Malley, P. (1996). Risk and responsibility. In A. Barry, T. Osborne, \& N. Rose, Foucault and political reason: Liberalism, neo-liberalism and rationalities of government (pp. 189-207). Chicago: University of Chicago Press.

Oregon Criminal Justice Commission. (2011). Longitudinal study of the application of Measure 11 and mandatory minimums in Oregon. Salem, OR: Oregon Criminal Justice Commission.

Oregon Legislative Fiscal Office. (2011). Budget information report: Correctional spending trends. Salem, OR: Oregon Legislative Fiscal Office.

Orlie, M. (1997). Living ethically, acting politically. Ithaca, NY: Cornell University Press. 
Pallone, N. J., \& Hennessy, J. J. (2003). To punish or to treat: Substance abuse within the context of oscillating attitudes toward correctional rehabilitation. Journal of Offender Rehabilitation, 37(3-4), 1-25.

Park, Y., \& Kemp, S. P. (2006). "Little alien colonies": Representations of immigrants and their neighborhoods in social work discourse, 1875-1924. Social Service Review, 80(4), 705-734.

Parton, N. (1998). Risk, advanced liberalism and child welfare: The need to rediscover uncertainty and ambiguity. British Journal of Social Work, 28(1), 5-27.

Parton, N. (2008). Changes in the form of knowledge in social work: From the 'social' to the 'informational'?. British Journal of Social Work, 38(2), 253-269.

Pease, B. (2002). Rethinking empowerment: A postmodern reappraisal for emancipatory practice. British Journal of Social Work, 32(2), 135-147.

Pew Center on the States. (2009). One in 31: The long reach of American corrections. Washington, DC: The Pew Charitable Trusts.

Pewewardy, N., \& Severson, M. (2003). A threat to liberty: White privilege and disproportionate minority incarceration. Journal of Progressive Human Services, 14(2), 53-74.

Phoenix, A., \& Pattynama, P. (2006). Intersectionality. European Journal of Women's Studies, 3(13), 187-192.

Pollack, S. (2004). Anti-oppressive social work practice with women in prison: Discursive reconstructions and alternative practices. British Journal of Social Work, 34(5), 693-707.

Pollack, S. (2005). Taming the shrew: Regulating prisoners through women-centered 
mental health programming. Critical Criminology, 13(1), 71-87.

Pollack, S. (2006). Therapeutic programming as a regulatory practice in women's prisons. In G. Balfour \& E. Comack (Eds.), Criminalizing Women (pp. 236-249). Halifax, NS: Fernwood Publishing.

Pollack, S. (2007). "I'm Just Not Good in Relationships": Victimization discourses and the gendered regulation of criminalized women. Feminist Criminology, 2(2), 158174.

Pollack, S. (2009). "You can't have it both ways": Punishment and treatment of imprisoned women. Journal of Progressive Human Services, 20(2), 112-128.

Pollack, S. (2010). Labeling clients 'risky': Social work and the neo-liberal welfare state. British Journal of Social Work, 40(4), 1263-1278.

Pollack, S. (2013). An imprisoning gaze: Practices of gendered, racialized and epistemic violence. International Review of Victimology, 19(1), 103-114.

Pollack, S., and Rossiter, A. (2010). Neoliberalism and the entrepreneurial subject: Implications for feminism and social work. Canadian Social Work Review, 27(2), pp. 155-69.

Pollock, J. M. (1995). Gender, justice, and social control: An historical perspective. In A. V. Merlo \& J. M. Pollack (Eds.), Women, law, and social control (pp. 1-24). Boston, MA: Allyn and Bacon.

Potts, K., \& Brown, L. (2005). Becoming an anti-oppressive researcher. In L. A. Brown \& S. Strega (Eds.), Research as resistance: Critical, Indigenous and antioppressive approaches (pp. 255-286). Toronto, ON: Canadian Scholars' Press. 
Praxis Center. (2018, April 17). Angela Davis and Michelle Alexander: End mass incarceration [Video file]. Retrieved from https://www.kzoo.edu/praxis/endmass-incarceration/

Qvortrup, J. (2005). Varieties of childhood. In J. Qvortrup (Ed.), Studies in modern childhood: Society, agency, culture (pp. 1-20). London: Palgrave MacMilllian.

Rafter, N. H. (1983). Prisons for women, 1790-1980. Crime and Justice, 5, 129-181. Rafter, N. (2017). Partial justice: Women, prisons and social control. New York, NY: Routledge.

Reich, J. (2005). Fixing families: Parents, power, and the child welfare system. New York, NY: Routledge.

Reisch, M. (2013). What is the future of social work?. Critical and Radical Social Work, $1(1), 67-85$.

Richie, B. (1996). Compelled to crime: The gender entrapment of black battered women. New York, NY: Routledge.

Richie, B. (2001). Challenges incarcerated women face as they return to their communities: Findings from life history interviews. Crime \& Delinquency, 47(3), $368-389$.

Rivest, M. P., \& Moreau, N. (2015). Between emancipatory practice and disciplinary interventions: Empowerment and contemporary social normativity. British Journal of Social Work, 45(6), 1855-1870.

Roberts, A. R., \& Springer, D. W. (2007). Social work in juvenile and criminal justice settings. Springfield, IL: Charles C. Thomas Publisher. 
Rogowski, S. (2011). Managers, managerialism and social work with children and families: The deformation of a profession? Practice, 23(3), 157-167.

Rose, N. (1998). Living dangerously: Risk-thinking and risk management in mental health care. Mental Health Care, 1(8), 263-266.

Rose, N. (1998b). Inventing our selves: Psychology, power, and personhood. Cambridge, UK: Cambridge University Press.

Rose, N. (2000). Government and control. British Journal of Criminology, 40, 321-339.

Rossiter, A. (2000). The professional is political: An interpretation of the problem of the past in solution-focused therapy. American Journal of Orthopsychiatry, 70(2), $150-161$.

Rossiter, A. (2001). Innocence lost and suspicion found: do we educate for or against social work? Critical Social Work, 2(1), 1-6.

Rowe, A. (2015). 'Tactics', agency and power in women's prisons. British Journal of Criminology, 56(2), 332-349.

Rubin, G. (1986). Thinking sex: Notes for a radical theory of the politics of sexuality. In A. Henry, M. Barale, \& D. Halpern (Eds.), The lesbian and gay studies reader (pp. 3-44). New York, NY: Routledge.

Sanchez, L. E. (2007). The carceral contract: From domestic to global governance. In M. Bosworth \& J. Flavin (Eds.), Race, gender, and punishment: From colonialism to the War on Terror (pp.167-183). Piscataway, NJ: Rutgers University Press.

Sawyer, W., \& Wagner, P. (2019). Mass incarceration: The whole pie 2019. Retrieved July 25, 2019, from https://www.prisonpolicy.org/reports/pie2019.html 
Schneider, C. J. (2003). Integrating critical race theory and postmodernism implications of race, class, and gender. Critical Criminology, 12, 87-103.

Seale, C. (2002). Quality issues in qualitative inquiry. Qualitative Social Work, 1(1), 97.

Sentencing Project (2018). Fact sheet: Incarcerated women and girls. Retrieved July 25, 2019, from https://www.sentencingproject.org/publications/incarcerated-womenand-girls/

Sentencing Project (2018b). Fact sheet: Trends in U.S. corrections. Retrieved July 25, 2019, from https://www.sentencingproject.org/publications/trends-in-u-scorrections/

Sered, S., \& Norton-Hawk, M. (2008). Disrupted lives, fragmented care: Illness experiences of criminalized women. Women \& Health, 48(1), 43-61.

Shantz, L., Kilty, J. M., \& Frigon, S. (2009). Echoes of imprisonment: Women's experiences of "successful (re) integration." Canadian Journal of Law and Society, 24(01), 85-106.

Shaw, M., \& Hannah-Moffat, K. (2004). How cognitive skills forgot about gender and diversity. In G. Mair (Ed.), What matters in probation (pp. 90-121). Cullompton, Devon: Willan Publishing.

Sheldon, R. G. (2008). Controlling the dangerous classes: A history of criminal justice in America. Boston: Pearson.

Sherr, S. A. (1999). Scenes from the political playground: An analysis of the symbolic use of children in presidential campaign advertising. Political Communication, 16(1), 45-59.

Shields, S. (2008). Gender: An intersectionality perspective. Sex Roles, 59, 301-311. 
Small, D. (2001). The war on drugs is a war on racial justice. Social Research, 68(3), 896-903.

Smoyer, A. B. (2015). Feeding relationships: Foodways and social networks in a women's prison. Affilia, 30(1), 26-39.

Sokoloff, N. (2005). Women prisoners at the dawn of the $21^{\text {st }}$ century. Women and Criminal Justice, 4(1), 127-137.

Solinger, R., Johnson, P.C., Raimon, M.L., Reynolds, T., Tapia, R.C. (Eds.). (2010). Interrupted life: Experiences of incarcerated women in the United States. Berkeley, CA: University of California Press.

Sowards, K. A., O'Boyle, K., \& Weissman, M. (2006). Inspiring hope, envisioning alternatives: The importance of peer role models in a mandated treatment program for women. Journal of Social Work Practice in the Addictions, 6(4), 55-70.

Spjeldnes, S., \& Goodkind, S. (2009). Gender differences and offender reentry: A review of the literature. Journal of Offender Rehabilitation, 48, 314-335.

Staller, K. M. (2013). Epistemological boot camp: The politics of science and what every qualitative researcher needs to know to survive in the academy. Qualitative Social Work, 12(4), 395-413.

Staples, W. G., \& Decker, S. K. (2008). Technologies of the body, technologies of the self: House arrest as neo-liberal governance. Sociology of Crime, Law and Deviance, 10, 131-149.

Steedman, C. (1986). Landscape for a good woman: The story of two lives. Piscataway, NJ: Rutgers University Press. 
Stengel, C. (2014). The risk of being 'too honest': Drug use, stigma and pregnancy. Health, Risk \& Society, 16(1), 36-50.

Strega, S. (2005). The view from the post-structural margins. In L. A. Brown \& S. Strega (Eds.), Research as resistance: Critical, Indigenous and anti-oppressive approaches (pp. 199-236). Canadian Scholars' Press.

Sudbury, J. (2000). Transatlantic visions: Resisting the globalization of mass incarceration. Social Justice, 27(3), 133-149.

Sudbury, J. (2002). Celling black bodies: Black women in the global prison industrial complex. Feminist Review, 70, 57-74.

Taylor, J. (2002). Invisible, underserved, and diverse: The health of women in prison. International Journal of Global Health, 2(1), 28-42.

Taylor, S. (2016). Moving beyond the other: A critique of the reductionist drugs discourse. Cultuur and Criminaliteit, 6(1), 100-118.

Tonry, M. (2006). Criminology, mandatory minimums, and public policy. Criminology \& Public Policy, 5(1), 45-56.

Tonry, M. (2007). Crime does not cause punishment: The impact of sentencing policy on levels of crime. SA Crime Quarterly, 20, 13-20.

Toscano, V. (2005). Misguided retribution: Criminalization of pregnant women who take drugs. Social and Legal Studies, 14, 359-386.

Travis, J. (2002). Invisible punishment: An instrument of social exclusion. In M. Mauer \& M. Chesney-Lind (Eds.), Invisible punishment: The collateral consequences of mass imprisonment (pp.15-36). New York, NY: The New York Press. 
Tripodi, S. J., Bledsoe, S. E., Kim, J. S., \& Bender, K. (2011). Effects of correctionalbased programs for female inmates: A systematic review. Research on Social Work Practice, 21(1), 15-31.

Tsang, A. K. T. (2001). Representation of ethnic identity in North American social work literature: A dossier of the Chinese people. Social Work, 46(3), 229-243.

Van Dijk, T. A. (2001). Critical Discourse Analysis. In D. Schiffrin, D. Tannen, \& H. E. Hamilton (Eds.), The handbook of discourse analysis (pp. 352-371). Malden, MA: Blackwell Publishing.

Van Dijk, T. A. (2009). Critical discourse studies: A sociocognitive approach. In R. Wodak \& M. Meyer (Eds.), Methods for Critical Discourse Analysis (pp. 62-86). Thousand Oaks, CA: Sage Publications.

Vincent, B. S., \& Hofer, P. J. (1994). The consequences of mandatory minimum prison terms: A summary of recent findings. Federal Sentencing Report, 7(1), 33-38.

Wahab, S. (2002). "For their own good?": Sex work, social control and social workers, a historical perspective. Journal of Sociology and Social Welfare, 29(4), 39-57.

Warner, S. (2001). Disrupting identity through visible therapy: A feminist poststructuralist approach to working with women who have experienced child sexual abuse. Feminist Review, 68(1), 115-139.

Webb, S. A. (2001). Some considerations on the validity of evidence-based practice in social work. British Journal of Social Work, 31(1), 57-79.

Webb, S. A. (2003). Technologies of care (pp. 223-38). Philadelphia, PA: Jessica Kingsley Publishers. 
Webb, S. A. (2006). Social work in a risk society: Social and political perspectives. New York, NY: Palgrave MacMillan.

Weedon, C. (1997). Feminist practice \& poststructuralist theory. Malden, MA: Blackwell Publishing.

Wheeler, D. P., \& McClain, A. (2015). Social work speaks, $10^{\text {th }}$ edition: National Association of Social Workers policy statement, 2015-2017. Cary, NC: NASW Press.

Weiler, H. N. (2006). Challenging the orthodoxies of knowledge: Epistemological, structural, and political implications for higher education. In G. Neave (Ed.), Knowledge, power and dissent: Critical perspectives on higher education and research in knowledge society (pp. 61-87). Paris: UNESCO Publishing.

Williams, N. (2007). Prison health and the health of the public: The ties that bind. Journal of Correctional Health, 13(2), 80-92.

Wilson, M. (2010). Criminal justice social work in the United States: Adapting to new challenges. Washington, DC: NASW Center for Workforce Studies.

Winker, G., \& Degele, N. (2011). Intersectionality as multi-level analysis: Dealing with social inequality. European Journal of Women's Studies, 18(1), 51-66.

Wodak, R. (2013). Critical Discourse Analysis: Challenges and perspectives. In R. Wodak (Ed.) Critical Discourse Analysis. Volume I: Concepts, History, and Theory (pp. 1-22). Thousand Oaks, CA: Sage Publications.

Wodak, R., \& Meyer, M. (2009). Critical Discourse Analysis: History, agenda, theory, and methodology. In R. Wodak \& M. Meyer (Eds.), Methods for Critical Discourse Analysis (pp. 1-33). Thousand Oaks, CA: Sage Publications. 
Wood, L. A., \& Kroger, R. O. (2000). Doing discourse analysis: Methods for studying action in talk and text. Thousand Oaks, CA: Sage Publications.

Young, I. M. (1994). Punishment, treatment, empowerment: Three approaches to policy for pregnant addicts. Feminist Studies, 20(1), 33.

Young, V., \& Spencer, Z. (2007). Multiple jeopardy: The impact of race, gender, and slavery on the punishment of women in antebellum America. In M. Bosworth \& J. Flavin (Eds.), Race, gender, and punishment: From colonialism to the War on Terror (pp. 13-31). Piscataway, NJ: Rutgers University Press.

Zedner, L. (1991). Women, crime, and penal responses: An historical account. Crime and Justice, 14, 307-362.

Zhang, Y., Maxwell, C. D., \& Vaughn, M. S. (2009). The impact of state sentencing policies on the U.S. prison population. Journal of Criminal Justice, 37(2), 190199.

Zinn, M. B., \& Thornton Dill, B. (1996). Theorizing difference from multiracial feminism. Feminist Studies, 22(2), 321-331. 


\section{Appendices}

APPENDIX A: List of Social Work Journals Generated from Eigenfactor

\begin{tabular}{|c|c|}
\hline \multicolumn{2}{|c|}{ Journal Title } \\
\hline Administration in Social Work & Journal of Social Work \\
\hline $\begin{array}{l}\text { Affilia: Journal of Women and Social } \\
\text { Work }\end{array}$ & Journal of Social Work Education \\
\hline British Journal of Social Work & Journal of Social Work Practice \\
\hline Child and Family Social Work & Qualitative Social Work \\
\hline Children and Youth Services Review & Research on Social Work Practice \\
\hline Clinical Social Work Journal & Social Service Review \\
\hline European Journal of Social Work & Social Work \\
\hline $\begin{array}{l}\text { Family in Society: The Journal of } \\
\text { Contemporary Social Service }\end{array}$ & Social Work in Health Care \\
\hline Health and Social Work & Social Work in Public Health \\
\hline $\begin{array}{l}\text { Human Service Organizations } \\
\text { Management Leadership and } \\
\text { Governance (formerly } \\
\text { known as Administration in Social } \\
\text { Work 1977-2013) }\end{array}$ & Social Work Research \\
\hline $\begin{array}{l}\text { International Journal of Social } \\
\text { Welfare }\end{array}$ & $\begin{array}{l}\text { Smith College Studies in Social } \\
\text { Work }\end{array}$ \\
\hline International Social Work & Trauma, Violence, and Abuse \\
\hline Journal of Social Service Research & \\
\hline
\end{tabular}


APPENDIX B: The Dataset

\begin{tabular}{|c|c|c|c|c|}
\hline Author(s) & Article Title & Source & Year & $\begin{array}{l}\text { Type of } \\
\text { Article }\end{array}$ \\
\hline $\begin{array}{l}\text { Allen, S, Flaherty, } \\
\text { C., \& Ely, G. }\end{array}$ & $\begin{array}{l}\text { Throwaway Moms: Maternal } \\
\text { Incarceration and the } \\
\text { Criminalization of Female Poverty }\end{array}$ & $\begin{array}{l}\text { Affilia-Journal of } \\
\text { Women and } \\
\text { Social Work }\end{array}$ & 2010 & $\begin{array}{l}\text { Qualitative } \\
\text { Research }\end{array}$ \\
\hline $\begin{array}{l}\text { Berry, M., Johnson, } \\
\text { T., Severson, M., \& } \\
\text { Postmus, J. L. }\end{array}$ & $\begin{array}{l}\text { Wives and Mothers At Risk: The } \\
\text { Role of Marital and Maternal } \\
\text { Status in Criminal Activity and } \\
\text { Incarceration }\end{array}$ & $\begin{array}{l}\text { Families in } \\
\text { Society }\end{array}$ & 2009 & $\begin{array}{l}\text { Quantitative } \\
\text { Research }\end{array}$ \\
\hline Buttell, F. P. & $\begin{array}{l}\text { Levels of moral reasoning among } \\
\text { female domestic violence } \\
\text { offenders: Evaluating the impact of } \\
\text { treatment }\end{array}$ & $\begin{array}{l}\text { Research on } \\
\text { Social Work } \\
\text { Practice }\end{array}$ & 2002 & $\begin{array}{l}\text { Quantitative } \\
\text { Evaluation }\end{array}$ \\
\hline $\begin{array}{l}\text { Buttell, F. P., } \\
\text { Powers, D., \& } \\
\text { Wong, A. }\end{array}$ & $\begin{array}{l}\text { Evaluating Predictors of Program } \\
\text { Attrition Among Women } \\
\text { Mandated Into Batterer } \\
\text { Intervention Treatment. }\end{array}$ & $\begin{array}{l}\text { Research on } \\
\text { Social Work } \\
\text { Practice }\end{array}$ & 2012 & $\begin{array}{l}\text { Quantitative } \\
\text { Evaluation }\end{array}$ \\
\hline $\begin{array}{l}\text { Carney, M. M., \& } \\
\text { Buttell, F. P. }\end{array}$ & $\begin{array}{l}\text { A multidimensional evaluation of a } \\
\text { treatment program for female } \\
\text { batterers: A pilot study. }\end{array}$ & $\begin{array}{l}\text { Research on } \\
\text { Social Work } \\
\text { Practice }\end{array}$ & 2004 & $\begin{array}{l}\text { Quantitative } \\
\text { Evaluation }\end{array}$ \\
\hline $\begin{array}{l}\text { Carney, M. M., \& } \\
\text { Buttell, F. P. }\end{array}$ & $\begin{array}{l}\text { An evaluation of a court-mandated } \\
\text { batterer intervention program: } \\
\text { Investigating differential program } \\
\text { effect for African American and } \\
\text { White women. }\end{array}$ & $\begin{array}{l}\text { Research on } \\
\text { Social Work } \\
\text { Practice }\end{array}$ & 2006 & $\begin{array}{l}\text { Quantitative } \\
\text { Evaluation }\end{array}$ \\
\hline Cho, R. M. & $\begin{array}{l}\text { Maternal Incarceration and } \\
\text { Children's Adolescent Outcomes: } \\
\text { Timing and Dosage }\end{array}$ & $\begin{array}{l}\text { Social Service } \\
\text { Review }\end{array}$ & 2010 & $\begin{array}{l}\text { Quantitative } \\
\text { Research }\end{array}$ \\
\hline Condon, M. C. & $\begin{array}{l}\text { Early Relational Health: Infants' } \\
\text { Experiences Living with Their } \\
\text { Incarcerated Mothers. }\end{array}$ & $\begin{array}{l}\text { Smith College } \\
\text { Studies in Social } \\
\text { Work }\end{array}$ & 2017 & $\begin{array}{l}\text { Qualitative } \\
\text { Research }\end{array}$ \\
\hline $\begin{array}{l}\text { Epperson, M. W., } \\
\text { Platais, I., Valera, } \\
\text { P., Barbieri, R., } \\
\text { Gilbert, L., \& El- } \\
\text { Bassel, N. }\end{array}$ & $\begin{array}{l}\text { Fear, Trust, and Negotiating Safety } \\
\text { HIV Risks for Black Female } \\
\text { Defendants. }\end{array}$ & Affilia & 2009 & $\begin{array}{l}\text { Qualitative } \\
\text { Research }\end{array}$ \\
\hline $\begin{array}{l}\text { Fedock, G., \& } \\
\text { Sarantakos, S. }\end{array}$ & $\begin{array}{l}\text { Physical and Mental Health } \\
\text { Disparities for Young Women with } \\
\text { Arrest Histories. }\end{array}$ & $\begin{array}{l}\text { Health and } \\
\text { Social Work }\end{array}$ & 2017 & $\begin{array}{l}\text { Quantitative } \\
\text { Research }\end{array}$ \\
\hline Fedock, G. L. & $\begin{array}{l}\text { Women's Psychological } \\
\text { Adjustment to Prison: A Review } \\
\text { for Future Social Work Directions. }\end{array}$ & $\begin{array}{l}\text { Social Work } \\
\text { Research }\end{array}$ & 2017 & Conceptual \\
\hline $\begin{array}{l}\text { Ferreira, R. J., \& } \\
\text { Buttell, F. P. }\end{array}$ & $\begin{array}{l}\text { Can a "Psychosocial Model" Help } \\
\text { Explain Violence Perpetrated by } \\
\text { Female Batterers? }\end{array}$ & $\begin{array}{l}\text { Research on } \\
\text { Social Work } \\
\text { Practice }\end{array}$ & 2016 & $\begin{array}{l}\text { Quantitative } \\
\text { Evaluation }\end{array}$ \\
\hline
\end{tabular}




\begin{tabular}{|c|c|c|c|c|}
\hline Author(s) & Article Title & Source & Year & $\begin{array}{l}\text { Type of } \\
\text { Article }\end{array}$ \\
\hline $\begin{array}{l}\text { Fries, L., Fedock, } \\
\text { G., \& Kubiak, S. P. }\end{array}$ & $\begin{array}{l}\text { Role of Gender, Substance Use, } \\
\text { and Serious Mental Illness in } \\
\text { Anticipated Post-jail Homelessness }\end{array}$ & $\begin{array}{l}\text { Social Work } \\
\text { Research }\end{array}$ & 2014 & $\begin{array}{l}\text { Quantitative } \\
\text { Research }\end{array}$ \\
\hline Gilham, J. J. M. & $\begin{array}{l}\text { A Qualitative Study of } \\
\text { Incarcerated Mothers' Perceptions } \\
\text { of the Impact of Separation on } \\
\text { Their Children }\end{array}$ & $\begin{array}{l}\text { Social Work in } \\
\text { Public Health }\end{array}$ & 2012 & $\begin{array}{l}\text { Qualitative } \\
\text { Research }\end{array}$ \\
\hline $\begin{array}{l}\text { Hanlon, T. E., } \\
\text { Blatchley, R. J., } \\
\text { Bennett-Sears, T., } \\
\text { O'Grady, K. E., } \\
\text { Rose, M., \& } \\
\text { Callaman, J. M. }\end{array}$ & $\begin{array}{l}\text { Vulnerability of children of } \\
\text { incarcerated addict mothers: } \\
\text { Implications for preventive } \\
\text { intervention }\end{array}$ & $\begin{array}{l}\text { Children and } \\
\text { Youth Services } \\
\text { Review }\end{array}$ & 2005 & $\begin{array}{l}\text { Quantitative } \\
\text { Research }\end{array}$ \\
\hline Harris, M. S. & $\begin{array}{l}\text { Group Therapy at a Prison for } \\
\text { Women: A Therapist's } \\
\text { Perspective. }\end{array}$ & $\begin{array}{l}\text { Smith College } \\
\text { Studies in Social } \\
\text { Work }\end{array}$ & 2014 & $\begin{array}{l}\text { Qualitative } \\
\text { Research }\end{array}$ \\
\hline Harris, M. S. & $\begin{array}{l}\text { Incarcerated Mothers: Trauma and } \\
\text { Attachment Issues. }\end{array}$ & $\begin{array}{l}\text { Smith College } \\
\text { Studies in Social } \\
\text { Work }\end{array}$ & 2017 & $\begin{array}{l}\text { Mixed } \\
\text { Methods }\end{array}$ \\
\hline $\begin{array}{l}\text { Heidemann, G., } \\
\text { Cederbaum, J.A., \& } \\
\text { Martinez, S. }\end{array}$ & $\begin{array}{l}\text { Beyond Recidivism: How } \\
\text { Formerly Incarcerated Women } \\
\text { Define Success. }\end{array}$ & Affilia & 2016 & $\begin{array}{l}\text { Qualitative } \\
\text { Research }\end{array}$ \\
\hline Horton, A. & $\begin{array}{l}\text { Heroin Users: The Need for } \\
\text { Improved Treatment for } \\
\text { Incarcerated Women }\end{array}$ & $\begin{array}{l}\text { Social Work in } \\
\text { Public Health }\end{array}$ & 2011 & Conceptual \\
\hline $\begin{array}{l}\text { Jung, H., \& } \\
\text { LaLonde, R. }\end{array}$ & $\begin{array}{l}\text { The relationship between re- } \\
\text { incarceration and their own } \\
\text { childhood foster care experience of } \\
\text { women. }\end{array}$ & $\begin{array}{l}\text { Children and } \\
\text { Youth Services } \\
\text { Review }\end{array}$ & 2016 & $\begin{array}{l}\text { Quantitative } \\
\text { Research }\end{array}$ \\
\hline $\begin{array}{l}\text { Kernsmith, P., \& } \\
\text { Kernsmith, R. }\end{array}$ & $\begin{array}{l}\text { Treating Female Perpetrators: State } \\
\text { Standards for Batterer Intervention } \\
\text { Services }\end{array}$ & Social Work & 2009 & $\begin{array}{l}\text { Qualitative } \\
\text { Research }\end{array}$ \\
\hline $\begin{array}{l}\text { Kjellstrand, J. M., } \\
\text { Cearley, J., Eddy, J. } \\
\text { M., Foney, D., \& } \\
\text { Martinez, C. R. }\end{array}$ & $\begin{array}{l}\text { Characteristics of incarcerated } \\
\text { fathers and mothers: Implications } \\
\text { for preventive interventions } \\
\text { targeting children and families }\end{array}$ & $\begin{array}{l}\text { Children and } \\
\text { Youth Services } \\
\text { Review }\end{array}$ & 2012 & $\begin{array}{l}\text { Quantitative } \\
\text { Research }\end{array}$ \\
\hline Kubiak, S. P. & $\begin{array}{l}\text { The effects of PTSD on treatment } \\
\text { adherence, drug relapse, and } \\
\text { criminal recidivism in a sample of } \\
\text { incarcerated men and women }\end{array}$ & $\begin{array}{l}\text { Research on } \\
\text { Social Work } \\
\text { Practice }\end{array}$ & 2004 & $\begin{array}{l}\text { Quantitative } \\
\text { Research }\end{array}$ \\
\hline
\end{tabular}




\begin{tabular}{|c|c|c|c|c|}
\hline Author(s) & Article Title & Source & Year & $\begin{array}{l}\text { Type of } \\
\text { Article }\end{array}$ \\
\hline $\begin{array}{l}\text { Kubiak, S. P., } \\
\text { Kasiborski, N., } \\
\text { Karim, N., \& } \\
\text { Schmittel, E. }\end{array}$ & $\begin{array}{l}\text { Does Subsequent Criminal Justice } \\
\text { Involvement Predict Foster Care } \\
\text { and Termination of Parental Rights } \\
\text { for Children Born to Incarcerated } \\
\text { Women? }\end{array}$ & $\begin{array}{l}\text { Social Work in } \\
\text { Public Health }\end{array}$ & 2012 & $\begin{array}{l}\text { Quantitative } \\
\text { Research }\end{array}$ \\
\hline $\begin{array}{l}\text { Kubiak, S. P., } \\
\text { Kasiborski, N., \& } \\
\text { Schmittel, E. }\end{array}$ & $\begin{array}{l}\text { Assessing Long-Term Outcomes } \\
\text { of an Intervention Designed for } \\
\text { Pregnant Incarcerated Women }\end{array}$ & $\begin{array}{l}\text { Research on } \\
\text { Social Work } \\
\text { Practice }\end{array}$ & 2010 & $\begin{array}{l}\text { Quantitative } \\
\text { Evaluation }\end{array}$ \\
\hline $\begin{array}{l}\text { Kubiak, S. P., Kim, } \\
\text { W. J., Fedock, G., \& } \\
\text { Bybee, D. }\end{array}$ & $\begin{array}{l}\text { Testing a Violence-Prevention } \\
\text { Intervention for Incarcerated } \\
\text { Women Using a Randomized } \\
\text { Control Trial }\end{array}$ & $\begin{array}{l}\text { Research on } \\
\text { Social Work } \\
\text { Practice }\end{array}$ & 2015 & $\begin{array}{l}\text { Quantitative } \\
\text { Evaluation }\end{array}$ \\
\hline Mason, L. G. B. & $\begin{array}{l}\text { The Journey of One Pregnant } \\
\text { Incarcerated Woman Through } \\
\text { Systemic Bias: How Family } \\
\text { Support Workers Can Positively } \\
\text { Affect Change-A Case Study }\end{array}$ & Affilia & 2013 & $\begin{array}{l}\text { Conceptual } \\
\text { Case Study }\end{array}$ \\
\hline $\begin{array}{l}\text { Mignon, S. I., \& } \\
\text { Ransford, P. }\end{array}$ & $\begin{array}{l}\text { Mothers in Prison: Maintaining } \\
\text { Connections with Children }\end{array}$ & $\begin{array}{l}\text { Social Work in } \\
\text { Public Health }\end{array}$ & 2012 & $\begin{array}{l}\text { Mixed } \\
\text { Methods }\end{array}$ \\
\hline $\begin{array}{l}\text { Miller, A. L., } \\
\text { Weston, L. E., } \\
\text { Perryman, J., } \\
\text { Horwitz, T., } \\
\text { Franzen, S., \& } \\
\text { Cochran, S. }\end{array}$ & $\begin{array}{l}\text { Parenting While Incarcerated: } \\
\text { Tailoring the Strengthening } \\
\text { Families Program for use with } \\
\text { jailed mothers }\end{array}$ & $\begin{array}{l}\text { Children and } \\
\text { Youth Services } \\
\text { Review }\end{array}$ & 2014 & $\begin{array}{l}\text { Mixed } \\
\text { Methods } \\
\text { Evaluation }\end{array}$ \\
\hline Miller, K. M. & $\begin{array}{l}\text { Maternal criminal justice } \\
\text { involvement and co-occurring } \\
\text { mental health and substance abuse } \\
\text { problems: Examining moderation } \\
\text { of sex and race on children's } \\
\text { mental health }\end{array}$ & $\begin{array}{l}\text { Children and } \\
\text { Youth Services } \\
\text { Review }\end{array}$ & 2014 & $\begin{array}{l}\text { Quantitative } \\
\text { Research }\end{array}$ \\
\hline $\begin{array}{l}\text { Miller, K. M., \& } \\
\text { Bank, L. }\end{array}$ & $\begin{array}{l}\text { Moderating effects of race on } \\
\text { internalizing and externalizing } \\
\text { behaviors among children of } \\
\text { criminal justice and child welfare } \\
\text { involved mothers. }\end{array}$ & $\begin{array}{l}\text { Children and } \\
\text { Youth Services } \\
\text { Review }\end{array}$ & 2013 & $\begin{array}{l}\text { Quantitative } \\
\text { Research }\end{array}$ \\
\hline $\begin{array}{l}\text { Miller, K. M., } \\
\text { Orellana, E. R., } \\
\text { Johnson, A. B., } \\
\text { Krase, K., \& } \\
\text { Anderson-Nathe, B. } \\
\end{array}$ & $\begin{array}{l}\text { Maternal Criminal Justice and } \\
\text { Child Welfare Involvement: } \\
\text { Associations between Risk } \\
\text { Exposures and Childhood Mental } \\
\text { Health } \\
\end{array}$ & $\begin{array}{l}\text { Social Work } \\
\text { Research }\end{array}$ & 2013 & $\begin{array}{l}\text { Quantitative } \\
\text { Research }\end{array}$ \\
\hline $\begin{array}{l}\text { O'Brien, P., \& } \\
\text { Bates, R. }\end{array}$ & $\begin{array}{l}\text { Negotiating the waves: Challenges } \\
\text { of conducting in-prison and } \\
\text { follow-up research with women }\end{array}$ & Affilia & 2003 & Conceptual \\
\hline
\end{tabular}




\begin{tabular}{|c|c|c|c|c|}
\hline Author(s) & Article Title & Source & Year & $\begin{array}{l}\text { Type of } \\
\text { Article }\end{array}$ \\
\hline $\begin{array}{l}\text { O'Brien, P., \& } \\
\text { Ortega, D. M. }\end{array}$ & $\begin{array}{l}\text { Feminist Transformation } \\
\text { Deconstructing Prisons and } \\
\text { Reconstructing Justice With } \\
\text { Criminalized Women. }\end{array}$ & Affilia & 2015 & $\begin{array}{l}\text { Conceptual - } \\
\text { Editorial }\end{array}$ \\
\hline $\begin{array}{l}\text { Phillips, S. D., \& } \\
\text { Erkanli, A. }\end{array}$ & $\begin{array}{l}\text { Differences in patterns of maternal } \\
\text { arrest and the parent, family, and } \\
\text { child problems encountered in } \\
\text { working with families }\end{array}$ & $\begin{array}{l}\text { Children and } \\
\text { Youth Services } \\
\text { Review }\end{array}$ & 2008 & $\begin{array}{l}\text { Quantitative } \\
\text { Research }\end{array}$ \\
\hline $\begin{array}{l}\text { Salina, D. D., } \\
\text { Lesondak, L. M., } \\
\text { Razzano, L. A., \& } \\
\text { Parenti, B. M. }\end{array}$ & $\begin{array}{l}\text { Addressing Unmet Needs in } \\
\text { Incarcerated Women With Co- } \\
\text { occurring Disorders }\end{array}$ & $\begin{array}{l}\text { Journal of Social } \\
\text { Service Research }\end{array}$ & 2011 & $\begin{array}{l}\text { Quantitative } \\
\text { Research }\end{array}$ \\
\hline $\begin{array}{l}\text { Schlager, M. D., \& } \\
\text { Moore, B. }\end{array}$ & $\begin{array}{l}\text { Risk and Resiliency of } \\
\text { Incarcerated Mothers }\end{array}$ & $\begin{array}{l}\text { Families in } \\
\text { Society }\end{array}$ & 2014 & $\begin{array}{l}\text { Mixed } \\
\text { Methods }\end{array}$ \\
\hline $\begin{array}{l}\text { Scudder, A. T., } \\
\text { McNeil, C. B., } \\
\text { Chengappa, K., \& } \\
\text { Costello, A. }\end{array}$ & $\begin{array}{l}\text { Evaluation of an existing parenting } \\
\text { class within a women's state } \\
\text { correctional facility and a } \\
\text { parenting class modeled from } \\
\text { Parent-Child Interaction Therapy }\end{array}$ & $\begin{array}{l}\text { Children and } \\
\text { Youth Services } \\
\text { Review }\end{array}$ & 2014 & $\begin{array}{l}\text { Quantitative } \\
\text { Evaluation }\end{array}$ \\
\hline $\begin{array}{l}\text { Siefert, K., \& } \\
\text { Pimlott, S. }\end{array}$ & $\begin{array}{l}\text { Improving pregnancy outcome } \\
\text { during imprisonment: A model } \\
\text { residential care program }\end{array}$ & Social Work & 2001 & $\begin{array}{l}\text { Descriptive } \\
\text { Review with } \\
\text { Quantitative } \\
\text { Evaluation }\end{array}$ \\
\hline $\begin{array}{l}\text { Smith, C. J., \& } \\
\text { Young, D. S. }\end{array}$ & $\begin{array}{l}\text { The multiple impacts of TANF, } \\
\text { ASFA, and mandatory drug } \\
\text { sentencing for families affected by } \\
\text { maternal incarceration }\end{array}$ & $\begin{array}{l}\text { Children and } \\
\text { Youth Services } \\
\text { Review }\end{array}$ & 2003 & Conceptual \\
\hline Smoyer, A. B. & $\begin{array}{l}\text { Feeding Relationships: Foodways } \\
\text { and Social Networks in a Women's } \\
\text { Prison }\end{array}$ & Affilia & 2015 & $\begin{array}{l}\text { Qualitative } \\
\text { Research }\end{array}$ \\
\hline $\begin{array}{l}\text { Staton-Tindall, M., } \\
\text { Webster, J. M., } \\
\text { Oser, C. B., Havens, } \\
\text { J. R., \& Leukefeld, } \\
\text { C. G. }\end{array}$ & $\begin{array}{l}\text { Drug Use, Hepatitis C, and Service } \\
\text { Availability: Perspectives of } \\
\text { Incarcerated Rural Women }\end{array}$ & $\begin{array}{l}\text { Social Work in } \\
\text { Public Health }\end{array}$ & 2015 & $\begin{array}{l}\text { Qualitative } \\
\text { Research }\end{array}$ \\
\hline $\begin{array}{l}\text { Strozier, A. L., } \\
\text { Armstrong, M., } \\
\text { Skuza, S., Cecil, D., } \\
\text { \& McHale, J. }\end{array}$ & $\begin{array}{l}\text { Coparenting in Kinship Families } \\
\text { With Incarcerated Mothers: A } \\
\text { Qualitative Study. }\end{array}$ & $\begin{array}{l}\text { Families in } \\
\text { Society }\end{array}$ & 2011 & $\begin{array}{l}\text { Qualitative } \\
\text { Research }\end{array}$ \\
\hline $\begin{array}{l}\text { Tripodi, S. J., } \\
\text { Bledsoe, S. E., Kim, } \\
\text { J. S., \& Bender, K. }\end{array}$ & $\begin{array}{l}\text { Effects of Correctional-Based } \\
\text { Programs for Female Inmates: A } \\
\text { Systematic Review }\end{array}$ & $\begin{array}{l}\text { Research on } \\
\text { Social Work } \\
\text { Practice }\end{array}$ & 2011 & $\begin{array}{l}\text { Quantitative } \\
\text { Research }\end{array}$ \\
\hline
\end{tabular}




\begin{tabular}{|c|c|c|c|c|}
\hline Author(s) & Article Title & Source & Year & $\begin{array}{l}\text { Type of } \\
\text { Article }\end{array}$ \\
\hline $\begin{array}{l}\text { Valentine, P. V., \& } \\
\text { Smith, T. E. }\end{array}$ & $\begin{array}{l}\text { Evaluating traumatic incident } \\
\text { reduction therapy with female } \\
\text { inmates: A randomized controlled } \\
\text { clinical trial }\end{array}$ & $\begin{array}{l}\text { Research on } \\
\text { Social Work } \\
\text { Practice }\end{array}$ & 2001 & $\begin{array}{l}\text { Quantitative } \\
\text { Evaluation }\end{array}$ \\
\hline $\begin{array}{l}\text { Vandermause, R., } \\
\text { Severtsen, B., \& } \\
\text { Roll, J. }\end{array}$ & $\begin{array}{l}\text { Re-creating a vision of } \\
\text { motherhood: Therapeutic Drug } \\
\text { Court and the narrative }\end{array}$ & $\begin{array}{l}\text { Qualitative } \\
\text { Social Work }\end{array}$ & 2013 & $\begin{array}{l}\text { Qualitative } \\
\text { Research }\end{array}$ \\
\hline White, G. D. & $\begin{array}{l}\text { Gender-Responsive Programs in } \\
\text { U.S. Prisons: Implications for } \\
\text { Change }\end{array}$ & $\begin{array}{l}\text { Social Work in } \\
\text { Public Health }\end{array}$ & 2012 & Conceptual \\
\hline $\begin{array}{l}\text { Willison, J. S., \& } \\
\text { O'Brien, P. }\end{array}$ & $\begin{array}{l}\text { A Feminist Call for Transforming } \\
\text { the Criminal Justice System }\end{array}$ & Affilia & 2017 & Conceptual \\
\hline $\begin{array}{l}\text { Woodard, T., \& } \\
\text { Copp, J. E. }\end{array}$ & $\begin{array}{l}\text { Maternal incarceration and } \\
\text { children's delinquent involvement: } \\
\text { The role of sibling relationships }\end{array}$ & $\begin{array}{l}\text { Children and } \\
\text { Youth Services } \\
\text { Review }\end{array}$ & 2016 & $\begin{array}{l}\text { Quantitative } \\
\text { Research }\end{array}$ \\
\hline
\end{tabular}




\section{APPENDIX C: Number of Articles, Per Journal, Included in Sample}

It is notable that of the 25 journals I searched, my final sample came from only half $(n=12)$ of the original list. The other half did not contain articles meeting inclusion criteria from the specified time period. The breakdown is listed below.

\begin{tabular}{ll}
\hline Journal & $\begin{array}{l}\text { Number of } \\
\text { Articles in Sample }\end{array}$ \\
\hline Children and Youth Services Review & 10 \\
Research on Social Work Practice & 10 \\
Affilia: Journal of Women and Social Work & 8 \\
Social Work in Public Health & 6 \\
Families in Society: The Journal of Contemporary Social & 3 \\
Service & \\
Smith College Studies in Social Work & 3 \\
Social Work Research & 3 \\
Social Work & 2 \\
Health and Social Work & 1 \\
Journal of Social Service Research & 1 \\
Social Service Review & 1 \\
Qualitative Social Work & 1 \\
\hline
\end{tabular}

The following journals did not contain articles that met inclusion criteria:

Administration in Social Work

British Journal of Social Work

Child and Family Social Work

Clinical Social Work Journal

European Journal of Social Work

Human Service Organizations Management Leadership and Governance

International Journal of Social Welfare

International Social Work

Journal of Social Work

Journal of Social Work Education

Journal of Social Work Practice

Social Work in Health Care

Trauma, Violence, and Abuse 
APPENDIX D: Detailed Breakdown of Articles per Journal

\section{Children and Youth Services Review - 10}

Hanlon, T. E., Blatchley, R. J., Bennett-Sears, T., O'Grady, K. E., Rose, M., \& Callaman, J. M. (2005). Vulnerability of children of incarcerated addict mothers: Implications for preventive intervention.

Jung, H., \& LaLonde, R. (2016). The relationship between re-incarceration and their own childhood foster care experience of women.

Kjellstrand, J. M., Cearley, J., Eddy, J. M., Foney, D., \& Martinez, C. R. (2012).

Characteristics of incarcerated fathers and mothers: Implications for preventive interventions targeting children and families.

Miller, A. L., Weston, L. E., Perryman, J., Horwitz, T., Franzen, S., \& Cochran, S. (2014). Parenting While Incarcerated: Tailoring the Strengthening Families Program for use with jailed mothers.

Miller, K. M. (2014). Maternal criminal justice involvement and co-occurring mental health and substance abuse problems: Examining moderation of sex and race on children's mental health.

Miller, K. M., \& Bank, L. (2013). Moderating effects of race on internalizing and externalizing behaviors among children of criminal justice and child welfare involved mothers.

Phillips, S. D., \& Erkanli, A. (2008). Differences in patterns of maternal arrest and the parent, family, and child problems encountered in working with families.

Scudder, A. T., McNeil, C. B., Chengappa, K., \& Costello, A. H. (2014). Evaluation of an existing parenting class within a women's state correctional facility and a parenting class modeled from Parent-Child Interaction Therapy.

Smith, C. J., \& Young, D. S. (2003). The multiple impacts of TANF, ASFA, and mandatory drug sentencing for families affected by maternal incarceration.

Woodard, T., \& Copp, J. E. (2016). Maternal incarceration and children's delinquent involvement: The role of sibling relationships.

\section{Research on Social Work Practice - 10}

Buttell, F. P. (2002). Levels of moral reasoning among female domestic violence offenders: Evaluating the impact of treatment.

Buttell, F. P., Powers, D., \& Wong, A. (2012). Evaluating Predictors of Program Attrition Among Women Mandated into Batterer Intervention Treatment.

Carney, M. M., \& Buttell, F. P. (2004). A multidimensional evaluation of a treatment program for female batterers: A pilot study.

Carney, M. M., \& Buttell, F. P. (2006). An evaluation of a court-mandated batterer intervention program: Investigating differential program effect for African American and White women.

Ferreira, R. J., \& Buttell, F. P. (2016). Can a "Psychosocial Model" Help Explain Violence Perpetrated by Female Batterers?

Kubiak, S. P. (2004). The effects of PTSD on treatment adherence, drug relapse, and criminal recidivism in a sample of incarcerated men and women.

Kubiak, S. P., Kasiborski, N., \& Schmittel, E. (2010). Assessing Long-Term Outcomes of an Intervention Designed for Pregnant Incarcerated Women. 
Kubiak, S. P., Kim, W. J., Fedock, G., \& Bybee, D. (2015). Testing a Violence-Prevention Intervention for Incarcerated Women Using a Randomized Control Trial.

Tripodi, S. J., Bledsoe, S. E., Kim, J. S., \& Bender, K. (2011). Effects of Correctional-Based Programs for Female Inmates: A Systematic Review.

Valentine, P. V., \& Smith, T. E. (2001). Evaluating traumatic incident reduction therapy with female inmates: A randomized controlled clinical trial.

\section{Affilia: Journal of Women and Social Work - 8}

Allen, S., Flaherty, C., \& Ely, G. (2010). Throwaway Moms: Maternal Incarceration and the Criminalization of Female Poverty.

Epperson, M. W., Platais, I., Valera, P., Barbieri, R., Gilbert, L., \& El-Bassel, N. (2009).

Fear, Trust, \& Negotiating Safety HIV Risks for Black Female Defendants.

Heidemann, G., Cederbaum, J. A., \& Martinez, S. (2016). Beyond Recidivism: How Formerly Incarcerated Women Define Success.

Mason, L. G. B. (2013). The Journey of One Pregnant Incarcerated Woman Through Systemic Bias: How Family Support Workers Can Positively Affect Change-A Case Study.

O'Brien, P., \& Bates, R. (2003). Negotiating the waves: Challenges of conducting in-prison and follow-up research with women.

O'Brien, P., \& Ortega, D. M. (2015). Feminist Transformation Deconstructing Prisons and Reconstructing Justice with Criminalized Women.

Smoyer, A. B. (2015). Feeding Relationships: Foodways and Social Networks in a Women's Prison.

Willison, J. S., \& O'Brien, P. (2017). A Feminist Call for Transforming the Criminal Justice System.

\section{Social Work in Public Health -6}

Gilham, J. J. M. (2012). A Qualitative Study of Incarcerated Mothers' Perceptions of the Impact of Separation on Their Children.

Horton, A. (2011). Heroin Users: The Need for Improved Treatment for Incarcerated Women.

Kubiak, S. P., Kasiborski, N., Karim, N., \& Schmittel, E. (2012). Does Subsequent Criminal Justice Involvement Predict Foster Care and Termination of Parental Rights for Children

Born to Incarcerated Women?

Mignon, S. I., \& Ransford, P. (2012). Mothers in Prison: Maintaining Connections with Children.

Staton-Tindall, M., Webster, J. M., Oser, C. B., Havens, J. R., \& Leukefeld, C. G. (2015).

Drug Use, Hepatitis C, and Service Availability: Perspectives of Incarcerated Rural Women.

White, G. D. (2012). Gender-Responsive Programs in U.S. Prisons: Implications for Change.

\section{Family in Society - The Journal of Contemporary Social Service -3}

Berry, M., Johnson, T., Severson, M., \& Postmus, J. L. (2009). Wives and Mothers At Risk: The Role of Marital and Maternal Status in Criminal Activity and Incarceration.

Schlager, M. D., \& Moore, B. (2014). Risk and Resiliency of Incarcerated Mothers. 
Strozier, A. L., Armstrong, M., Skuza, S., Cecil, D., \& McHale, J. (2011). Coparenting in Kinship Families With Incarcerated Mothers: A Qualitative Study.

\section{Smith College Studies in Social Work - 3}

Condon, M. C. (2017). Early Relational Health: Infants' Experiences Living with Their Incarcerated Mothers.

Harris, M. S. (2014). Group Therapy at a Prison for Women: A Therapist's Perspective.

Harris, M. S. (2017). Incarcerated Mothers: Trauma and Attachment Issues.

\section{Social Work Research -3}

Fedock, G. L. (2017). Women's Psychological Adjustment to Prison: A Review for Future Social Work Directions.

Fries, L., Fedock, G., \& Kubiak, S. P. (2014). Role of Gender, Substance Use, and Serious Mental Illness in Anticipated Postjail Homelessness.

Miller, K. M., Orellana, E. R., Johnson, A. B., Krase, K., \& Anderson-Nathe, B. (2013). Maternal Criminal Justice and Child Welfare Involvement: Associations between Risk Exposures and Childhood Mental Health.

\section{Social Work -2}

Kernsmith, P., \& Kernsmith, R. (2009). Treating Female Perpetrators: State Standards for Batterer Intervention Services.

Siefert, K., \& Pimlott, S. (2001). Improving pregnancy outcome during imprisonment: A model residential care program.

\section{Health and Social Work -1}

Fedock, G., \& Sarantakos, S. (2017). Physical and Mental Health Disparities for Young Women with Arrest Histories.

\section{Journal of Social Service Research - 1}

Salina, D. D., Lesondak, L. M., Razzano, L. A., \& Parenti, B. M. (2011). Addressing Unmet Needs in Incarcerated Women With Co-occurring Disorders.

\section{Social Service Review - 1}

Cho, R. M. (2010). Maternal Incarceration and Children's Adolescent Outcomes: Timing and Dosage.

\section{Qualitative Social Work - 1}

Vandermause, R., Severtsen, B., \& Roll, J. (2013). Re-creating a vision of motherhood: Therapeutic Drug Court and the narrative. 


\section{APPENDIX E: Template for Structural Analysis}

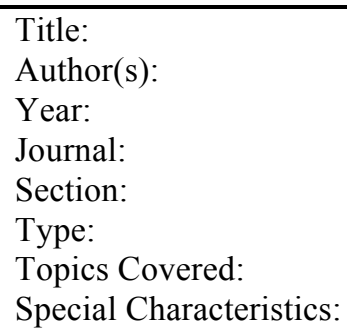

Vocabulary/ Word Choice:

\section{Theoretical Orientation:}

Collective Symbolism:

Argument/framing (Overarching explanations/goal?):

Attitudes/ Tone:

Discursive Entanglements:

Overall Discourse Position:

\section{Other Notes:}

- Depoliticizing Social work: Yes/No?

- Strategies for staying neutral/depoliticizing topic?

- Contradictions

- Binaries

- Omissions

- Reliance on risk

- Goals and values of social work or other fields? 
APPENDIX F: Illustration of Structural and Detailed Analysis

Allen, S., Flaherty, C., \& Ely, G. (2010). Throwaway Moms: Maternal Incarceration and the Criminalization of Female Poverty.

\section{Structural Analysis}

Title: Throwaway Moms Maternal Incarceration and the Criminalization of Female Poverty Author(s): Suzanne Allen, Chris Flaherty, Gretchen Ely

Year: 2010

Journal: Affilia

Section: Articles

Type: Qualitative Research Study

Topics Covered: Maternal Incarceration; Issues Faced; Causes; Interventions/Responses

Sub-Topics/Themes: Impact on Mothers, Impact on Mother-Child Relationship; Poverty, Substance Use Issues, Mental Health Issues, Abuse/Victimization, Marginalization, Custody/Child Welfare; Sentencing Policies, Structural Barriers, Individual Level Factors; Substance Use Treatment, Parenting Programming, Life Skills Development, Gender Specific Programming, Advocacy, Recidivism

Vocabulary/word choice: "Drug Offending" "criminalization" "poverty" "victimization" "addiction" "behaviors" "giving voice" "powerless" (a lot) "substance abusing" "policy vacuum" "long ignored population" "troubled life histories" "impossible odds" "criminality" "gender specific" "inflexible child welfare policies" "recidivism" "radical criminal justice policies" "deeply reflective" "often philosophical" "struggled fiercely" "enthusiastic and grateful" "profound powerlessness" "devastating cycle of poverty" "deep shame, remorse and sadness" "prostituted themselves" "trade sex for drugs" "AFSA" "invisible population"

"maternal love" "mentors and advocates" "criminality" "life skills training" "treatment" "case advocates"

Theoretical Orientation: Feminist Standpoint Epistemological framework

Collective Symbols: "imprisoned by their own guilt and shame" "giving the women a voice makes the political personal" "impossible odds" "crack subculture in America's poor struggling communities" "deep layers of abuse and social problems the women endured"

Argument/framing (Overarching explanations/goal?): Policy issues propel increases in incarceration. Criminal justice involvement and crime is caused by individual level factors. Calls for gender responsive programming to better deal with these individual level issues. There are structural barriers to "success" but these are framed as individual issues that can be solved through individual level programming. Goal is to help women take personal responsibility, which will then improve their circumstances and decrease recidivism.

Goals and values of social work or other fields?): Micro-level social work values and emphasis. Compassion. 
Social justice?: No explicit mention. Ambiguity-social justice analysis of criminalization but its undermined by the individual level analysis. The social justice analysis is also not embedded in meaningful calls for action and because of the paternalistic discussion of women.

Attitudes: Generally positive toward women though fairly paternalistic

Tone: paternalistic

Reliance on risk?: Not overtly, but the framing of women's powerlessness and vulnerability ultimately constructs them as "at risk."

What's Missing?(omissions/textual silences): Race (even though half of their sample is comprised of people of color). No discussion of racism. Completely silent on the issue of race though they use a lot of coded language for it.

Depoliticizing Social work (Yes/No?) If yes, Strategies for staying neutral/depoliticizing topic?): Yes. Decontextualize through a silence on race and racism. Undermines discussion of structural issues with emphasis on individual problems and interventions. Also undermines their assertions of a feminist social justice agenda through focus on individual choice.

Contradictions: Policy issues cause increase in incarceration, but substance abuse and mental health issues cause crime. Despite recognition of policy and programmatic issues, authors still primarily call for change at the individual level. Article focuses on poverty, yet does not include implications/recommendations for dealing with poverty.

Binaries/Dichotomy: Idealized mother/incarcerated mother $=$ expectation that incarcerated mothers would be different than "normal" mothers. Authors are surprised when mothers express love and fear for children.

Discursive Entanglements: Child welfare and criminal justice.

Overall Discourse Position: Women are powerless and tragic. Constructed as voiceless and vulnerable. Social work framed as savior.

Other Notes: "crack subculture in America's poor struggling communities" (code for black). Lots of intently descriptive language to create symbolism and construct women as tragic.

Things that need further exploration/research: $\mathrm{n} / \mathrm{a}$ 


\section{Context}

\section{Detailed Analysis}

1. Why was the article selected for detailed analysis? Why is it typical?

This article was chosen because it represented a variety of themes that emerged in the structural analysis. It was particularly strong on the 'object of pity' and 'social work as savior' themes. Though this is a distinct construction of criminalized women and social work, it always relied on the rhetoric of risk and choice, ultimately showing a preference for individualized service delivery. It also displayed the typical contradiction I saw emerge in the structural analysis of mentioning policy issues and structural context as causes for incarceration but falling back on individual level understandings and responses. I would describe this as "well intentioned" article.

2. Who is the author? What is their position and status within social work? What is their area of expertise, and so on?

Authors are Suzanne Allen, Chris Flaherty, and Gretchen Ely. At the time of the publication, they were all based in Lexington, KY.

Suzanne Allen was a social work consultant and the other two were at the University of Kentucky's College of Social Work.

Chris Ely is still at UK and is an associate professor with a focus on mental health.

Gretchen Ely is now an Associate Professor at the University of Buffalo, SUNY. It appears that her area of expertise is abortion and reproductive rights. These two have written some other articles together on social justice education. I could not find more info on the lead author.

3. What journal was it published in? What is the aim, scope, and political orientation of the journal? In which section of the journal does the article appear? What kind of article is it? (empirical, conceptual?) Is the article a part of a special issue?

Affilia: Journal of Women in Social Work. It is a journal oriented toward feminist theories, social justice, and values qualitative research. The article is a qualitative research study published in the 'articles section of the journal.

4. What year was the article written? Was there a specific occasion or event that it was written in relation to? How does this compare to newer/older articles in the sample by the same author?

2010. Does not appear to be written in relation to anything in particular. Date is in the middle of the sample range though. Three other articles are in my sample that were published in the same year. 


\section{Surface of the Text}

1. How is the information organized and structured? What are the headings and subheadings? What role does the title, abstract, introduction and conclusion play in the overall scheme of things?

The article is organized as most academic are: intro, lit review, methods, findings, conclusion. It is interesting to note how the title implies a structural focus with the use of the word "criminalization" and emphasis on poverty. Yet, the abstract immediately contradicts this by the use of intense individualizing language and focus on behaviors, The abstract (and intro and conclusion) draws on powerful imagery to frame women as powerless to their own selves from which they need to be "rehabilitated", which then turns the focus on to the individual rather than the structural, such as poverty. Assumes incarceration has rehabilitative aims that are worthy given women's behaviors and problem, rather than aims of punishment. Leaves logic of punishment and criminalization unquestioned.

2. What topics are addressed in the article? What key themes are communicated about it? Do the topics/themes relate to each other and/or overlap? (discursive entanglements)?

Topics: Impact on Mothers, Impact on Mother-Child Relationship; Poverty, Substance Use Issues, Mental Health Issues, Abuse/Victimization, Marginalization, Custody/Child Welfare; Sentencing Policies, Structural Barriers, Individual Level Factors; Substance Use Treatment, Parenting Programming, Life Skills Development, Gender Specific Programming, Advocacy, Recidivism

Themes: Women framed as powerless: shame, remorse, guilt.

Policy issues propel increases in incarceration, yet criminal justice involvement and crime framed as being caused by individual level factors such as substance abuse, victimization. Even poverty is turned into an individual level issue that can be addresses through increased access to individual treatment.

Call for gender responsive programming to better deal with these individual level issues.

There are structural barriers to "success" but these are framed as individual issues that can be solved through individual level programming. Goal is to help women take personal responsibility, which will then improve their circumstances and decrease recidivism.

Women are framed as powerless, tragic, objects of pity while social work framed as their savior. 


\section{Rhetorical Means}

\section{What kind and form of argumentation does the article follow? What argumentation strategy is used?}

Stirring up emotions - main argumentation strategy used. Particularly in relation to characterizing women - Lots of emotive language - Feels manipulative. This can be put in contrast to the discussions of policy and structural issues, which use statistics and "objective" facts and are discussed in dispassionate, descriptive, matter of fact way. When reading these passages on policy and systems issues, I, as reader, am not asked to have feelings or emotions. Inadvertently puts the emphasis on women's tragic circumstances in which we should 'feel for them.' Using empathy as a tool rather than reason. Why am I not asked to have feelings or take a position when they write about things that highlight structural inequity. Despite trying to make the "personal political," as they state, the authors are inherently depoliticizing the issue. Emotive language shapes the argumentation.

Despite recognizing structural and policy issues, they primarily keep the discussion and analysis of results located at site of individual choices, feelings, and behaviors.

Attribution of agency to crack cocaine and its use, not policies that criminalize crack in a highly radicalized manner. Representation of crack cocaine is decontextualized, deracialized. Example: "Women's rates of incarceration have increased...Much of this increase is due to the advent of crack cocaine, which has had a huge impact on lowincome women and the resulting increase in nonviolent crimes that are typically associated with its use."

Binary of idealized mother vs. unfit mother. Example: "Perhaps, the most outstanding quality of these interviews was how deeply reflective-often philosophical-these women were about all the subjects they covered but particularly with regard to the topic of motherhood. Many of the women also struggled fiercely with their negative selfperceptions as parents. In many ways, the women expressed the same themes one would expect from any mother, including the aforementioned idealized mother. These themes included love for their children, pride in their children's accomplishments, and worry about their children's circumstances and future challenges. However, unlike idealized mothers, these poor and incarcerated mothers also expressed feelings of profound powerlessness: powerless at being separated from their children, powerless to protect their children from sharing their same fate, powerless against the child welfare system, powerless against their addictions, and powerless against the society from which they have become so disenfranchised."

It is as though they assume that idealized mothers don't ever feel powerless? Setting them up within the dichotomy so as to challenge their difference, but it only reinforces dichotomy and notion of idealized mother. In this binary authors are still drawing on the unfit mother narrative.

Example: "Although many may assume that these children would be better off without their mothers, this may not be the case. With proper treatment and ample opportunity to complete a case plan, these women may be able to achieve a life in which they can nurture their children-the children they so desperately love." 


\section{What implications and allusions/insinuations does the article contain?}

Assumes that incarceration is about rehabilitation not punishment and if women could get better access to treatment they could be rehabilitated to be the "better" selves they so long to be. There is an emphasis placed on women rehabilitating themselves, which implies responsibility and individual causes of crime and criminal justice involvement. Example: "those who had lost custody of their children felt they had no remaining reason to rehabilitate themselves."

Lots of implications that women are powerless and the all-powerful social worker can help empower them.

Allusions to race without ever explicitly mentioning. Example: "Poor and marginalized women, such as the participants in our study, do not fit the idealized portrayal of motherhood.". Color-blind discourse using coded language for race. One focus in article is on crack cocaine and despite it being a highly racialized drug in the way it is criminalized, there is no mention of race or racism. Example of coded language: "These women are more likely to live in poverty, are less likely to have been employed, and are more likely to have lower educational levels and lower household incomes than their incarcerated male counterparts (Moe \& Ferraro, 2006). They also have high rates of recidivism (Alleyne, 2006; Richie, 2001). That most of these women live in high-crime neighborhoods with increased levels of homelessness to which they must return on their release from jail poses serious problems for successful reentry into the community and is a contributing factor in the women's high rates of recidivism." Here a discussion of racism is circumvented through a discussion of poverty. Dismiss race and focus on neighborhood and poverty to explain involvement in CJ and recidivism.

Equates prison to treatment. Example: "The average prison sentence for a woman is 18 months (Women's Prison Association, 2006), and the time frame for a woman to complete treatment varies from woman to woman, but is often lengthy."

Focus on guilt and shame in both their analysis and on the women's narratives they choose to include, implies that women's behavior is the cause of their problems. It also invokes normative expectations regarding mothering.

Authors discuss marginalization, yet he way they draw on structural issues, and then emphasize personal ones implies that women and substance users cause their own marginalization. They do this thru passive language as well. Example: "Those who are addicted to crack are often the poorest of the poor and subsequently the most frequently arrested, victimized, disabled, and marginalized by its use." Marginalized by the use of crack or by the criminalization of it? Implying that crack user brings on their marginalization themselves.

\section{What collective symbolism or 'figurativeness', symbolism, metaphors, etc. is used?}

This article is wrought with symbolism and metaphorical language that creates a sense of pity and tragedy, conveys representations of powerlessness. 
Examples:

"impossible odds the women face in terms of mothering."

"women whose shame and regret were often palpable."

Conjuring up images that equate these emotions with incarceration. Example: "Many of the women were imprisoned by their own guilt and remorse." - what does this legitimize? Perhaps individual level services that focus on their feelings and individual failings?

Drug use and incarceration are depicted as cycles - conveys image that it is hard to escape, which furthers their construction of women as powerless. Example: "revolving door of incarceration, recidivism, and homelessness" - a bit passive and powerless.

"The repeated lament of all these women was that they were painfully snared in a tangled web of addictions without the resources to help them find a way out." - Addiction depicted as web that they are stuck it.

Use of numbers and statistics to paint picture of context and larger structural issues.

\section{What idioms, sayings, and clichés are used?}

"we can ....give voice to this long ignored population"

"giving women a voice makes the personal political"

"salvage their own lives for the sake of their children"

"ASFA clock would have already been ticking."

\section{What are the vocabulary and style?}

There is an exaggerated use of adjectives and adverbs to conjure images of powerlessness and evoke feelings of empathy and pity throughout the article. Enhances authors' representation of women as tragic and vulnerable.

Examples:

"The mothers expressed profound feelings of guilt and remorse for the impact that their behaviors had on their children and expressed hope that their children would experience better lives than they have."

"extremely troubled and often tragic life histories in the lives of these women"

"Their multiple marginality, combined with the stigma and shame of incarceration, renders this powerless population essentially disposable in the eyes of society."

"these women's stories indicate that more typically it is not as the women recount their experiences of feeling powerless and ensnared in and betrayed by the child welfare and criminal justice systems." 
"The majority expressed feelings of profound powerlessness with regard to their status and their rights within the system."

"bravely confided their experiences"

Doing something with adjectives... maybe trying to humanize but inadvertently also being demeaning. Maybe trying to manipulate audience away from dominant narrative?

Strong emotive language is used to describe women and detached, descriptive language is used to discuss context. This inadvertently deemphasized the context and emphasizes women's individual feelings and behaviors.

Example: "They talked at great length about their children, and the majority expressed deep feelings of remorse, guilt, sadness, and love when talking about their children. Most of these dialogues were extremely emotional, and most of the women told their stories through tears and even sobs."

In this, the reader is not asked to have feelings or an emotional response to the policy and structural issues but is asked to have a strong emotional response to the women. "struggled fiercely" "powerless"; "terrified"

The use of such emotive language also has the effect of being 0thering and patronizing. Example: "Perhaps, the most powerful and heartbreaking themes were those of the maternal love that these women consistently expressed for their children and the profound sense of guilt and staggering remorse they were all struggling with when they discussed the impact of their actions on their children. It became abundantly clear that their substance abuse problems and criminal justice involvement were symptomatic of extremely troubled life histories"

The nouns they use create a sense of risk. Example: "They are convicted criminals, viewed by society as social outcasts"

Verbs used to create imagery and drum up sympathy. Example: “... was passed in response to the growing number of children lingering in the foster care system"

Use of modifiers to emphasize researchers good intentions. Example: "project was inspired by our strong desire to hear directly from incarcerated, substance abusing mothers."

Evidentialities or lack thereof. Example: "Perhaps, the most outstanding quality of these interviews was how deeply reflective - often philosophical-these women were about all the subjects they covered but particularly with regard to the topic of motherhood" Sentence framed in a way that assumes that they would not be expected to be reflective and philosophical. If these were middle class women, would this be considered a finding? Use of "most outstanding" un-naturalized women as good mothers. Authors could have also said "of course" which would have propelled a very different attitude toward the women. 
Passive language: used to shirk responsibility of social work in implementing and sustaining problematic policies (side note: also no mention of changing them. Example: "Although termination of parental rights (TPR) proceedings have increased more than $100 \%$ since the enactment of ASFA, the precise number of TPR proceedings that have been filed against incarcerated women is not known (Women in Prison Project, 2006). Child welfare policies on children of incarcerated women have not been modified to adapt to the rapidly increasing rates of female incarceration" - Passivity - leaves out the social worker's part in this. Who is responsible? Action of social workers in policy processes is hidden. After all, who is responsible for the policy implementation and thus the possibilities for disrupting it? All of this talk regarding problematic policy but the focus in the end is still on the individual and nowhere is social work's responsibility toward changing these policies mentioned. Leaves the profession untouched and "innocent."

Remain neutral through use of passive language. Example: "It can be argued, then, that many of these women are suffering not only from radical criminal justice policies, but from inflexible child welfare policies." - here they are noting intersections of systems and policies that impact women. On the surface this seems "progressive" but again, they ultimately circumvent their argument but relying on individual levels of change. There is also a level of passivity here, "it can be argued" by who? who does the arguing? This has a bit of a neutralizing effect - Rather than saying "we argue" they are can "it can be argued" - in this they are not claiming the argument, therefore remaining neutral on the issue despite raising the issue.

Locus of attention is on the individual "plight" rather than structural injustice. Example: "Through the telling of these stories, we hope to bring attention to the plight of these and other incarcerated mothers, raise awareness of the obstacles that the women face because of their incarceration and troubled life histories, and bring to the forefront the virtually impossible odds the women face in terms of mothering their children by conveying their subjective experiences to a larger audience." - calling attention to individual life problems.

Local coherence through article with the repeated use of guilt and shame. Example: "Virtually all the women expressed deep shame, remorse, and sadness for the mistakes they have made."

Racially coded language. Example: "Although crack has been less popular in mainstream culture, a crack subculture is found in America's poor, struggling communities." mainstream culture - white; poor struggling communities - black

\section{What actors are mentioned, and how are they portrayed/characterized?}

Criminalized women: Portrayed as tragic and powerless. Terms used to describe: "long ignored population" "vulnerable" "poorly served" "one thing that incarcerated women share is their invisibility." 
"The experiences reported by the women in our study certainly corroborate the notion that the needs of children and mothers are often at odds with one another as a result of the intersection of policy mandates. Indeed, as is evidenced by the following interviews, the mothers' experiences indicate that child welfare protocols operate, often incorrectly, under the assumption that the welfare of the child is separate from the welfare of the mother. Although this may sometimes be the case, these women's stories indicate that more typically it is not as the women recount their experiences of feeling powerless and ensnared in and betrayed by the child welfare and criminal justice systems." - Building argument to create image of tragic mother - Are their needs at odds or are the policy mandates at odds? Are the assumed needs embedded in the policies an accurate reflection of their actual needs? Positioning women and children needs at odds not the mandates of the policy. However, in next sentence, they clarify and put the focus on intersecting welfare of mom and child, not just the child. Most pieces focus solely on narrowly construed well being a child (and so do the policies to which these authors refer). In this they are disrupting the bad or unfit mother narrative but along with the next sentence, they are instead creating an image of a tragic mother.

"The stigma of women who use crack and other drugs is further deepened by cultural expectations of women as nurturers and caretakers. As Campbell (2000, p. 3) stated, "When women violate gender norms by using illicit drugs, they are represented as spectacular failures - callously abandoning babies or becoming bad mothers, worse wives, or delinquent daughters." - They use this gender analysis to challenge the construction of the unfit mother yet at other times they draw on this construction to construct them.

Use of adverbs and adjectives to create and emphasize image of loving mother. But why are their feelings of grief defined as a problem of guilt and remorse? Focus on guilt emphasizes their responsibility and renders them worthy of our empathy ad understanding. Guilt used as a responsibilizing tactic?

Authors also deemphasize agency through article. Example: "Many women voluntarily opt to place their children in the custody of others to protect them from..." - they could highlight that this is a protective factor but they use this to point to powerlessness instead.

Consistently include narratives from the participants that emphasize failings, psychological problems, and individual issues. Contradicts their expressed emphasis on poverty and structural issues. Turns structural issues into individual ones

The researchers: portrayed as the ones who can empower the powerless.

Examples: "by listening to their stories, we began to understand and give voice..."

"Hence, it became our mission to learn more, and the best way to do so, we thought, would be to hear from the women themselves."

"Giving the women a voice makes the political personal." 
The description of the research procedures (pg. 164) also has the effect of framing the researchers as saviors/do gooders/helpers and continues to frame the women as powerless.

Consistently textually emphasize researcher positive qualities. And often use women's own experiences in the research to do so. Example: "Nearly all the women expressed gratitude for the chance to talk about their stories so freely." or "all the women were enthusiastic and grateful to have the opportunity to speak about their children in such an open and nonjudgmental venue." - Why is it important to include that they expressed gratitude? Using women's expressions to emphasize the researchers positive qualities and do gooderness. Their positive qualities are textually emphasized through discussion of this type of interaction.

"By giving voice to this invisible population through a standpoint perspective, we revealed complex stories of unfinished lives, of victimization and abuse, of poverty and exploitation, of cyclical and generational obscurity, of classism and sexism, and of stigma and shame." - researchers revealed, not the women.

\section{What references are made? (e.g. cultural references, references to other disciplines/professions, media or policy referenced, does the text imply knowledge from other sources?)}

I did not notice anything particularly notable about this. Lots of references to other academic sources, as is standard for this genre. Draw on outside empirical and theoretical literature to support their points and make their case. Draw on women stories to emphasize their results. Noting seems particularly questionable about the sources they used or how they used them, except that the excerpts from the data they used could be interpreted differently, but research of this type is already subjective.

However, there are some notable quotations they use to support their point but they use them in a way that does not appear to be supported by the quote. For example, on pg. 161 , the authors assert, "By listening to these experiences, we can begin to understand and give voice to this long-ignored population. As Comack (1999, p. 296) stated, "the voices of women behind bars have for too long been silenced; it is time we begin to listen to what they have to say." " - The authors frame themselves as giving voice to the powerless and then use Comack's words to support this as a noble endeavor, but what Comack actually says is very different than "giving voice". Her words imply that they have a voice that has not been heard and our job as researchers is to listen to them, not "give them their voice."

Gender specific programming - but left undefined. Are we to know what this means? With lack of discussion, the presupposition is that it focuses on parenting, trauma, and substance abuse, the only characteristics they defined as gendered. And no discussion of how gender interacts with race, so concept of gender is universalizing. 


\section{Content and Ideological Statements}

1. What notion of social work does the article presuppose and convey?

Social work: innocence. Portrayed as helper/do gooders. Savior - use of passive language when describing policy creation and implementation shirks responsibility from SW to disembodied "policies." Lots of language of whiteness as goodness "give voice" "our mission"

Purpose is to help individuals. "Raise them up" through individual level service delivery and "giving voice."

2. What notion of criminalized women does the article presuppose and convey?

Tragic and powerless. Victim and vulnerable. She wants to be a good, loving mother and with enough treatment she can be.

3. What kinds of understandings of crime, criminality, and punishment does the article presuppose and convey? What explanations for criminalization are given? Where does the problem for a woman's crime/criminalization lie? (i.e. individual? structural? socially constructed? a pathology?) Who/what needs to change?

Ends up being individualized despite discussion of policy and professed social justice intentions.

Constantly framing meaning in individual level understandings.

Does not question underlying logic of punishment and ultimately assumes problematic behaviors are cause of crime and therefore solution rest in changing individuals and providing them support so they can change.

\section{What notions of normality $\backslash$ does the article presuppose and convey?}

Invokes normative expectations of motherhood

5. What notions of practice and intervention does the article presuppose and convey? What is the focus of intervention? What is deemed as "effective" practice? How are outcomes defined?

Fall back on individual problems that can be addressed through individual level treatment and advocacy without systemic change. Nothing about addressing poverty to policies that criminalize, focus is on increasing access to behavioral change programs.

Calls for community based programs and probation programs that do not question the underlying logic of punishment.

"All the women had negative self-perceptions as mothers, because many expressed feelings of inadequacy related to their motherhood. At the programmatic level, this 
finding indicates that these women could perhaps benefit from parenting classes and even mentoring programs both in jail and after their release. Mentors and advocates could also help the mothers negotiate other systems in which they and their children are involved. Another thing to be addressed is the consistent lack of successful treatment services, as reported by the women, that are geared specifically to crack cocaine addiction in the jail setting and in the larger community that address the financial barriers and obstacles related to social support, extensive waiting lists, and child care. As the literature has demonstrated and indeed as these women verified, all programming must be developed to be gender specific. In addition, because the women expressed so much frustration and powerlessness in dealing with the systems, case advocates are needed, who can help these women navigate both the child welfare and the legal systems. Ideally, reentry programs that would implement all these elements in the form of wraparound services would be developed. These services could include treatment for substance abuse and parenting and life-skills training to prepare the women for life on the outside in an attempt to combat the high rates of recidivism reported herein. To combat some of the issues surrounding reentry and recidivism, community-based programs that help neighborhoods work with these women and connect them with needed services could be most beneficial. Community probation programming should include ways in which these women can explore what led them to incarceration by examining their multiple marginality, family histories, and experiences of abuse as a means of gaining a better understanding of the cycles and patterns that led them to criminality."

"Although many may assume that these children would be better off without their mothers, this may not be the case. With proper treatment and ample opportunity to complete a case plan, these women may be able to achieve a life in which they can nurture their children - the children they so desperately love"

Outcomes ultimately defined in terms of reducing recidivism.

\section{What frameworks of thought/rationalities are these practices embedded in? (i.e. Risk? Welfare? Morality?)}

Neoliberal psychologizing framework with a concern for welfare. It's like there is this discursive struggle between risk and welfare.

\section{How are gender, race, and class discussed, explained, and exposed?}

The article is completely silent on the issue of race and racism. Only time they even come close to discussing race is in the following passage: "The ethnicity of the sample was dependent on the ethnic makeup of the inmate population at the time of the study and did not serve as a selection or exclusion criterion." - Does ethnicity equal race here? Later they describe their sample: "Of the 26, 15 were Caucasian, 9 were African American, and 2 were other races." Half of their sample were POC but they do not mention race or racism anywhere in the article. Not even disproportionality. Is this sentence a way to mention disproportionality without mentioning it? Does this operate as a proxy for disproportionality? 
Lack of discussion on racism inherently limits their analysis and further individualizes the issue by not focusing on perhaps the largest structural issue causing and impacting high incarceration rates. Also serves as a way to stay neutral despite professed feminist and progressive intentions. (social justice light). In the rest of the article the only time the mention anything related to race is when they are naming the White racial identity of a participant in some way. Despite describing their sample here, this really has the effect to whitewashing the study and their participants.

What effect does this have? Definitely neutralizing but does it make it more appealing to a broader (and racist audience)? Is that their intention? The silence on race and racism is so stark in this article, it is hard to believe it is unintentional. The use of coded language and how they blatantly leave out race, like in the following example, "These women are already marginalized by their gender, class, and victimization status and the systemic barriers they consistently face." makes me think there was some effort involved in this process. Are the authors drawing on colorblind ideology of "goodness"? Doesn't matter, it still rein scribes whiteness. What good does this do given the racism embedded in the CJS?

Gender analysis is present around motherhood but they also draw on the analysis to construct the women. Thereby they invoke normative standards for mothering and naturalize them by "showing" that "these" women also fit into the box of the idealized mother, rather than calling into question what it means to be a good mother. Gender ultimately is defined through describing them as mothers, victims of abuse and trauma, and people with substance abuse issues. The emphasis on the above aspects of "gendered experience" are then assumed to lead to criminal behavior. "substance use, in turn, often leads to criminal behavior" - gendering crime?

Gender specific - With lack of clarity on what constitutes gender specific, the presupposition is that it focuses on parenting, trauma, and substance abuse, the only characteristics they defined as gendered. Again, no discussion of how gender interacts with race, or any other aspect of experience.

"these women's unique needs may be addressed." - seems to be in relation to guilt and shame if they are building on their own discussion, which then leads directly to treatment as mean of addressing incarceration. Behavior is problem, not prison.

\section{Other peculiarities of the article.}

Missing discussion of race and racism. Only mention race in demos and when describing participants who are white. Sort of has this whitewashing effect on their whole article. This whitewashing is significant given that they deploy the discourse of tragedy and pity (similar to the fallen woman of the reformatories) rather than a discourse of risk and danger. Though still limited given he population, this article has the most in depth description of their consent process out of the whole sample (pg. 164).

\section{Discourse position and overall message of the article.}

Object of Pity. 
APPENDIX G: Categories for Analysis at the Level of Language

\begin{tabular}{|c|c|}
\hline Discursive Device & Function/Purpose \\
\hline Lexical Choices/Word Groups & $\begin{array}{l}\text { Creates contextual reasoning. Regularities in } \\
\text { lexical choice can shed light on the kind of } \\
\text { logic the text implies. Reveals interests, } \\
\text { ideology, and positions. }\end{array}$ \\
\hline Grammar Features & $\begin{array}{l}\text { Adjectives and adverbs can illuminate } \\
\text { judgments in the text. Active or passive speech } \\
\text { can obscure relationships. Pronouns can } \\
\text { suggest protagonists and antagonists }\end{array}$ \\
\hline $\begin{array}{l}\text { Direct and Indirect } \\
\text { Speech/Attribution of Agency }\end{array}$ & $\begin{array}{l}\text { Can be used to assert or shirk responsibility, to } \\
\text { take a stand or remain neutral. }\end{array}$ \\
\hline Modalities & Used to create a sense of urgency. \\
\hline Evidentialities & $\begin{array}{l}\text { Suggest factuality. Naturalizes certain } \\
\text { statements as common sense. }\end{array}$ \\
\hline $\begin{array}{l}\text { Rhetorical and Literary } \\
\text { Figures/Symbolism/Metaphorism }\end{array}$ & $\begin{array}{l}\text { Helps construct certain kinds of categories and } \\
\text { associations, which shape the argument. Used } \\
\text { to explain or enhance the representation of } \\
\text { something. }\end{array}$ \\
\hline Modes of Reasoning & $\begin{array}{l}\text { Used to justify or legitimate } \\
\text { arguments/ideology. Logic and rationale } \\
\text { behind meaning. Are representations } \\
\text { contextualized or decontextualized? }\end{array}$ \\
\hline Characterization & $\begin{array}{l}\text { Words and expressions used to characterize } \\
\text { events, people, and situations can be used to } \\
\text { justify ideological positions. }\end{array}$ \\
\hline Exclusion & $\begin{array}{l}\text { Used to justify arguments. What information } \\
\text { has been left out or only implied? }\end{array}$ \\
\hline Specificity & $\begin{array}{l}\text { Level of detail in the presentation of } \\
\text { information used to legitimize claims. What is } \\
\text { emphasized/deemphasized (topically, } \\
\text { stylistically, rhetorically)? Look for } \\
\text { generalizations? }\end{array}$ \\
\hline Difference/Contrasts & $\begin{array}{l}\text { Used to establish meaning is established. } \\
\text { Meaning is made sensible through } \\
\text { differentiation-through oppositional and } \\
\text { hierarchical pairing. Binaries. Contradictions. }\end{array}$ \\
\hline
\end{tabular}

